\title{
EFECTO DE UNA DIETA RICA EN LICOPENO Y DE LA PRÁCTICA DE EJERCICIO FÍSICO SOBRE LOS NIVELES DE LIPIDOS EN SANGRE Y EL PORCENTAJE DE GRASA CORPORAL EN ADULTOS CON DISLIPEMIA
}

\author{
Da. Reyna María Cruz Bojórquez \\ León, 2013
}





\section{universidad \\ deleón}

INFORME DEL DIRECTOR DE LA TESIS

(R.D. 99/2011, de 28 de enero y Normativa de la ULE)

Los Dres. Dạ Pilar Sánchez Collado y D. Javier González Gallego como Directores de la Tesis Doctoral titulada "Efecto de una dieta rica en licopeno y de la práctica de ejercicio físico sobre los niveles de lipidos en sangre y el porcentaje de grasa corporal en adultos con dislipemia" realizada por Dā Reyna María Cruz Bojorquez en el programa de doctorado "Ciencias de la Actividad Física y el Deporte" informan favorablemente el depósito de la misma, dado que reúne las condiciones necesarias para su defensa.

Lo que firman, en León a de de 



\section{universidad deleón}

\section{ADMISIÓN A TRÁMITE DE LA TESIS DOCTORAL}

(R.D. 99/2011, de 28 de enero y Normativa de la ULE)

El órgano responsable del programa de doctorado "Ciencias de la Actividad Física y el Deporte" en su reunión celebrada el día de de ha

acordado dar su conformidad a la admisión a trámite de lectura de la tesis doctoral titulada "'Efecto de una dieta rica en licopeno y de la práctica de ejercicio físico sobre los niveles de lipidos en sangre y el porcentaje de grasa corporal en adultos con dislipemia"'”dirigida por los Dres. Dª Pilar Sánchez Collado y D. Javier González Gallego, elaborada por Dª Reyna María Cruz Bojorquez y cuyo título en inglés es el siguiente "Effect of a lycopene-enriched diet and physical exercise on blood levels of lipids and body fat percentage in adults with dyslipemia".

Lo que firmo en León a de de

El Secretaria de la Comisión Académica/

Fdo.: Pilar Sánchez Collado

CONFORMIDAD

El Coordinador de la Comisión Académica/

Fdo.: Javier González Gallego 



\section{ABREVIATURAS UTILIZADAS}

A

Apoproteína A

A I

Apolipoproteina I

A II Apoproteina II

A IV ApoproteínalV

ABC-A1 ATP Binding Cassette Class A type 1

Acetona G.R Acetona grado reactivo

ACSM American College of Sports Medicine

ADN Ácido desoxirribonucléico

AGL Ácidos grasos libres

AMF Actualizaciones en Medicina de Familia

ANOVA Análisis de varianza

Apos Apoproteínas

Apo A 1 Apolipoproteína A1 (Componente principal del HDL)

Apo B Apolipoproteína B (Componente principal del LDL)

ATP Trifosfato de adenosina

ATP-II Adult Treatment Panel II (1993)

ATP-III Adult Treatment Panel III (2001)

$A_{2}$ tromboxano

Agregante plaquetario metabolito del ácido araquisónico

B 100

Apoproteína B100 (Componente del LDL)

baPWV

Velocidad de onda pulsátil braquial-tobillo

$\mathrm{BPH}$

Hiperplasia prostática banigna

${ }^{\circ} \mathrm{C} \quad$ Grados centígrados

C II Apoproteína CII

C III Apoproteína CIII

CA Circunferencia abdominal

CAT Catalaza

CD69 Activador precoz linfocitario

CETP Enzima proteína de transferencia de ésteres de colesterol

cm Centímetros

$\mathrm{cm}^{2} \quad$ Centímetros al cuadrado

$\mathrm{CL} \quad$ Colesterol

CONAPO Consejo Nacional de Población

$\mathrm{E}$

Apoproteína E

ECG Electrocardiograma 


\begin{tabular}{|c|c|}
\hline EFSA & Autoridad Europea de Seguridad Alimentaria \\
\hline EIC & Enfermedad isquemica del corazón \\
\hline ECV & Enfermedades cardiovasculares \\
\hline EKG & Hipertrofia ventricular izquierda \\
\hline ENEC & Encuesta Nacional de Enfermedades Crónicas (1993) \\
\hline ENSA & Encuesta Nacional de Salud (2000) \\
\hline ENSANUT & Encuesta Nacional de Salud y Nutrición (2006) \\
\hline ENSE & Encuesta Nacional de Seroepidemiología (1988) \\
\hline eNOS & Óxido nítrico sintetasa endotelial \\
\hline EROS & Especies reactivas de oxígeno \\
\hline EUFIC & European Food Information Council \\
\hline FACAD & Formación Continua a Distancia \\
\hline FAO & Organización para la Agriculatura y la Alimentación \\
\hline FC & Frecuencia cardíaca \\
\hline FCM & Frecuencia cardíaca máxima \\
\hline FRCV & Factores de riesgo cardiovascular \\
\hline FRIMEX & Factores de Riesgo en México \\
\hline GC & Grupo control \\
\hline GE & Grupo Experimental \\
\hline GISSI & Studi della Sopravienza nell 'Infarto Miocardio Prevenzione \\
\hline HDL & Lipoproteínas de alta densidad \\
\hline HF & Hipercolesterolemia familiar \\
\hline HCF & Hiperlipemia familiar combinada \\
\hline HMGCOA & Enzíma 3 hidroxi-3-metilglutaril coenzima A reductasa \\
\hline HOCL & Ácido hipocloroso \\
\hline HTA & Hipertensión arterial \\
\hline HTG & Hipertrigliceridemia \\
\hline HTGF & Hipertrigliceridemia Familiar \\
\hline ICAM-1 & Expresión molecular de adhesión intracelular \\
\hline IDA & Ingesta diaria admisible \\
\hline IDL & Lipoprotrínas de densidad intermedia \\
\hline NTx-N & Telopéptido de colágeno tipo 1 \\
\hline OCDE & Organización para la Cooperación y el Desarrollo Económico \\
\hline DMS/WHO & Organización Mundial de la Salud/ World Health Organization \\
\hline OPS & Organización Panamericana de la Salud \\
\hline PEPEF & Programa Experimental para la Promoción de la Actividad Física \\
\hline PGC & Porcentaje de grasa corporal \\
\hline $\mathrm{PGD}_{2}$ & Prostaglandina \\
\hline PIB & Producto interno bruto \\
\hline PIBN & Producto interno bruto nominal \\
\hline
\end{tabular}




\begin{tabular}{|c|c|}
\hline PLP & Lipoproteínlipasa \\
\hline PLTP & Proteína de transporte de fosfolípidos \\
\hline ppm & Partes por Millón \\
\hline PROCAM & Prospective Cardiovascular Münsder \\
\hline PROCESA & Programa Sectorial de Salud \\
\hline PROFECO & Procuraduría Federal del Consumidor \\
\hline Q & Quilomicrones \\
\hline RFA & Respuesta de fase aguda \\
\hline RCG & Riesgo cardiovascular global \\
\hline RCV & Riesgo cardiovascular \\
\hline SAGARPA & $\begin{array}{l}\text { Secretaría de Agricultura, Ganadería, Desarrollo Rural, Pesca y } \\
\text { Alimentación }\end{array}$ \\
\hline SCORE & Systematic Coronary Risk Evaluation \\
\hline SEED & Sistema Epidemiológico y Estadístico de las Defunciones \\
\hline SFA & Subsecretaría de Fomento a los Agronegocios \\
\hline ST & $\begin{array}{l}\text { Segmento ST, señal eléctrica que corresponde a la } \\
\text { repolarización, cuando en el elctrocardiograma aparece reducido } \\
\text { es signo de isquemia y si está elevado de infarto de miocardio. }\end{array}$ \\
\hline SOD & Superóxido Dismutasa \\
\hline SPSS & Statistical Package for Social Sciencies \\
\hline SS & Secretaría de Salud \\
\hline TA o PA & Tensión Arterial o Presión Arterial \\
\hline TAC & Capacidad antioxidante total \\
\hline TG & Triglicéridos \\
\hline TNF- $\alpha$ & Factor de Necrosis Tumoral Alfa \\
\hline TRC & Transporte reverso de colesterol \\
\hline TSH & Tirotropina \\
\hline UADY & Universidad Autónoma de Yucatán \\
\hline UDSA & Departamento de Agricultura de los Estados Unidos \\
\hline UV-vis & Espectroscopia Ultavioleta Visible \\
\hline VCAM-1 & Molécula Celular de Adhesión Vascular \\
\hline VLDL & Lipoproteínas de muy Baja Densidad \\
\hline NTx-N & Telopéptido de colágeno tipo 1 \\
\hline OCDE & Organización para la Cooperación y el Desarrollo Económico \\
\hline OMS/WHO & Organización Mundial de la Salud/ World Health Organization \\
\hline OPS & Organización Panamericana de la Salud \\
\hline PEPEF & Programa Experimental para la Promoción de la Actividad Física \\
\hline PGC & Porcentaje de grasa corporal \\
\hline $\mathrm{PGD}_{2}$ & Prostaglandina \\
\hline PIB & Producto interno bruto \\
\hline PIBN & Producto interno bruto nominal \\
\hline PLP & Lipoproteínlipasa \\
\hline
\end{tabular}




\begin{tabular}{|c|c|}
\hline PLTP & Proteína de transporte de fosfolípidos \\
\hline ppm & Partes por Millón \\
\hline PROCAM & Prospective Cardiovascular Münsder \\
\hline PROCESA & Programa Sectorial de Salud \\
\hline PROFECO & Procuraduría Federal del Consumidor \\
\hline $\mathbf{Q}$ & Quilomicrones \\
\hline RFA & Respuesta de fase aguda \\
\hline RCG & Riesgo cardiovascular global \\
\hline $\mathrm{RCV}$ & Riesgo cardiovascular \\
\hline SAGARPA & $\begin{array}{l}\text { Secretaría de Agricultura, Ganadería, Desarrollo Rural, Pesca y } \\
\text { Alimentación }\end{array}$ \\
\hline SCORE & Systematic Coronary Risk Evaluation \\
\hline SEED & Sistema Epidemiológico y Estadístico de las Defunciones \\
\hline SFA & Subsecretaría de Fomento a los Agronegocios \\
\hline ST & $\begin{array}{l}\text { Segmento ST, señal eléctrica que corresponde a la } \\
\text { repolarización, cuando en el elctrocardiograma aparece reducido } \\
\text { es signo de isquemia y si está elevado de infarto de miocardio. }\end{array}$ \\
\hline SOD & Superóxido Dismutasa \\
\hline SPSS & Statistical Package for Social Sciencies \\
\hline SS & Secretaría de Salud \\
\hline TA o PA & Tensión Arterial o Presión Arterial \\
\hline TAC & Capacidad antioxidante total \\
\hline TG & Triglicéridos \\
\hline TNF- $\alpha$ & Factor de Necrosis Tumoral Alfa \\
\hline TRC & Transporte reverso de colesterol \\
\hline TSH & Tirotropina \\
\hline UADY & Universidad Autónoma de Yucatán \\
\hline UDSA & Departamento de Agricultura de los Estados Unidos \\
\hline UV-vis & Espectroscopia Ultavioleta Visible \\
\hline VCAM-1 & Molécula Celular de Adhesión Vascular \\
\hline VLDL & Lipoproteínas de muy Baja Densidad \\
\hline
\end{tabular}




\section{INDICE GENERAL}

CAPÍTULO 1. INTRODUCCIÓN-1

CAPÍTULO 2. ANTECEDENTES-8

2.1. Definición de dislipemias-8

2.2. Epidemiología de las dislipemias-8

2.3. Metabolismo de las lipoproteínas-11

2.3.1. Metabolismo de los quilomicrones-14

2.3.2. Metabolismo de las lipoproteínas de muy baja densidad-15

2.3.3. Metabolismo de las lipoproteínas de baja densidad16

2.3.4. Metabolismo de las lipoproteínas de alta densidad-17

2.4. Relación entre inflamación y dislipemias-19

2.5. Clasificación de las dislipemias-20

2.6. Riesgo cardiovascular-23

2.7. Diagnóstico diferencial de las dislipemias-31

2.7.1. Hipercolesterolemia-32

2.7.1.1. Hipercolesterolemia familiar-33

2.7.1.2. Hipercolesterolemia poligénica-34

2.7.1.3. Hiperlipemia familiar combinada-34

2.7.2. Hipertrigliceridemia-35

2.7.2.1. Hipertrigliceridemia familiar-37

2.7.2.2. Deficiencia familiar de lipoproteínas-37

2.7.3. Hiperlipemia mixta-37

2.7.4. Disbetalipoproteinemia-38

2.7.5. Hipoalfalipoproteinemia-38

2.8. Tratamiento de las dislipemias-41

2.8.1. Tratamiento farmacológico de las dislipemias -42

2.8.1.1. Fármacos hipolipemiantes-43

2.8.1.1.1. Estatinas-44

2.8.1.1.2. Ácido nicotínico-46 
2.8.1.1.3. Secuestradores de ácidos biliares-(resinas)- 47

2.8.1.1.4. Fibratos -47

2.8.1.1.5. Acetimiba- 48

2.8.1.1.6. Ácidos grasos omega-3-48

2.9. Tratamiento no farmacológico de las dislipemias-50

2.9.1. Ejercicio físico-51

2.9.1.1. Efecto del ejercicio en la salud cardiovascular-53

2.9.1.2. Valoración previa al inicio de un programa de ejercicio -59

2.9.1.3. El ejercicio físico en las dislipemias-6o

2.9.1.4. Prescripción de un programa de ejercicio físico-61

2.10. Tratamiento dietético- 64

2.10.1. Alimentación correcta-66

2.10.2 Dieta y dislipemias-68

2.10.3. Importancia del licopeno en el tratamiento de las dislipemias-75

2.10.3.1. Biodisponibilidad-82

2.10.3.2. Toxicidad-83

2.10.4. Dieta rica en licopeno para el tratamiento de las dislipemias-84

CAPÍTULO 3. OBJETIVOS-90

3.1. Pregunta de investigación-9o

3.2. Objetivo general-go

3.3. Objetivos específicos-9o

3.4. Hipótesis-91

3.5. Definición de las variables de estudio-91

3.6. Justificación-93

CAPÍTULO 4 METODOLOGÍA-95

4.1. Tipo de estudio-95

4.2. Diseño de la investigación-95

4.3. Población de estudio-95

4.4. Diseño general de la investigación-100

4.4.1. Cuantificación del contenido de licopeno en los alimentos fuente-101

4.4.2. Diseño de la dieta estándar-105

4.4.3. Diseño del programa de ejercicio físico-107

4.4.4. Diagnóstico de dislipemia, índice aterogénico de 
Castelli tipo I, indicadores del estado de nutrición y tensión arterial-114

4.5. Diseño estadístico y análisis de los datos-120

CAPÍTULO 5 RESULTADOS-120

5.1. Determinación de las raciones de alimentos ricos en licopeno-121

5.2. Diseño de la dieta rica en licopeno-123

5.3. Diseño del programa de ejercicio-123

5.4. Dislipemia, indicadores del estado de nutrición e hipertensión arterial-125

5.4.1. Dislipemias-125

5.4.2. Indicadores del estado de nutrición: porcentaje de grasa corporal, Indice de Masa Corporal, circunferencia abdominal y tensión arterial-126

5.5. Factores de riesgo de la población de estudio-128

5.5.1. Factores de riesgo no modificables-128

5.5.2. Factores de riesgo modificables-129

5.5.3. Padecimientos de la población de estudio-130

5.6. Efecto de la intervención-131

5.6.1. Colesterol-132

5.6.2. Lipoproteínas de alta densidad-133

5.6.3. Triglicéridos- 135

5.6.4. Lipoproteínas de baja densidad -136

5.6.5. Porcentaje de grasa corporal-137

5.6.6. Índice aterogénico de Castelli-141

CAPÍTULO 6 DISCUSIÓN-145

6.1. Determinación de las raciones de alimentos ricos en licopeno-145

6.2. Datos generales de la población de estudio-149

6.3. Dislipemia, indicadores del estado de nutrición e hipertensión arterial-150

6.4. Factores de riesgo de la población de estudio-153

6.5. Efecto de la intervención-154

6.6. Limitaciones del estudio-162

CAPÍTULO 7 CONCLUSIONES-164

CAPÍTULO 8 BIBLIOGRAFÍA-166

ANEXOS

Anexo I Programa de actividades 
Anexo II Carta de consentimiento informado

Anexo III Historia clínica

Anexo IV Ejemplo de un programa de ejercicio físico

Anexo V Menús para hombres tratados con dieta estándar (grupo control)

Anexo VII Menús para mujeres tratadas con dieta estándar (grupo control)

Anexo VII Menús para hombres tratados con dieta rica en licopeno (grupo experimental)

Anexo VIII Menús para mujeres tratadas con dieta rica en licopeno (grupo experimental) 


\section{ÍNDICE DE \\ TABLAS, FIGURAS Y GRÁFICOS}

\section{CAPÍTULO 1. INTRODUCCIÓN•}

Tabla 1. Mortalidad por enfermedad isquémica, cardiovascular y enfermedad hipertensiva. México 2000-2006-3

Tabla 2. Principales causas de mortalidadgeneral en México, 2008-4

Tabla 3. Principales causas de mortalidad en Yucatán, 2008-5

Tabla 4. Principales factores de riesgo para mortalidad en México-6

\section{CAPÍTULO 2. ANTECEDENTES}

Figura 1. Estructura de las Lipoproteínas-12

Tabla 5.Composición de las lipoproteínas plasmáticas-13

Tabla 6. Clasificación de las lipoproteínas por su densidad de flotación-13

Tabla 7. Funciones de las lipoproteínas-14

Figura 2. Metabolismo de los Quilomicrones-15

Figura 3. Metabolismo de las lipoproteínas de muy baja densidad-16

Figura 4. Metabolismo de las lipoproteínas de baja densidad-17

Figura 5. Metabolismo de las lipoproteínas de alta densidad-18

Tabla 8. Dislipemias primarias-21

Tabla 9.Causas de las dislipemias secundarias-22

Tabla 10.Clasificación de las dislipemiasde acuerdo con el Consenso Europeo-23

Tabla 11.Clasificación fenotípica de las dislipemias (Fredickson)-23

Tabla 12. Clasificación del riesgo cardiovascular global-25

Tabla 13. Puntos críticos en el diagnóstico y tratamiento de las dislipemias-28

Tabla 14. Niveles de lípidos de acuerdo con NCEP-29 
Tabla 15. Objetivos del LDL según el cálculo de riesgo de evento coronarioa 10 años ATP-III (NCEP), 2004-30

Tabla 16.Principales factores de riesgo para enfermedad coronariaque modifican los objetivos de $L D L-31$

Figura 6.Diagnóstico diferencial dela hipercolesterolemia-33

Figura 7.Diagnóstico diferencial de la hipertrigliceridemia-36

Figura8.Diagnóstico diferencial de la hiperlipemia mixta-39

Figura 9.Diagnóstico diferencial de la hipoalfalipoproteinemia-40

Tabla 17. Valores meta para las $L D L$ y el colesterol no-HDL de acuerdo con el riesgo a 10 años-41

Tabla 18. Fármacos utilizados en el tratamiento de las dislipemias-43

Tabla 19. Recomendaciones para la utilización de los fármacos hipolipemiantes-50

Tabla 20.Objetivos de la valoración funcional en medicina del deporte-59

Tabla 21. Actividades para un programa de ejercicio físico-63

Tabla 22. Recomendaciones de actividad física del ACSM para varias poblaciones64

Figura 10.El Plato del Bien Comer-67

Tabla 23. Grupos de alimentos de acuerdo con la NOM-043SSA2-2005-68

Tabla 24. Recomendaciones de alimentos para hipercolesterolemia-73

Tabla 25.Recomendaciones de alimentos para la hipertrigliceridemia-74

Tabla 26.Causas endógenas y exógenas de las EROS-78

Tabla 27.Sustancias fitoquímicas benéficas para la salud-84

Tabla 28. Fuentes de licopeno86

\section{CAPÍTULO 4. METODOLOGÍA•}

Tabla 29. Criterios que deben cumplir los participantes en el estudio-97

Tabla 30. Distribución de la población de estudio por intervención-99

Tabla 31. Media de edad y desviación estándar de la población de estudio por grupos de tratamiento-99

Tabla 32. Características sociodemográficas de la población de estudio-100

Figura 11. Diseño general de la investigación-101

Tabla 33. Reactivos, material y equipo utilizados en la extracción de licopeno-102

Figura 12. Curva de calibración de los estándares de licopeno a diferente concentración-104

Tabla 34. Contenido de licopeno en las muestras de alimentos analizadas-105

Tabla 35. Métodos breves para calcularlas necesidades energéticas-105 
Tabla 36. Distribución de nutrientes y energía para el diseño de menús para hombres (con base ene 1800 kilocalorías)-106

Tabla 37. Distribución de nutrientes y energía para el diseño de menús para mujeres (con base ene 1500 kilocalorías)-106

Tabla 38. Recomendaciones de la NOM-037-SSA2-2002 referentes al aporte de energía y nutrientes para el tratamiento nutricionalde las dislipemias-107

Figura 13. Escala de Borg-109

Tabla 39. Clasificación de los niveles de funcionalidadde las pruebas de esfuerzo de acuerdo con el gasto energético-111

Tabla 40. Protocolo de Bruce para prueba de esfuerzo-113

Tabla 41. Valores normales de los niveles de lípidos en sangre-115

Tabla 42. Clasificación del índice aterogénico de Castelli por sexo y sus valores de referencia-116

Tabla 43. Rangos normales de porcentaje de grasa en el cuerpo-117

Tabla 44. Puntos de corte para Índice de Masa Corporal-118

Tabla 45. Puntos de corte para circunferencia abdominal-119

Tabla 46. Clasificación de la tensión arterial-120

\section{CAPÍTULO 5. RESULTADOS}

Tabla 47. Raciones de alimentos ricos en licopeno en medidas caseras y gramos-122

Tabla 48. Raciones de alimentos que aportan $50 \mathrm{mg}$ de licopeno-123

Tabla 49. Programa de ejercicio-124

Tabla 50. Clasificación de la población de estudio de acuerdo con el tipo de dislipemia (NCEP-III)-125

Tabla 51. Clasificación de la población de estudio con el indicador porcentaje de grasa corporal-126

Tabla 52. Clasificación de la población de estudio con el indicador Índice de Masa Corporal-127

Tabla 53. Clasificación de la población de estudio con el indicador circunferencia abdominal-127

Tabla 54. Clasificación de la población de estudio de acuerdo con su tensión arterial128

Tabla 55. Antecedentes heredo-familiares de la población de estudio-129

Tabla 56. Consumo de tabaco, alcohol y práctica de ejercicio físico de la población de estudio por intervención-130

Tabla 57. Padecimientos de la población de estudio-131

Tabla 58. Medias de los niveles de Colesterol ( $\mathrm{mg} / \mathrm{dL}$ ) de la población, previa y posterior a la intervención por grupos de tratamiento y sus diferencias post-pre-132 
Tabla 59. Medias de los niveles de lipoproteínas de alta densidad ( $\mathrm{mg} / \mathrm{dL}$ ) de la población, previa y posterior a la intervención por grupos de tratamiento y sus diferencias post-pre-133

Figura 14. Diferencia post-pre de las medias de los niveles de colesterol y HDL $(\mathrm{mg} / \mathrm{dL})$ de la población de estudio por grupos de tratamiento-134

Tabla 6o. Medias de los niveles de triglicéridos ( $\mathrm{mg} / \mathrm{dL}$ ) de la población, previa y posterior a la intervención por grupos de tratamiento y sus diferencias post-pre-135

Tabla 61. Medias de los niveles de lipoproteínas de baja densidad ( $\mathrm{mg} / \mathrm{dL}$ ) de la población, previa y posterior a la intervención por grupos de tratamiento y sus diferencias post-pre-136

Tabla 62. Medias de porcentaje de grasa corporal (puntos porcentuales) de la población, previa y posterior a la intervención por grupos de tratamiento y sus diferencias post-pre-137

Figura 15. Diferencia post-pre de las medias de los niveles de TG y HDL $(\mathrm{mg} / \mathrm{dL})$ y $P G C$ (puntos porcentuales) de la población de estudio por grupos de tratamiento-138

Tabla 63. Resultado del análisis de varinza (ANOVA) para el inidcador triglicéridos, previo y posterior a la intervención-139

Tabla 64. Comparación de la diferencia de medias entre grupos para la variable CL (prueba post hoc de Tukey)-140

Tabla 65. Comparación de la diferencia de medias entre grupos para la variable $L D L$ (prueba post hoc de Tukey)-141

Tabla 66. Medias del índice aterogénico de Castelli tipo I de la población, previas y posteriores a la intervención, por grupos de tratamiento y sus diferencias post-pre-

142

Tabla 67. Resultado del análisis de varianza (ANOVA) para las diferencias de medias post-pre del índice aterogénico de Castelli tipo I-142

Figura 16. Diferencia post-pre de las medias del índice aterogénico de Castelli tipo I de la población de estudio por grupos de tratamiento-143 


\section{CAPÍTULO 1.}

INTRODUCCIÓN

Las enfermedades crónicas no transmisibles se han convertido en las primeras causas de muerte y de discapacidad en los adultos a nivel mundial en los últimos 20 años.

La obesidad, la diabetes mellitus, la hipertensión arterial (HTA) y las dislipemias son enfermedades crónicas que poseen factores etiológicos genéticos pero están mas asociadas con estilos de vida inadecuados (De Souza et al., 2003; World Health Organization, 2005; Lim et al., 2007; Belser et al., 2012).

El consumo excesivo de hidratos de carbono simples, de grasas saturadas y la ingesta deficiente de fibra en la dieta; la falta de ejercicio físico, así como el consumo de alcohol y tabaco son los factores que siendo modificables, están favoreciendo de manera alarmante la incidencia de dichas enfermedades (Cáez et al., 2007).

De acuerdo con el estudio INTERHEART (A Global Case-Control Study of Risk Factors for Acute Myocardial Infraction) cuyos resultados se publicaron en el año 2004, el factor de riesgo más importante para desarrollar enfermedad cardiovascular, es la dislipemia.

La relación $A p o B / A p o A 1$, o relación colesterol LDL (C$\mathrm{LDL}$ )/colesterol HDL (C-HDL) es el factor que más aumenta el riesgo cardiovascular y los individuos con elevadas concentraciones de lipoproteínas de baja densidad (LDL) o con bajos niveles de liporpoteínas de alta densidad (HDL) son los que tienen mayor riesgo (Yusuf et al., 2004).

De acuerdo con Backer et al. (2004), la dislipemia se ha destacado por ser un factor causal de aterosclerosis, que es una enfermedad sistémica, lenta y progresiva que se desarrolla silenciosamente a lo largo de muchos años, cuyos síntomas aparecen cuando la patología está muy avanzada. 
La dislipemia puede afectar distintos tejidos y puede presentarse de diferentes formas clínicas, como son: la enfermedad arterial coronaria, la enfermedad cerebro-vascular y la enfermedad vascular periférica.

Estas enfermedades son un problema de salud pública creciente, ya que aparecen entre las primeras cinco causas de mortalidad, de discapacidad y del incremento de los costos de asistencia sanitaria en el mundo. (De Souza et al., 2003; Mataix et al., 2009; Miguel, 2009).

El Ministerio de Sanidad y Consumo de España (2000) reportó que en un estudio realizado en Estados Unidos se puso de manifiesto que el $8 \%$ de las consultas que se realizan en ese país están relacionadas con problemas en los niveles de los lípidos.

Jiménez et al. (2004) afirman que la asociación entre la aterosclerosis y la enfermedad cardiovascular fue demostrada desde 1930 por varios autores, pero hasta 1971, Kannel y colaboradores confirmaron estas observaciones desde el punto de vista epidemiológico, y revelaron una fuerte correlación positiva entre las concentraciones elevadas de colesterol y el desarrollo de enfermedad cardiovascular, como consta en el estudio Framingham. Esta relación positiva entre las concentraciones de colesterol y la morbi-mortalidad por enfermedad cardiovascular se observa en hombre y mujeres, en jóvenes, adultos y ancianos y en todas las razas.

En el Reino Unido la enfermedad cerebrovascular es la causa más común de muerte prematura (28\% en hombres y $17 \%$ en mujeres), con una relación 1:4 muertes en hombres y 1:5 en mujeres (Munguía et al., 2008).

De acuerdo con la American Heart Association (2001) en Estados Unidos de América, las enfermedades cardiovasculares (ECV) fueron la causa más importante de muerte, afectando alrededor de 13 millones de personas (Anderson, 2007).

Datos reportados por la misma asociación en 2006 confirman que los costos directos y no directos derivados de esta enfermedad ascendieron a 142 mil millones de dólares (American Heart Association, 2006).

Munguía et al., (2008) afirman que en México, en el año 2000 el $60.5 \%$ de la población presentaba al menos un factor de riesgo cardiovascular, siendo la cardiopatía isquémica la segunda causa de muerte general y afectando a cerca de 30 millones de adultos.

El $48.4 \%$ de los adultos (20-69 años) que viven en zonas urbanas tienen concentraciones bajas $(<35 \mathrm{mg} / \mathrm{dL}$ ) de $\mathrm{HDL}, 42.3 \%$ tienen concentraciones altas de triglicéridos ( $>150 \mathrm{mg} / \mathrm{dL}$ ) y el $27.1 \%$ niveles altos de colesterol (>200 $\mathrm{mg} / \mathrm{dL}$ ). La prevalencia se incrementa si los 
sujetos padecen diabetes mellitus, HTA o sobrepeso (Mooradian, 2009).

En 2007, Meaney et al. (2007) mostraron a través del estudio Factores de Riesgo en México (FRIMEX) que de los 140,017 participantes el $71.9 \%$ padecía sobrepeso u obesidad, $26.5 \%$ hipertensión arterial, $19.4 \%$ diabetes y $40 \%$ hipercolesterolemia y que estas enfermedades representaban el 30\% de todas las muertes en el país. Estos factores de riesgo, pueden reducir hasta el 10\% de años de vida saludable (Anderson, 2007).

Datos de la Subsecretaría de Prevención y Promoción de la Salud, de la Secretaría de Salud (SS) en el 2008, muestran (en la tabla No.1) el constante incremento de la mortalidad provocada por las enfermedades cardiovasculares en México, situando los valores más altos en el norte y centro del país, donde es particularmente frecuente la enfermedad isquémica cardiaca, con tasas entre 49,1 a 79,8 defunciones por 100 mil habitantes durante 2006; en contraste, la enfermedad cerebrovascular, presenta valores más altos en el centro, sur y sureste con tasas que van de 36,4 a 65,2 defunciones durante el mismo año.

Tabla No. 1 Mortalidad por enfermedad isquémica, cerebrovasculary enfermedad hipertensiva. México 2000-2006

\begin{tabular}{|c|c|c|c|c|c|c|}
\hline Año & \multicolumn{2}{|c|}{$\begin{array}{c}\text { Enfermedad } \\
\text { isquémica del corazón }\end{array}$} & \multicolumn{2}{c|}{$\begin{array}{c}\text { Enfermedad } \\
\text { cardiovascular }\end{array}$} & \multicolumn{2}{c|}{$\begin{array}{c}\text { Enfermedad } \\
\text { hipertensiva }\end{array}$} \\
\cline { 2 - 7 } & Defunciones & Tasa & Defunciones & Tasa & Defunciones & Tasa \\
\hline 2000 & 43,753 & 43,5 & 25,357 & 25,2 & 9,747 & 9,7 \\
\hline 2006 & 53,823 & 51,3 & 39,295 & 37,5 & 24,819 & 23,7 \\
\hline
\end{tabular}

Tasa por 100,000 habitantes

Fuente: Secretaría de Salud. Subsecretaría de Prevención y Promoción de la Salud. (2008) Anuarios de mortalidad SEED/DGESS/INEGI, 2000-2006.

En México la Dirección General de Información en Salud (DGIS) de la Secretaría de Salud y del Instituto Nacional de Economía, Geografía e Informática (INEGI) dan cuenta de la mortalidad general en el año 2008 en todo el país, poniéndose de manifiesto que las enfermedades isquémicas del corazón y la enfermedad cerebrovascular se encontraron como segunda y tercera causas de muerte respectivamente como se observa en la tabla No. 2 
Tabla No. 2 Principales causas de mortalidad general en México 2008

\begin{tabular}{|c|c|c|c|c|}
\hline \multicolumn{2}{|c|}{ Descripción } & \multirow{2}{*}{$\begin{array}{c}\text { Defunciones } \\
538,288\end{array}$} & \multirow{2}{*}{$\begin{array}{c}\text { Tasa } \\
\text { 1/ 100,000 } \\
\text { habitantes } \\
70,8\end{array}$} & \multirow{2}{*}{$\begin{array}{c}\text { Porcentaje } \\
100 \% \\
14,0\end{array}$} \\
\hline 1 & Diabetes mellitus & & & \\
\hline 2 & $\begin{array}{l}\text { Enfermedades } \\
\text { isquémicas del corazón }\end{array}$ & 59,579 & 55,8 & 11,1 \\
\hline 3 & $\begin{array}{l}\text { Enfermedad } \\
\text { cerebrovascular }\end{array}$ & 30,212 & 28,3 & 5,6 \\
\hline 4 & $\begin{array}{l}\text { Cirrosis y otras } \\
\text { enfermedades } \\
\text { crónicas del hígado }\end{array}$ & 28,422 & 26,6 & 5,3 \\
\hline 5 & $\begin{array}{l}\text { Enfermedad pulmonar } \\
\text { obstructiva crónica }\end{array}$ & 20,565 & 19,3 & 3,8 \\
\hline 6 & $\begin{array}{l}\text { Accidentes de vehículo } \\
\text { de motor }\end{array}$ & 16,882 & 15,8 & 3,1 \\
\hline 7 & $\begin{array}{l}\text { Enfermedades } \\
\text { hipertensivas }\end{array}$ & 15,694 & 14,7 & 2,9 \\
\hline 8 & $\begin{array}{l}\text { Infecciones } \\
\text { respiratorias agudas } \\
\text { bajas }\end{array}$ & 15,096 & 14,2 & 2,8 \\
\hline 9 & $\begin{array}{l}\text { Ciertas afecciones } \\
\text { originadas en el } \\
\text { periodo perinatal }\end{array}$ & 14,676 & 13,8 & 2,7 \\
\hline 10 & $\begin{array}{l}\text { Agresiones } \\
\text { (homicidios) }\end{array}$ & 13,900 & 13,0 & 2,6 \\
\hline
\end{tabular}

Fuente: Modificado de Secretaría de Salud/Dirección General de Información en Salud (DGIS). Sistema Nacional de Información en Salud. (SINAIS)(2012). Principales causas de mortalidad en México, 2008. Elaborado a partir de la base de datos de defunciones 1979-2008 INEGI/SS y de las Proyecciones de la Población de México 2005-2050, y proyección retrospectiva 1990-2004. CONAPO 2006.

En la tabla No. 3, se puede apreciar que específicamente en el Estado de Yucatán la primera causa de muerte general para el mismo periodo fue la cardiopatía isquémica.

Para la aterosclerosis y sus manifestaciones (enfermedad arterial coronaria, enfermedad cerebro-vascular y enfermedad vascular periférica) existen múltiples factores de riesgo, que son condiciones biológicas, estilos de vida o hábitos adquiridos poco saludables que pueden ser modificables como el tabaquismo, el sedentarismo, el consumo de alcohol, la dieta, la obesidad, las LDL elevadas, las HDL bajas, la hipertensión arterial (HTA) y la diabetes mellitus descontrolada, o no modificables como la hipertrofia ventricular izquierda (EKG), la predisposición genética a la diabetes, a la HTA y a la dislipemia, la edad, sexo y la raza, entre otros. 
Tabla No. 3 Principales causas de mortalidad general en Yucatán 2008

\begin{tabular}{|c|c|c|c|c|}
\hline \multicolumn{2}{|r|}{ Descripción } & \multirow{2}{*}{$\begin{array}{c}\text { Defunciones } \\
10,172 \\
1,494\end{array}$} & \multirow{2}{*}{$\begin{array}{c}\text { Tasa } \\
\text { 1/ 100,000 } \\
\text { habitantes } \\
78,7\end{array}$} & \multirow{2}{*}{$\begin{array}{c}\begin{array}{c}\text { Porcentaje } \\
100 \%\end{array} \\
14,7\end{array}$} \\
\hline 1 & $\begin{array}{l}\text { Enfermedades isquémicas } \\
\text { del corazón }\end{array}$ & & & \\
\hline 2 & $\begin{array}{l}\text { Tumores malignos } \\
\text { (estómago, hígado y cuello } \\
\text { del útero) }\end{array}$ & 1,202 & 63,3 & 11,8 \\
\hline 3 & Diabetes mellitus & 1,107 & 58,3 & 10,9 \\
\hline 4 & Enfermedades del hígado & 850 & 44,8 & 8,4 \\
\hline 5 & $\begin{array}{l}\text { Enfermedades cerebro- } \\
\text { vasculares }\end{array}$ & 643 & 33,9 & 6,3 \\
\hline 6 & $\begin{array}{l}\text { Accidentes de tráfico de } \\
\text { vehículos de motor }\end{array}$ & 283 & 14,9 & 2,8 \\
\hline 7 & Neumonía e Influenza & 330 & 17,4 & 3,2 \\
\hline 8 & $\begin{array}{l}\text { Ciertas afecciones } \\
\text { originadas en el periodo } \\
\text { perinatal }\end{array}$ & 248 & 13,1 & 2,4 \\
\hline 9 & $\begin{array}{l}\text { Enfermedades pulmonares } \\
\text { obstructivas crónicas, } \\
\text { excepto bronquitis, } \\
\text { bronquiectasia, efisema y } \\
\text { asma }\end{array}$ & 241 & 12,7 & 2,4 \\
\hline 10 & $\begin{array}{l}\text { Malformaciones } \\
\text { congénitas, deformidades y } \\
\text { anomalías cromosómicas }\end{array}$ & 182 & 9,6 & 1,8 \\
\hline
\end{tabular}

Fuente: Modificado deSecretaría de Salud/Dirección General de Información en Salud (DGIS). Sistema Nacional de Información en Salud. (SINAIS)(2012). Principales causas de mortalidad en Yucatán, 2008. Elaborado a partir de la base de datos de defunciones 1979-2008 INEGI/SS y de las Proyecciones de la Población de México 2005-2050, y proyección retrospectiva 1990-2004. CONAPO 2006.

Dentro de los principales factores de riesgo para mortalidad en México, las dislipemias ocupan el octavo lugar como se puede observar en la tabla No. 4i es importante destacar que estos primeros ocho factores de riesgo podrían corregirse mediante estilos de vida saludables.

Las dislipemias en México representan un gran reto para los profesionistas de la salud, con el objeto de lograr reducir la gran carga económica que se presenta debido a las enfermedades crónicas y sus secuelas y aunque existen organismos internacionales y nacionales que han emitido recomendaciones, normas y pautas concretas para la prevención, la detección y el tratamiento de la dislipemia, la prevalencia e incidencia de estas enfermedades se ha incrementado de manera acelerada en los últimos años y hacen probable que en un futuro las instituciones de seguridad social colapsen y no sean capaces de solventar los costos derivados de estas enfermedades y sus complicaciones. 
Tabla 4. Principales factores de riesgo para mortalidad en México

\begin{tabular}{|l|}
\hline Glucosa alta \\
\hline Sobrepeso \\
\hline Hipertensión arterial \\
\hline Alcohol \\
\hline Tabaco \\
\hline Pocas frutas y vegetales \\
\hline Inactividad física \\
\hline Colesterol \\
\hline Contaminación \\
\hline Sexo no seguro \\
\hline
\end{tabular}

Fuente: modificado de Stevens et al. (2008). Characterizing the Epidemiological Transition in México: National and Subnational Burden of Diseases, Injuries, and Risk Factors. PLoS Med, 5(6), e 125

En general las recomendaciones emitidas se concretan a tres puntos principales: el control de los factores de riesgo (dejar el tabaco; adoptar una dieta baja en grasas saturadas y alta en antioxidantes; disminuir el peso y el porcentaje de grasa corporal y en caso necesario la utilización de fármacos); la adopción de programas de ejercicio físico supervisado y de apoyo psicológico (cambios en el comportamiento y motivación)(World Health Organization (WHO), 2000; American College of Sports Medicine (ACSM), 2001; Aguilar et al., 2004; Backer et al., 2004).

La Secretaría de Salud a través del Programa de Acción Específica 2007-2012 Riesgo Cardiovascular, de la Subsecretaría de Prevención y Promoción dela Salud (2008), ha realizado acciones para mejorar la vida de los mexicanos; dentro de sus objetivos se incuye, disminuir para el año 2012 15\% la tasa de mortalidad debida a las enfermedades isquémicas del corazón (EIC) en la población menor de 65 años respecto a la registrada en 2006 (de 13,6 a 11,5 defunciones por cada cien mil habitantes). Sin embargo, en 2010 la tasa de mortalidad por EIC se incrementó a 15,6 defunciones por cien mil habitantes menores de 65 años (15\% más que en 2006), lo que indica que la velocidad anual ha aumentado $2,8 \%$ en los últimos cinco años, siendo mayor en los hombres ( $3,2 \%$ anual) que en las mujeres ( $2 \%$ anual).

En 2010 la mortalidad por EIC en personas de o a 65 años fue de 22,3 defunciones por cien mil habitantes en el sexo masculino y 9,0 defunciones por cien mil habitantes en el sexo femenino, lo que indica que fallecer por este tipo de enfermedades es 2,5 veces mas probable en los hombres que en las mujeres de ese grupo de edad, presentándose con mayor frecuencia en el norte del país (Estado de 
Sonora) y con menor en el sur (Estado de Quintana Roo)(Secretaría de Salud, 2010).

Es imperante impulsar estrategias efectivas que fomenten el autocuidado, conductas saludables (reducir el consumo de tabaco y alcohol, fomentar la alimentación saludable y la práctica de ejercicio físico), así como el uso rutinario de los servicios de salud con el propósito de hacer mas eficiente la prevención, detección y control de estas enfermedades en la población, sobre todo en la masculina.

Parece lógico que una dieta rica en antioxidantes y fibra proveniente de las frutas y verduras y la práctica de ejercicio físico proporcionen beneficios sobre los niveles de glucosa y lípidos en sangre, sobre la tensión arterial y en la disminución ponderal y de grasa corporal; sin embargo, son muy pocas las personas con dislipemia que adoptan un estilo de vida saludable y muchos los que optan por el tratamiento farmacológico, el cual además de resultar de alto costo produce efectos colaterales.

Diseñar estrategias dietéticas y de actividad física de bajo costo y fáciles de seguir en Individuos con dislipemias y evaluar sus resultados sobre los niveles de lípidos después de la intervención, son los propósitos del presente proyecto. En particular se evaluarán los efectos de una dieta rica en licopeno, de la práctica de ejercicio físico o de ambos sobre los niveles de lípidos en sangre y el porcentaje de grasa corporal en adultos con dislipemia. Los resultados pueden contribuir al demostrar la eficacia de intervenciones no farmacológicas en el tratramiento de las dislipemias. 


\section{CAPÍTULO 2.}

ANTECEDENTES

\subsection{Definición de dislipemias}

Dislipemia es un término que se refiere a las alteraciones en el plasma del colesterol total (CL), de los triglicéridos (TG) o ambos, acompañados generalmente de niveles altos de LDL y bajos niveles de HDL (Liv et al., 2010).

Aguilar et al. (2004) la definen como la enfermedad asintomática detectada por concentraciones sanguíneas anormales de $\mathrm{CL}$, TG y/o HDL.

Jiménez et al. (2004) la definen como un factor de riesgo mayor reversible de las enfermedades cardiovasculares que constituye un problema de salud pública en el mundo y cuya prevención primaria es posible con la modificación de los comportamientos de riesgo involucrados en su causalidad.

\subsection{Epidemiología de las dislipemias}

En la mayor parte del mundo se está experimentando una gran epidemia de enfermedades crónicas con alta mortalidad cardiovascular como son la obesidad, la diabetes mellitus, la HTA, el cáncer y las dislipemias; es innegable la influencia del componente genético en estas enfermedades pero también es evidente que su incidencia y prevalencia están asociadas a los estilos de vida, principalmente el sedentarismo, el bajo consumo de frutas $y$ verduras y el consumo de tabaco.

De acuerdo con la Organización para la Cooperación y el Desarrollo Económico (OCDE), México ocupa el segundo lugar con personas que padecen obesidad en el mundo, encontrándose que tres de cada diez mexicanos presentan sobrepeso y siete de cada diez presentan obesidad. Además, lo más alarmante es que uno de 
cada tres niños en México padece sobrepeso u obesidad, por lo que se ha considerado que el país llega a ocupar el primer lugar a nivel mundial en obesidad infantil (Gurría, 2011).

Entre otras muchas de las comorbilidades desarrolladas en el paciente con sobrepeso $u$ obesidad se encuentran las enfermedades cardiovasculares, que explica el $16 \%$ de las muertes en México y constituyen la principal causa de muerte (Gutiérrez et al., 2003; Casales et al., 2008).

Estas enfermedades, al ser crónicas y degenerativas requieren de revisiones constantes y periódicas, y demandan atención integral del equipo de salud (médico, enfermera, nutriólogo, psicólogo, entrenador físico, trabajador social, etc.) (INEGI, 2010). Esto podría explicar el aumento constante de las consultas externas impartidas en los servicios de salud del país, resultando en un incremento del $2,8 \%$, es decir cerca de 7,5 millones de consultas de 2007 a 2008 (Gobierno Federal, 2008) y un aumento del 2,1\% de 2008 a 2009, lo que representa cerca de 5,9 millones de consultas adicionales en ese año.

La Organización Mundial de la Salud (OMS) (2001) en su reporte "Prevención de enfermedades crónicas: una inversión vital", estimó que 2,6 millones de muertes prematuras a nivel mundial ocurren como consecuencia del sobrepeso u obesidad; 4,4 millones como resultado de niveles altos de colesterol y 7,1 millones como resultado de la HTA. Por otro lado en México, la mortalidad hospitalaria por enfermedades no transmisibles representa el $73 \%$ del total de muertes, siendo las enfermedades cardiovasculares y la diabetes mellitus tipo 2 las principales.

La falta de adherencia al tratamiento, el incremento en las consultas y medicamentos requeridos, las diferentes y múltiples comorbilidades que el paciente con sobrepeso $u$ obesidad debe atender demandan un gran porcentaje del gasto en salud, representando el $0,5 \%$ del $\mathrm{PIB}$, el $24,9 \%$ del presupuesto de salud pública nacional y generando un costo por mortalidad prematura de 25 mil millones de pesos; los ahorros que se generarían al evitar las consultas externas tan recurrentes serían de 655 millones de pesos (Gobierno Federal, 2008.b). En 2006, el gasto público en salud como porcentaje del PINB fue de 2,9\%, es decir 265,89 millones de pesos, de esto se destinaron 29,541 millones (11\%) a la prestación de servicios de salud para la diabetes mellitus tipo 2, las enfermedades cardiovasculares, cerebrales, HTA y diferentes tipos de cáncer relacionados con el sobrepeso y la obesidad (Secretaría de Salud, 2006). Además, es necesario considerar los costos generados a la economía del país por la pérdida de productividad por muerte prematura atribuible al sobrepeso y la obesidad, siendo el cálculo de 
25,100 millones de pesos en el 2008, cifra mayor a la calculada en 2000 ( 9,146 millones de pesos); este costo indirecto ha afectado a 45,504 familias únicamente durante el año 2008, las cuales tuvieron que enfrentar gastos catastróficos y empobrecimiento por motivos de salud (consultas, medicamentos, incapacidades, etc.) (Secretaría de Salud, 2009).

Tapia et al. (1992) ya mostraron evidencia de alteraciones en los lípidos sanguíneos en la población mexicana desde 1998, cuando se realizó la Encuesta Nacional de Seroepidemiología (ENSE-1988). En dicha encuesta se observó que la media de CL en adultos fue 184 $\mathrm{mg} / \mathrm{dL}$ para los hombres y $185 \mathrm{mg} / \mathrm{dL}$ para las mujeres, encontrando en jóvenes menores de 20 años cifras de $145 \mathrm{mg} / \mathrm{dL}$ y $149 \mathrm{mg} / \mathrm{dL}$ respectivamente. Estas cifras fueron más altas en el norte del país que en el sur, siendo menores que las encontradas en estudios realizados en Estados Unidos y algunos países de Europa (Barquera et al., 2009).

Sin embargo con el transcurso de los años y el incremento en el consumo de grasa en la dieta y de hidratos de carbono simples provenientes principalmente del consumo de refrescos embotellados, golosinas y comida rápida, la prevalencia de hipercolesterolemia ha aumentado, como muestran datos de la Encuesta Nacional de Enfermedades Crónicas (ENEC, 1993), en la que se observa una concentración promedio general de $\mathrm{CL}$ total de $197,5 \mathrm{mg} / \mathrm{dL}$ lo que representa un incremento del $\sim 10 \%$ con respecto a los datos de 1988. Con respecto a los TG y el HDL, que no fueron considerados en la ENSE, el promedio general de nivel nacional fue de $181,7 \mathrm{mg} / \mathrm{dL}$ y $38,4 \mathrm{mg} / \mathrm{dL}$ respectivamente, no encontrando diferencias entre las regiones del país ni entre las zonas rural y urbana. Un dato importante fue encontrar hipoalfalipoproteinemia (niveles bajos de $\mathrm{HDL}$ ) en la población $(46,2 \mathrm{mg} / \mathrm{dL}$ en hombres y $28,7 \mathrm{mg} / \mathrm{dL}$ en mujeres). Otro hallazgo importante fue que el $85,9 \%$ de las personas diagnosticadas con hipercolesterolemia en el momento del estudio, ignoraban que presentaban esta condición, lo que debe ser un foco de alarma para las instituciones de salud (Secretaría de Salud, 1993; Aguilar et al., 2002).

Valdespino et al. (2003) en un análisis de una submuestra de la Encuesta Nacional de Salud (ENSA, 2000), destacan la probabilidad cuatro veces mayor de la presencia de hipertrigliceridemia, hipercolesterolemia, hipoalfalipoproteinemia o cualquier combinación entre ellas en adultos que presentan obesidad en comparación con los que presentan peso normal.

En Yucatán, los resultados de la última Encuesta de Salud y Nutrición (ENSANUT, 2006), muestran un panorama poco alentador, ya que el exceso de peso se presenta desde edades tempranas de la 
vida, lo que condiciona la aparición de enfermedades crónicas si no se toman las medidas adecuadas.

En escolares, la presencia de sobrepeso más obesidad afectó más las zonas urbanas $(37,8 \%)$ que rurales $(27,8 \%)$ y fue mayor en hombres $(38,1 \%)$ que en mujeres $(34,6 \%)$. En adolescentes la suma del sobrepeso y la obesidad se presentó más alta en zonas urbanas con un mayor porcentaje en hombres $(43,1 \%)$ que en mujeres $(38,4 \%)$ a diferencia de las zonas rurales donde las mujeres $(25,2 \%)$ presentaron mayor porcentaje que los hombres $(23,7 \%)$.

En los adultos mayores de 20 años la prevalencia de diabetes mellitus por diagnóstico médico previo se ha incrementado de $4,6 \%$ en 1993 , de $5,8 \%$ en 2000 , a $7 \%$ en 2006 ; la HTA, de $10,1 \%$ en 1993 , $12,5 \%$ en 2000 y $15,4 \%$ en 2006 . La hipercolesterolemia de $6,4 \%$ en 2000 y $8,6 \%$ en 2006.

En sobrepeso las mujeres $(37,4 \%)$ presentaron menor proporción que los hombres $(42,5 \%)$; sin embargo sucedió lo contrario con la obesidad (hombres $24,2 \%$ y mujeres $34,5 \%$ ) (Oláiz et al., 2006).

Dentro de los factores de riesgo para padecer enfermedades cardiovasculares se destacan los niveles elevados de $C L$ y otros lípidos en la sangre.

Estudios clínicos controlados tanto de prevención primaria como de prevención secundaria presentan evidencias concluyentes de que el CL total y las LDL son agentes causales de la aterosclerosis y que con la reducción del $\mathrm{CL}$ se consiguen disminuciones significativas de los eventos clínicos cardiovasculares y la mortalidad de los pacientes hasta en un 10\% (Backer et al., 2004; Jiménez et al., 2004; Varady et al., 2005; Matthew et al., 2009).

\subsection{Metabolismo de las lipoproteínas}

Los lípidos son moléculas orgánicas insolubles en agua, que forman parte de las membranas celulares constituyendo una barrera hidrofóbica. Son fuentes de energía y forman también parte de las vitaminas hidrosolubles ( $A, D, E$ y $K$ ), de las prostaglandinas y las hormonas esteroideas. Se transportan a través del plasma, unidas a las proteínas y formando partículas de lipoproteína.

Las lipoproteínas son moléculas complejas formadas por lípidos y proteínas específicas llamadas apolipoproteínas que proporcionan cubiertas hidrosolubles a los lípidos hidrofóbicos, lo que les permite su transporte en la sangre. Están compuestas por un núcleo lipídico hidrofóbico que contiene TG, esteres de colesterol o ambos y están rodeados por una cubierta de apolipoproteínas (apoproteínas), 
fosfolípidos y $C L$ no esterificado a manera de membrana antifática (tanto hidrofóbica como hidrofílica) (Figura 1).

Poseen un metabolismo dinámico es decir, se encuentran en constante estado de síntesis, degradación y remoción del plasma, dependiendo de la dieta, de la ingesta de alcohol, de los factores hereditarios, de la presencia o ausencia de apolipoproteínas (Apos), de la actividad enzimática y de la presencia de enfermedades como la diabetes mellitus, la hipertensión arterial, el síndrome nefrótico y el hipotiroidismo. Cuentan también con un mecanismo muy eficiente para suministrar el contenido de sus lípidos a los tejidos (Genest et al., 2005; Pérez, 2009; Miguel, 2009).

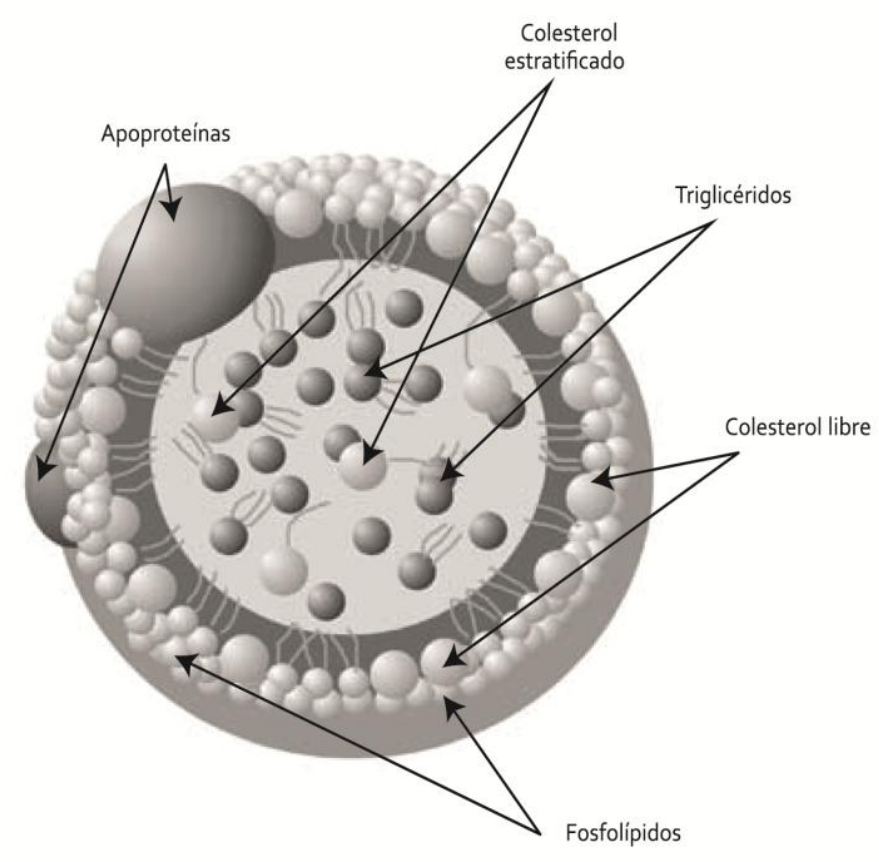

Figura 1. Estructura de las lipoproteínas

(Blanco et al., (2010). Dislipoproteinemias.

Los TG y el CL libre o esterificado, son los principales lípidos que transportan las lipoproteínas; son obtenidos generalmente de la dieta o por síntesis de novo, como se puede apreciar en la tabla No.5

El exceso de kilocalorías provenientes de la dieta se convierte en triglicéridos y se almacena en el adipocito (Matthew et al., 2009). 
Tabla 5. Composición de las lipoproteínas plasmáticas (\%)

\begin{tabular}{|l|c|c|c|c|c|c|}
\hline Lipoproteína & Q & VLDL & IDL & LDL & HDL & Lipoproteína \\
\hline Origen & Intestino & Hígado & VLDL & IDL & Tejidos & Hígado \\
\hline Apoproteína & $\begin{array}{c}\text { B48, E, } \\
\text { CII }\end{array}$ & $\begin{array}{c}\text { B100, } \\
\text { CII, CIII }\end{array}$ & $\begin{array}{c}\text { B100, } \\
\text { E }\end{array}$ & $\begin{array}{c}\text { B10 } \\
\text { o }\end{array}$ & $\begin{array}{c}\text { Al,AII, } \\
\text { AIV }\end{array}$ & B100, A \\
\hline Triglicéridos & 90 & 60 & 50 & 8 & 5 & \\
\hline $\begin{array}{l}\text { Colesterol y } \\
\text { esteres de } \\
\text { colesterol }\end{array}$ & 5 & 20 & 20 & 50 & 40 & \\
\hline Proteínas & 2 & 10 & 18 & 25 & $40-55$ & $30-50$ \\
\hline Fosfolípidos & 3 & & & 22 & 30 & \\
\hline
\end{tabular}

Fuente: Genest, et al. (2005). Dyslipoproteinemias /Atheroesclerosis. Cardiovascular therapeutics. A companion to Braunwald heart disease. W.B. Saunders Company, 1013-1053.

Existen tres maneras para clasificar a las lipoproteínas: por su densidad de flotación, por su movilidad electroforética y por su contenido en apolipoproteínas. A la densidad de flotación se le conoce como el estándar de oro para clasificar a las lipoproteínas, se conocen cinco clases, en la tabla No.6 se pueden apreciar sus características.

Tabla No. 6 Clasificación de las lipoproteínas por su densidad de flotación

\begin{tabular}{|l|c|c|c|}
\hline Lipoproteínas & $\begin{array}{c}\text { Densidad de } \\
\text { flotación }(\mathbf{m g} / \mathbf{m l})\end{array}$ & $\begin{array}{c}\text { Apolipoproteínas } \\
\text { principals }\end{array}$ & $\begin{array}{c}\text { Diámetro } \\
(\mathbf{c m})\end{array}$ \\
\hline O & $<0.94$ & $\begin{array}{c}\text { Apo B48, apo Cl, apo } \\
\text { CII, apo CIII, apo E }\end{array}$ & $>70$ \\
\hline VLDL & $1.006-1.019$ & $\begin{array}{c}\text { Apo B 100, apoCl, apo } \\
\text { CII, apo CIII, apo E }\end{array}$ & $30-70$ \\
\hline IDL & $1.019-1.063$ & $\begin{array}{c}\text { Apo B 100, apoCl, apo } \\
\text { CII, apo CIII, apo E }\end{array}$ & $20-30$ \\
\hline LDL & $1.063-1.120$ & Apo B 100, apo E & $18-25$ \\
\hline HDL & $1.120-1.210$ & $\begin{array}{c}\text { Apo Al, apo All, apo } \\
\text { AIV, apo Cl, apo, CII, } \\
\text { apo CIII, apo E }\end{array}$ & $7.5-12.5$ \\
\hline
\end{tabular}

Fuente: Pérez (2009). Anormalidades de las lipoproteínas que contienen ApoB. En: S, Barquera et al., Dislipidemias, epidemiología, evaluación, adherencia y tratamiento (pp.33-51). México. Instituto Nacional de Salud Pública.

Por su movilidad electroforética se clasifican en tres tipos: $\alpha, \beta$ y pre- $\beta$ que corresponde respectivamente a las HDL, a las LDL y a las VLDL (lipoproteínas de muy baja densidad), lo que dio origen a lo que se conoce como dislipoproteinemia considerando la fracción electroforética alterada, naciendo así las hipoalfalipoproteinemias y las abetalipoproteinemias. 
Por su contenido en apolipoproteínas se dividen en dos clases: las lipoproteínas que contienen apo $B$ que a su vez se dividen en apo B100 que corresponde a las lipoproteínas LVDL, IDL y LDL y las que contienen apo $B$ 48que corresponde a los $Q$, y las liporpoteínas que contienen apo AI (LpAl) que corresponde a las HDL (Pérez, 2009).

Las principales funciones de las lipoproteínas son las de transportar los diferentes lípidos ( $C L$ y TG) de donde se producen a los diferentes destinos, al hígado y a los tejidos periféricos como puede observarse en la tabla No. 7

Tabla No. 7 Funciones de las lipoproteínas

\begin{tabular}{|l|l|}
\hline \multicolumn{1}{|c|}{ Lipoproteínas } & \multicolumn{1}{c|}{ Función } \\
\hline Q & Transporta TG de intestino a tejidos periféricos \\
\hline VLDL & Transporta TG de intestino a tejidos periféricos \\
\hline IDL & Transporta CL y TG al hígado \\
\hline LDL & Transporta CL a tejidos periféricos e hígado \\
\hline HDL & Transporta CL a tejidos periféricos e hígado \\
\hline
\end{tabular}

Fuente: Genest et al. (2005). Dyslipoproteinemias /Atheroesclerosis .Cardiovascular therapeutics. A companion to Braunwald heart disease. W.B. Saunders Company, 1013-1053.

\subsubsection{Metabolismo de los quilomicrones}

Los quilomicrones (Q) son lipoproteínas generadas por las células intestinales y secretadas al sistema circulatorio a través del conducto torácico; contienen grandes cantidades de TG sobre todo en su núcleo, así como pequeñas cantidades de esteres de colesterol, ambos provenientes de la dieta. Poseen una cubierta compuesta de $\mathrm{CL}$ no estratificado, fosfolípidos, apoB48 y apo $\mathrm{E}$ y tienen una vida media de 20 minutos e intervienen en el transporte de lípidos que provienen de los alimentos. Las grasas provenientes de la dieta generalmente son TG, que al ser ingeridos son hidrolizados por medio de la lipasa pancreática en el intestino y degradados a ácidos grasos y monoglicéridos para que puedan entrar a la mucosa intestinal, donde se resintetizan como TG y se incorpora a los $\mathrm{Q}$.

Los $\mathrm{Q}$ pasan a la circulación y se ponen en contacto con la enzima lipoproteína lipasa que se encuentra en la superficie de los capilares, retirando los TG del núcleo y pasándolos al tejido adiposo para su almacenamiento. Cuando llegan al plasma repletos de TG (remanentes de Q) pasan al hígado debido a la existencia de 
receptores de $\mathrm{Q}$ por medio de la apo B48, apo $\mathrm{E}$ y apo Cll. No se consideran aterogénicos. (Ascaso et al., 2007; Pérez, 2009; Blanco et al., 2010).

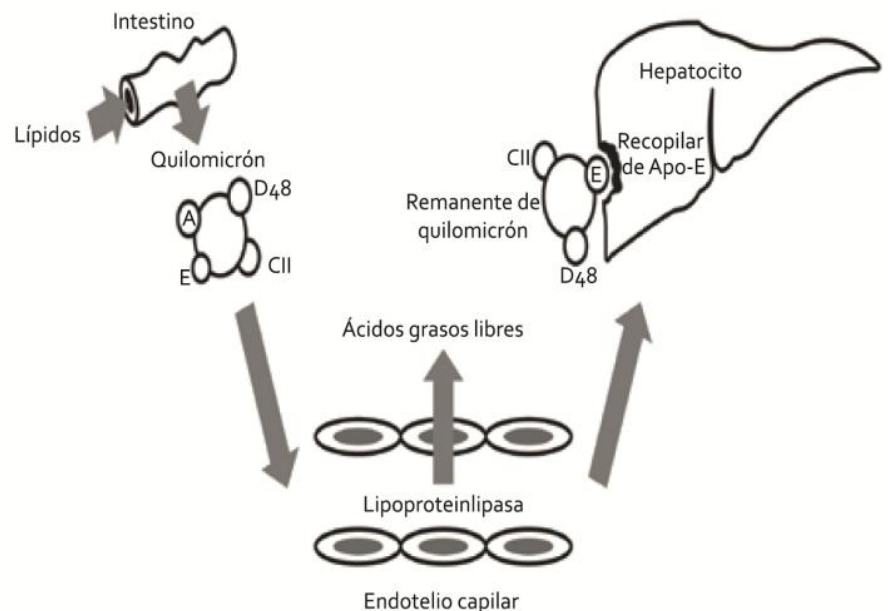

Figura 2. Metabolismo de los quilomicrones (Blanco et al. (2010). Dislipoproteinemias)

\subsubsection{Metabolismo de las lipoproteínas de muy baja densidad}

Las VLDL son lipoproteínas que se forman en el hígado, son ricas en TG pero de origen endógeno, con una vida media de 4 a 6 horas. Tienen menos TG en su núcleo y su cubierta contiene abundante cantidad de apoB100 y también contiene menores cantidades de Cll y CIII (figura 3).

Cuando las VLDL pasan a la circulación periférica interactúan con la enzima lipoproteina lipasa, perdiendo TG por hidrólisis y transformándose en remanentes de VLDL, algunos con un rango mayor de densidad llamados lipoproteínas de densidad intermedia (IDL) y dos tercios de ellos se convierten en LDL o son removidos por el hígado.

Cuando los niveles de TG son muy elevados en el plasma, se produce mayor cantidad de remanentes de VLDL, haciéndolos aterogénicos (Pérez, 2009; Blanco et al., 2010). 


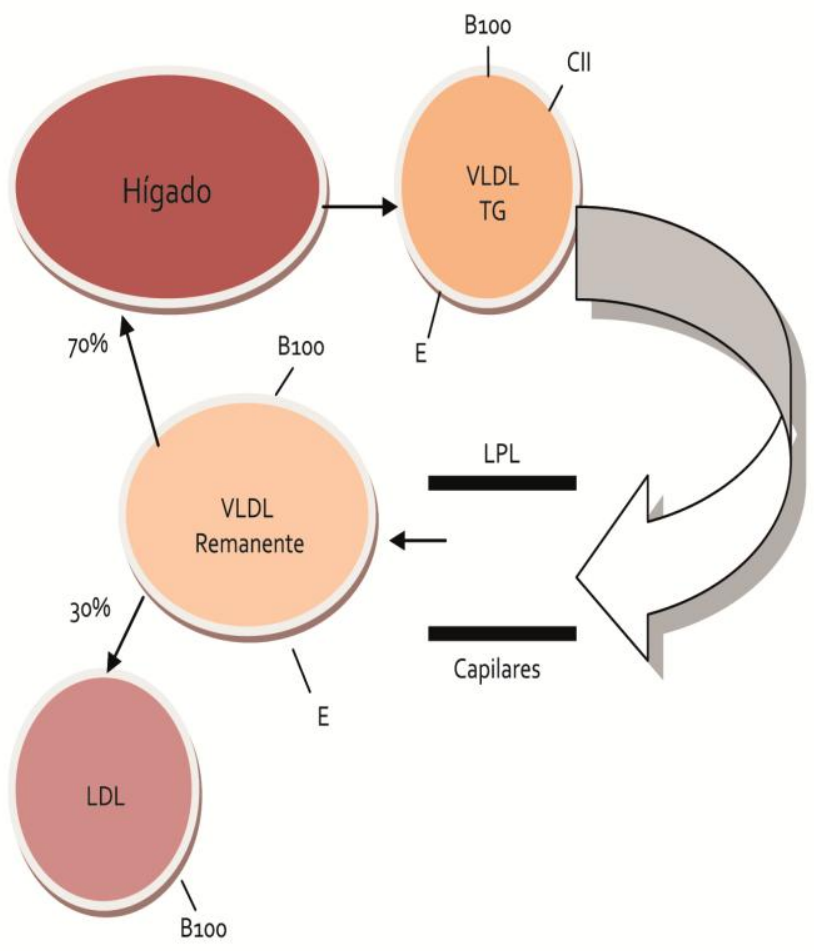

Figura 3. Metabolismo de las lipoproteínas de muy baja densidad (Blanco et al. (2010). Dislipoproteinemias)

\subsubsection{Metabolismo de las lipoproteínas de baja densidad}

Las LDL son lipoproteínas que se forman del catabolismo de las VLDL y las IDL y en menor proporción en el hígado. Su núcleo está constituido por un alto contenido de $\mathrm{CL}$ y su membrana superficial está formada por apo B100.

Su retirada de la circulación es muy lenta, aproximadamente tarda de 2 a 3 días y depende de la enzima proteína de transferencia de esteres de colesterol (CETP).

Casi dos tercios del CT sérico se encuentran en el plasma en forma de LDL y se metaboliza en el hígado. Cuando se incrementa el contenido de $\mathrm{CL}$ dentro del hígado debido a la ingestión en la dieta de alimentos ricos en $C L$ y ácidos grasos saturados, se suprime la síntesis de receptores de LDL. Las LDL se eliminan lentamente del compartimento plasmático y se exponen por más tiempo a la acción de la lipasa, particularmente la hepática, que por su acción lipolítica, 
reduce el contenido del núcleo haciendo las partículas de LDL más pequeñas y densas de lo normal. Estas partículas penetran con más facilidad al espacio subendotelial donde son más susceptibles de ser oxidadas, lo que las hace altamente proaterogénicas (Pérez, 2009) (figura 4).

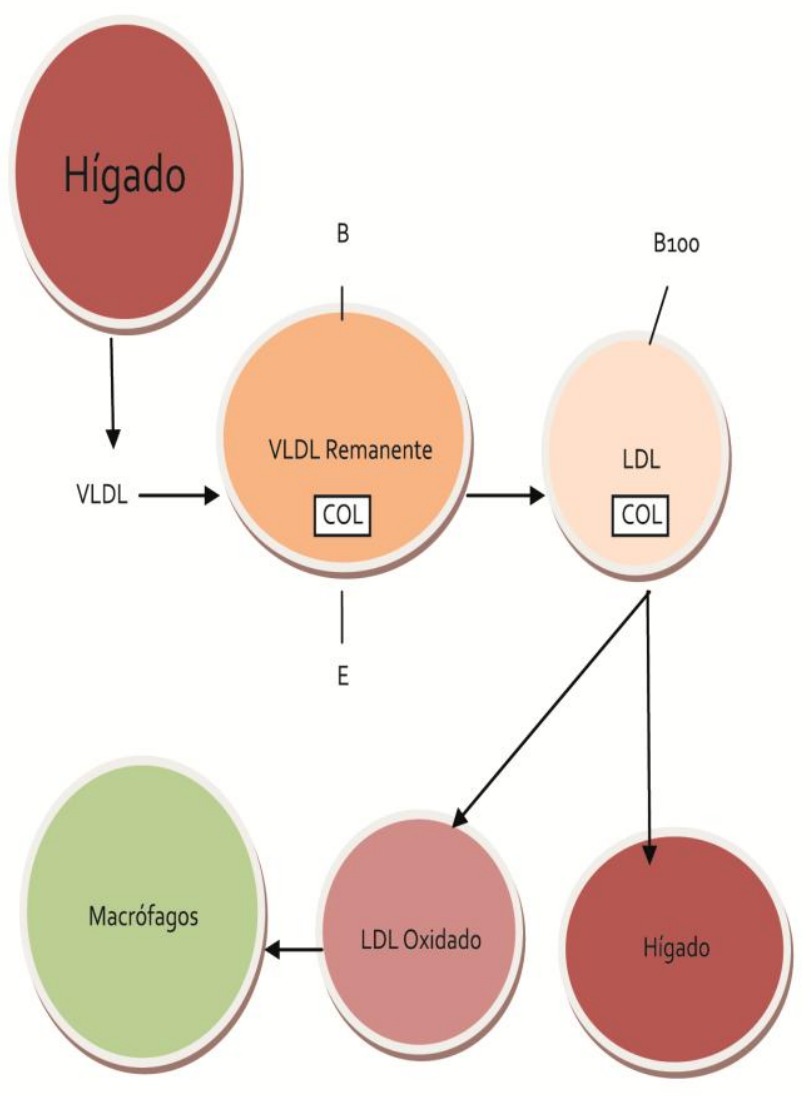

Figura 4. Metabolismo de las lipoproteínas de baja densidad (Blanco et al. (2010). Dislipoproteinemias)

\subsubsection{Metabolismo de las lipoproteínas de alta densidad}

Las HDL son lipoproteínas formadas de CL libre y fosofolípidos en su superficie y por CL esterificado y TG en su núcleo. Se estabilizan con apo Al principalmente, apo All, y además contiene apo $\mathrm{E}$, apo $\mathrm{Cl}$, Apo CII, apo CIII y apo AIV.

Debido a la heterogeneidad de la familia de HDL y a que la función que realizan depende de su estructura, las HDL tienen muchas clasificaciones, sin embargo, las más utilizadas son dos: de acuerdo su densidad de flotación y a su contenido en apoproteínas. 
De acuerdo a su densidad de flotación se dividen en HDL2 (densidad entre 1.063 y $1.12 \mathrm{~g} / \mathrm{mL}$ ) y HDL3 (densidad entre 1.12 y $1.21 \mathrm{~g} / \mathrm{mL}$ ). La otra clasificación las divide en HDLA-I porque contienen apo Al y HDL A-I: A-Il porque posee apo Al y apo All.

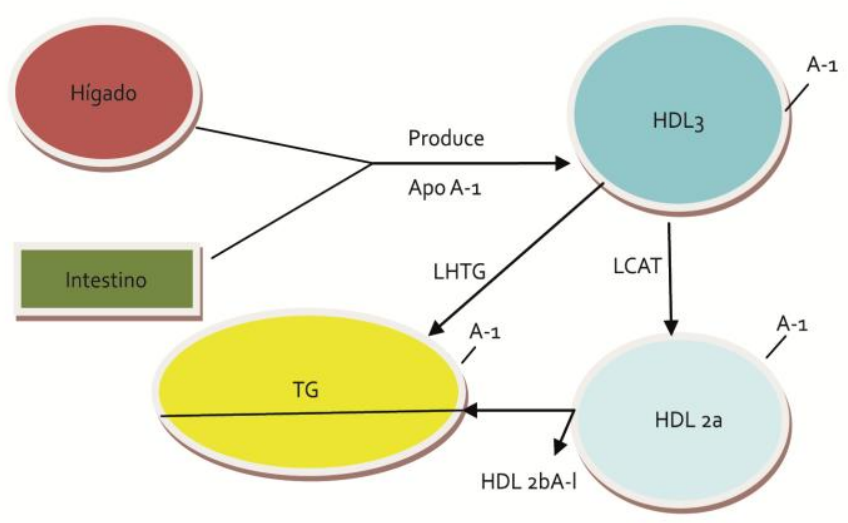

Figura 5.Metabolismo de las lipoproteínas de alta densidad (Blanco et al. (2010). Dislipoproteinemias)

El metabolismo de esta lipoproteína se comprende mejor cuando se estudia como un ciclo ya que es muy complejo y no totalmente conocido.

Las HDL evitan la formación de ateromas a través de un mecanismo conocido como transporte reverso de colesterol (TRC), que se define como el regreso del colesterol excedente de las células periféricas hacia el hígado para su excreción o reciclamiento. Primero ocurre la biosíntesis de HDL por parte del hepatocito.

El hepatocito secreta la proapo $\mathrm{Al}$, que contiene un hexapéptido señal que se elimina en plasma. Durante el proceso de secreción la proteína se une a los fosfolípidos de la membrana y forma las partículas pre- $\beta_{1}$ (tipo de HDL discoidal), que tienen mucha afinidad por el $C L$ excedente de las células periféricas. 
Posteriormente ocurre el eflujo de $\mathrm{CL}$ de las células hacia las partículas pre- $\beta_{1}$, para lo cual se utiliza una proteína de membrana llamada ABC-A1 (ATP binding cassette Class $A$ type 1 ), que emplea ATP para bombear $C L$ y fosfolípidos de manera activa hacia las HDL (pre- $\beta_{1}$ ) ubicadas en el exterior de la célula. Después del eflujo, el CL captado por las HDL tipo pre $\beta_{1}$ es esterificado por la enzima plasmática lecitina colesterol acil transferasa (LCAT), lo que provoca que el CL pierda su carácter anfipático, abandonando la superficie de la lipoproteína para situarse en el interior de la partícula incrementando su tamaño. Entonces puede ser intercambiado por TG que provengan de lipoproteínas que contienen apoB, principalmente VLDL, IDL y $\mathrm{Q}$ en estado postprandial. Este intercambio de lípidos hidrofóbicos es facilitado por la proteína de transferencia de esteres de colesterol (CETP).

Los TG que llegaron a las HDL por efecto de la CETP son hidrolizados por la lipasa hepática (LH), que unida a la actividad de la proteína de transporte de fosfolípidos (PLTP) disminuye el tamaño de las HDL2 transformándolas en HDL3 y en partículas pre- $\beta_{1}$ que pueden reiniciar el ciclo de captación de CL (Pérez, 200gb).

\subsection{Relación entre inflamación y dislipemias}

Cuando en el organismo humano ocurre un daño tisular, infecciones, inflamación o malignidad, aparece una respuesta fisiológica y bioquímica llamada fase aguda, durante la cual varias proteínas se sintetizan de manera aumentada, principalmente en los hepatocitos, como respuesta a la presencia de citocinas que se originan en el sitio de la agresión.

La interleucina-1 (IL-1) es la citocina más importante que induce la síntesis de proteínas durante la respuesta de fase aguda (RFA), sin embargo, también participan la interleucina-6 (IL-6) y el factor de necrosis tumoral alfa (TNF- $\alpha$ ). La IL-1 y el TNF- $\alpha$ inhiben la liporpotein lipasa, lo que genera altas concentraciones de VLDL, hipertrigliceridemia y bajas concentraciones de HDL. La IL-6 se produce en varios tejidos, sobre todo en el adiposo y se considera una molécula que promueve la aterosclerosis debido a su capacidad de incrementar la resistencia a la insulina y la HTA.

En el proceso de la aterosclerosis suceden varios eventos inflamatorios que tienen relación con la oxidación de las LDL que transportan los ácidos grasos y CL del hígado a los tejidos; las LDL se exponen a los peróxidos hidrogenados de las células vasculares, produciéndose así la oxidación.

Las LDL oxidadas dañan la células e inducen la secreción de moléculas de adhesión que promueven la unión de monocitos y 
linfocitos a las células endoteliales, lo que hace que los monocitos de convierten en macrófagos. Así se estimula la producción IL-1 y especies reactivas de oxígeno que transforman las LDL en moléculas muy oxidadas que son capturadas por los macrófagos para formar las células espumosas. A éstas células espumosas se unen monocitos y macrófagos que lesionan la estructura de la célula hasta formar un tejido fibroso.

El proceso de inflamación se incrementa al quedar las LDL capturadas en el espacio endotelial, ya que modifican la expresión genética de las células de la pared vascular que mantienen la respuesta inflamatoria promotora de la aterosclerosis (González et al., 2009).

Los cambios que ocurren en los lípidos circulantes durante la RFA son mediados por las citocinas y tienen como finalidad redistribuir los nutrientes a las células que participan en la defensa del huésped, reparar las membranas celulares (ricas en $\mathrm{CL}$ ) dañadas durante el proceso agudo, destruir los parásitos y destruir las sustancias tóxicas.Esta situación provoca un incremento en la concentración sérica de $\mathrm{TG}$, disminución de las $\mathrm{HDL}$, así como cambios en el $\mathrm{CL}$ total y las LDL (Flores et al., 2009).

\subsection{Clasificación de las dislipemias}

Ya se definió la dislipemia como una alteración de los lípidos sanguíneos principalmente el CL, los TG o ambos; sin embargo para clasificarla es importante considerar otros aspectos como la etiología, el tipo de dislipemia y su severidad, como puede observarse en la tabla No. 8.

Si se considera su etiología, se pueden clasificar en primarias y secundarias. Las dislipemias de etiología primaria corresponden a mutaciones genéticas en donde aparecen cambios en la secuencia de bases nitrogenadas del ADN que afectan a las apoproteínas, a las enzimas que intervienen en su metabolismo (lipoproteína lipasa [LPL], lipasa hepática [LH], lecitina colesterol aciltransferasa [LCAT] o a los receptores celulares de las lipoproteínas circulantes.; se sospecha de su existencia cuando aparecen signos de dislipemia en niños, en enfermedades ateroscleróticas prematuras (menores de 60 años) y con niveles de $C L$ en sangre por arriba de $6,2 \mathrm{mmol} / \mathrm{L}$ (Miguel, 2009).

Las dislipemias de origen genético más frecuentes son la hipercolesterolemia familiar (HF), la hiperlipemia combinada familiar (HCF) la hipercolesterolemia poligénica y la hiperlipemia tipo III. 
Tabla No. 8 Dislipemias primarias

\begin{tabular}{|l|l|}
\hline \multicolumn{1}{|c|}{ Dislipemia } & \multicolumn{1}{|c|}{ Aspectos clínicos } \\
\hline Hipercolesterolemia familiar(HF) & $\begin{array}{l}\text { Pronóstico pobre: requiere detección } \\
\text { precoz y tratamiento agresivo. }\end{array}$ \\
\hline Defecto familiar apo B-100 & $\begin{array}{l}\text { Pronóstico variable; puede requerir } \\
\text { tratamiento agresivo. }\end{array}$ \\
\hline Hiperlipoproteinemia familiar Lp (a) & $\begin{array}{l}\text { Potencial aterotrombogénico alto si Lp } \\
(\text { a) de } 40 \text { mg/dL o más y si LDL/HDL alto } \\
(>3,5)\end{array}$ \\
\hline Hipertrigliceridemia familiar (HTGF) & $\begin{array}{l}\text { Evaluar historia familiar y } \\
\text { manifestaciones de enfermedad } \\
\text { coronaria (EC). }\end{array}$ \\
\hline Hiperlipemia familiar & $\begin{array}{l}\text { LDL y TG altos y HDL bajo; es la } \\
\text { combinación más dañina; con obesidad } \\
\text { e insulinoresistencia. }\end{array}$ \\
\hline Dislipemia tipo III & $\begin{array}{l}\text { Muy aterogénica; debido en la mayoría } \\
\text { de los casos a la presencia homocigota } \\
\text { de la apo E2. }\end{array}$ \\
\hline Sindromes familiares de déficit de & $\begin{array}{l}\text { Mutaciones de diversos genes: Al, } \\
\text { grupo Al-CII-AIV y lecitina colesteril } \\
\text { HDL }\end{array}$ \\
\hline
\end{tabular}

Fuente: modificadoa de Campos et al. (2009). Diagnóstico de las Dislipidemias. En: S. Barquera et al. Dislipidemias, epidemiología, evaluación, adherencia y tratamiento, (pp.81-104). México: Instituto Nacional de Salud Pública.

Las dislipemias secundarias constituyen la mayoría de los casos de dislipemia en adultos. Se producen por alteraciones adquiridas en la función de algunos de los lípidos por efecto del tipo de alimentación, de fármacos o de patologías subyacentes.

La causa más frecuente es el estilo de vida sedentario con ingesta elevada de grasas saturadas (como la mantecas de origen animal, la carne de cerdo y otras) y colesterol.

Estas causas perturban las distintas etapas del transporte lipídico o debidas a varios factores, entre ellos causas de origen endocrino (diabetes mellitus), renal (glomérulonefritis y el síndrome nefrótico), hepático (cirrosis), hormonal (hipotiroidismo) y medicamentoso (inmunosupresores, corticoesteroides, terapia antirretroviral muy activa), el consumo excesivo de alcohol, entre otros, que pueden observarse en la tabla No. 9. 
Tabla No. 9 Causas de Dislipemia Secundaria

\begin{tabular}{|c|c|}
\hline Tipo de dislipemia & Causas \\
\hline Hipercolesterolemia & $\begin{array}{l}\text { - Hipotiroidismo } \\
\text { - Síndrome de Cushing } \\
\text { - Diabetes mellitus tipo II } \\
\text { - Enfermedad renal terminal } \\
\text { - Síndrome nefrótico } \\
\text { - Enfermedad hepática crónica obstructiva } \\
\text { - Porfiria intermitente aguda } \\
\text { - Cirrosis biliar primaria } \\
\text { - Anticonceptivos orales } \\
\text { - Dieta rica en ácidos grasos saturados } \\
\text { - Disglobulinemia } \\
\text { - Anorexia nerviosa }\end{array}$ \\
\hline Hipertrigliceridemia & $\begin{array}{l}\text { - Obesidad } \\
\text { - Dieta rica en hidratos de carbono } \\
\text { - Consumo excesivo de alcohol } \\
\text { - Embarazo } \\
\text { - Diabetes mellitus } \\
\text { - Lupus eritematoso sistémico } \\
\text { - Insuficiencia renal crónica } \\
\text { - Síndrome de Cushing } \\
\text { - Hipopituitarismo } \\
\text { - Disglobulinemia } \\
\text { - Pancreatitis } \\
\text { - Bulimia } \\
\text { - Lipodistrofia } \\
\text { - Porfiria intermitente aguda } \\
\text { - Betabloqueadores } \\
\text { - Estrógenos } \\
\text { - Diuréticos } \\
\text { - Glucocorticoides }\end{array}$ \\
\hline Disminución de HDL & $\begin{array}{l}\text { - Diabetes mellitus tipo II } \\
\text { - Síndrome de Cushing } \\
\text { - Enfermedad renal terminal } \\
\text { - Síndrome nefrótico } \\
\text { - Cirrosis biliar primaria } \\
\text { - Alcohol } \\
\text { - Diuréticos tiazídicos } \\
\text { - Betabloqueadores } \\
\text { - Ciclosporinas. }\end{array}$ \\
\hline
\end{tabular}

Fuente: modificado de International Lipid Information Bureau (ILIB)(1998). Enfoque escalonado para la evaluación y el tratamiento de la dislipidemia en adultos. Manual ILIBsobre lípidos para la nrártica rlínica Walverlv Hicnánica ৎ A

De acuerdo al tipo de dislipemia existen varias clasificaciones pero la más aplicable a la mayoría de los pacientes y más sencilla para hacer el diagnóstico diferencial es la propuesta por el Consenso Europeo en 1994 (Campos et al., 2009) que las cataloga de acuerdo con la alteración básica de los lípidos, distinguiéndose tres grupos (Tabla No.10). 
Tabla No. 10 Clasificación de las dislipemias de acuerdo con el Consenso Europeo

\begin{tabular}{|l|c|c|}
\hline \multicolumn{1}{|c|}{ Tipo de dislipemia } & Colesterol & Triglicéridos \\
\hline Hipercolesterolemia & $>200 \mathrm{mg} / \mathrm{Dl}$ & $<200 \mathrm{mg} / \mathrm{dL}$ \\
\hline Leve & $200-250 \mathrm{mg} / \mathrm{dL}$ & \\
\hline Moderada & $250-300 \mathrm{mg} / \mathrm{dL}$ & \\
\hline Severa & $>300 \mathrm{mg} / \mathrm{dL}$ & \\
\hline Dislipemia mixta & $>200 \mathrm{mg} / \mathrm{dL}$ & $>200 \mathrm{mg} / \mathrm{dL}$ \\
\hline Hipertrigliceridemia & $<200 \mathrm{mg} / \mathrm{dL}$ & $>200 \mathrm{mg} / \mathrm{dL}$ \\
\hline
\end{tabular}

Fuente: modificadoa de Campos et al. (2009). Diagnóstico de las Dislipidemias. En: S. Barquera et al., Dislipidemias, epidemiología, evaluación, adherencia y tratamiento, (pp.81-104).México: Instituto Nacional de Salud Pública.

En esta clasificación no se ha considerado la hipoalfalipoproteinemia (HDL bajo) que tiene grandes implicaciones, ya que las lipoproteínas de alta densidad tienen efecto protector contra los eventos cardiovasculares y presentar cifras por debajo de las recomendadas puede causar eventos cardiovasculares.

Otra clasificación que ha sido ampliamente utilizada es la de Frederickson, que se basa en la tipificación de lipoproteínas elevadas sin tomar en cuenta los niveles de HDL, ni diferenciar etiologías. En la actualidad se utiliza principalmente para identificar la hiperlipemia familiar tipo III cuando no es posible determinar la isoforma apo $\mathrm{E}_{i}$ además permite diferenciar si las hipertrigliceridemias son de origen exógeno (dieta) o endógeno (VLDL producidas por el hígado) como se puede apreciar en la tabla No.11

Tabla No.11 Clasificación Fenotípica de las dislipemias (Fredrickson)

\begin{tabular}{|l|c|c|}
\hline Fenotipo & Lipoproteínas aumentadas & Lípidos aumentados \\
\hline I & Q & Triglicéridos \\
\hline Ila & LDL & Colesterol \\
\hline IIb & LDL y VLDL & Colesterol y triglicéridos \\
\hline III & VLDL y residuos de O & Triglicéridos y cholesterol \\
\hline IV & VLDL & Triglicéridos \\
\hline V & Q y VLDL & Triglicéridos y cholesterol \\
\hline
\end{tabular}

Fuente: Miguel, P. (2009) Dislipidemias. Revista Cubana de Información en Ciencias de la Salud (ACIMED), 20(6), 265-273.

\subsection{Riesgo cardiovascular}

De acuerdo con Miguel et al. (2008) desde el punto de vista epidemiológico, el riesgo cardiovascular $(\mathrm{RCV})$ se refiere al número 
de nuevos acontecimientos cardiovasculares que aparecen en una población durante un periodo determinado en el contexto de un estudio prospectivo o de seguimiento.

El RCV estimado, según el mismo autor, es la probabilidad que tiene la persona de presentar un acontecimiento cardiovascular en un tiempo, estimada mediante un cálculo numérico (tablas) y /o una etiqueta (riesgo alto, moderado y bajo).

Existen dos métodos generales para estimar el RCV: cualitativo y cuantitativo. El método cualitativo considera para clasificar a los individuos en los diferentes niveles de riesgo la presencia o ausencia de factores de riesgo cardiovascular (FRCV). Tanto los FRCV como los niveles de riesgo son diferentes de acuerdo con los distintos textos, guías y consensos.

El método cuantitativo considera y pondera la presencia y magnitud o ausencia de FRCV y utiliza ecuaciones para obtener una estimación numérica de la probabilidad de presentar un episodio en un periodo determinado, que se expresa con distintas categorías de riesgo (alto, moderado y bajo).

Para evaluar el RCV las sociedades científicas y los organismos oficiales en todo el mundo han utilizado principalmente las tablas construida a partir de la segunda cohorte de Framingham publicada por Anderson en 1991. Sin embargo, al considerar las características de cada población, como la epidemiología de la dislipemia y notar que las tablas no son pruebas de tamizaje (no detectan casos a confirmar con pruebas posteriormente), ni son pruebas diagnósticas (no confirman un diagnóstico) se observó que no deben convertirse en instrumentos para la toma de decisiones, sino que deben simplemente ayudar a evaluar la intervención $o$ no en un determinado paciente, por lo general con fármacos.

De ahí se han realizado adecuaciones en los diferentes países cuyas diferencias se aprecian en las variables o factores de riesgo utilizados, su categorización, la predicción que realizan y el tiempo para el que realizan la predicción. Así nacieron las tablas como la PROCAM (1993) en Alemania, la GISSI (2001) en Italia, la Procock (2001) de Inglaterra, SCORE (2003) en España, entre otras.

En México el manejo de las dislipemias ha pasado por numerosos consensos en los que las principales diferencias se encuentran en las estrategias de escrutinio, los criterios diagnósticos y la selección de los fármacos a utilizar, concluyendose que las estrategias para prevenir los eventos vasculares deben adaptarse a las características de la población a la cual van a ser aplicadas y dar respuesta a los factores de riesgo más comunes. 
Por lo anterior los consensos realizados en Estados Unidos o en Europa no pueden ser aplicados sin tomar en cuenta que la epidemiología de la dislipemia en México se caracteriza por niveles bajos de HDL e hipertrigliceridemia (Aguilar et al., 2004).

Para obtener mejores resultados se plantea la estrategia de utilizar la medición del riesgo cardiovascular global (RCG), que se determina considerando en el individuo, los factores que se presentan a continuación (Campos et al., 2009):

1.- Edad y sexo: Hombre $>45$ años

Mujer > 55 años

2.- Hipertensión arterial

3.- Tabaquismo

4.- Diabetes mellitus

5.- Colesterol $\mathrm{HDL}<35 \mathrm{mg} / \mathrm{dL}$

6.- Antecedentes familiares de patología vascular en personas jóvenes.

Los resultados de evaluar los riesgos se contrastan con la clasificación que se encuentra a continuación en la tabla No. 12

Tabla No. 12 Clasificación del riesgo cardiovascular global

\begin{tabular}{|l|l|}
\hline \multicolumn{1}{|c|}{ Riesgo } & \multicolumn{1}{c|}{ Parámetros } \\
\hline Bajo & Con menos de dos factores \\
\hline Alto & Con dos o más factores \\
\hline Máximo & $\begin{array}{l}\text { Con manifestaciones clínicas de patología } \\
\text { ateroesclerótica y diabetes }\end{array}$ \\
\hline
\end{tabular}

Fuente: Campos et al. (2009). Diagnóstico de las Dislipidemias. En: S. Barquera et al., Dislipidemias, epidemiología, evaluación, adherencia y tratamiento, (pp.81-104).México: Instituto Nacional de Salud Pública.

Los tres más importantes FRCV modificables son el consumo de tabaco, la HTA y la hipercolesterolemia; secundarimente se encuentran la diabetes, la obesidad, el sedentarismo y el excesivo consumo de alcohol.

El consumo de tabaco es la principal causa de morbimortalidad prematura y prevenible en el mundo. En México, Villalobos et al. (2007) reportaron disminución en la prevalencia de consumo de tabaco en los jóvenes de $14,5 \%$ en el año 2000 a 10,8\% en el 2006 en los hombres, y de 5,0\% en el año 2000 a 4,3\% en el 2006 en las mujeres. 
La HTA está asociada a incrementos en la incidencia de enfermedad cardiovascular aun con elevaciones ligeras, especialmente la enfermedad cerebrovascular.

Los resultados de la Encuesta Nacional de Salud y Nutrición 2006 (ENSANUT, 2006), muestran una prevalencia en mayores de 20 años de $30,8 \%$.

Con diagnóstico previo a la encuesta, las mujeres reportaron un $18,7 \%$ y los hombres $11,4 \%$ y los hallazgos durante la encuesta fueron inversos, presentándose con $20,1 \%$ en hombres y $12,1 \%$ en mujeres (Oláiz et al., 2006).

Con respecto a la hipercolesterolemia, 8,5\% de los adultos presentaron el CL alto con diagnóstico previo a la ENSANUT 2006, en mayor proporción las mujeres $(9,3 \%)$ que los hombres $(7,6 \%)$.

El hallazgo durante la encuesta (por encima de $200 \mathrm{mg} / \mathrm{dL}$ ) fue de $18 \%$ para ambo sexos, siendo mayor en las mujeres $(19,5 \%)$ que en los hombres (15,1\%) (Oláiz et al., 2006).

En la tercera versión del Programa Nacional de Educación en Colesterol (NCEP-ATPIII) que se publicó en 2001 y en su actualización en 2003, se hizo la recomendación de que la medición del perfil de lípidos ( $C L, T G$ y $H D L$ ) se realice al menos cada 5 años en adultos con 20 años o mayores y que las evaluaciones para personas con múltiples factores de riesgo o con niveles limítrofes altos de $C L$ deben ser más frecuentes.

Esta periodicidad se propuso debido a que las concentraciones de colesterol se incrementan con la edad, al igual que el peso corporal. Se resaltó la importancia de la medición del perfil de lípidos en todos los adultos que vivan en países con alta prevalencia de cardiopatía isquémica, sobre todo aquellos que la padecen o que presentan cualquier otra enfermedad cardiovascular, hipertensión arterial, diabetes mellitus y en personas con antecedentes familiares de cardiopatía isquémica prematura, xantoma, arco corneal o xantelasma o al detectar el RCG.

La cardiopatía isquémica es una de las principales causas de muerte en México, por lo que su prevención es una meta prioritaria. Por ello se recomienda que la concentración de $\mathrm{CL}$, TG y HDL sea medida en todo adulto como parte de cualquier chequeo médico. Si sus valores son normales, la medición debe ser repetida cada 5 años (NCEP, 2001; Campos et al., 2009).

Las personas deben saber cuáles son sus cifras de lípidos sanguíneos para que puedan tomar las riendas de su tratamiento; para ello deben conocer primero cuáles son los parámetros normales, los cuales han sido definidos de acuerdo al riesgo cardiovascular. 
Con respecto a las HDL, en el ATP-Il está definido, como punto de corte la concentración menor de $35 \mathrm{mg} / \mathrm{dL}_{\text {; }}$ en el ATP-III la sensibilidad del criterio se incrementó a menor de $40 \mathrm{mg} / \mathrm{dL}$ argumentando que la obesidad y el sedentarismo se asocian a niveles entre 35 y $40 \mathrm{mg} / \mathrm{dL}$.

Este sustento no es muy convincente, sobre todo porque propone el mismo criterio para hombres y mujeres, siendo que las últimas tienen concentraciones promedio más altas.

Por otro lado, el Consenso Europeo de 2003 propone el uso de puntos de corte diferentes para hombres $(40 \mathrm{mg} / \mathrm{dL}$ ) y mujeres $(46 \mathrm{mg} / \mathrm{dL})$.

En México se afecta significativamente el número de casos, puesto que $48,4 \%$ de los adultos entre 20 y 69 años de las zonas urbanas tienen $\mathrm{HDL}<35 \mathrm{mg} / \mathrm{dL}$ y al aplicar el criterio de $40 \mathrm{mg} / \mathrm{dL}$, dicho porcentaje se incrementa a $60 \%$.

Aguilar et al. (2004) en un documento avalado por la Sociedad Mexicana de Nutrición y Endocrinología, presentan recomendaciones sobre el diagnóstico y tratamiento de las dislipemias basadas en datos obtenidos en población mexicana y de estudios controlados publicados en los últimos 15 años, los cuales se presentan en el tabla No.13.

Sin embargo, al no contar con estudios prospectivos realizados en población abierta que permitan identificar las concentraciones óptimas de HDL en población mexicana y ante la necesidad de detectar personas en riesgo cardiovascular, se sugiere que sean definidos los niveles bajos de HDL por debajo de 40mg/dL con el objetivo de ganar sensibilidad en la predicción de riesgo cardiovascular, reduciendo los casos que resulten falsos negativos.

Sin embargo, aun cuando es considerado un importante factor de riesgo cardiovascular cuando se encuentra en niveles bajos, no se hacen las recomendaciones para el nivel óptimo ni se cuenta con recomendaciones específicas para el tratamiento de sus concentraciones bajas; sólo se presentan recomendaciones generales en el estilo de vida como disminuir el peso corporal, incrementar la actividad física para reducir la grasa abdominal, abstenerse en el consumo de tabaco y en caso necesario utilizar el tratamiento farmacológico a base de estatinas, fibratos o ácido nicotínico.

Por lo tanto, se recomienda entonces utilizar los valores de lípidos considerados normales según el Third Report of the National Colesterol Education Program, que se presentan en la tabla No. 14. 
Tabla No. 13 Puntos críticos en el diagnóstico y tratamiento de las dislipemias

1. El escrutinio de una dislipidemia es costo/efectivo en todo adulto mayor de 20 años. 2. El abordaje diagnóstico inicia al clasificar los casos por síndromes (hipercolesterolemia aislada, hipertrigliceridemia aislada, hiperlipidemia mixta e hipoalfalipoproteinemia). 3. El diagnóstico etiológico de la dislipidemia puede ser identificado en la mayoría de los casos.

4. La identificación de la etiología ayuda a la estimación del riesgo cardiovascular. 5. No se recomienda el uso sistemático de las tablas de Framingham.

6. Se identifican como condiciones que requieren tratamiento prioritario de la dislipidemia a: la cardiopatía isquémica, la insuficiencicia carotídea, la insuficiencia arterial de miembros inferiores, la diabetes, la intolerancia a la glucosa, el síndrome metabólico, la hipercolesterolemia familiar, la hiperlipidemia familiar combinada, otras dislipidemias primarias (disbetalipoproteinemia, la hipertrigliceridemia familiar, la hipoalfalipoproteinemia familiar) si coexisten con otro factor de riesgo cardiovascular, la dislipidemia por trasplante, por síndrome nefrótico o por antirretrovirales. Individuos con un riesgo superior al $20 \%$ a 10 años al momento de su evaluación o al extrapolar su pronóstico a la edad de 60 años también serán considerados como prioritarios para recibir tratamiento. Los casos considerados como de alta prioridad son candidatos para recibir tratamiento farmacológico.

7. Los casos no incluidos en el número previo se consideran como no prioritarios; su tratamiento deberá basarse en modificaciones del estilo de vida.

8. El colesterol-LDL es la meta primaria del tratamiento en la hipercolesterolemia aislada. El colesterol no-HDL (LDL, IDL y VLDL) es la meta en pacientes con triglicéridos $>200 \mathrm{mg} / \mathrm{dL}$. En la hipertrigliceridemia con colesterol HDL bajo, la normalización de los TG y del colesterol HDL son la meta de tratamiento. Si coexiste con niveles limítrofes de colesterol no HDL (> 16o mg/dL) su corrección también debe ser considerada como un objetivo terapéutico. En la hipoalfalipoproteinemia aislada, el objetivo debe ser normalizar la concentración de colesterol HDL. Sin embargo, ante la dificultad de lograrlo, la reducción del colesterol LDL es la meta a alcanzar en los casos en quienes el colesterol HDL no pueda ser corregido.

9. No se recomienda el uso de metas estratificadas para el colesterol LDL. Las metas de tratamiento para cada componente del perfil de lípidos son: colesterol $L D L<100$, colesterol no $\mathrm{HDL}<130$, triglicéridos $<150 \mathrm{mg} / \mathrm{dL}$ y colesterol $\mathrm{HDL}>40 \mathrm{mg} / \mathrm{dL}$. 10. Las estatinas son los fármacos de primera elección en casos con hipercolesterolemia aislada; los fibratos lo son para la hipertrigliceridemia aislada.

Fuente: Aguilar et al. (2004). Diagnóstico y tratamiento de las dislipidemias: posición de la Sociedad Mexicana de Nutrición y Endocrinología. Revista de Endocrinología y Nutrición, 12 (1), 141

Los TG por su lado, han sido tipificados por el ATP-III como un factor de riesgo independiente, sugiriendo el empleo de $150 \mathrm{mg} / \mathrm{dL}$ como punto de corte para el diagnóstico de hipertrigliceridemia. Esto debido a que las LDL se incrementan por encima de ese punto de corte.

Además, la presencia de dislipemias aterogénicas como la hiperlipemia familiar combinada o la producida por síndrome metabólico se asocian a valores de TG entre 150 y $200 \mathrm{mg} / \mathrm{dL}$, casos que hubiesen sido considerados normales con el anterior criterio de $>200 \mathrm{mg} / \mathrm{dL}$. También la hipoalfalipoproteinemia se incrementa por arriba de ese punto de corte. 
Tabla No. 14 Niveles de lípidos de acuerdo con NCEP

\begin{tabular}{|l|l|c|c|c|l|}
\hline \multicolumn{1}{|c|}{ Lípidos } & \multicolumn{1}{c|}{ Óptimo } & $\begin{array}{c}\text { Casi } \\
\text { óptimo }\end{array}$ & $\begin{array}{c}\text { Límite } \\
\text { alto }\end{array}$ & $\begin{array}{c}\text { Nivel } \\
\text { alto }\end{array}$ & Muy alto \\
\hline $\mathrm{CL}(\mathrm{mg} / \mathrm{dL})$ & $<200$ & & $200-239$ & $>240$ & \\
\hline $\mathrm{TG}(\mathrm{mg} / \mathrm{dL})$ & $<150$ & & $150-199$ & $200-499$ & $>500$ \\
\hline $\begin{array}{l}\mathrm{LDL} \\
(\mathrm{mg} / \mathrm{dL})\end{array}$ & $<100$ & $100-129$ & $130-159$ & $160-189$ & $>190$ \\
\hline $\begin{array}{l}\mathrm{HDL} \\
(\mathrm{mg} / \mathrm{dL})\end{array}$ & Alto & Bajo & & & \\
\cline { 2 - 6 } & $\geq 60$ & $\geq 40$ & & & \\
\hline
\end{tabular}

Fuente: Expert Panel on Detection, evaluation and treatment of high blood colesterol in adults. Executive summary of the third report of the National Cholesterol Education Program (NCEP) (2001) Expert Panel on Detection, evaluation and treatment of high blood cholesterol in adults (Adult Treatment Panel II). Journal of the American Medical Association (JAMA), 1, 627-633

El CL total de acuerdo con el ATP-III tiene un punto de corte de 200 $\mathrm{mg} / \mathrm{dL}$, mismo considerado adecuado en la población mexicana para la definición de hipercolesterolemia. Las LDL son calculadas con la fórmula de Friedewald:

\section{Colesterol-LDL=Colesterol total-(Colesterol-HDL [Triglicéridos/5])}

Esta fórmula resulta casi perfecta para personas con TG menores a $200 \mathrm{mg} / \mathrm{dL}$, pero en presencia de hipertriglicedidemia se recomienda utilizar el CL no-HDL cuya fórmula es:

\section{Colesterol no-HDL: Colesterol total -Colesterol-HD}

Este parámetro asume que todo el $\mathrm{CL}$ que no es transportado en las HDL es potencialmente aterogénico, lo cual es cierto en la mayoría de los casos. A excepción de los individuos que presentan acumulación de $\mathrm{Q}$ en el plasma manifestado por un valor de TG > $1000 \mathrm{mg} / \mathrm{dL}$, en cuyo caso el CL no-LDL no debe ser utilizado (Aguilar et al., 2004; Campos et al., 2009).

El riesgo de un individuo a presentar un evento coronario se puede calcular siguiendo tres pasos:

1.-Primer paso: consiste en conocer el riesgo a 10 años de padecer un evento coronario que variará de acuerdo con la patología de base, 
antecedentes o al número de factores de riesgo en prevención primaria, como puede resumirse en la tabla No.15.

Tabla No. 15 Objetivo del LDL según el cálculo de riesgo de evento coronario a 10 años. ATP III (NCEP) 2004

\begin{tabular}{|c|c|}
\hline Riesgo a 10 años de evento coronario & $\begin{array}{c}\text { Meta LDL } \\
(\mathrm{mg} / \mathrm{dL})\end{array}$ \\
\hline $\begin{array}{l}>20 \% \\
\text {-Alto riesgo: } \\
\text { a) Enfermedad coronaria } \\
\text { b) Diabetes mellitus tipo II } \\
\text { c) Enfermedad ateriosclerótica no coronaria (carotidea, miembros } \\
\text { inferiores, aorta) } \\
\text { d) Dislipidemia aterogénica prematura } \\
\text { e) Riesgo calculado > } 20 \% \text { en prevención primaria según tablas de } \\
\text { Framingham. } \\
\text {-Muy alto riesgo: } \\
\text { a) Enfermedad cardiovascular asociada a: diabetes mellitus, } \\
\text { múltipoles factores de riesgo, factores de riesgo no controlados, } \\
\text { varios factores de riesgo del síndrome metabólico. b) Evento } \\
\text { coronario agudo }\end{array}$ & $\begin{array}{l}\text { Menor a } \\
100 \mathrm{mg} / \mathrm{dL}\end{array}$ \\
\hline $\begin{array}{l}10 \text { al } 20 \% \text { (Más de dos factores de riesgo) } \\
\text {-Moderado: } \\
\text { a) A pesar de más de dos factores de riesgo calculado a } 10 \text { años } \\
\text { según Framingham es menor al 10\%. } \\
\text { b) Síndrome metabólico } \\
\text { c) Diabetes mellitus I } \\
\text { d) Diabetes mellitus // sin otro factor de riesgo incluido } \\
\text { microalbuminuria. } \\
\text {-Moderadamente alto: } \\
\text { a) Que incluya dentro de los factores de riesgo a la historia familiar } \\
\text { de enfermedad coronaria prematura o varios factores de riesgo no } \\
\text { controlados. } \\
\text { b) Que se asocie con síndrome metabólico }\end{array}$ & $\begin{array}{l}\text { Menor a } \\
130 \mathrm{mg} / \mathrm{dL} \\
\text { (Sólo en } \\
\text { estos } \\
\text { casos) }\end{array}$ \\
\hline $\begin{array}{l}<10 \% \\
\text {-Bajo o latente: } 0-1 \text { factor de riesgo }\end{array}$ & $\begin{array}{l}\text { Menor a } \\
160 \mathrm{mg} / \mathrm{dL}\end{array}$ \\
\hline
\end{tabular}

Fuente: Merchán et al. (2010). Estratificación del riesgo de enfermedad coronaria, metas del perfil lipídico y tratamiento de acuerdo con el riesgo. En Blanco et al. (2010). Dislipoproteinemias. (pp. 329-334).

2.-Segundo paso: se realiza en personas que sólo tienen más de dos factores de riesgo en prevención primaria. Primero se calcula el número de factores de riesgo de los que aparecen en el tabla No.16 pues son los que presentan mayor asociación con enfermedad coronaria. Se excluyó de la tabla la diabetes mellitus por considerarse equivalente a enfermedad coronaria y el CL debido a que es el factor a controlar. 
Tabla No. 16 Principales factores de riesgo para enfermedad coronaria, que Modifican los objetivos de LDL

- Tabaquismo

- Hipertensión Arterial: PA > $140 \mathrm{mmHg}$

- HDL $<40 \mathrm{mg} / \mathrm{dL}$ para ambos sexos

- Edad $\geq 45$ años en hombres $y \geq 55$ en mujeres

- Antecedente familiar de cardiopatía coronaria antes de los 55 años en familiar de sexo masculino de primer grado de consanguinidad y antes de los 65 años en familiar de sexo femenino de primer grado de consanguinidad.

Fuente: Merchán, et al. (2010). Estratificación del riesgo de enfermedad coronaria, metas del perfil lipídico y tratamiento de acuerdo con el riesgo. En Blanco et al. (2010). Dislipoproteinemias. (pp. 329-334).

Con los factores ya identificados y utilizando las tablas de Framingham se observan cuatro posibilidades:

a) Cuando el paciente tiene o y 1 factor de riesgo a 10 años, es menor al $10 \%$ de acuerdo con las tablas de Frmingham y no se requiere utilizarlas.

b) Cuando el paciente tiene dos o más factores de riesgo para enfermedad coronaria, el riesgo a 10 años puede ser mayor a $20 \%$ al utilizar las Tablas de Framingham.

c) Con dos o más factores de riesgo, puede ser que el riesgo calculado se encuentre entre 10 y $20 \%$ al aplicar las Tablas de Framingham.

d) En algunas ocasiones a pesar de tener dos o más factores de riesgo, el cálculo al utilizar las Tablas de Framingham puede encontrarse menor al 10\%.

Se puede concluir que las Tablas de Framingham se deben utilizar en personas sin patología previa (prevención primaria) y en quienes tengan más de dos factores de riesgo con el objetivo de calcular el riesgo de eventos coronarios a 10 años y tratar de lograr una meta en el control del LDL (Merchan et al., 2010).

3.- Tercer paso: consiste en utilizar las tablas de Framingham para hombres y mujeres con el propósito de establecerel riesgo coronario a 10 años y saber si pacientes de prevención primaria que cursan con dos a más factores de riesgo será mayor al $20 \%$, entre 10 y $20 \%$ o menor al 10\%.

\subsection{Diagnóstico diferencial de las dislipemias}

Para realizar el diagnóstico diferencial de las dislipemias se utiliza frecuentemente la clasificación de las dislipemias del Consenso 
Europeo de 1994. (Ver tabla No. 10) Sin embargo, en México se han realizado algunas adecuaciones en los puntos de corte que han sido avaladas por la Sociedad Mexicana de Endocrinología y Nutrición (Aguilar et al., 2004).

\subsubsection{Hipercolesterolemia}

Se considera que padecen hipercolesterolemia las personas que presentan niveles de CL mayores de $200 \mathrm{mg} / \mathrm{dL}$ y TG menores de 150 $\mathrm{mg} / \mathrm{dL}$.

Pare establecer estrategias adecuadas de tratamiento se debe conocer en primer término si la hipercolesterolemia es causada por el acumulo de HDL o LDL. En el primer caso, las HDL deben presentarse en una concentración mayor a $60 \mathrm{mg} / \mathrm{dL}$, lo que se considera con frecuencia como una situación protectora contra la aparición de aterosclerosis ya que las HDL se encargan del transporte del $\mathrm{CL}$ de los tejidos periféricos hacia el hígado para ser eliminados.

Pero cuando es debida a efectos en la proteína CETP, la prevalencia de complicaciones cardiovasculares se presenta con mayor frecuencia que en la población general.

Existen otras causas que incrementan el HDL, como el empleo de estrógenos, la práctica de ejercicio aeróbico en atletas, en niños el daño renal incipiente y en sujetos delgados y sanos el consumo regular de cantidades pequeñas de alcohol. Causas primarias raras son las anormalidades en la región reguladora del gen de la apoproteína Al.

En el segundo caso, cuando la hipercolesterolemia es provocada por las LDL, éstas se presentan en una concentración mayor a 130 $\mathrm{mg} / \mathrm{dL}$, situación considerada de riego aterogénico.

Las causas de esta anormalidad son la diabetes mellitus tipo II no controlada, el síndrome de resistencia a la insulina, el uso de diuréticos, corticoesteroides, retinoides, ciclosporina, esteroides anabólicos, presencia de síndrome nefrótico, hipotiroidismo, anorexia nerviosa, consumo alto en la dieta de grasas saturadas y colesterol.

También causas primarias como la hipercolesterolemia familiar, hiperlipemia familiar combinada e hipercolesterolemia poligénica, como se puede ver en la figura 6 (Aguilar et al., 2004; Campos et al., 2009; Matthew et al., 2009) 


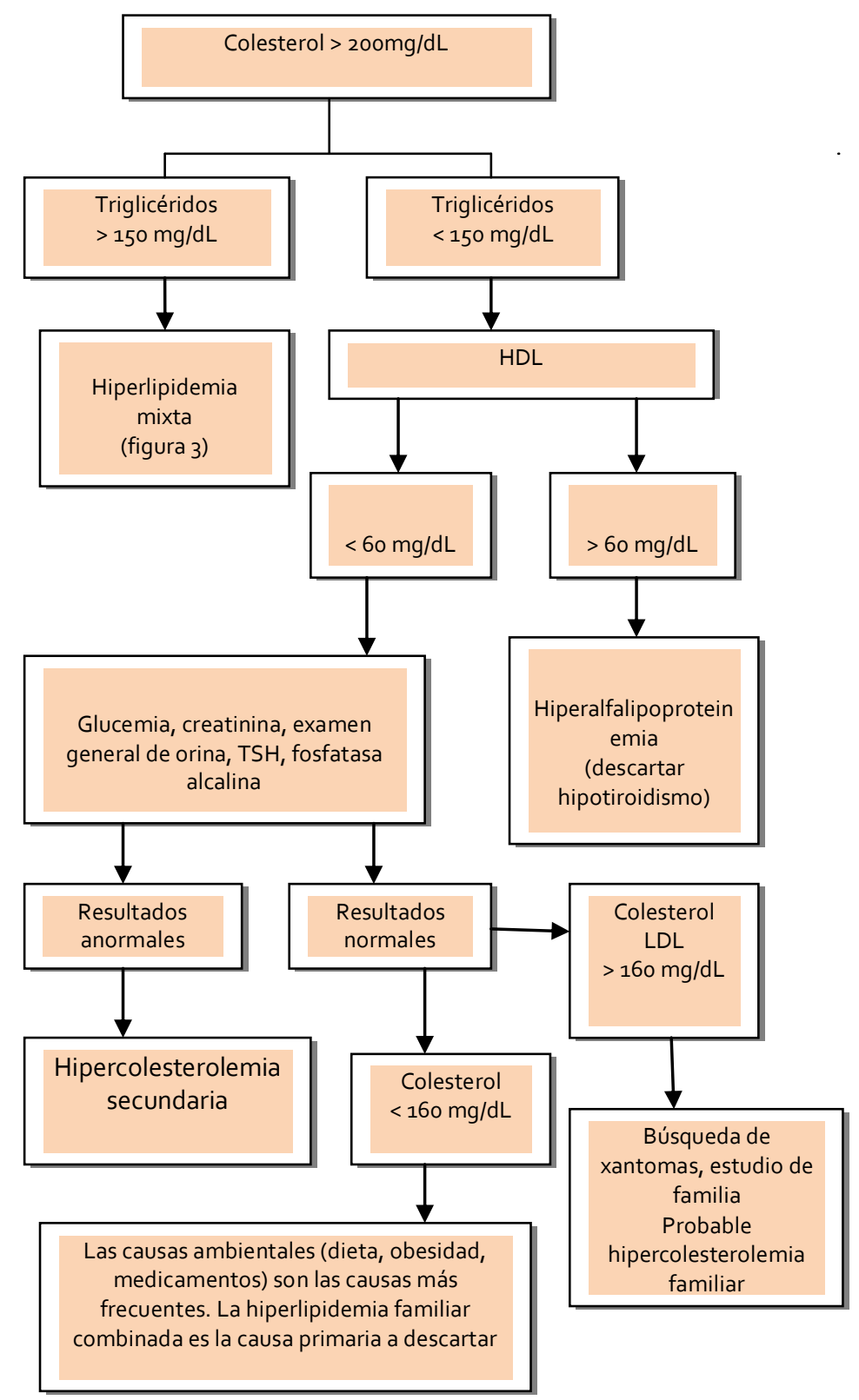

Figura 6. Diagnóstico diferencial de la hipercolesterolemia

Fuente: Aguilar et al. (2004) Diagnóstico y tratamiento de las dislipidemias: posición de la Sociedad Mexicana de Nutrición y Endocrinología. Revista de Endocrinología y Nutrición, 12 (1), 1-41

\subsubsection{Hipercolesterolemia familiar}

Este tipo de dislipemia, considerada con mayor riesgo de aterosclerosis, tiene un patrón de herencia autosómica dominante, aunque también puede ser recesiva. Presenta una prevalencia de 1/500 habitantes para los heterocigotos y de 1/ 1,000,000 para los homocigotos en los grupos étnicos. 
La prevalencia más alta encontrada es en judíos ashkenasi (1:67 para heterocigotos), pero en franco-canadienses, sudafricanos $y$ libaneses también es común (1:270).

En México no existen datos epidemiológicos, pero en la Encuesta Nacional de Enfermedades Crónicas (ENEC-1994) se encontraron hallazgos que sugieren que menos del $1 \%$ de la población adulta urbana presenta perfiles de lípidos compatibles con este padecimiento.

Además, se observó que también está presente en el $5 \%$ de los casos de sobrevivientes mexicanos de infarto del miocardio. Se presenta clínicamente de dos maneras: la heterocigota que es la más común y la homocigota. La primera se caracteriza por presentar niveles de $C L$ entre 300 y $400 \mathrm{mg} / \mathrm{dL}$, presencia de arco corneal y xantomas tendinosos principalmente en el talón de Aquiles, los tendones de las manos y de los codos; cuando los niveles de CL son muy altos (por encima de los $300 \mathrm{mg} / \mathrm{dL}$ ), se presentan cuadros de tendinitis o poliartritis (en el $40 \%$ de los casos) en tobillos, rodillas, muñecas e interfalángicas proximales que ceden de manera espontánea.

La forma homocigota es muy rara, y se debe a anormalidades en el receptor $L D L$, en la apoproteína $B$ o en las proteínas que regulan el tránsito del receptor LDL a la superficie celular; presenta niveles muy elevados de CL (entre 600 y $1,200 \mathrm{mg} / \mathrm{dL}$ ), se acompaña de arco corneal, xantomas tendinosos y tuberosos y se asocia a cardiopatía isquémica prematura, con presencia de síntomas coronarios en el $45 \%$ de los hombres a los 50 años y el $20 \%$ en las mujeres a la misma edad. El riesgo relativo global en adultos es de 10:12 en hombres y de 5:36 en mujeres (Aguilar et al., 2004; Campos et al., 2009).

\subsubsection{Hipercolesterolemia poligénica}

La causa de este tipo de hipercolesterolemia es desconocida, pero se asocia a cardiopatía isquémica; su diagnóstico se establece cuando la persona y sus familiares de primer grado presentan niveles de LDL por debajo de $190 \mathrm{mg} / \mathrm{dL}$ en ausencia de xantomas.

\subsubsection{Hiperlipemia familiar combinada}

La HLFC es la más común de las dislipemias de origen genético; se desconoce su etiología pero se asocia a los del complejo de apoproteínas Al/CIII/AIV localizados en el cromosoma 11 y existe ligamiento con la región 1q 21- 23. Participa en la patogénesis de la cardiopatía isquémica familiar con una frecuencia entre el 30 y 50\%. 
Su prevalencia en la población general es de $0,5 \%$ a $2 \%$ y de $14 \%$ en las personas con enfermedad cardiovascular prematura. En estudios de población la prevalencia general es de $5,7 \%$ y de $9,9 \%$ en casos con cardiopatía isquémica.

En México, debido a los criterios diagnósticos vigentes no se conoce su prevalencia, pero se deduce que es alta por sus manifestaciones más frecuentes como la hiperlipemia mixta $(12,6 \%)$ y la hipertrigliceridemia $(24,3 \%)$, que se presentan en un alto porcentaje de adultos que viven en zonas urbanas.

Para su diagnóstico en población mexicana se utilizan los siguientes criterios: hipercolesterolemia, hipertrigliceridemia y de una hiperlipemia mixta en tres miembros distintos de una familia; concentraciones altas de apo $\beta$ (108 mg/dL en hombres y $99 \mathrm{mg} / \mathrm{dL}$ en mujeres) y ausencia de xantomas (Aguilar et al., 2004; Campos, et al., 2009).

\subsubsection{Hipertrigliceridemia}

Se puede afirmar que una persona padece hipertrigliceridemia cuando presenta niveles mayores de $150 \mathrm{mg} / \mathrm{dL}$ de TG y menores de $200 \mathrm{mg} / \mathrm{dL}$ de $\mathrm{CL}$ (figura 7).

Las causas de la hipertrigliceridemia pueden ser diversas. Cuando los niveles de TG se encuentran por debajo de $300 \mathrm{mg} / \mathrm{dL}$ se puede atribuir a causas secundarias como la diabetes mellitus descontrolada, cetoacidosis diabética, obesidad, síndrome de resistencia a la insulina, alcoholismo, uso de diuréticos, corticosteroides, betabloqueadores, esteroides anabólicos, estrógenos por vía oral, alimentación parenteral, insuficiencia renal, hemodiálisis, diálisis peritoneal, dietas vegetarianas, embarazo, bulimia, síndrome de inmunodeficiencia adquirida, uso de antirretrovirales, entre otras causas. Las más comunes son la obesidad, el consumo de hidratos de carbono simples, el tabaquismo, el consumo de alcohol y el síndrome metabólico.

Cuando la concentración de TG es superior a $300 \mathrm{mg} / \mathrm{dL}$, las causas generalmente son primarias como la hiperlipemia familiar combinada, hipertrigliceridemia familiar, disbetalipoproteinemia, deficiencia familiar de lipasa lipoproteica o de apo CII.

También se puede deber a la coexistencia de una causa primaria y una secundaria. Cuando la concentración es superior a $500 \mathrm{~g} / \mathrm{dL}$ se corre el riesgo de sufrir pancreatitis y al alcanzar los $1000 \mathrm{mg} / \mathrm{dL}$ de xantomas eruptivos localizados en los sitios de apoyo, hepatoesplenomegalia, disnea, mareo, ataque al estado general y dolor abdominal (Aguilar et al., 2004; Campos et al., 2009). 


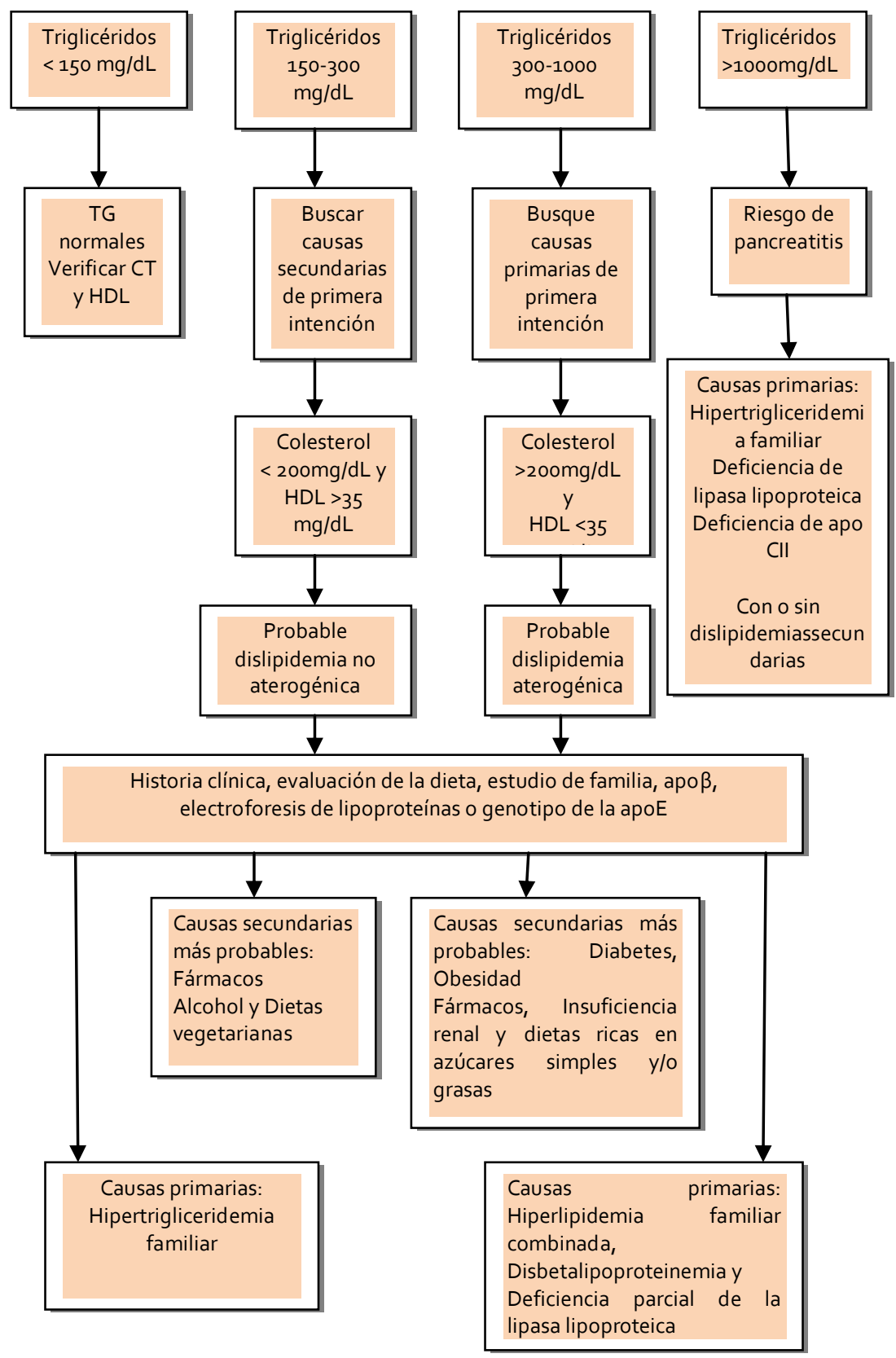

Figura 7. Diagnóstico diferencial de la hipertrigliceridemia

Fuente: Aguilar et al. (2004) Diagnóstico y tratamiento de las dislipidemias: posición de la Sociedad Mexicana de Nutrición y Endocrinología. Revista de Endocrinología y Nutrición, 12 (1), 1-41

En un estudio en el que se compararon los perfiles de lípidos en suero de 653 pacientes con enfermedad arterial coronaria prematura con 1029 sujetos control, se encontró que el riesgo asociado con niveles elevados de TG ( $\geq 500 \mathrm{mg} / \mathrm{dL}$ ) y niveles medios o altos de 
$H D L$, fue diez veces mayor que en los sujetos que presentaron niveles $<100 \mathrm{mg} / \mathrm{dL}$. Por lo que se puede afirmar que los niveles de TG tienen impacto en el riesgo coronario independientemente de los niveles de LDL y HDL (Eliot et al., 2009).

\subsubsection{Hipertrigliceridemia familiar}

Las causas de la hipertrigliceridemia familiar no se conocen concretamente, pero se diagnostica cuando la concentración de TG es superior a $200 \mathrm{mg} / \mathrm{dL}$, las LDL se encuentran en cifras normales o por debajo y la apoproteína $\beta$ se encuentra con niveles normales. Cuando las concentraciones de TG se elevan demasiado (1000 $\mathrm{mg} / \mathrm{dL}$ ) los niveles de HDL disminuyen.

Este tipo de hipertrigliceridemia es la causa más frecuente de pancreatitis y xantomas eruptivos en México y generalmente se acompaña con síndrome metabólico y diabetes mellitus tipo 2; cuando se asocia a obesidad, diabetes, alcoholismo, o al uso de glucocorticoides aumenta el grado de hipertrigliceridemia.

La mortalidad cardiovascular debida a hipertrigliceridemia familiar es alta y se debe a la coexistencia de síndrome metabólico; el diagnóstico se establece cuando la persona y uno más de sus familiares presentan el patrón descrito previamente (Eliot et al., 2009).

\subsubsection{Deficiencia familiar de lipoproteinas}

Estas alteraciones son muy raras, se observan en el $5 \%$ de la población y se presentan desde la infancia como consecuencia de la falta de actividad de la lipasa lipoproteica o su cofactor, la apoCll.

Se manifiestan por hipertrigliceridemia moderada, pero cuando se combina con otra causa secundaria, la concentración de TG puede rebasar los $300 \mathrm{mg} / \mathrm{dL}$. No se asocian a cardiopatía isquémica pero su complicación principal es la pancreatitis (Aguilar et al., 2004; Campos et al., 2009).

\subsubsection{Hiperlipemia mixta}

Este tipo de dislipemia se caracteriza por tener una de las tasas más alta de eventos coronarios (después de la hipercolesterolemia familiar), debido a que se acumulan en el plasma lipoproteínas que tienen la capacidad de depositarse en las paredes de las arterias, a la presencia de cambios protombóticos y a la disminución de la actividad fibrinolítica.

Las concentraciones de CL y TG se encuentran por arriba de lo normal (200mg/dL y $150 \mathrm{mg} / \mathrm{dL}$ respectivamente); el nivel de HDL 
más bajo y colesterol no HDL (LDL,IDL y VLDL) más alto que el resto de la población, debido a diferentes causas secundarias como son la diabetes mellitus descontrolada, la obesidad, el síndrome de resistencia a la insulina, la utilización de diuréticos, betabloqueadores, corticoesteroides, esteroides anabólicos, alimentación parenteral, insuficiencia renal con albuminuria, hemodiálisis, diálisis peritoneal, consumo alto de azúcares simples y grasas saturadas, embarazo, entre otras. Así como de causas primarias como hiperlipemia familiar combinada y disbetalipoproteinemia (figura 8).

En México es la dislipemia más frecuente en los adultos que viven en zonas urbanas que padecen sobrepeso $u$ obesidad; se presenta más en los hombres y su prevalencia se incrementa con la edad.

En hombres menores de 30 años la prevalencia es cuatro veces más alta que en las mujeres de la misma edad (Aguilar et al., 2004; Campos et al., 2009).

\subsubsection{Disbetalipoproteinemia}

Tipo de dislipemia poco común en México; la frecuencia es mayor en personas que padecen diabetes tipo 2 o síndrome de resistencia a la insulina; se presenta con concentraciones de $C L$ y LDL más bajas que el resto de la población con presencia de xantomas tuberosos y daña principalmente las arterias periféricas (aorta, femorales $y$ carótida) y con menor frecuencia las coronarias.

Se produce por la presencia de una isoforma de la apoproteina $E$ (apo E2) que presenta poca afinidad por los receptores de remanentes o de LDL, lo que provoca su acumulo en el plasma al no poder eliminarse.

Para que la enfermedad se exprese clínicamente debe coexistir otra causa de dislipemia como la obesidad, la diabetes mellitus, el hipotiroidismo y el empleo de betabloqueadores y diuréticos que disminuya el número o función del receptor LDL.

\subsubsection{Hipoalfalipoproteinemia}

Es un tipo de trastorno de los lípidos caracterizado por concentraciones anormalmente bajas de liporpoteínas de alta densidad (HDL) en la sangre; puede estar asociada a mutaciones a genes que codifican la Apoliporpoteína A-1, lecitina colesterol.acetil transferasa y transportadores de casetes de la unión a ATP. 


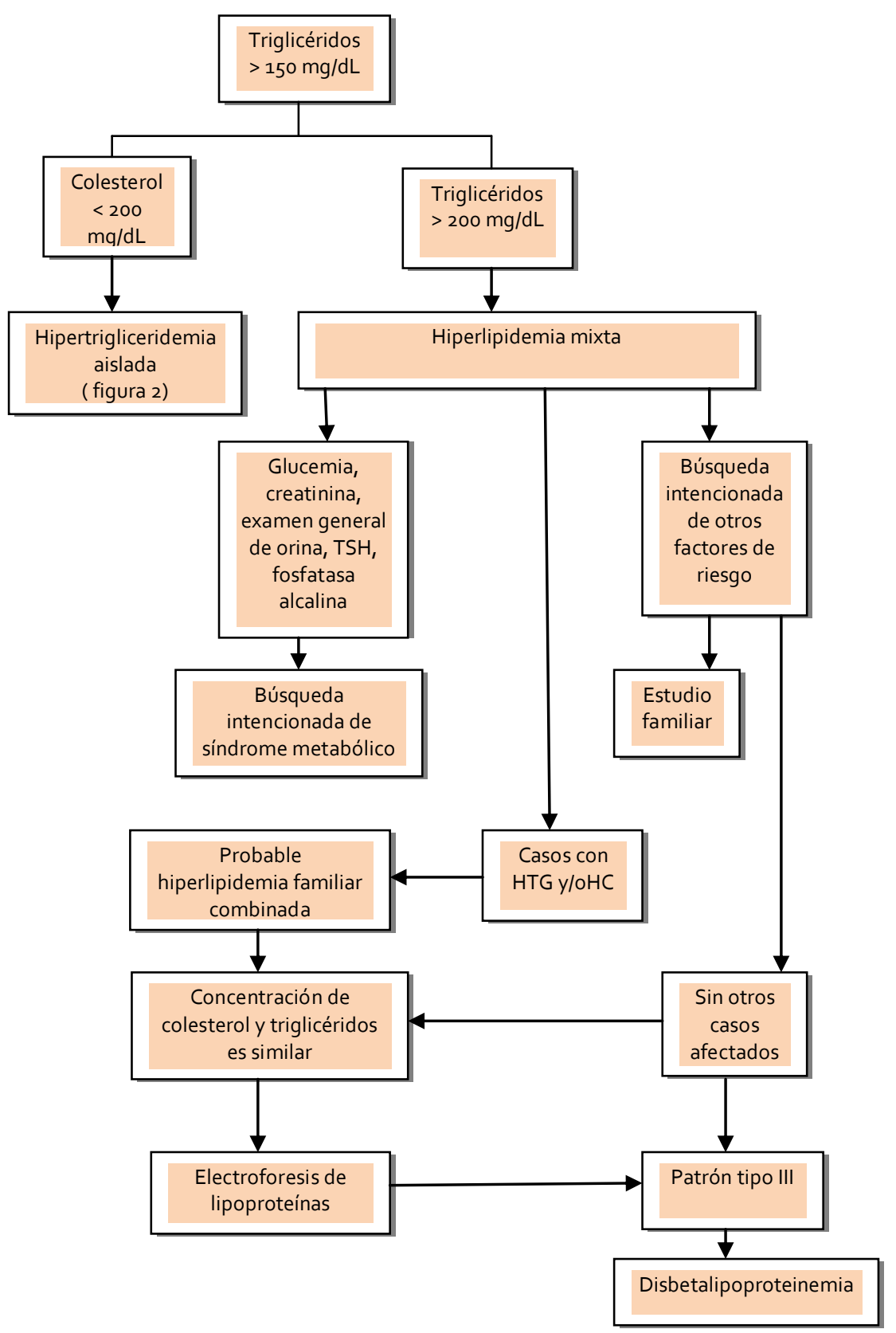

Figura 8. Diagnóstico diferencial de la hiperlipidemia mixta

Fuente: Aguilar et al. (2004) Diagnóstico y tratamiento de las dislipidemias: posición de la Sociedad Mexicana de Nutrición y Endocrinología. Revista de Endocrinología y Nutrición, 12 (1), 1-41

También puede desarrollarse debido a la ausencia de la apoproteína $\mathrm{E}$ por defectos en la estructura de su gen o por la ausencia de la lipasa hepática (figura 9). Se debe sospechar de su presencia cuando se elevan simultáneamente el CL y los TG a 300 $\mathrm{mg} / \mathrm{dL}$ y se confirma cuando en la electroforesis de lipoproteínas se 
encuentra un patrón tipo III o si se cuenta con los métodos de ultracentrifugación, una relación VLDL/ TG >0,3. Es muy sensible al tratamiento con fibratos y estatinas o con la eliminación de la causa precipitante (Aguilar et al., 2004; Campos et al., 2009).

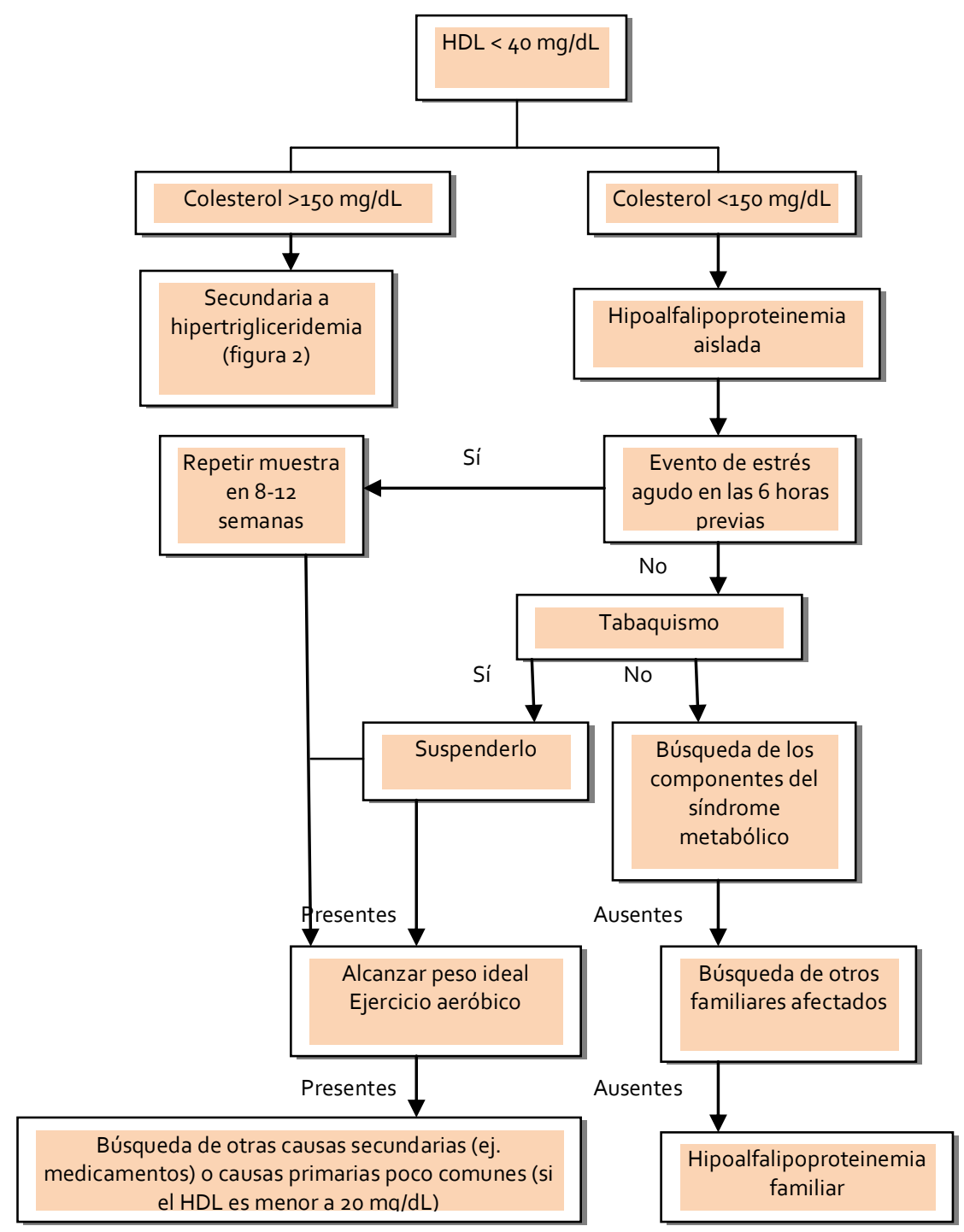

Figura 9. Diagnóstico diferencial de una hipoalfalipoproteinemia

Fuente: Aguilar et al. (2004) Diagnóstico y tratamiento de las dislipidemias: posición de la Sociedad Mexicana de Nutrición y Endocrinología. Revista de Endocrinología y Nutrición, 12(1), 1-41 


\subsection{Tratamiento de las dislipemias}

El principal objetivo del tratamiento de las dislipemias en México, de acuerdo con la Norma Oficial Mexicana NOM-037-SSA2-2002. Para la prevención, tratamiento y control de las dislipidemias, es la prevención de la aparición o recurrencia de eventos cardiovasculares a través de la reducción de los niveles plasmáticos de las LDL.

Como objetivos secundarios se observan el incremento de las HDL y lograr los valores óptimos del colesterol no-HDL menores a 130, 160 y $190 \mathrm{mg} / \mathrm{dL}$ en riesgo alto, moderado y bajo respectivamente (Aguilar et al., 2004; Merchán et al., 2010). El colesterol no-HDL es el resultado de la resta del HDL al CL total, quedando sólo las partículas altamente aterogénicas (LDL, IDL y VLDL). El objetivo del tratamiento consiste en aumentar en 30 $\mathrm{mg} / \mathrm{dL}$ el valor ideal para HDL de acuerdo con el riesgo del individuo a 10 años para eventos coronarios, como se puede observar en la tabla No.17

Tabla No. 17 Valores meta para las $L D L$ y el colesterol no-HDL de acuerdo con el riesgo a 10 años

\begin{tabular}{|l|c|c|}
\hline $\begin{array}{c}\text { Riesgo a 10 años de } \\
\text { evento coronario } \\
\text { Framingham }\end{array}$ & Objetivos del LDL & $\begin{array}{c}\text { Objetivos del } \\
\text { colesterol no-HDL }\end{array}$ \\
\hline Alto $(>20 \%)$ & $<100 \mathrm{mg} / \mathrm{dL}$ & $<130 \mathrm{mg} / \mathrm{dL}$ \\
\hline Intermedio (10-20\%) & $<130 \mathrm{mg} / \mathrm{dL}$ & $<160 \mathrm{mg} / \mathrm{dL}$ \\
\hline Bajo $<10 \%)$ & $<160 \mathrm{mg} / \mathrm{dL}$ & $<190 \mathrm{mg} / \mathrm{dL}$ \\
\hline
\end{tabular}

Fuente: Merchán et al. (2010). Estratificación del riesgo de enfermedad coronaria, metas del perfil lipídico y tratamiento de acuerdo con el riesgo. En Blanco et al. (2010). Dislipoproteinemias. (pp. 329334).

La Sociedad Mexicana de Nutrición y Endocrinología en 2004, publicó su posición sobre el diagnóstico y tratamiento de las dislipidemias; ahí se plantea considerar al colesterol no-HDL como objetivo primario del tratamiento en personas que presenten TG $>200 \mathrm{mg} / \mathrm{dL}$ y se elimine como objetivo al colesterol LDL por las dificultades para estimar su concentración.

Cuando las personas presentan hipertrigliceridemia y HDL bajo, el incremento de HDL predice mejor la reducción de mortalidad cardiovascular en $22 \%$ sin modificar las concentraciones de LDL, por lo tanto el objetivo del tratamiento será la normalización de los TG y de HDL. Si coexisten niveles limítrofes de colesterol no-HDL ( $>160$ $\mathrm{mg} / \mathrm{dL}$ ) su corrección también debe ser considerada como un objetivo terapéutico; en personas con hipoalfalipoproteinemia 
aislada, normalizar la concentración de HDL es el objetivo. Sin embargo, en la mayoría de los casos es difícil de lograr, por lo que se recomienda disminuir la concentración de las partículas potencialmente aterogénica; en este caso la reducción de LDL es la meta a alcanzar (Aguilar et al., 2004).

Para lograr todo esto es necesario identificar y tratar todos los factores de riesgo modificables, como el tabaquismo, la HTA, la diabetes mellitus, entre otros, ya que es la única alternativa para reducir la mortalidad pre-hospitalaria del infarto al miocardio.

El tratamiento de las dislipemias comprende dos aspectos primordiales: el tratamiento farmacológico hipolipemiante y el tratamiento no farmacológico (modificaciones en el estilo de vida).

\subsubsection{Tratamiento farmacológico de las dislipemias}

El tratamiento con fármacos es una de las terapias más efectivas porque produce reducción en la concentración de las lipoproteínas aterogénicas y con ello la disminución de sus efectos tóxicos sobre la función endotelial, dando como resultado menor contenido de lípidos, macrófagos, linfocitos e inflamación en las placas, con el consecuente incremento en el espesor de la capa fibrosa que le sirve de protección para no exponer su contenido a la circulación. Esto modifica la respuesta trombogénica y fibrinolítica, produciendo decremento en la aparición de complicaciones cardiovasculares e incremento de la posibilidad de mejorar la calidad de vida en el futuro (Eliot et al., 2009).

El tratamiento hipolipemiante, independientemente del género, debe centrarse en las personas con mayor riesgo como son aquellos que han experimentado un evento cardiovascular, ya que tienen el riesgo absoluto más alto (superior al $20 \%$ a 10 años) de volver a sufrir un nuevo evento coronario, situación que se incrementa con la edad.

A este grupo se unen las personas sin cardiopatía isquémica que tengan riesgo absoluto debido a padecer de acuerdo con el ATP-III condiciones equivalentes de cardiopatía isquémica como la insuficiencia carotídea, con una obstrucción mayor al 50\%; la insuficiencia arterial de miembros inferiores con una relación tobillo/brazo disminuida; el aneurisma de la aorta y la diabetes mellitus tipo 2, así como las condiciones que preceden a su aparición como la resistencia a la insulina y el síndrome metabólico, ya que el daño macrovascular que puede provocar aterosclerosis en algún momento futuro, inicia en esas etapas.

La diabetes tipo 1 sin importar el tiempo de evolución también está considerada en este grupo debido a la mortalidad cardiovascular incrementada que se presenta en estos pacientes, 
cuya incidencia es de menos del $20 \%$ en 10 años, sobre todo si existe presencia de microalbuminuria.

Otro grupo importante por su riesgo absoluto de sufrir un evento coronario superior al $20 \%$ en 10 años son las personas con hipercolesterolemia familiar y la hiperlipemia familiar combinada (18\% a 10 años). Por lo tanto, el beneficio del tratamiento será mayor cuando la reducción de la concentración de CL también lo sea, de tal manera que para los casos definidos como prioritarios para el tratamiento hipolipemiante, es importante alcanzar la concentración de LDL óptima (<100 mg/dL), mientras para los no prioritarios será suficiente la reducción que resulte del tratamiento no farmacológico (Aguilar et al., 2004).

\subsubsection{Fármacos hipolipemiantes}

El tratamiento farmacológico hipolipemiante se utiliza en los casos en los que las medidas no farmacológicas han sido insuficientes para alcanzar la meta y debe durar el tiempo que el paciente esté expuesto al factor de riesgo; a las seis semanas de iniciado el tratamiento debe evaluarse el efecto y hacer seguimiento cada seis meses (Aguilar, 2004).

Existe en el mercado un gran número de fármacos conocidos como hipolipemiantes por sus funcione sobre los diferentes lípidos sanguíneos, se resumen en la tabla No.18

Tabla No. 18. Fármacos utilizados en el tratamiento de las dislipemias

\begin{tabular}{|c|c|c|c|}
\hline \multicolumn{2}{|c|}{ Grupo } & Fármaco & Dosis Diaria \\
\hline \multirow{6}{*}{ Estatinas } & \multirow{3}{*}{ Naturales } & Lovastatina & $20-80 \mathrm{mg}$ \\
\hline & & Simvastatina & $5-80 \mathrm{mg}$ \\
\hline & & Pravastatina & $10-80 \mathrm{mg}$ \\
\hline & \multirow{3}{*}{ Sintéticas } & Atorvastatina & $10-80 \mathrm{mg}$ \\
\hline & & Fluvastatina & $20-80 \mathrm{mg}$ \\
\hline & & Rosuvastatina & $5-40 \mathrm{mg}$ \\
\hline \multicolumn{2}{|l|}{ Niacina } & Ácido nicotínico & $500-1000 \mathrm{mg}$ \\
\hline \multirow{3}{*}{\multicolumn{2}{|c|}{ Secuestradores de ácidos biliares }} & Colestiramina & 49 \\
\hline & & Colestipol & $5-30 \mathrm{~g}$ \\
\hline & & Colesevelam & $2,4-4,5 \mathrm{~g}$ \\
\hline \multirow{4}{*}{\multicolumn{2}{|c|}{ Fibratos }} & Gemfibrozilo & $600 \mathrm{mg}$ \\
\hline & & Clofibrato & $1 \mathrm{~g}$ \\
\hline & & Ciprofibrato & $100-200 \mathrm{mg}$ \\
\hline & & Fenofibrato & $67-201 \mathrm{mg}$ \\
\hline \multicolumn{2}{|l|}{--------- } & Acetimiba & $10 \mathrm{mg}$ \\
\hline \multicolumn{2}{|c|}{ Suplemento nutricional } & Ácidos grasos omega-3 & $1-6 \mathrm{~g}$ \\
\hline
\end{tabular}

Fuente: modificado de Beers, M.H. Porter, R.S. Jones, T.V. Kaplan, J.L. Berkwits. M. (Eds.). (2007). El Manual Merck de Diagnóstico y Tratamiento. (11 a. Ed.). España: Elsevier. 
En un estudio realizado por el Sistema Nacional de Salud y Nutrición de Estados Unidos entre 2003 y 2004, se recomendó al $89 \%$ de las personas mayores de 20 años $(2,800)$ sin enfermedad cardiovacular o con comorbilidades, después de analizar sus nivelesde lípidos en suero, que se apegaran a las recomendaciones nacionales de los niveles de LDL, HDL y no-HDL, y TG. Sólo el 37\% de las personas con enfermedades cardiovasculares 0 comorbilidades relacionadas cumplió con las metas de LDL, HDL y no-HDL recomendadas y sólo el $17 \%$ se apegó a las recomendaciones para todos los lípidos de la prueba.

Aquellos que recibieron tratamiento farmacológico para la dislipemia tenían significativamente más bajos niveles de IDL, LDL y no-HDL en comparación con los individuos no tratados, sin embargo, el HDL y los TG se mantuvieron controlados.

Este estudio refuerza la necesidad de tratar las dislipidemias con fármacos como las estatinas, los fibratos, la niacina y los ácidos grasos omega-3, agentes que reducen los TG, el CL remanente y el número de partículas y eleva los niveles de $\mathrm{HDL}$, con un enfoque en su utilidad y costo-efectividad y por otro lado reducen el riesgo de enfermedad coronaria en pacientes con dislipidemia mixta (McKenney, 2009).

\subsection{Estatinas}

Las estatinas son los medicamentos que tienen efecto en la reducción de LDL (de 17 a 54\%), con incremento discreto en HDL (del 5 al 10\%) y descenso de los TG en algunos de los casos.

Su efecto sobre los niveles de lipoproteínas en sangre se aprecia después de 4 a 6 semanas de tratamiento $y$ se utilizan preferentemente en pacientes que padecen hipercolesterolemia aislada.

Su mecanismo de acción consiste en inhibir competitivamente la enzima 3-hidroxi-3-metilglutaril coenzima $A$ reductasa (HMGCoA) que es la responsable en limitar la síntesis de $\mathrm{CL}_{i}$ de esta manera disminuyen algunos de los factores que favorecen la trombosis, mejorando la fibrinólisis, disminuyendo la proliferación de las células del músculo liso de la pared vascular y la producción de enzimas proteolíticas que facilitan la ruptura de las placas de ateroma.

La actividad inflamatoria en los vértices de las placas de ateroma también disminuye y con ello la producción de eventos trombóticos por ruptura de la placa (Ascaso et al., 2007; Matthew et al., 2009).

Las estatinas se clasifican en dos grupos: naturales, que producen mejores efectos, son obtenidas por fermentación de los hongos 
como el Aspergillus terrus y Penicillum citrinum los cuales dan origen a la lovastatina y mevastatina, respectivamente; además se encuentran también en este grupo la simvastatina y la pravastatina; y las estatinas sintéticas, que son la fluvastatina, la atorvastatina, cerivastatina y la rosuvastatina.

En México, están disponibles seis estatinas las cuales difieren en su potencia, pero es posible alcanzar las metas con cualquiera de ellas. Cuando se utilizan las dosis máximas de las más potentes, se pueden alcanzar reducciones de LDL hasta del 60\%.

En un estudio realizado con 120 pacientes (71 hombre y 49 mujeres) con dislipemia, que tenía como objetivo determinar el porcentaje de pacientes que alcanzan las metas terapéuticas de LDL tratados con estatinas, fibratos y ambos, Meaney et al. (2004), encontraron poco alcance $(42 \%)$ de las metas establecidas por el NCP ATP III y poca adherencia al tratamiento.

Resultados similares se encontraron en un estudio realizado en la ciudad de México por González et al. (2009) donde participaron voluntariamente 676 hombres y mujeres mayores de 18 años con hipercolesterolemia primaria o mixta tratados con estatinas, cuyo objetivo era determinar el porcentaje de pacientes que disminuyeran sus niveles de LDL, utilizando dicho fármaco, alcanzando la meta recomendada por el NCP ATP III, se encontró que los resultados mostraron que sólo el $20,4 \%$ de los participantes alcanzaron dicha meta, lo que demuestra que para el tratamiento de las dislipemias es necesario un nuevo manejo para reducir las LDL y con ello el riesgo de eventos cardiovascualres.

Generalmente las estatinas son bien toleradas, sin embargo, pueden provocar elevaciones de las transaminasas, sobre todo en pacientes que consumen alcohol (5\%), por lo que deben ser medidas las enzimas hepáticas durante el primer mes de tratamiento y una vez al año, en caso de elevarse 3 veces por arriba del límite superior normal, debe suspenderse su consumo.

Otro efecto secundario que se presenta con mayor frecuencia en pacientes con insuficiencia renal o que consumen ciclosporina, fibratos, ácido nicotínico, eritromicina e itraconazol, es la presencia de miopatía con una frecuencia de $0,5 \%$ y sólo el $0,1 \%$ con rabdomiólisis.

En los pacientes que consumen warfarina el riesgo es mayor lo que potencializa su efecto por lo que debe medirse el tiempo de protombina frecuentemente. 


\subsubsection{2. Ácido nicotínico}

Es una vitamina del complejo $B$, hidrosoluble, que tiene efectos hipolipemiantes en dosis que rebasan el requerimiento diario. Se utiliza en el tratamiento tanto de la hipercolesterolemia como de la hipertrigliceridemia y además incrementa los niveles de HDL.

La importancia de su efecto radica en que disminuye significativamente la producción de las lipoproteínas de muy baja densidad (VLDL) disminuyendo así los niveles de IDL y LDL, pero sus efectos colaterales como hiperemia cutánea, náuseas, sequedad de la piel, dolores abdominales, visión borrosa y alteraciones en los niveles séricos de ácido úrico, glucosa, aminotransferasas y fosfatasa alcalina son tan comunes que limitan la tolerancia del medicamento en los pacientes.

La niacina se asocia con un mayor riesgo de hepatotoxicidad y un aumento de $4 \mathrm{mg} / \mathrm{dL}$ la glucemia en ayunas.

Produce enrojecimiento en la piel como efecto secundario más común que no presenta ningún peligro, pero puede llevar al incumplimiento o interrupción de la droga por parte de los pacientes.

Las investigaciones recientes sobre el mecanismo del enrojecimiento de la piel pueden reducir el impacto de este efecto secundario lateral. Un receptor de niacina se ha identificado en los adipocitos, así como en células del sistema inmune y la piel.

El enrojecimiento es provocado por la estimulación de los receptores de la niacina en las células epidérmicas de Langerhans, dando como resultado una mayor producción de ácido araquidónico y posteriormente, una serie de prostaglandinas, incluyendo PGD2. El enrojecimiento es causado por la dilatación de los vasos capilares debido a la unión de la PGD2 a los receptores periféricos DP-1. La laropiprant, un antagonista del receptor DP-1, fue desarrollado para bloquear la respuesta inducida por el rubor de niacina.

Cuando este antagonista se agregó a la terapia de niacinaER, aproximadamente $90 \%$ de los pacientes presentaron disminución del enrojecimiento en la primera semana de la terapia de niacina (McKenney, 2009).

Se recomienda la utilización de la presentación de acción prolongada; además otras recomendaciones, que incluyen el consumo de una tableta de aspirina 30 minutos antes de su utilización e incrementar la dosis paulatinamente cada semana o combinarla con una estatina.

De acuerdo con McKenney, (2009) la niacina se evaluó en Estados Unidos como parte del estudio del Proyecto de Drogas Coronarias para la prevención de eventos cardiovasculares secundarios en los 
hombres con infarto de miocardio previo. En este estudio, la niacina se asoció con una reducción pequeña pero significativa en el infarto al miocardio no fatal y muerte por enfermedad coronaria relacionada con relación al placebo.

La niacina ha demostrado ser el mejor agente para incrementar el HDL mientras el gemfibrosil mejora la reducción de los TG. La niacina por lo general no aumenta los niveles de LDL y ambos tratamientos tienen un efecto positivo sobre el colesterol no-HDL.

\subsection{Secuestradores de ácidos biliares (resinas)}

La respuesta de los pacientes al tratamiento con resinas en muy variable ya que al no absorberse no presenta toxicidad sistémica, a dosis máxima disminuye el colesterol LDL en 15-25\%; sin embargo presenta problemas de tolerancia ya que a menudo produce constipación (hasta en un $40 \%$ de los pacientes), esofagitis, dispepsia, interacción con otros medicamentos e incremento en la producción hepática de $T G$, por lo que no debe ser utilizado en pacientes con cifras de TG mayores a $500 \mathrm{mg} / \mathrm{dL}$.

Su mecanismo de acción consiste en capturar las sales biliares en la luz intestinal, disminuyendo la absorción del CL que proviene de la dieta y al mismo tiempo la producción del CL hepático debido a la estimulación de la síntesis de ácidos biliares en el hígado (McPherson et al., 2006).

Se recomienda iniciar el tratamiento con dosis bajas para probar tolerancia o combinar su efecto con estatinas, ácido nicotínico o fibratos. Las principales resinas son colestiramina, colestipol y colesevelam.

\subsection{Fibratos}

Los fibratos están indicados como tratamiento de la hipertrigliceridemia, de la disbetalipoproteinemia, las hiperlipemias mixtas, las dislipemias secundarias a diabetes, resistencia a la insulina y daño renal, pero tienen poca aplicación como tratamiento de la hipercolesterolemia; tienen el efecto de modificar la concentración y la composición de las lipoproteínas de muy baja densidad (VLDL) y de intermedia densidad (IDL) lo que provoca una disminución en la concentración de los TG en ayuno y post-prandial (McPherson et al., 2006).

En los pacientes con hipertrigliceridemia moderada a severa, al principio del tratamiento con fibratos se observa un incremento transitorio de las LDL, que se corrige después de 4 a 6 semanas 
debido al incremento de la conversión de VLDL a LDL provocado por la actividad de la lipasa lipoproteica.

Otro efecto importante de los fibratos es que al producir reducción de los TG séricos, incrementan la concentración de las HDL (entre 15-20\%).

Por lo general son bien tolerados, sin embargo alrededor del $5 \%$ de los pacientes presentan ansiedad, vértigo, cefalea, molestias gastrointestinales como malestar abdominal y náuseas, urticaria, prurito y dolor muscular que puede llegar a ser grave (rabdomiólisis); estos medicamentos están contraindicados en pacientes que padecen problemas renales y hepáticos (Mckenney, 2009).

En un meta-análisis que incluyó a 36,489 pacientes de 10 ensayos clínicos controlados aleatorizados realizado para evaluar el efecto de los fibratos sobre la prevención de efectos cardivasculares,

Saha et al. (2007) encontraron, que a largo plazo, estos fármacos no reducen el riesgo de mortalidad cardiovascular, ni eventos cerebrovasculares, ni infartos del miocardio fatales de manera significativa.

Los hallazgos positivos del estudio demostraron un incremento del $9 \%$ global de HDL y la disminución en un $22 \%$ de riesgo de infarto al miocardio no fatal.

\subsection{Acetimiba}

Es un inhibidor selectivo de la absorción de $\mathrm{CL}$ en el intestino que reduce su concentración hasta en un $15 \%$. Se recomienda su utilización cuando los pacientes son susceptibles al tratamiento con estatinas y cuando las LDL basales no rebasen el $15 \%$ de la meta del tratamiento.

Al combinarla con una estatina sus efectos se potencializan y aun con una a dosis baja permite alcanzar reducciones en las LDL similares a las esperadas con las dosis máximas de la estatina; esta combinación permite que pacientes con hipercolesterolemia familiar heterocigota, que no han podido alcanzar las metas de tratamiento con las dosis máximas de las estatinas más potentes, puedan lograr concentraciones de LDL menores de $100 \mathrm{mg} / \mathrm{dL}$. Otro dato importante es que no tiene efectos adversos significativos (McPherson et al., 2006; Eliot et al., 2009).

\subsubsection{6. Ácidos grasos omega -3 (n-3)}

Existen varios mecanismos posibles del efecto protector de los ácidos grasos omega-3 (n-3) sobre la salud cardiovascular, entre ellos 
destacan: la capacidad que presentan los ácidos grasos n-3 para influenciar la coagulación sanguínea y la trombosis, en el perfil de los lípidos plasmáticos, la presión sanguínea, la arritmia y la inflamación; los ácidos grasos n-3 derivados de la ingesta se incorporan a los fosfolípidos de las membranas celulares, sustituyendo parcialmente el ácido araquidónico (n-6) como sustrato inicial para la producción de eicosanoides.

Carrero et al. (2005) afirman que cuando las células vasculares sufren algún tipo de daño, se desencadena el proceso de agregación plaquetaria. Los intermediarios derivados del metabolismo de los ácidos grasos $n-3$ son menos protrombóticos y vasoconstrictores que los derivados procedentes del n-6.

El contenido en ácidos grasos de las plaquetas origina la producción de tromboxano $A 2$ a partir de la familia $n-6$, o de tromboxano $A_{3}$ a partir de la familia n-3. Este último posee un efecto proagregante menor que el tromboxano $\mathrm{A} 2$, reduciendo por tanto, la agregación plaquetaria y la trombosis.

Por otro lado, en pacientes que sufren de arritmia, que es una irregularidad en la actividad eléctrica del músculo cardiaco que en muchas ocasiones puede ser la causa de muerte súbita, se ha sugerido la ingesta moderada de ácidos grasos n-3 para reducir el riesgo de paro cardíaco debido al efecto regulador que estos ácidos grasos tienen sobre las propiedades eléctricas del miocardio, disminuyendo la susceptibilidad a las arritmias ventriculares y por consiguiente, el riesgo de muerte súbita.

El más conocido de los efectos de los ácidos grasos n-3 es concretamente su efecto reductor sobre los TG plasmáticos en sujetos sanos o con hiperlipemias y un aumento en las HDL de un $10 \%$, aunque éste depende del alimento y de las cantidades de $n-3$ ingeridas (Carrero et al., 2005; McKenney, 2009).

Sin embargo, existen estudios en donde no se encontraron efectos de la suplementación con n-3 sobre los lípidos y las lipoproteínas, como en el caso de Wooten et al. (2009).

La verdadera importancia de la utilización de los fármacos hipolipemiantes radica en la disminución del riesgo de sufrir eventos cardiovasculares debido a su acción en los diferentes lípidos por diferentes mecanismos mejorando su perfil.

Las indicaciones de su utilización son determinadas por los efectos probados de su utilización como puede observarse en tabla No. 19. 
Tabla No. 19. Recomendaciones para la utilización de los fármacos Hipolipemiantes

\begin{tabular}{|l|l|l|}
\hline \multicolumn{1}{|c|}{ Dislipemias } & \multicolumn{2}{c|}{ Fármacos hipolipemiantes } \\
\cline { 2 - 3 } & \multicolumn{1}{|c|}{$\begin{array}{c}\text { Primera } \\
\text { opción }\end{array}$} & \multicolumn{1}{c|}{ Segunda opción } \\
\hline Hipercolesterolemia aislada & Estatinas & $\begin{array}{l}\text { Esetimibas } \\
\text { Secuestradores de sales } \\
\text { biliares (resinas) } \\
\text { Ácido nicotínico }\end{array}$ \\
\hline Hiperlipemia mixta & $\begin{array}{l}\text { Estatinas } \\
\text { Fibratos }\end{array}$ & Ácido nicotínico \\
\hline Hipertigliceridemia aislada & Fibratos & $\begin{array}{l}\text { Ácido nicotínico } \\
\text { Ácidos grasos omega-3 }\end{array}$ \\
\hline Hipoalfalipoproteinemia & $\begin{array}{l}\text { Fibratos } \\
\text { Ácido } \\
\text { nicotínico }\end{array}$ & \\
\hline
\end{tabular}

Fuente: Aguilar et al. (2004) Diagnóstico y tratamiento de las dislipidemias: posición de la Sociedad Mexicana de Nutrición y Endocrinología. Revista de Endocrinología y Nutrición, 12 (1), 141

\subsection{Tratamiento no farmacológico de las dislipemias}

El manejo de las dislipemias a través de modificaciones en el estilo de vida es un gran reto debido a factores como el carácter asintomático de las mismas que explica su bajo porcentaje de adherencia al tratamiento, así como la ausencia de beneficios palpables a corto plazo. Sin embargo, está bien fundamentado que la adopción de un estilo de vida saludable que incluya: modificaciones en la dieta, el apego a una rutina de ejercicio físico, el consumo moderado de bebidas alcohólicas, el mantenimiento del peso adecuado y eliminar el consumo de tabaco produce la reducción de los niveles de LDL y por consiguiente la reducción del riesgo para eventos coronarios mayores (Rincón et al., 2010).

Por lo anterior, el objetivo primordial del tratamiento no farmacológico es que las personas adopten un estilo de vida saludable a largo plazo y que elimine todos los factores de riesgo ambientales para lo cual la información y la educación son las herramientas más efectivas. Ciruana et al. $(2005$, p.202) afirman que "la tarea de los profesionistas de la salud consiste en confrontar, clarificar, explicar, instruir y recomendar a pacientes para convencerlos de la bondad de una determinada conducta, con el propósito de mejorar su estado de salud y su bienestar". Por lo que los integrantes del equipo de salud encargados de la atención de los pacientes con dislipemias deben ser capaces de evaluar su conocimiento y su motivación, así como proveer información, modificar hábitos nocivos, reforzar determinados comportamientos y monitorizar su progreso a largo plazo. 
Existe evidencia científica de que algunos consejos proporcionados por los profesionistas de la salud son susceptibles a ser atendidos por los pacientes adultos en beneficio de su salud: en mayor grado, limitar la grasa saturada, evitar el consumo de tabaco y su exposición pasiva y evitar el consumo de alcohol; en grado moderado, llevar un equilibrio calórico nutricional y realizar actividad física, y en menor grado, consumir una dieta rica en frutas $y$ vegetales (5 porciones al día). (Institute for Clinical Systems Improvement, 2001).

\subsubsection{Ejercicio físico}

El ejercicio físico es un factor importante en la prevención y tratamiento de las enfermedades crónica; diferentes autores (Varo et al., 2003; Varady et al. 2005; Ekelund et al., 2005; Roldán et al., 2008; Torres et al., 2009; Voeghtly et al., 2012; Golbidi et al., 2012) coinciden en que la falta de ejercicio duplica el riesgo de enfermedades cardiovasculares, obesidad y diabetes e incrementa también el riesgo de hipertensión arterial. Foster et al. (2005) sugieren que las intervenciones que recomiendan la realización de atividad física consiguen que los pacientes incrementen la actividad física y su forma física cardiorespiratoria.

Grandes, et al. (2009) opinaron que en España, el Programa Experimental para la Promoción de la Actividad Física (PEPEF) ha probado que la prescripción del ejercicio físico por el médico de atención primaria produce un incremento de la población físicamente activa.

En el informe sobre la salud en el mundo 2002, la OMS declaró que los estilos de vida sedentarios son una de las diez causas de mortalidad y discapacidad en el mundo (World Health Organization, 2002; Palatini, 2012).

Con ese panorama, la Organización para la Agricultura y la Alimentación (FAO) y la OMS, insisten en la necesidad de establecer modificaciones en los estilos de vida y en la alimentación como medida preventiva para disminuir la carga global de enfermedad en el mundo, para lo cual la OMS propuso entre sus objetivos de "Salud para todos en el año 2010" reducir la prevalencia de sobrepeso y obesidad e incrementar la proporción de personas que realicen actividad física moderada en forma regular (OMS, 2001; Varo et al., 2003).

El riesgo de cardiopatía isquémica en la población estadounidense es del $33 \%$ y se atribuye al sedentarismo, el cual podría reducirse si las personas sedentarias realizaran un poco de ejercicio físico (Elosua, 2005). 
La relación del efecto del ejercicio físico en la salud está ampliamente documentada: fisiológicamente reduce el riesgo de cardiopatía isquémica, de accidentes cerebrovasculares, de ictus; disminuye la tensión arterial, el peso corporal, la concentración de grasa abdominal, la apnea obstructiva del sueño, la resistencia a la insulina, la prevalencia e incidencia de osteoporosis y de cáncer de colon; incrementa la masa muscular, las HDL, entre otros (Zerceño et al. 2009).

Existe evidencia de la relación inversa entre los niveles plasmáticos de HDL y la morbilidad y mortalidad cardiovascular, debido a que las HDL inhiben la oxidación de las LDL. El ejercicio físico tiene efecto cardio-protector debido a que eleva los niveles de HDL, (Fan et al., 2009). Kodama et al., (2007) realizaron un metaanálisis para evaluar el efecto del ejercicio aeróbico sobre las HDL utilizando 25 ensayos clínicos controlados donde participaron más de 1,400 personas. Los resultados demostraron que el ejercicio incrementa las $\mathrm{HDL}$ en $2,65 \mathrm{mg} / \mathrm{dL}$, con un gasto promedio semanal de 900 kilocalorías, lo que corresponde a 120 minutos de ejercicio a la semana, y por cada 10 minutos que se prolongue el ejercicio, se produce un incremento de las HDL de $1,4 \mathrm{mg} / \mathrm{dL}$. Además, la práctica de ejercicio reduce el riesgo relativo de muerte entre 20 y $35 \%$ en todas las causas de mortalidad (Golbidi et al., 2012).

Una revisión de 44 estudios observacionales realizada para identificar la dosis-respuesta entre el ejercicio físico y la mortalidad por cualquier causa, demostró que existe una relación inversa entre el volumen del ejercicio y todas las causas de mortalidad, por lo que el gasto de 1,000 Kcalorías a la semana a través del ejercicio parece ser la dosis adecuada para reducir el riesgo de mortalidad entre 20 y $30 \%$ (Lee et al., 2001).

Un estudio realizado por Madden et al., (2009) con adultos mayores que padecen diabetes tipo 2 y otras comorbilidades como hipertensión arterial e hipercolesterolemia, comprobó que una intervención de ejercicio aeróbico relativamente corto puede reducir la rigidez arterial multifactorial.

En los últimos años se ha observado alta prevalencia (88\%) de hipertensión arterial en los niños y jóvenes lo que incrementa el riesgo en estos sujetos a padecer enfermedades cardiovasculares en edades adultas tempranas. Se ha demostrado que el ejercicio físico, entre otras medidas no farmacológicas puede reducir la tensión arterial en sujeto con hipertensión fase I $(\geq 140 / 90 \mathrm{mmHg}$ y $<$ 160/100) antes de iniciar la terapia con medicamentos. Existe suficiente evidencia científica de los beneficios del ejercicio físico sobre los niveles de tensión arterial, sin embargo aun cuando las recomendaciones han estado enfocadas al ejercicio de intensidad 
moderada, algunas experiencias sustentan que no existe diferencia en los niveles de tensión arterial entre los jóvenes con hipertensión que realizan actividad física de moderada intensidad y los sedentarios por lo que parece que se requieren programas de actividad mas intensa, mientras que en edades más avanzadas, que son generalmente más sedentarios los efectos del ejercicio moderado podría ser benéfico (Palatini, 2012).

Desde el punto de vista psicológico la práctica regular de ejercicio físico mejora los niveles de ansiedad, depresión, la autoestima y disminuye el estrés (Jiménez et al., 2008). Es importante recalcar que la práctica de ejercicio físico también influye positivamente en la adopción de otras conductas saludables como mejorar la alimentación y reducir o evitar el consumo de alcohol y tabaco (Espeitx, 2006).

Voeghtly et al., (2012) realizaron un estudio, con 152 participantes voluntarios ( 76 asignados al grupo control y 76 al grupo experimental pareados por edad y sexo) donde se evaluaron los cambios en los niveles circulantes de insulina y leptina durante un programa de salud cardiovascular de 52 semanas semanas de duración, cuyo objetivo fue estabilizar o revertir la progresión de la enfermedad de la arteria coronaria mediante modificaciones en la dieta, la inclusión de un programa de ejercicio y el control del estrés mediante grupos de apoyo; los autores afirman que los cambios en el estilo de vida pueden modificar con éxito los factores de riesgo cardiovascular por el efecto anti-inflamatorio y antioxidante que las modificaciones en la dieta, como la reducción de la ingesta de kilocalorías (de 2,000 a 1,700 por día), de grasas saturadas $(>60 \%)$ y el incremento en el consumo de hidratos de carbono (>30\%), que presentaron los participantes del grupo experimental en comparación con el grupo control. Se observó además la disminución de los niveles de leptina ($33 \%)$ y de insulina (-19\%) en el plasma de los participantes del grupo experimental en comparación con el grupo control. Todas estas modificaciones fueron similares entre hombres y mujeres.

En un estudio realizado en Brasil con 43 pacientes, Pontes et al. (2008) al analizar la relación entre la actividad física y la presencia de dislipemia, encontraron que las personas sedentarias o que practicaron ejercicio insuficiente, presentaron 1.5 veces mayor probabilidad de presentar dislipemia.

\subsubsection{Efecto del ejercicio en la salud cardiovascular}

Diversos estudios demuestran que el ejercicio físico mejora la función cardiovascular en las personas sanas; sin embargo el mayor 
benefico lo obtienen las personas con factores de riesgo o enfermedades crónicas. En las personas sanas es necesario un protocolo de ejercicio más intenso para inducir cambios mensurables en los parámetros cardiovasculares, mientras que en las personas con enfermedades crónicas o los adultos mayores, responden de manera sorprendente a regímenes menos intensos (Golbidi et al., 2012).

Durante la práctica del ejercicio todos los sistemas corporales se adaptan, pero el sistema cardiovascular y respiratorio son los que más modificaciones realizan.

\section{Sistema cardiovascular}

El riego del corazón se realiza a través de la circulación coronaria, la cual durante el ejercicio incrementa su flujo entre cuatro y cinco veces al que se presenta en estado de reposo debido principalmente, a la acción del sistema nervioso central que provoca incremento en la actividad simpática y decremento en la parasimpática; esto con el propósito de suministrar oxígeno y los sustratos energéticos a las células (hidratos de carbono, grasas y ácido láctico), eliminar los productos de desecho, transportar el calor desde el interior de la célula al exterior y transportar las hormonas que provocan vasoconstricción de las zonas inactivas. Lo recomendable siempre es, desde la condición de reposo, empezar a realizar ejercicio progresivo con lo que se incrementan las necesidades energéticas y la necesidad de oxígeno de los músculos; para hacer frente a estas necesidades, el corazón va incrementando progresivamente su gasto cardíaco. Si se llegara a esfuerzos intensos o muy intensos, entonces el gasto cardíaco llegará a alcanzar un nivel máximo que ya no puede sobrepasar (límite superior de respuesta cardiovascular). El gasto cardíaco (volumen de sangre que expulsa el corazón durante determinado período de tiempo) está supeditado a las variaciones de dos factores, la frecuencia cardíaca y el volumen sistólico. La frecuencia cardíaca es el número de contracciones del corazón en un minuto que en condiciones de reposo es de aproximadamente 60 latidos/minuto y depende de la edad, el sexo, la posición del cuerpo, la temperatura, la altitud, la humedad, los ritmos circadianos y algunas patologías. Durante el ejercicio, la frecuencia cardíaca se incrementa cuando el bulbo raquídeo recibe la información de la modificación de parámetros de diferentes partes del sistema circulatorio como la tensión arterial, la presión parcial de oxígeno y también por el aumento de la presión auricular derecha que indica un incremento del retorno venoso que provoca, mediante los barorreceptores, un impulso a los nervios simpáticos para asegurar el aumento del débito cardíaco mediante el incremento de la 
frecuencia cardíaca. Si el ejercicio se realiza con una intensidad progresiva creciente, la frecuencia cardíaca se incrementa de la misma forma, sin embargo, llegará el momento en que la elevación de la frecuencia cardíaca será inferior a la elevación producida en la intensidad del ejercicio, con lo que produce un punto de inflexión llamado umbral anaeróbico (Calderón, 2007).

El volumen sistólico (cantidad de sangre que expulsa el corazón en una contracción o sístole) es variable entre las personas, tanto en reposo (50-70 mL) como en el ejercicio $(120-160 \mathrm{~mL}$ ) y se incrementa con el esfuerzo, principalmente debido al aumento del retorno venoso causado por las contracciones de los músculos esqueléticos y un llenado ventricular mayor, provocado por la distensibilidad ventricular incrementada, que permite que el corazón puede expulsar mayor cantidad de sangre aumentando el volumen sistólico. Además, otro aspecto importante está relacionado directamente con el aumento de la actividad del sistema nervioso simpático, que provoca que el corazón se contraiga con más fuerza expulsando mayor cantidad de sangre del ventrículo al final de la sístole. El volumen sistólico aumenta con ritmos crecientes de esfuerzo, pero solamente hasta intensidades de ejercicio de entre el 40 y el $60 \%$ de capacidad máxima.

Otro aspecto que se modifica durante la práctica del ejercicio físico es la presión arterial. La presión sistólica (alta) se incrementa, tanto en ejercicios dinámicos como estáticos, con el aumento del gasto cardíaco provocado por la activación del sistema nervioso simpático. La presión diastólica (baja), depende de las resistencias periféricas debido a la viscosidad de la sangre y por el pequeño diámetro de las arterias y capilares. Por lo tanto en los ejercicios dinámicos se produce una dilatación muscular con lo que las resistencias periféricas disminuyen, mientras que con los ejercicios estáticos aumenta, debido a la contracción isométrica que impide que se produzca una vasodilatación arteriolar. Esto explica que la presión arterial (tanto sistólica como diastólica) se incremente cuando se realiza ejercicios estáticos, dinámicos contra resistencia o esfuerzo con la parte superior o las extremidades superiores ya que existe mayor resistencia al flujo de sangre debido a la menor masa muscular y al menor número de vasos. Por eso el ejercicio más recomendable es el que involucra a las extremidades inferiores y superiores (Calderón, 2007; Woolf-May, 2008)

Existe descenso rápido de la presión arterial al finalizar el ejercicio, debido a la disminución del gasto cardíaco, a la vasodilatación y al descenso del retorno venoso, por lo que es importante no detener súbitamente el ejercicio ya que se puede producir un descenso brusco en la presión arterial (hipotensión) 
acompañada de vértigo, malestar general y en casos extremos pérdida del conocimiento.

También durante la práctica del ejercicio se produce una redistribución del flujo sanguíneo, debido a un cambio en las prioridades de los diferentes órganos y aparatos. La parte vascular de los músculos activos aumenta considerablemente por la dilatación de las arteriolas locales, al igual que en el corazón, mientras los vasos reducen el flujo sanguíneo a los tejidos que pueden soportar un flujo menor como son el sistema digestivo y renal. El sistema nervioso aun cuando tiene mucha actividad durante la práctica del ejercicio se mantiene constante.

En ocasiones cuando la temperatura ambiental es alta y el ejercicio es prolongado, se produce un direccionamiento de la sangre a la piel con el propósito de evacuar el calor y mantener una temperatura corporal más o menos estable. También se reduce el volumen sanguíneo debido a la pérdida de agua a través de la sudoración y al paso de los líquidos de la sangra hacia los tejidos lo que incrementa la frecuencia cardíaca y disminuye el volumen sistólico, manteniendo de ésta manera el gasto cardíaco lo que permite continuar con la práctica del ejercicio de intensidad baja o moderada.

Cuando la práctica del ejercicio se convierte en habitual, el corazón se adapta al entrenamiento presentando: hipertrofia que se acompaña de aumento del volumen de las cavidades, incremento en la capilarización del miocardio y en el número de mitocondrias. (González et al., 2006).

El ejercicio también tiene un impacto positivo en la morfología de los vasos sanguíneos ya que al inducir la angiogénesis, se produce la expansión de la red capilar para la formación de sangre nueva en los capilares y las arteriolas de resistencia, además la ampliación de los vasos existentes. También incrementa el diámetro de las arteriolas grandes y pequeñas arterias e induce a la formación de arterias grandes (arteriogénesis) que son capaces de compensar la pérdida de la función de las arterias ocluidas en las personas con aterosclerosis. Golbidi et al., (2012) mencionan que existen estudios donde se encontró evidencia de la correlación significativa entre la práctica regular de ejercicio físico y el aumento del diámetro de la luz de la arteria coronaria, destacando el estudio de Belardinelli et al. (1998) donde un grupo de pacientes con enfermedad crónica de la arteria coronaria y una eyección ventricular izquierda menor al 40\% fueron sometidos a 8 semanas de entrenamiento. Los resultados mostraron incremento de la respuesta contráctil a dosis bajas de dobutamina, lo que deja ver que el entrenamiento físico leve o moderado a corto plazo puede mejorar la calidad de vida mediante la 
mejora de la función sistólica ventricular izquierda en pacientes que padecen miocardiopatía isquémica.

\section{Sistema respiratorio}

La principal función del sistema respiratorio es proporcional el oxigeno necesario para que las células del organismo puedan realizar sus funciones metabólicas, y al mismo tiempo, eliminar el dióxido de carbono que se produce como resultado del metabolismo.

Durante la práctica de ejercicio se eleva el consumo de oxígeno y la producción de dióxido de carbono, lo que aumenta la ventilación corporal con respecto a situaciones de reposo. Para que el intercambio de oxígeno y dióxido de carbono entre el pulmón y la sangre se realice se requiere de dos funciones primordiales: la ventilación y la difusión (Castellano et al., 2009).

La ventilación es el proceso mecánico que permite los desplazamientos de aire en el interior y exterior del pulmón, que consta de dos fases: la inspiración y la espiración.

La inspiración se lleva a efecto cuando el diafragma se contrae moviéndose hacia adelante y hacia abajo, entonces los pulmones se dilatan provocando la reducción de la presión intrapulmonar por debajo de la presión atmosférica, permitiendo el paso del aire a los pulmones.

En situaciones de reposo el diafragma realiza todo el trabajo inspiratorio, pero durante la práctica de ejercicio, los músculos intercostales, pectorales y escalenos ayudan al diafragma a aumentar el volumen torácico facilitando la inspiración.

La espiración en estado de reposo se realiza de manera pasiva, durante la práctica del ejercicio se requiere de la participación de los músculos de la pared abdominal para empujar el diafragma hacia arriba y las costillas hacia el interior y abajo, aumentando la presión intrapulmonar facilitando la espiración (Calderón, 2007).

La difusión es el movimiento aleatorio de las moléculas de oxígeno de los alvéolos pulmonares (zona de elevada concentración) hacia la sangre que llega al capilar pulmonar (zona de baja concentración) a través de la membrana alveolo-capilar por difusión pasiva; este proceso es muy rápido (menos de un segundo) y para poder realizarse se requiere de la unión del oxígeno a la hemoglobina que es la encargada de distribuirlo a todas las células del cuerpo.

Por el contrario, el dióxido de carbono se encuentra en mayor concentración en la sangre que llega al capilar alveolar que la existente en el alveolo, lo que permite que pase fácilmente de la 
sangre a los alveolos pulmonares para ser eliminado (Calderón, 2007).

Durante el ejercicio, se genera más energía lo que requiere una demanda aumentada de oxígeno; el sistema respiratorio responde con un aumento de la ventilación minuto el cual se incrementa mediante el aumento del volumen corriente (respiraciones más profundas) y el aumento de la frecuencia respiratoria.

La ventilación minuto a una intensidad constante de ejercicio presenta cinco fases conocidas: al inicio se incrementa rápidamente la actividad respiratoria; en la segunda fase sigue aumentando pero de manera más lenta; en la tercera fase, al mantenerse constantes los niveles de esfuerzo, se estabilizan también los niveles de la ventilación minuto; en la cuarta fase en la cual el sistema respiratorio se empieza a recuperar, se nota un fuerte y rápido descenso de la ventilación minuto y en la quinta se observa un descenso lento y sostenido hasta recuperar los valores en reposo.

Cuando el ejercicio se realiza con aumento progresivo de la intensidad, suceden tres fases conocidas: en la primera fase se presenta un desequilibrio precoz entre las exigencias musculares y los aportes de oxígeno, a lo que se le llama deuda de oxígeno.

La deuda de oxígeno se define como la diferencia entre el oxígeno consumido durante el ejercicio y el total que se habría consumido si se hubiese alcanzado un ritmo aeróbico estable desde el principio hasta el final de la prueba.

En la segunda fase, se consigue un equilibrio entre el aumento de la ventilación minuto y la intensidad del ejercicio, aunque se puede llegar al momento de encontrar un incremento mayor de la ventilación minuto que la intensidad del ejercicio.

En la tercera fase, se presenta una cierta caída del volumen corriente por lo que la ventilación minuto se hace a expensas del aumento de la frecuencia respiratoria que aumenta desmesuradamente.

Si la intensidad del ejercicio es muy alta, puede suceder que la adaptación respiratoria resulte insuficiente para compensar las necesidades, produciéndose de nuevo una deuda de oxígeno, pasando entonces al metabolismo anaerobio apareciendo una intensa disnea (González et al., 2006).

De ahí la importancia de realizar el ejercicio de manera paulatina tanto en tiempo como en intensidad, permitiendo al organismo la adaptación adecuada y evitando situaciones cardio-respiratorias comprometedoras. 


\subsubsection{Valoración previa al inicio de un programa de ejercicio}

Antes de iniciar cualquier programa de ejercicio físico se recomienda (Rodas et al., 2004; Gomes et al., 2004) apegarse a tres condiciones importantes: en primer término, la valoración funcional y cardiológica que consiste en medir la adaptación funcional del organismo sometido a un esfuerzo físico determinado utilizando test funcionales o pruebas de esfuerzo.

Uno de los objetivos de la valoración funcional a través de las pruebas de esfuerzo (Tabla No. 20) es someter al organismo a estrés físico-psíquico que facilite su control y permita cuantificarlo, mediante la determinación de un grupo de variables biológicas como la frecuencia cardíaca, la tensión arterial, consumo de oxígeno, entre otras y parámetros mecánicos como la velocidad, el trabajo y las revoluciones, ya que la manifestación de una elevación exagerada de la presión arterial sistólica indica un mayor riesgo de enfermedad arterial coronaria, accidente cerebrovascular y muerte cardiovascular.

En los individuos jóvenes, la hipercolesterolemia es uno de los factores que favorece el desarrollo y presentación de elevación exagerada de la presión arterial sistólica a través de una combinación de la disfunción endotelial y el aumento de la reactividad simpática cardiovascular (Kurl et al., 2001).

Tabla No. 20 Objetivos de la valoración funcional en medicina del deporte

\begin{tabular}{|l|l|}
\hline \multicolumn{2}{|c|}{ Objetivos } \\
\hline \multirow{3}{*}{ Generales } & $\begin{array}{l}\text { Evaluar la adaptación y capacidad funcional del } \\
\text { sistema cardiovascular y el respiratorio } \\
\text { Determinación del nivel de fitness de base } \\
\text { Estudio del perfil fisiológico }\end{array}$ \\
\hline \multirow{3}{*}{ Específicos } & Valoración de un determinado programa de \\
& entrenamiento \\
& Detección de talentos \\
& Optimización y control del entrenamiento \\
\hline
\end{tabular}

Fuente: Rodas et al. (2006). Valoración funcional y cardiológica previa al entrenamiento físico. En: Serra et al. Prescripción de Ejercicio Físico para la Salud. (pp. 27-55). España. Edit. Paidotribo.

Es importante también que durante la prueba de esfuerzo se realice un electrocardiograma (ECG), lo que permite detectar anormalidades no presentes en el ECG en reposo que frecuentemente son indicativas de enfermedad coronaria.

La segunda recomendación, es seguir un programa progresivo de ejercicio físico de acuerdo a los principios básicos del entrenamiento. 
Y como último punto apegarse a una serie de normas higiénicodietéticas.

\subsubsection{El ejercicio físico en las dislipemias}

Estudios científicos afirman (Elosua, 2005; Jacobs et al., 2006; Dancy et al., 2008) que la práctica regular de ejercicio físico es capaz de mejorar las alteraciones de los lípidos plasmáticos reduciendo de igual manera el riesgo cardiovascular; éstos cambios son el efecto en parte de la disminución de la grasa corporal y el incremento de la masa magra.

El ejercicio físico produce disminución en los niveles de TG, lo que reduce la formación de partículas LDL pequeñas y densas las cuales se asocian a un mayor potencial aterogénico; esto se debe a que se produce una mayor actividad de la lipoproteínlipasa (LPL) tanto en el músculo como en el tejido adiposo al catabolizar las partículas VLDL ricas en TG, proporcionando más elementos para la síntesis hepática de HDL donde se ven involucrados también debido al ejercicio físico, la disminución de la actividad de la lipasa hepática (LH), reduciendo el paso de $\mathrm{HDL}_{2}$ a $\mathrm{HDL}_{3}$ y el incremento de la actividad de la lecitina colesterol aciltransferasa (LCAT) que cataliza la transferencia de ácidos grasos desde lecitina y CL estratificado (Torres et al., 2009).

El incremento de los niveles $\mathrm{HDL}$ en los adultos parece relacionarse con cambios en el IMC en hombres y con el índice cintura/cadera en las mujeres; estos efectos se producen tanto en personas que padecen dislipemias como en las personas sanas, como sucedió en el estudio de Grandjean et al. (2000), realizado con varones con y sin hipercolesterolemia, en donde se encontró que no existe diferencia en los cambios inducidos por el ejercicio en los niveles de HDL y TG.

Los niveles de $C L$ y de LDL no parecen ser susceptibles al ejercicio físico sin embargo, se ha observado el descenso en el contenido de $\mathrm{CL}$ de algunas partículas sobre todo si se acompaña de descenso en el peso corporal (Pérez et al., 2004).

El ejercicio reduce la grasa epicárdica, el peso corporal, el IMC, la circunferencia de cintura, la grasa visceral independientemente de la edad y el sexo del individuo. Por lo tanto, el incremento de la actividad física reduce la secreción de adipocinas pro-inflamatorias. Kim et al., (2009), evaluaron los efectos del ejercicio aeróbico (sin restricción de la dieta) en el espesor de la grasa del apicardio ventricular y demostraron reducción significativa del espesor de la grasa epicárdica después del ejercicio aeróbico, que se asoció también con disminución del tejido adiposo visceral. Sin embargo, el ejercicio puede llevar a resultados contrarios, es decir, el ejercicio 
que produce estrés físico puede provocar anomalías en el perfil de los lípidos plasmáticos (Ruiz et al., 2004).

Por otro lado, el ejercicio también tiene efectos sobre el daño celular mediado por las especies reactivas de oxígeno (EROS), ya que mejora los mecanismos de protección antioxidante en el miocardio e induce la cardioprotección antioxidante del superóxido dismutasa de manganeso (MnSOD), el cual protege contra infarto de miocardio al actuar contra la isquemia-reperfusión inducida por arritmias cardiacas (Golbidi et al., 2012).

\subsubsection{Prescripción de un programa de ejercicio físico}

Para obtener los beneficios de un programa de ejercicio es necesario que represente un esfuerzo, con el propósito de incrementar el gasto calórico; además, que su práctica sea con regularidad, ya que los efectos después de suspenderlo sólo duran unos días.

De acuerdo con la Norma Oficial Mexicana NOM-037-SSA2-2002, para la prevención, tratamiento y control de las dislipidemias, un programa de ejercicio físico debe tomar en cuenta los siguientes aspectos:

1. Tipo de ejercicio: el más recomendado es el ejercicio aeróbico de poca o moderada intensidad, que involucre grandes grupos musculares por largo periodo como caminar, trotar, correr, nadar y andar en bicicleta; que provoque un incremento en el consumo de oxígeno $\left(\mathrm{VO}_{2}\right)$ y de la frecuencia cardíaca (FC); puede complementarse con ejercicios de resistencia, fuerza y flexibilidad.

La ventaja de este tipo de ejercicio es que puede realizarse al aire libre, en parques y deportivos; se debe procurar realizarlo en superficies planas y de preferencia sin pendientes. Además no requiere de equipos costosos, ni complicados.

2. Frecuencia: es el número de veces que la persona realiza ejercicio en una semana; se recomienda al menos cuatro días a la semana, siendo el ideal 5 días. Puede realizarse en una o varias sesiones dependiendo de la disponibilidad de tiempo.

3. Intensidad: se conoce como la relación entre el esfuerzo físico requerido para su realización y el esfuerzo físico máximo que la persona puede tolerar; se caracteriza por el trabajo realizado por unidad de tiempo (Vasconcelos, 2005). 
Utilizar la frecuencia cardíaca para la evaluación del ejercicio, en términos de intensidad relativa, es una buena alternativa ya que refleja el porcentaje de capacidad aeróbica utilizada durante el ejercicio, expresada en porcentaje de frecuencia cardíaca máxima $(\% \mathrm{FCM})$ o porcentaje de $\mathrm{VO}_{2}$ max.

Los datos obtenidos de la prueba de esfuerzo sobre la frecuencia cardíaca y el consumo de oxígeno se utilizan para realizar la prescripción del ejercicio, considerando la salud del individuo y su aptitud.

El American College of Sports Medicine (ACSM) y la Asociación Americana de Cardiología recomiendan que la intensidad mínima de entrenamiento para jóvenes y adultos saludables puede ser $60 \%$ de la FCM o $50 \%$ del $\mathrm{VO}_{2} \max _{1} 0$ frecuencia cardiaca de reserva.

Tambien se puede calcular con la siguiente fórmula:

FCmax. $=220$-edad en años

4. Duración: es el tiempo que se le dedica a la ejecución de ejercicio que de acuerdo con el American College of Cardiology y la American Heart Association debe ser igual o mayor a 30 minutos de ejercicio moderado al inicio, siendo más recomendable 60 minutos.

5. Progresión: al inicio se tendrá un tiempo de adaptación que requiere de baja intensidad y que posteriormente irá aumentando paulatinamente la duración o la intensidad del ejercicio hasta llegar a una fase de mantenimiento.

6. Supervisión: es importante que antes de iniciar y finalizar cada sesión, las personas midan su frecuencia cardíaca y de ser posible se tensión arterial para prevenir cualquier evento que pueda significar riesgo.

Por otro lado, el Colegio Mexicano de Nutriólogos (2006) publicó su postura sobre orientación en actividad física para la prevención y manejo de las enfermedades crónicas en el ciclo de la vida asociadas con la nutrición, donde destaca seis actividades que deben considerarse en un programa de ejercicio las cuales se presentan en la tabla No. 21. 
Tabla No. 21. Actividades para un programa de ejercicio físico

\begin{tabular}{|c|c|}
\hline Actividades & Descripción \\
\hline $\begin{array}{l}\text { Calentamiento y } \\
\text { estiramiento }\end{array}$ & $\begin{array}{l}\text { En el inicio de la sesión, son ejercicios de tipo calisténico } \\
\text { y de estiramiento de baja intensidad para incrementar } \\
\text { la frecuencia cardíaca y respiratoria que prepara al } \\
\text { organismo para el funcionamiento eficaz del corazón, } \\
\text { los pulmones, los músculos, etc., para ejercicios más } \\
\text { intensos. } \\
\text { Se inicia con } 10 \text { minutos de estiramiento y } 10 \text { de } \\
\text { calentamiento. }\end{array}$ \\
\hline $\begin{array}{l}\text { Entrenamiento de } \\
\text { resistencia }\end{array}$ & $\begin{array}{l}\text { Son el núcleo del programa de ejercicio, su función es } \\
\text { mejorar la capacidad cardiovascular, respiratoria y } \\
\text { metabólica del organismo, como caminar, correr, nadar, } \\
\text { remar, aerobics y ciclismo, etc. }\end{array}$ \\
\hline $\begin{array}{l}\text { Enfriamiento y } \\
\text { estiramiento }\end{array}$ & $\begin{array}{l}\text { Consiste enreducir la intensidad de la actividad de } \\
\text { resistencia para lograr el enfriamiento en los últimos } \\
\text { minutos de la sesión, para evitar la acumulación de } \\
\text { sangre en las extremidades, disminuir los niveles de } \\
\text { catecolaminas y se recomienda hacer ejercicios de } \\
\text { estiramiento. }\end{array}$ \\
\hline $\begin{array}{l}\text { Entrenamiento de } \\
\text { flexibilidad }\end{array}$ & $\begin{array}{l}\text { Son complementarios al calentamiento; se } \\
\text { recomiendan para las personas que padecen problemas } \\
\text { musculares o articulares o que tienen poca flexibilidad. }\end{array}$ \\
\hline $\begin{array}{l}\text { Entrenamiento contra } \\
\text { resistencia }\end{array}$ & $\begin{array}{l}\text { Este tipo de actividad se realiza con peso de acuerdo a } \\
\text { las capacidades que el individuo posee y que debieron } \\
\text { ser evaluadas antes de iniciar su entrenamiento. } \\
\text { Generalmente se inicia con el equivalente a una } \\
\text { repetición máxima o 1-RM (peso máximo que puede } \\
\text { levantar el individuo de una sola vez). Si puede realizar } \\
\text { 10 repeticiones con ese peso es adecuado, si realiza más } \\
\text { debe incrementarse y si realiza menos requiere } \\
\text { disminuirse. }\end{array}$ \\
\hline $\begin{array}{l}\text { Actividades } \\
\text { recreativas }\end{array}$ & $\begin{array}{l}\text { Son las actividades que se realizan por placer como } \\
\text { jugar tenis, excursionismo, etc. Que ayudan a mejorar el } \\
\text { nivel de acondicionamiento físico. }\end{array}$ \\
\hline
\end{tabular}

Fuente: Colegio Mexicano de Nutriólogos. (2006).Postura del colegio Mexicano de Nutriólogos sobre orientación en actividad física para la prevención y manejo de las enfermedades crónicas en el ciclo de la vida asociadas con la nutrición. México.

Desde 1978 el ACSM publicó sus primeras recomendaciones sobre ejercicio y actividad físisca, las cuales se han modificado de acuerdo con los resultados de investigaciones científicas realizadas en el área; también ha dado a conocer otros consensos relacionados con padecimientos específicos, los cuales se presentan en la tabla No. 22 
Tabla No. 22. Recomendaciones de actividad física del ACSM para varias poblaciones.

\begin{tabular}{|l|l|}
\hline \multicolumn{1}{|c|}{ Población } & \multicolumn{1}{c|}{ Recomendaciones } \\
\hline \multirow{4}{*}{ Adultos sanos } & $\begin{array}{l}\text { 20-6o minutos de actividad aeróbica de 3 a 5 días por } \\
\text { semana para la salud cardiorespiratoria. }\end{array}$ \\
\cline { 2 - 3 } & Actividad de resistencia 2 a 3 días por semana. \\
\cline { 2 - 3 } & $\begin{array}{l}\text { Ejercicios de flexibilidadpor lo menos 2 a 3 días por } \\
\text { semana. }\end{array}$ \\
\hline $\begin{array}{l}\text { Adultos, } \\
\text { adolescentes y niños } \\
\text { con énfasis en } \\
\text { prevención de } \\
\text { osteoporosis }\end{array}$ & $\begin{array}{l}\text { Adultos: actividad aeróbica 3 a 5 días por semana y } \\
\text { ejercicio de resistencia 2 a 3 días por semana, con un total } \\
\text { de 30 a 6o minutos por día. }\end{array}$ \\
\cline { 2 - 3 } & $\begin{array}{l}\text { Adolescentes y niños: actividad incluyendo levantamiento } \\
\text { de pesas, 10 a 20 minutos, por lo menos 3 días a la } \\
\text { semana. }\end{array}$ \\
\hline $\begin{array}{l}\text { Adultos con } \\
\text { hipertensión }\end{array}$ & $\begin{array}{l}\text { Por lo manos 30 minutos diarios de actividad moderada, } \\
\text { todos o casi todos los días de la semana. }\end{array}$ \\
\hline $\begin{array}{l}\text { Adultos con diabetes } \\
\text { mellitus tipo 2 }\end{array}$ & $\begin{array}{l}\text { Por lo menos 30 minutos diarios de actividad leve a } \\
\text { moderada, de 3 a } 5 \text { días a la semana. }\end{array}$ \\
\hline
\end{tabular}

Fuente: Colegio Mexicano de Nutriólogos. (2006). Postura del colegio Mexicano de Nutriólogos sobre orientación en actividad física para la prevención y manejo de las enfermedades crónicas en el ciclo de la vida asociadas con la nutrición. México

\subsection{Tratamiento dietético}

Para el común de las personas la palabra "dieta" ha adquirido un significado de privación, es decir, significa estar sometido a un régimen en donde se restringe la cantidad de energía (kilocalorías) y el consumo de determinados alimentos generalmente con el propósito de perder peso. Sin embargo su verdadero significado es otro; la Norma Oficial Mexicana NOM-037-SSA2-2002, para la prevención, tratamiento y control de las dislipidemias en sus definiciones contempla la palabra "dieta" como "el conjunto de alimentos que se consumen cada día".

Por otro lado, la NOM-043-SSA2-2005. Servicios básicos de salud. Promoción y educación para la salud en materia alimentaria. Criterios para brindar orientación la define como "el conjunto de alimentos y platillos que se consumen cada día y constituye la unidad de la alimentación".

La dieta entonces puede favorecer el desarrollo adecuado de la persona y mantenerla sana o por el contrario provocarle deficiencias o excesos y por ende enfermedad.

En México en los últimos años se ha visto modificaciones en los estilos de vida; cada vez son menos las personas que comen en casa, 
debido entre otras muchas causas a la lejanía de su lugar de trabajo, a los horarios de oficina y a la cercanía de establecimientos de comida rápida o la facilidad de llevarlos hasta el lugar de trabajo, lo que ha repercutido en el incremento en el consumo de alimentos ricos en grasas saturadas y ácidos grasos trans característicos de la comida rápida y los "snacks" y a la utilización de refrescos embotellados, ricos en azúcares simples, como bebida en lugar de agua.

Como aseguran Cáez et al. (2007) además del aumento de las cantidades de comida, debido entre otros factores, a la mayor accesibilidad a alimentos ya listos para el consumo, se destaca el mayor tamaño de las raciones y un mayor contenido en grasas saturadas en los productos elaborados.

Son muchos los factores que intervienen en el consumo de alimentos, que repercuten directamente en el estado de nutrición como son el ingreso familiar, la disponibilidad de alimentos, la religión, las costumbres y los hábitos alimentarios, entre otros.

Los hábitos alimentarios son decisivos en la adopción de una dieta correcta; son conductas adquiridas por repetición referentes a la selección, preparación y consumo de los alimentos que dependen del entorno social donde se desenvuelve el individuo, pero que tienen la ventaja de ser sustituidos por otros. Por lo tanto, cambiar hábitos inadecuados en adecuados es factible y depende mucho de los conocimientos sobre alimentación que posean las personas, lo que les permite tomar decisiones sobre el tipo y cantidad de alimentos que deben consumir de acuerdo con sus posibilidades, garantizando así un aporte adecuado de energía y nutrientes.

Una herramienta importante de los profesionistas de la salud para informar a la población sobre la dieta correcta es la orientación alimentaria, la cual se define como un conjunto de acciones que proporcionan información básica científicamente validada y sistematizada, tendiente a desarrollar habilidades, actitudes y prácticas relacionadas con los alimentos y la alimentación, para favorecer la adopción de una dieta correcta a nivel individual, familiar y colectivo, tomando en cuenta las condiciones económicas, geográficas, culturales y sociales (NOM-043-SSA2-2005).

La orientación alimentaria debe ser proporcionada por personal calificado o capacitado, con base en un programa y utilizar material educativo gráfico y audiovisual, que permita promover conductas saludables en la población, orientadas a la adopción de un estilo de vida saludable. 


\subsubsection{Alimentación correcta}

El estilo de vida saludable se basa en dos aspectos importantes el ejercicio físico tratado anteriormente y la alimentación correcta. La alimentación correcta es la dieta que cumple con las necesidades específicas de las diferentes etapas de la vida; en los niños permite el crecimiento y desarrollo adecuados y en los adultos permite mantenerlos en su peso adecuado para la estatura y prevenir el desarrollo de enfermedades. (NOM-043-SSA2-2005).

Para que la dieta sea correcta debe cumplir con seis características que de acuerdo con la NOM-043-SSA2-2005 son:

1. Completa: que contenga todos los nutrientes (hidratos de carbono, proteínas, lípidos, vitaminas y minerales), lo cual se consigue con el consumo de alimentos de todos los grupos.

2. Equilibrada: que los nutrientes guarden las proporciones apropiadas entre sí: hidratos de carbono entre 55 y $60 \%$; proteínas entre el 10 y $15 \%$ y lípidos entre 30 y $35 \%$

3. Inocua: que su consumo habitual no implique riesgos para la salud, porque esté exenta de organismos patógenos, toxinas y contaminantes, y se consuma con moderación.

4. Suficiente: que cubra las necesidades de todos los nutrimentos (hidratos de carbono, proteínas, lípidos, vitaminas y minerales), de tal manera que el sujeto adulto tenga una buena nutrición y un peso saludable y en caso de los niños que crezcan y se desarrollen de manera correcta.

5. Variada: que incluya diferentes alimentos de cada grupo en los diferentes tiempos de comida.

6. Adecuada: que esté acorde con los gustos y la cultura de quien la consume y ajustada a sus recursos económicos, sin que ello signifique que se deben sacrificar sus otras características.

La figura 10 "El Plato del Bien Comer" es la representación gráfica de las recomendaciones alimentarias para la población mexicana; se consideran tres grupos de alimentos: el primero formado por frutas $y$ verduras, el segundo por cereales y tubérculos y el tercero por leguminosas y productos de origen animal, que se encuentran de manera explícita en la tabla No. 23 


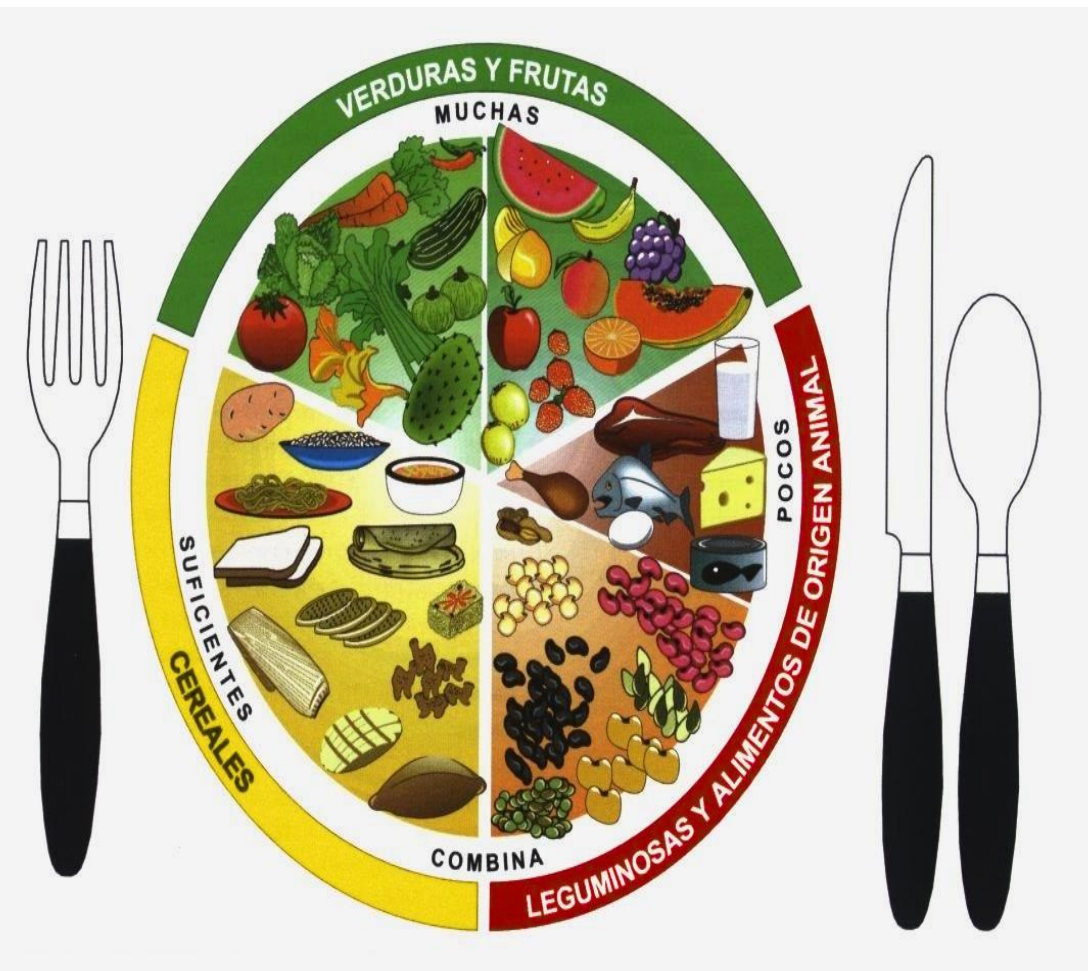

Figura 10. El Plato del Buen Comer

Fuente: Norma Oficial Mexicana. Servicios básicos de salud. Promoción y educación para la salud en materia alimentaria. Criterios para brindar orientación. NOM-043-SSA2-2005.

El primer grupo se observa en el esquema con una franja exterior de color verde, lo que significa que se promueve el consumo de muchas frutas y verduras, de preferencia crudas, que se produzcan en la región y de la estación, como fuente de vitaminas, minerales y fibra dietética.

El segundo grupo, se reconoce con franja color ámbar y la recomendación es consumir suficientes cereales, preferentemente integrales y sus derivados, así como de tubérculos, por su importante aporte de fibra y energía a la alimentación.

El tercer grupo, se reconoce por la franja color rojo; la recomendación es el consumo de las leguminosas por su aporte de fibra y proteínas de origen vegetal, y poco consumo de los productos de origen animal por su alto contenido en grasas saturadas $y$ colesterol. Preferir las carnes blancas y en menor frecuencia las carnes rojas.

Es importante recalcar que en cada tiempo de comida se debe consumir por lo menos un alimento de cada uno de los grupos y 
variarlos para asegurar el aporte de una mayor variedad de nutrientes.

Tabla No. 23 Grupos de Alimentos de acuerdo a la NOM-043-SSA2-2005

\begin{tabular}{|c|c|c|}
\hline Grupo & Frutas & Verduras \\
\hline $\begin{array}{l}1 \\
\text { Frutas y } \\
\text { Verduras }\end{array}$ & $\begin{array}{l}\text { Guayaba, papaya, melón, toronja, } \\
\text { lima, naranja, mandarina, } \\
\text { plátano, zapote, ciruela, pera, } \\
\text { manzana, toronja, fresa, } \\
\text { chicozapote, mango, mamey, } \\
\text { chabacano, uvas, entre otras. }\end{array}$ & $\begin{array}{l}\text { Acelgas, verdolagas, } \\
\text { espinacas, flor de } \\
\text { calabaza, col, nopales, } \\
\text { brócoli, coliflor, calabaza, } \\
\text { chayote, chícharo, } \\
\text { tomate, jitomate, hongos, } \\
\text { betabel, chile poblano, } \\
\text { zanahoria, aguacate, } \\
\text { pepino, lechuga entre } \\
\text { otras. }\end{array}$ \\
\hline \multirow[b]{2}{*}{$\begin{array}{l}2 \\
\text { Cereales y } \\
\text { Tubérculos }\end{array}$} & Cereales & Tubérculos \\
\hline & $\begin{array}{l}\text { Maíz, trigo, avena, centeno, } \\
\text { cebada, amaranto, arroz y sus } \\
\text { productos derivados como: } \\
\text { tortillas y productos de nixtamal, } \\
\text { cereales industrializados, pan y } \\
\text { panes integrales, galletas y } \\
\text { pastas. }\end{array}$ & Papa, camote y yuca. \\
\hline \multirow{2}{*}{$\begin{array}{l}3 \\
\text { Leguminosas } \\
\text { y Productos } \\
\text { de Origen } \\
\text { Animal }\end{array}$} & Leguminosas & $\begin{array}{l}\text { Productos de origen } \\
\text { animal }\end{array}$ \\
\hline & $\begin{array}{l}\text { Frijol, haba, lenteja, garbanzo, } \\
\text { arveja, alubia y soya. }\end{array}$ & $\begin{array}{l}\text { Leche, queso, yogurt, } \\
\text { huevo, pescado, mariscos, } \\
\text { pollo, carnes rojas y } \\
\text { vísceras. }\end{array}$ \\
\hline
\end{tabular}

Fuente: Norma Oficial Mexicana. Servicios básicos de salud. Promoción y educación para la salud en materia alimentaria. Criterios para brindar orientación. NOM-043-SSA2-2005.

Además, es necesario limitar en la preparación de los alimentos el contenido de sal, azúcar y grasas y revisar las etiquetas de los productos industrializados para conocer su contenido nutrimental y la fecha de caducidad.

También es necesario cumplir con las normas de higiene en la preparación y manipulación de los alimentos y las técnicas de conservación adecuadas; higienizar los utensilios, el área de preparación y la higiene personal para evitar en lo posible la contaminación.

\subsubsection{Dieta y dislipemias}

Aclarando el concepto de dieta, es necesario comentar que existen diferentes tipos de acuerdo con el objetivo que se desea 
conseguir; en el caso en particular de las dislipemias, la evidencia científica apunta a la reducción de la ingestión de la grasa saturada y $\mathrm{CL}$, incrementando el consumo de frutas, verduras y fibra cuyos efectos son diversos en los diferentes factores etiopatogénicos de las enfermedades cardiovasculares.

La dieta, es la primera medida terapéutica para las dislipemias y debe estar presente aun en los casos en los que se requiera tratamiento farmacológico.

Aunque la dieta no produjera resultados significativos en la reducción de los niveles de lípidos, siempre tendrá efectos antioxidativos y antitrombogénicos benéficos para la salud (NOM043-SSA2-2005).

Es importante recalcar que la terapia nutricional en las dislipemias se basa en las mismas pautas que para la población en general explicadas anteriormente (dieta correcta), haciendo ajustes en algunos aspectos muy concretos dependiendo del tipo de dislipemia, aunque coinciden entre ellas, es decir, las pautas alimentarias recomendadas para la reducción del $\mathrm{CL}$ son igualmente benéficas para la reducción de los TG, como por ejemplo el incremento en el consumo de verduras, la preferencia por los lácteos descremados, el incremento en el consumo de pescado, sin embargo, existen algunas pautas específicas como es el caso de limitar a las porciones recomendadas el consumo de frutas por su alto contenido en hidratos de carbono, la disminución en el consumo de azúcares simples (refrescos embotellados, dulces, azúcar) que son esenciales en la disminución de los TG. (Neuhouser et al., 2002; NOM-043SSA2-2005)

Es innegable el efecto de la dieta sobre los factores que producen las enfermedades cardivasculares, sobre todo sobre el $\mathrm{CL}$, ya que a medida que éste aumenta, se incrementa también el riesgo de cardiopatía.

El CL proveniente de la dieta tiene un efecto directo sobre el $\mathrm{CL}$ sanguíneo y las LDL (entre o y $300 \mathrm{mg} / \mathrm{dL}$ al día) disminuyendo su absorción intestinal cuando sobrepasa los $500 \mathrm{mg} / \mathrm{dL}$; se estima que por cada $100 \mathrm{mg} / \mathrm{dL}$ de $\mathrm{CL}$ ingerido se incrementa el sanguíneo 2,2 $\mathrm{mg} / \mathrm{dL}$ (Mataix et al., 2009).

Cuando la ingesta de $\mathrm{CL}$ de la dieta está aumentada los niveles hepáticos de $\mathrm{CL}$ se incrementan también, disminuyendo la densidad de receptores para las VLDL remanentes y las LDL; esto produce incremento en los niveles circulantes de LDL aumentando su captación por los macrófagos agravando el proceso aterosclerótico. De ahí la importancia de su disminución en el tratamiento dietoterapéutico. 
Otro aspecto importante en el incremento del $C L$ es la ingesta de ácidos grasos saturados de cadena larga (laúrico, mirístico y palmítico) que actúan de la misma manera que el $C L$ de la dieta disminuyendo los receptores de las VLDL e incrementando las LDL, y lo mismo sucede con los ácidos grasos trans que cuando se consumen abundantemente representan un riesgo aterogénico alto.

Esta condición se hace mayor en el caso de sobrepeso y obesidad, es decir, por cada kilogramo más de peso se incrementan aproximadamente $4 \mathrm{mg} / \mathrm{dL}$ de $\mathrm{CL}$ en sangre.

Por otro lado, los hidratos de carbono, las proteínas, los ácidos grasos omega-3 y el alcohol no modifican los niveles sanguíneos de $\mathrm{CL}$. Mientras el ácido oleico y el linolénico, disminuyen el CL total y las LDL.

Sobre los TG, es más evidente el efecto de los hidratos de carbono simples, el consumo de alcohol y los ácidos grasos saturados de cadena media que al ser consumidos incrementan la síntesis de TG en el hígado y por lo tanto las VLDL. El efecto contrario se observa cuando se consume ácidos grasos oléico, linoléico y omega -3.

Las proteínas y la fibra no ejercen ninguna influencia sobre los niveles sanguíneos de triglicéridos.

Con respecto a las $\mathrm{HDL}$, el ácido oleico cuya fuente alimentaria principal es el aceite de oliva, tiene un efecto muy importante en su incremento, aumentando también los niveles de las apoproteínas A I y A II.

El consumo de 100 a $300 \mathrm{ml}$ de alcohol proveniente de vino tinto, rosado, blanco o cerveza ejercen un efecto protector contra las enfermedades cardiovasculares debido a que incrmentan los niveles de $\mathrm{HDL}$, esto debido a la gran cantidad de antioxidantes que contienen, específicamente polifenoles.

El CL y los ácidos grasos saturados también incrementan las HDL, sin embargo sus efectos sobre el CL total y LDL son motivos para no considerar utilizarlos para este fin.

Por otro lado, el consumo de hidratos de carbono simples, de ácidos grasos omega-3, ácido linolénico y ácidos grasos trans, disminuyen los niveles de $\mathrm{HDL}$, efecto que se incrementa en presencia de sobrepeso y obesidad (Mataix et al., 2009).

Aun con sus diferencias, los principales objetivos que se persiguen con la terapia nutricional en el caso de las dislipemias son:

1. Lograr o mantener un peso adecuado.

2. Apegarse a las recomendaciones alimentarias (dieta correcta) con los ajustes adecuados con el tipo de dislipemia o su severidad. 
3. Conservar en lo posible los hábitos alimentarios, siempre y cuando no representen un riesgo para la salud.

La Norma Oficial Mexicana NOM-037-SSA2-2002, para la prevención, tratamiento y control de las dislipidemias propone dos etapas para el tratamiento nutricional:

Primera Etapa: En esta etapa se aplicarán los criterios nutricionales que se recomiendan para la población en general, orientada a reducir el consumo de alimentos ricos en grasas saturadas y $\mathrm{CL}$.

El porcentaje de macronutrientes recomendado es: hidratos de carbono de 50 a $60 \%$, prefiriendo los complejos y ricos en fibra soluble; proteínas de 10 al $20 \%$ y grasas de 25 a $35 \%$ de las cuales no más del 10 por ciento corresponderá a las saturadas; la relación entre grasas saturadas, poliinsaturadas y monoinsaturadas será de 1:1:1, es decir que cada tipo de grasa contribuirá con el 10\% de las kilocalorías, procurando que el $C L$ de la dieta no exceda a los 300 $\mathrm{mg} / \mathrm{dí}$.

Deberá tener un contenido en fibra, superior a los $30 \mathrm{~g}$ por día, por lo que se necesita consumir frutas, verduras y cereales integrales.

Después de iniciado el tratamiento, se evaluará la adherencia al plan alimentario y se medirá el $\mathrm{CL}, \mathrm{HDL}$ y $\mathrm{TG}$ al mes y a los tres meses.

Los valores de $C L$ podrán emplearse para monitorear la reducción de LDL, evitando de esa manera la toma de sangre en ayunas, para el cálculo de los niveles de LDL. Para tal efecto se asumirá que los valores de $C L$ de 240 y $200 \mathrm{mg} / \mathrm{dl}$ corresponderán aproximadamente a 160 y a $130 \mathrm{mg} / \mathrm{dl}$ de $L D L$, respectivamente.

En aquellos pacientes en los que se pretende reducir el nivel de LDL a $<100 \mathrm{mg} / \mathrm{dl}$, el uso de las equivalencias mencionadas en el numeral anterior, es inadecuado.

Si no se logran las metas en la Etapa I del tratamiento nutricional, el paciente deberá ser referido a personal especializado en nutrición, ya sea para iniciar la Etapa II del tratamiento, o bien para hacer otro intento con la Etapa I.

Segunda Etapa: Esta etapa del tratamiento requiere asesoría por profesionistas de la nutrición, a fin de lograr que el régimen dietético de reducción de grasas, no provoque una dieta desbalanceada, haciendo el seguimiento exclusivamente con los valores de $\mathrm{CL}, \mathrm{HDL}$ y TG, y a partir de ellos, estimar los valores del LDL.

Deberán medirse también los niveles de $C L$ y la adherencia al tratamiento nutricional a las cuatro o seis semanas y a los tres meses de iniciado este tipo de tratamiento. Si se logra la meta del $C L$, se 
medirán las Lp para calcular el LDL y se confirmará que, efectivamente, así ha ocurrido.

A partir de ese momento el paciente será ingresado a un programa de vigilancia a largo plazo, en el cual, durante el primer año se le revisará trimestralmente y después, dos veces por año. En estas visitas, además de la medición del $\mathrm{CL}$, se reforzarán las medidas dietéticas y de actividad física.

Si el LDL continúa por arriba de la meta, tras haber aplicado de manera intensiva las medidas nutricionales durante un periodo no menor de seis meses, se evaluará la conveniencia de usar recursos farmacológicos.

Se recomienda un periodo de prueba, para el tratamiento no farmacológico, de un año en sujetos sin evidencia de enfermedad del corazón y de 3 a 6 meses en aquellos con evidencia de enfermedad coronaria; el periodo de prueba puede reducirse, a criterio del médico, por ejemplo: en pacientes con LDL $\geq 220 \mathrm{mg} / \mathrm{dl}$ (NOM-037SSA2-2002).

Existe evidencia sustancial que muestra que la adherencia a las recomendaciones dietéticas antes mencionadas disminuye el riesgo de complicaciones a largo plazo y la recurrencia de comorbilidades.

Por otro lado, el incumplimiento de las recomendaciones implica mayor riesgo de progresión de la enfermedad y de peor pronóstico, lo cual está fuertemente asociado con la calidad de vida, tiempo de vida menor y considerables costos económicos.

En la tabla No. 24 se pueden observar las recomendaciones alimentarias para la hipercolesterolemia y en la tabla No. 25, para la hipertrigliceridemia.

Neuhouser et al. (2002) realizaron un estudio cuyo objetivo fue identificar si los pacientes diagnosticados con diabetes mellitus, hipertensión, dislipemias y enfermedades cardiovasculares siguen las recomendaciones dietéticas estándar establecidas para dichas enfermedades. Participaron 1,782 hombres y mujeres adultos a quienes se les aplicó una historia clínica para identificar sus hábitos de salud y ejercicio así como la frecuencia de consumo de alimentos, mediciones corporales de peso, estatura y una muestra de sangre para determinar colesterol total, triglicéridos y carotenoides.

Los resultados mostraron que el $42 \%$ de los participantes presentaron riesgo o al menos una enfermedades modificable con la dieta. Presentaron además, niveles más altos de CL y TG que los no afectados. 
Tabla No. 24 Recomendaciones alimentarias para la hipercolesterolemia

\begin{tabular}{|c|}
\hline Alimentos ricos en proteínas \\
\hline Leche y derivados \\
\hline $\begin{array}{l}\text { Leche y yogur descremados y quesos frescos, evitar los grasosos como el } \\
\text { manchego }\end{array}$ \\
\hline Carnes \\
\hline $\begin{array}{l}\text { De las carnes preferir las magras, pollo y cerdo y sólo tres veces por semana; } \\
\text { evitar vísceras y carnes grasosas. }\end{array}$ \\
\hline Pescado \\
\hline $\begin{array}{l}\text { Tres veces a la semana, consumir atún, salmón de preferencia. Evitar los } \\
\text { mariscos si su consumo es habitual o consumirlos eventualmente. }\end{array}$ \\
\hline Huevo \\
\hline $\begin{array}{l}\text { Consumirlo entero dos o tres veces a la semana; puede consumir las claras } \\
\text { todos los días. Disminuir el consumo de mayonesa. }\end{array}$ \\
\hline Embutidos \\
\hline $\begin{array}{l}\text { Evitar el consumo de chorizo, longaniza, tocino y salchicha. Consumir jamón } \\
\text { bajo en grasa y sal. }\end{array}$ \\
\hline Leguminosas y frutos secos \\
\hline Se pueden consumir, siempre que se respete la porción recomendada. \\
\hline Alimentos ricos en grasas \\
\hline Aceites \\
\hline $\begin{array}{l}\text { Consumir preferentemente aceite de oliva virgen, aceites de semillas como } \\
\text { canola, soya, girasol. }\end{array}$ \\
\hline Otras grasas \\
\hline Evitar el consumo de nata, crema, manteca, mantequilla y margarina. \\
\hline Alimentos ricos en hidratos de carbono \\
\hline Panes, pasteles, cereales y pastas \\
\hline $\begin{array}{l}\text { Se recomienda el consumo de panes y cereales integrales, por su contenido de } \\
\text { fibra, tortillas de maíz y pastas, excepto las que son adicionadas con huevo. } \\
\text { Los pasteles, galletas y productos a base de huevo y manteca vegetal (coco o } \\
\text { palma), margarina o mantequilla deben ser limitados. }\end{array}$ \\
\hline Alimentos ricos en fibra \\
\hline Frutas y verduras \\
\hline Se recomienda consumirlas todos los días en las porciones recomendadas \\
\hline Bebidas alcohólicas \\
\hline $\begin{array}{l}\text { No se recomienda el consumo de bebidas alcohólicas, excepto el vino tinto sin } \\
\text { exceder de dos copas al día. }\end{array}$ \\
\hline
\end{tabular}

Fuente: modificada de Mataix et al. (2009). Enfermedad del Sistema Circulatorio. En: Mataix, J. Tratado de Alimentación y Nutrición. Tomo 2 situaciones Fisiológicas y Patológicas (pp. 1471-1517). España: Editorial Oceano/Ergon.

El $46 \%$ de los participantes presentaron sobrepeso u obesidad y el IMC fue significativamente mayor en los participantes que presentaron al menos una enfermedad modificable con la dieta. 
Tabla No. 25 Recomendaciones alimentarias para la hipertrigliceridemia

\begin{tabular}{|c|}
\hline Alimentos ricos en proteínas \\
\hline Leche y derivados \\
\hline $\begin{array}{l}\text { Leche y yogur descremados y quesos frescos, evitar los grasosos como el } \\
\text { manchego }\end{array}$ \\
\hline Carnes \\
\hline $\begin{array}{l}\text { De las carnes preferir las magras, pollo y cerdo y sólo tres veces por semana; } \\
\text { evitar vísceras y carnes grasosas. }\end{array}$ \\
\hline Pescado \\
\hline $\begin{array}{l}\text { Cuatro o cinco veces a la semana, consumir atún, salmón de preferencia. Evitar } \\
\text { los mariscos si su consumo es habitual o consumirlos eventualmente. }\end{array}$ \\
\hline Huevo \\
\hline $\begin{array}{l}\text { Consumirlo entero dos o tres veces a la semana; puede consumir las claras } \\
\text { todos los días. Disminuir el consumo de mayonesa. }\end{array}$ \\
\hline Embutidos \\
\hline $\begin{array}{l}\text { Evitar el consumo de chorizo, longaniza, tocino y salchicha. Consumir jamón } \\
\text { bajo en grasa y sal. }\end{array}$ \\
\hline Leguminosas y frutos secos \\
\hline $\begin{array}{l}\text { Deben limitarse, no excluirse, en función de la disminución de hidratos de } \\
\text { carbono que requiere el tratamiento y siempre respetando la porción } \\
\text { recomendada. }\end{array}$ \\
\hline Alimentos ricos en grasas \\
\hline Aceites \\
\hline $\begin{array}{l}\text { Consumir preferentemente aceite de oliva virgen, aceites de semillas como } \\
\text { canola, soya, girasol. }\end{array}$ \\
\hline Otras grasas \\
\hline Evitar el consumo de nata, crema, manteca, mantequilla y margarina. \\
\hline Alimentos ricos en hidratos de carbono \\
\hline Panes, pasteles, cereales y pastas \\
\hline $\begin{array}{l}\text { Se recomienda el consumo de panes y cereales integrales, por su contenido de } \\
\text { fibra, tortillas de maíz y pastas, excepto las que son adicionadas con huevo. } \\
\text { Los pasteles, galletas y productos a base de huevo y manteca vegetal (coco o } \\
\text { palma), margarina o mantequilla deben ser eliminados de la dieta }\end{array}$ \\
\hline Alimentos ricos en fibra \\
\hline Frutas y verduras \\
\hline $\begin{array}{l}\text { Se recomienda consumirlas todos los días en las porciones recomendadas, } \\
\text { limitando las que son ricas en hidratos de carbono como el plátano, el mango, } \\
\text { las uvas. }\end{array}$ \\
\hline Bebidas alcohólicas \\
\hline No deben consumirse bebidas alcohólicas. \\
\hline
\end{tabular}

Fuente: modificada de Mataix et al. (2009). Enfermedad del Sistema Circulatorio. En: Mataix, J. Tratado de Alimentación y Nutrición. Tomo 2 situaciones Fisiológicas y Patológicas (pp. 1471-1517). España: Editorial Oceano/Ergon.

En las personas con diabetes mellitus se pudo observar que en su ingesta, un mayor porcentaje de la energía fue proveniente de la grasa; en los hombres con HTA se observó un porcentaje mayor de consumo de grasa saturada en comparación con los participantes sanos. 
Con relación al ejercicio físico se encontró que tanto sanos como enfermos se ejercitan en promedio 17 minutos al día, situación que no cumple con las recomendaciones para un estilo de vida saludable.

En general, la mayoría de los participantes sanos y enfermos realizan dietas que no corresponden a las recomendaciones para la prevención o tratamiento de las enfermedades modificables con la dieta.

Este estudio concluye con la necesidad de desarrollar nuevas estrategias para ayudar a los pacientes con enfermedades modificables con la dieta a adoptar sus recomendaciones y mantenerlas por largo plazo con el objeto de reducir el riesgo y las complicaciones

\subsubsection{Importancia del licopeno en el tratamiento de las dislipemias}

Una estrategia importante en el tratamiento de las dislipemias, es la utilización de compuestos presentes en forma natural en los alimentos que poseen propiedades biológicas antioxidantes, es decir, participan en la eliminación de especies activas de oxígeno (radicales libres), formadas o no por el metabolismo humano, que además de otras funciones como regular la función genética, realizar modulación hormonal e inmune y participan en el metabolismo carcinogénico y en la ruta metabólica mediante la inducción de enzimas.

Algunos investigadores (Cáez et al., 2007; Henson et al., 2008; Waliszewski et al., 2010) Ilaman alimentos funcionales a los que contienen este tipo de compuestos, porque se ha demostrado que además de sus efectos nutricionales adecuados, tienen efectos benéficos en una o más funciones del organismo humano que incrementan su estado de salud y previenen o reducen el riesgo de enfermedades.

Tal es el caso del licopeno, que es un carotenoide de estructura acíclica, isómero del beta-caroteno, pero sin actividad provitamina $\mathrm{A}$ (al carecer de anillo de beta-ionona), cuya fórmula es $\mathrm{C}_{40} \mathrm{H}_{56}$; se encuentra en la naturaleza como pigmento natural liposoluble responsable del color rojo y naranja de algunas frutas y verduras.

Posee una estructura química de cadena abierta alifática, formada por cuarenta átomos de carbono con trece enlaces dobles, de los cuales once son conjugados, por lo que es muy reactivo frente al oxígeno y a los radicales libres. Se sintetiza exclusivamente por las plantas y los microorganismos y una de sus funciones principales es absorber la luz durante la fotosíntesis para proteger a la planta contra la fotosensibilización. Se encuentra principalmente en los 
tomates, la sandía, la toronja rosada, la guayaba rosada y la papaya y en algunos productos procesados como el puré y jugo de tomate (Vitale et al., 2010)

El licopeno es uno de los carotenoides que además de encontrarse en los alimentos se encuentra distribuido en mayores cantidades en el suero humano (21-43\%) y los diferentes tejidos (hígado, riñón, glándulas renales, testículos, ovarios y próstata) y su concentración depende de su ingestión alimentaria, pero poco influenciada por la variación del día a día, debido a que la vida media del licopeno en plasma es de 12 a 33 días (Casso et al. ,2000; Waliszewski et al., 2010).

El tomate y sus productos contienen el isómero todo-trans del licopeno (79-91\%), mientras el suero y los diferentes tejidos humanos y animales acumulan preferentemente los isómeros cis del licopeno (79-88\%). Vitale et al., (2010) citan un estudio de Stahl et al., (1996), donde fue medido el suero de individuos sanos encontrando que contenía $50 \%$ de isómeros cis de licopeno después del consumo de jugo de tomate, el cual sólo contenía $20 \%$ de isómeros cis de licopeno.

El mecanismo que pueden explicar el papel del licopeno en la prevención de las enfermedades crónicas es complejo: cuando se produce un enlace químico normal (iónico o covalente), un par de electrones opuestos comparten la misma órbita nuclear y los átomos quedan integrados en un compuesto estable. En un radical libre, el átomo tiene en su última órbita un electrón impar por lo que se comporta de una manera inestable buscando otro electrón para completar su configuración. Esta inestabilidad lo convierte en un agente oxidante.

Durante la oxidación metabólica y en la cadena de citocromos se liberan la cascada de electrones, produciéndose ATP y bióxido de carbono, mientras que el oxígeno sufre una reducción tetravalente sin que se produzcan productos intermedios. Los electrones fueron cedidos por la cadena, pero un porcentaje de ese oxígeno $(1,2 \%)$ sufre una reducción univalente y no alcanza a unirse al hidrógeno para formar agua, por lo que se forman tres subproductos intermedios (radicales libres) que son altamente tóxicos comunmente conocidos como EROS (especies reactivas de oxígeno): el anión superóxido por reducción univalente $\left(\mathrm{O}_{2}+1 \mathrm{e}-\left(\mathrm{O}_{2}\right)\right)$; el anión peróxido de hidrógeno por reducción bivalente $\left(\mathrm{O}_{2}+2 \mathrm{e}-+2 \mathrm{H}\left(\mathrm{H}_{2} \mathrm{O}_{2}\right)\right)$ y el anión hidroxilo por reducción trivalente $\left(\mathrm{O}_{2}+3 \mathrm{e}-+3 \mathrm{H}(-\mathrm{OH})\right)$.

Existe una forma de oxígeno que no deriva de la reducción del oxígeno, sino de una forma mutante de energía producida por la transferencia de energía luminosa de luz solar; es birradical y posee una órbita molecular en la cual dos electrones "sin" se sistematizan 
en dos órbitas diversas llamado anión oxígeno singlete $\left(\mathrm{O}_{2}+3 \mathrm{e}-{ }_{3} \mathrm{H}\right.$ ['O2]).

Las EROS se producen de manera endógena con el proceso metabólico normal y también de manera exógena (ver tabla No. 26); su formación pueden dañar algunos componentes celulares como es el caso de los lípidos, las proteínas, los hidratos de carbono y los ácidos nucleicos, cuyo daño se manifiesta a través de la aparición de arrugas, ateroesclerosis, manchas cafés en la piel o efélides, artrosis, fibrosis arterio-capilar, deterioro en las funciones enzimáticas, mutaciones celulares que pueden ser origen de cáncer, entre otras (Shi et al., 2004; Shixian et al., 2005; Rao et al., 2007; Waliszewski et al., 2010).

Los radicales libres se pueden inactivar a través de los sistemas antioxidantes con que cuenta el cuerpo humano: el sistema enzimático de acción intracelular como catalasa (CAT), superóxido dismutasa (SOD) y glutatión peroxidasa, y los sistemas no enzimáticos que son sustancias secuestradoras de EROS como la vitamina $E$, el ácido ascórbico, los carotenos, el glutatión y el licopeno (Madrid et al., 2006).

Los antioxidantes como el licopeno, tienen la habilidad de interactuar con las EROS mitigando el daño ya que en sus estructuras moleculares poseen electrones extra capaces de ceder el radical libre a fin de completar el faltante en su órbita externa; las EROS al recibir los electrones se convierten en moléculas estables e inofensivas, con lo que la reacción en cadena se detiene y las moléculas que resultan al perder su electrón se neutralizan.

El estrés oxidativo es uno de los factores más importantes en la generación de las enfermedades crónicas, por lo que los antioxidantes juegan un papel muy importante en la prevención de enfermedades como el cáncer de próstata, de intestino, de estómago, de colon y recto en hombres y de cérvix, seno, estómago y ovario en las mujeres.

Existe evidencia de que el consumo de licopeno disminuye el riesgo de cáncer de próstata, Magbanua et al. (2011) examinaron los efectos del licopeno y del aceite de pescado en un estudio clínico aleatorizado doble ciego, en el que ochenta y cuatro hombres con cáncer de próstata de bajo riesgo se asignaron al azar a una intervención con duración de tres meses; 29 recibieron licopeno, 27 aceite de pescado y 28 placebo. No se encontraron diferencias significativas en genes individuales entre los tres grupos, pero los análisis exploratorios pusieron de manifiesto vías de señalización in vivo que podrían estar moduladas por el licopeno, tales como el estrés oxidativo mediado por el factor nuclear eritroide $2(\mathrm{Nrf} 2)$. 
Tabla No. 26 Causas endógenas y exógenas de las EROS

\begin{tabular}{|c|c|}
\hline \multicolumn{2}{|c|}{ Fuentes } \\
\hline Endógenas & Exógenas \\
\hline $\begin{array}{l}\text { Respiración aeróbica: la mitocondria } \\
\text { consume oxígeno hasta producir agua y } \\
\text { ATP, quedando oxígeno, agua y } \\
\text { radicales hidroxilo como subproductos. }\end{array}$ & $\begin{array}{l}\text { Exposición al humo del cigarro: que } \\
\text { produce grandes cantidades de } \\
\text { radicales libres causantes de cáncer } \\
\text { de pulmón, estómago, vejiga y } \\
\text { recto. }\end{array}$ \\
\hline $\begin{array}{l}\text { Respuesta inmunológica fagocitaria: las } \\
\text { células fagocitarias destruyen las células } \\
\text { infectadas por bacterias y virus, } \\
\text { produciendo radicales libres altamente } \\
\text { nocivos que pueden dañar el ADN de } \\
\text { otras células sanas. }\end{array}$ & $\begin{array}{l}\text { Contaminación atmosférica: } \\
\text { disminuye los niveles de enzimas } \\
\text { antioxidantes debido a los productos } \\
\text { de combustión de combustibles } \\
\text { fósiles. }\end{array}$ \\
\hline $\begin{array}{l}\text { Metabolismo lipídico: Los ácidos grasos } \\
\text { insaturados y poliinsaturados al } \\
\text { degradarse producen aldehídos y } \\
\text { alquilos. }\end{array}$ & $\begin{array}{l}\text { Dietas ricas en carnes rojas: por su } \\
\text { contenido en sales de hierro y cobre, } \\
\text { promueves la formación de radicales } \\
\text { libres oxidantes tipo peróxido que } \\
\text { son factor de riesgo de } \\
\text { enfermedades cardiovasculares y } \\
\text { cáncer. }\end{array}$ \\
\hline $\begin{array}{l}\text { Detoxificación hepática: la acción } \\
\text { detoxificadora del citocromo } \mathrm{P} 450 \text { que } \\
\text { protege al hígado contra las toxinas } \\
\text { químicas de la dieta origina productos } \\
\text { que dañan el ADN de las células. }\end{array}$ & $\begin{array}{l}\text { Dietas ricas en grasa de origen } \\
\text { animal }\end{array}$ \\
\hline \multirow{4}{*}{$\begin{array}{l}\text { Oxígeno singulete: activa las } \\
\text { prostaglandinas y produce } \\
\text { hidroperóxidos, lo que favorece la } \\
\text { producción de coágulos y trombosis. }\end{array}$} & $\begin{array}{l}\text { Exposición a rayos ultravioleta: que } \\
\text { provocan reacciones fotooxidativas } \\
\text { afectando la piel. }\end{array}$ \\
\hline & Exposición al asbesto \\
\hline & $\begin{array}{l}\text { Quemaduras, heridas e infecciones } \\
\text { agudas: producen radicales libres en } \\
\text { su proceso de reparación y en la } \\
\text { lucha del organismo contra los } \\
\text { agentes infecciosos. }\end{array}$ \\
\hline & $\begin{array}{l}\text { Consumo de alcohol: produce } \\
\text { lipoperoxidación en la membrana de } \\
\text { los hepatocitos y de los eritrocitos. }\end{array}$ \\
\hline
\end{tabular}

Fuente: elaborado con información de Vitale et al. (2010). Carotenoides en quimioprevención: licopeno. Acta Bioquim Clin Latinoam, 44(2), 195-238 y Rao et al. (2001). Lycopene inhibits osteoclastic bone resorption mediated by reactive oxygen species (ROS). J Bone Min Res, 16 (sl), $\mathrm{S}_{3} 82$

Otro estudio doble ciego aleatorizado se realizó en afroamericanos, con el objetivo de evaluar el efecto de los suplementos de licopeno en pacientes con hiperplasia benigna de próstata o cáncer de próstata. Cuarenta y siete sujetos consumieron $30 \mathrm{mg}$ de licopeno al día (oleorresina de tomate) o placebo durante 21 días antes de la biopsia de próstata. Se produjo un incremento significativo de la concentración de licopeno en suero en 
comparación con el grupo placebo. En los pacientes diagnosticados con cáncer y los que presentaron hiperplasia prostática benigna $(\mathrm{BPH})$, las concentraciones plasmáticas de licopeno también se incrementaron significativamente en el grupo experimental en comparación con el placebo, no detectandose modificaciones significativas en el biomarcador de daño oxidativo al ADN 8-oxo-7,8dihidro-2'-desoxiguanosina (8-oxo-dG) en el tejido prostático ni en los niveles plasmáticos de MDA como indicador de estrés oxidativo sistémico (Van Breemen et al., 2011).

Van Breemen et al. (2008) estudiaron líneas celulares cancerosas de diferentes tejidos humanos y demostraron que el licopeno es capaz de promover la apoptosis en estas células y por lo tanto podría funcionar como agente quimioterapéutico. También se le atribuyen funciones antiinflamatorias, puesto que tanto en concentraciones bajas como en fisiológicas en el suero, el licopeno es capaz de suprimir la proliferación de las células mitogénicas que inhiben la activación de las células $T$ a través de la modulación de la expresión del activador precoz linfocitario CD69 y la secreción de la interleucina 2 (IL-2) (Mills et al., 2012)

Existen estudios (Giovannucci et al., 1994; Shi et al., 2004; Omoni et al., 2005; Vitale et al.,2010) que han demostrado que la ingesta de licopeno se correlaciona con la disminución de riesgo a padecer cáncer, enfatizando su asociación al consumo de salsa de tomate, tomate crudo y salsa para pizza, que poseen propiedades que alteran la producción de xenobióticos, modulan y controlan el crecimiento celular anormal e inducen la comunicación intercelular que regula el crecimiento rápido y descontrolado de células. Sin embargo, existen otros estudios que no demuestran significativamente sus efectos como el caso de Kirsh et al. (2006) y Stram et al. (2006) citados por Waliszewski et al. (2010), donde no se encontró suficiente evidencia de que el licopeno proteja contra este tipo de enfermedades.

Además de sus efectos contra el cáncer, se está estudiando el papel del licopeno en la osteoporosis mediante el cultivo de tejidos con osteoclastos y osteoblastos incubados en diferentes concentraciones de licopeno; los resultados han mostrado una activación de los osteoblastos que forman el hueso y una reducción en la descalcificación. Mackinnon et al. (2011) realizaron un estudio aleatorio controlado de intervención, cuyo objetivo fue determinar si el licopeno disminuye los marcadores de recambio y con ello el riesgo de osteoporosis en mujeres post-menopáusicas. Participaron 60 mujeres post-menopáusicas entre 50-60 años las cuales fueron suplementadas dos veces al día durante cuatro meses de la siguiente manera: el grupo 1 con jugo de tomate regular (30 $\mathrm{mg}$ de licopeno), el grupo 2 con jugo de tomate rico en licopeno (70 mg de licopeno), el grupo 3 con cápsulas de licopeno (30 mg de licopeno) y el grupo 4 
con cápsulas de placebo. Se midió la oxidación de los lípidos, las proteínas y el marcador de resorción ósea $\mathrm{N}$-telopéptido de colágeno tipo I (NTx), el contenido de carotenoides y la capacidad antioxidante total (TAC). Los resultados demuestran que en comparación con el placebo, el licopeno incrementó su concentración en suero al igual que la TAC, encontrándose una disminución significativa de la oxidación de los lípidos, las proteínas y el NTx.

Se está realizando estudios para identificar el efecto del licopeno en la hipertensión arterial, el enfisema, el asma y el Alzheimer (Rao et al., 2003 y Rao et al., 2007; Galhardo et al., 2009).

Se ha demostrado (Rao, 2002; Kun et al., 2007; Santosh et al., 2010;) que el consumo de antioxidantes como el licopeno pueden reducir el riesgo de enfermedades cardiovasculares, protegiendo a las biomoléculas críticas como los lípidos y las LDL, pues debido a su función antioxidante evita que las LDL se oxiden y produzcan daños en la membrana celular. La mitad de las moléculas de ácidos grasos en las partículas de LDL son piliinsaturadas y por lo tanto susceptibles a la oxidación en presencia de radicales libres $u$ otras especies reactivas de oxígeno; cuando las partículas de LDL son oxidadas desencadenan una serie de eventos que conducen al desarrollo de lesiones ateroescleróticas; atraen a los monocitos a la pared del vaso a través de la mayor producción de células endoteliales de proteína quimiotáctica de monocitos- 1 (MCP-1), la expresión molecular de adhesión intercelular (ICAM-1) y la molécula celular de adhesión vascular (VCAM-1). Una vez atraídos por la pared del vaso, los monocitos transmigran através de la célula endotelial a la capa íntima de la pared del vaso donde son diferenciadas de los macrófagos. La estimulación inflamatoria del endotelio juega un rol importante en el desarrollo de la aterosclerosis, puesto que oxida las LDL haciéndolas citotóxicas para las células vasculares, lípidos y enzimas lisosomales que son liberados en el espacio extracelular; esto da como resultado una respuesta inflamatoria. Se liberan las citocinas que ayudan a convertir los monocitos en macrófagos y las enzimas proteolíticas liberadas se cree que debilitan las capas fibrosas de las lesiones ateroscleróticas conduciendo a la ruptura de la placa. Los macrófagos atacan grandes cantidades de LDL lo que conduce a la formación de células espumosas que se acumulan formando estrías grasas, que caracterizan la primera etapa de formación de lesiones ateroscleróticas.

Burton et al. (2012) realizaron un estudio cuyo objetivo fue evaluar los efectos del consumo de tomate procesado en una comida rica en grasas sobre los marcadores postprandiales oxidativos y de inflamación en hombres y mujeres con peso saludable, se concluyó que $94 \mathrm{~g}$ de pasta de tomate lograba atenuar de manera significativa 
la oxidación postprandial de las LDL en los participantes del grupo experimental en comparación con el grupo control, posiblemente debido a la reducción de IL-6 y TNF $\alpha$. Considerando que muchas horas del día el cuerpo humano se encuentra en estado postprandial con LDL oxidadas circulantes, la susceptibilidad de activación de daño celular es elevada, provocando la iniciación y progresión de la aterosclerosis, por lo que la inclusión de fuentes de licopeno en la dieta podría tener un impacto significativo en la disminución del riesgo.

Se ha encontrado asociación entre las concentraciones de licopeno en suero y diferentes tejidos y la reducción del grosor de la pared de la íntima en pacientes con aterosclerosis. (Rissanen et al., 2000)

Kim et al. (2010), realizaron un estudio con mujeres coreanas cuyo objetivo fue conocer la asociación entre la concentración de licopeno en suero con y la rigidez arterial, estimada mediante la velocidad de onda pulsátil braquial-tobillo (baPWV) y encontraron una relación inversa independiente entre la concentración de licopeno y baPWV. Este efecto del licopeno sobre la rigidez arterial parece estar asociado a la reducción de la oxidación de las LDL. En un estudio similar realizado en hombres coreanos Yeo et al. (2010) confirmaron que los niveles elevados de licopeno en suero, no sólo se asociaban a la baPWV, sino también a una reducción en el número de factores de riesgo para el síndrome metabólico.

Se ha encontrado también que una dieta rica en tomates tuvo efecto importante en el incremento de las HDL; Blum et al. (2006) pudieron comprobar que el consumo de $300 \mathrm{~g}$ de tomates al día durante un mes incrementó el nivel de HDL en un $15,2 \%$.

En un estudio de intervención con 21 individuos sanos quienes estuvieron tres semanas con una dieta sin productos de tomate y 3 semanas con una dieta alta en productos de tomate $(400 \mathrm{ml}$. de jugo de tomate y $30 \mathrm{mg}$ de ketchup por día), se encontró que la concentración de los niveles de CL total se redujo en $5.9 \%$ y de LDL en $12.9 \%$ con la dieta alta en tomate en comparación con la baja en tomate (Silaste et al., 2007).

En un estudio realizado en Lituania y Suecia, Kritenson et al. (1997) encontraron asociación entre los bajos niveles séricos de licopeno y el incremento de mortalidad por enfermedades cardiovasculares.

En un análisis de casos y controles con 108 adultos mayores se encontró asociación inversa entre el licopeno en suero y la presencia de aterosclerosis; el efecto más severo se encontró en los fumadores (Klipstein-Grobusch et al., 2000). 
Estudios in vitro e in vivo han demostrado el efecto hipocolesterolémico del licopeno. Fuhrman et al. (1997) citados por Waliszewski et al. (2010), investigaron el efecto del licopeno como reductor del $\mathrm{CL}$ en macrófagos in vitro, incubando las células de macrófagos con licopeno, encontrando una disminución de $73 \%$ de la síntesis de $\mathrm{CL}$ debido a que posiblemente el licopeno inhibe la enzima 3 hidroxi-3- metilglutaril reductasa (HMGOCoa).

Los mismos autores realizaron un estudio in vivo, suplementaron a seis hombres sanos durante tres meses con 6omg/día de licopeno, encontrando al final del tratamiento reducción del $14 \%$ de los niveles de CL plasmático. (Fuhrman et al., 2000)

Según Pennathur et al. (2010) la regulación de los eventos inflamatorios e infecciosos se deben a la alteración que sufre el licopeno al oxidarse y fragmentarse en presencia de concentraciones elevadas de ácido hipocloroso $(\mathrm{HOCl})$.

Aun con toda esta evidencia, existe mucha controversia entre los diferentes tipos de estudios, por un lado se encuentran aquellos que se han realizado en población sana y por lo tanto pretenden identificar los efectos preventivos del licopeno; por otro lado, se encuentran los que han sido realizados con sujetos que presentan patologías principalmente aterosclerosis, diabetes mellitus e hipertensión. La duración de las intervenciones, el tipo de población (sólo hombres, sólo mujeres o ambos), las dosis utilizadas y las diferentes mezclas y alimentos utilizados hace difícil la comparación entre los resulados de los diferentes estudios y entre éstos y los realizados in vitro. De hecho, es necesario acercar los modelos de los estudios in vitro a las condiciones fisiológicas en humanos para poder entender con mayor claridad los efectos de este carotenoide (Böhm, 2012).

\subsubsection{Biodisponibilidad}

El licopeno una vez ingerido se incorpora dentro de las micelas de los lípidos que forman parte de la dieta y por difusión pasiva es absorbido en la mucosa intestinal; ahí se incorpora a los quilomicrones de donde luego se libera para ser transportado por las lipoproteínas (LDL y VLDL) a través del sistema linfático hacia el hígado y otros órganos (glándulas suprarrenales, próstata y testículos). Sólo entre el 10 y $30 \%$ del licopeno es absorbido, el resto es excretado, lo que depende de algunos factores biológicos y de estilo de vida como son el sexo, la edad, la composición corporal, el estado hormonal, los niveles de lípidos en sangre, el consumo de alcohol y de tabaco y la presencia de carotenoides en la dieta. (Willcox et al., 2003; Shi et al., 2004; Waliszewsky et al., 2010). 
Se ha comprobado que el licopeno cuando se somete a procesos de cocción mejora su absorció; esto se debe a que dentro de las frutas o las verduras el licopeno se encuentra ligado a la matriz del alimento, lo que impide su liberación completa. El procesamiento mediante el calor, rompe las paredes celulares debilitando las fuerzas de enlace entre el licopeno y la matriz del tejido, lo que aumenta el área superficial disponible para la digestión, mejorando la biodisponibilidad. Adicionalmente, el tratamiento térmico de la cocción, transforma las formas isoméricas trans del licopeno, a cis lo que mejora su absorción en el cuerpo. (Willcox et al., 2003; Shi et al., 2004; Jones, 2007; Capanoglu et al., 2010).

Debido a que el licopeno es un caroteno liposoluble, para mejorar su absorción basta con agregar aceite a la preparación, pero no cualquier aceite, su mayor potencia se presenta en presencia de aceite de oliva. La presencia de grasa en el intestino promueve la formación de las micelas ya que facilita el flujo de la bilis desde la vesícula biliar. (Shixian et al., 2005; Rao et al., 2007; Waliszewski et al., 2010).

También es un factor importante para la biodisponibilidad del licopeno la sinergia que se produce con otros compuestos como sucede con la vitamina E. Fuhrman et al. (2000) comprobaron que la óleo-rresina del tomate (extracto lipídico de los tomates que contiene $6 \%$ de licopeno, $0.1 \%$ de $\beta$-caroteno, $1 \%$ de vitamina $E$ y polifenoles) tiene cinco veces más capacidad para inhibir la oxidación de las LDL que el licopeno puro, debido a que contiene vitamina $E$, glabridina, ácido fenólico rosmarínico, ácido carnósico y ajo los que en conjunto previenen la peroxidación lipídica ya sea por bloqueo del oxígeno singlete o por medio de la captura de los radicales peroxilo.

\subsubsection{Toxicidad}

El extracto de oleorresina de tomate natural (NTOE) por sus siglas en inglés, contiene $6 \%$ de licopeno y se utiliza como suplemento dietético o se adiciona a los alimentos para incrementar su ingesta.

Matulka et al. (2004) evaluaron toxicológicamente el extracto de oleorresina de tomate natural (NTOE), en ratas Sprague-Dawley. Se reportó que el $50 \%$ de la dosis letal derivada de la toxicidad oral aguda fue superior a $5,000 \mathrm{mg} / \mathrm{kg}$ de peso corporal, la que no se presentó cuando se utilizaron 2,00omg/ $\mathrm{Kg}$ de peso corporal.

McClain et al. (2003) realizaron estudios para medir la toxicidad del NTOE en ratas y encontraron bajos niveles de toxicidad aguda.

Es importante recordar que la mayoría de los estudios de toxicidad del licopeno y otros carotenos se han realizado en roedores, que absorben los carotenos con menor eficiencia que los 
humanos. Sin embargo, en fumadores y trabajadores del asbesto, cuando se administran los carotenos en dosis altas puede ser perjudicial ya que el $\beta$-caroteno y el ácido retinoico producen una fuerte sinergia para producir células cancerígenas. El ácido retinoico es un modulador de la proliferación y diferenciación en las células del epitelio pulmonar (suprime la carcinogénesis en algunos tejidos epiteliales).

En algunos estudios realizados en animales in vivo, se encontró que la exposición al humo del cigarro y una dosis farmacológica de $30 \mathrm{mg}$ de $\beta$-caroteno por día o su tratamiento combinado durante seis meses, disminuye las concentraciones de ácido retinoico significativamente, lo que conduce a la aparición de células precancerosas. Por lo contrario cuando se administra $\beta$-caroteno en dosis pequeñas $(6 \mathrm{mg} / \mathrm{día})$ podría actuar suministrando suficiente ácido retinoico para aliviar la metaplasia. (Kun et al., 2007).

\subsubsection{Dieta rica en licopeno para el tratamiento de las dislipemias}

Todas las guías dietéticas a lo largo del mundo recomiendan incrementar el consumo de frutas y verduras, cereales integrales y leguminosas por su contenido en sustancias fitoquímicas benéficas para la salud humana (Ver tabla No. 27).

La OMS a través de la "Estrategia Mundial sobre Régimen Alimentario, Actividad Física y Salud. Fomento del Consumo Mundial de Frutas y Verduras", recomienda que para prevenir las enfermedades crónicas y mantenerse sano es necesario el consumo de $\geq 400 \mathrm{~g}$ de frutas y verduras al día (excluyendo patatas y otros tubérculos ricos en almidón).

Tabla No. 27 Sustancias fitoquímicas benéficas para la salud humana

\begin{tabular}{|l|}
\hline \multicolumn{1}{|c|}{ Sustancias fitoquímicas } \\
\hline Carotenoides ( $\beta$ caroteno y licopeno) \\
\hline Terpenoides (saponinas) \\
\hline Fitosteroles \\
\hline Flavonoides \\
\hline Indoles \\
\hline Isoflavonas \\
\hline Isotiocianates \\
\hline Lignanos \\
\hline Fitatos \\
\hline Fibra (soluble e insoluble) \\
Fuente: Rao et al. (2007). Biologically active phytochemicals in human health: \\
Lycopene.International Journal of Food Properties, 10, 279-288
\end{tabular}


Datos de la Autoridad Europea de Seguridad Alimentaria (EFSA) revelan que el consumo promedio de verduras (incluyendo legumbres y nueces) y frutas en Europa es de $386 \mathrm{~g}$ por día, siendo el sur donde se consumen más verduras que en el norte, y en el centro y el este mayor consumo de frutas.

Polonia, Alemania, Italia, Austria Hungría y Bélgica son los países que cumplen con las recomendaciones de la OMS respecto al consumo de frutas y verduras (EFSA, 2010).

En América sólo Chile, México y Brasil tienen una oferta de frutas y verduras en sus mercados igual o mayor a los $146 \mathrm{~kg} /$ persona/año, mientras que los demás países fluctúan entre 80 y $138 \mathrm{~kg}$ (FAO, 2012).

Este fenómeno del bajo consumo de frutas y verduras es una consecuencia de la modernización de los patrones de alimentación influenciados por la rápida urbanización y la innovación tecnológica en la producción, procesamiento y comercialización de los alimentos, con la consecuente disminución también en el consumo de cereales, legumbres y tubérculos y el incremento en el consumo de alimentos altos en energía y grasas y de bajo valor nutricional (Jacoby et al., 2006).

Willcox et al. (2003) afirman que la dieta juega un papel importante en el desarrollo, la prevención y control de las enfermedades cardiovasculares; modificaciones sencillas como la inclusión de fuentes de carotenoides pueden hacer cambios sustanciales en la oxidación de los lípidos insaturados de las LDL.

Los carotenoides, sobre todo el licopeno actúa reduciendo la expresión de moléculas de adhesión y la adhesión de los monocitos a la pared de las arterias.

En particular para las enfermedades cardiovasculares el licopeno, por sus propiedades antioxidantes, es el carotenoide principal a considerar en un régimen de alimentación efectivo.

En un estudio realizado en Australia, se relacionó el contenido de carotenoides en el suero con la frecuencia diaria de consumo de frutas y verduras, considerando además los "snacks" y los jugos. Solamente un $7,6 \%$ de los participantes informaron de una ingesta diaria de frutas y verduras suficiente (4 porciones de fruta y 2 de verdura). Los resultados mostraron que los carotenoides del plasma tuvieron asociación positiva con la frecuencia de consumo de frutas y verduras; a excepción del licopeno, debido a que el mismo está asociado más a la ingesta de productos procesados del tomate (puré, pasta, jugo) que al consumo del tomate crudo (Hodge et al., 2011).

El contenido de licopeno es mayor en los primeros (salsa de tomate, entre 9,9-13,4 mg/10og) que en los alimentos frescos 
(tomate, entre 0,88-7,74 mg/1oog de peso húmedo) (Ordóñez et al., 2009).

En un estudio donde se utilizó jugo concentrado de tomate como suplemento dietario de licopeno se encontró, que luego de 7 días de suplementación los niveles de HDL se incrementaron, pero volvieron a sus cifras iniciales después de 7 días de dieta habitual no suplementada; no se encontró variación en los niveles de $C L$ total, TG, LDL y VLDL.

La elevación rápida y significativa de HDL después de la suplementación proporciona evidencia de la susceptibilidad del organismo a la acción del licopeno que representa una potencial capacidad terapéutica para los pacientes que padecen dislipemias (Madrid et al., 2006).

Aproximadamente el $85 \%$ del licopeno presente en la dieta proviene del tomate y sus subproductos (jugo, salsa, pasta, sopas, concentrado), el resto se obtiene de otra fuentes como la sandía, la guayaba rosada, la papaya, la toronja rosada, entre otros, como se puede observar en la tabla No. 28.

Tabla No. 28 Fuentes de licopeno

\begin{tabular}{|l|c|}
\hline \multicolumn{1}{|c|}{ Alimentos } & $\begin{array}{c}\text { Contenido de licopeno en mg/gr } \\
\text { húmedo }\end{array}$ \\
\hline Tomates frescos & $8,8-42,0$ \\
\hline Tomate cocinado & 37,0 \\
\hline Salsa de tomate & 62,0 \\
\hline Pasta de tomate & $54,0-1500,0$ \\
\hline Sopa de tomate (condensada) & 79,9 \\
\hline Tomate en polvo & $1126,3-1264,9$ \\
\hline Jugo de tomate & $50,0-116,0$ \\
\hline Salsa para pizza & 127,1 \\
\hline Salsa Catsup & $99,0-134,4$ \\
\hline Sandía & $23,0-72,0$ \\
\hline Guayaba rosada & 54,0 \\
\hline Toronja rosada & 33,6 \\
\hline Papaya & $20,0-53,0$ \\
\hline Durazno & $<0,1$ \\
\hline
\end{tabular}

Fuente: modificado Rao et al. (2007). Biologically active phytochemicals in human health: Lycopene. International Journal of Food Properties, 10, 279-288

Existe controversia en cuanto a las recomendaciones de consumo de licopeno debido a varias situaciones, una de ellas es que existe una gran variabilidad en los niveles reportados en los diferentes alimentos fuente; los niveles de ingesta encontrados varían de 3,7 a 
16,2 en Estados Unidos, 25,2 mg en Canadá, 1,3 mg en Alemania, 1,1 mg en Reino Unido, 0,7 mg en Finlandia (Galhardo et al., 2009).

Torresani (2009), realizó un estudio en el que midió la ingesta de licopeno en mujeres pre y post menopáusicas, utilizando una encuesta semanal de consumo en número de porciones y $\mathrm{mg} / \mathrm{día}$. Dividió los alimentos en dos categorías: los que son fuente de licopeno (tomate y sus derivados como el jugo, la salsa cátsup, el puré) y los demás alimentos que contienen licopeno, la sandía, la calabaza, la zanahoria, el pomelo rosa, entre otros. Estandarizó las porciones por modelos visuales de alimentos y la composición química del licopeno se obtuvo de la base de datos del Departamento de Agricultura de los Estados Unidos (USDA).

Los resultados mostraron una relación inversa entre el consumo de alimentos ricos en licopeno y la presencia de riesgo cardiovascular $(R C V)$. Además, dentro de los resultados se encontró un consumo promedio de licopeno entre 5 y $7 \mathrm{mg} /$ día, provenientes principalmente de productos procesados del tomate.

Otra de las situaciones muy importante, es que el licopeno a pesar de sus beneficios, aún no ha sido considerado un nutrimento esencial por los profesionistas de la salud ni por organismos gubernamentales que le den el soporte para establecer una ingesta diaria recomendada (IDR) de manera oficial (Rao et al., 2007).

Rao et al. (2002) reportaron que la ingesta diaria entre 5 y $7 \mathrm{mg}$ de licopeno es suficiente para combatir el estrés oxidativo y prevenir las enfermedades crónicas. Sin embargo, los mismos autores concluyeron que para el tratamiento de las enfermedades como el cáncer o las cardiovasculares es necesario incrementar de 35 a $75 \mathrm{mg}$ de ingesta por día.

Sesso et al. (2003) recomiendan de 7 a 10 porciones a la semana de alimentos fuentes de licopeno o 30 a $60 \mathrm{mg} / \mathrm{día}$ de licopeno presente en los mismos.

Como se puede observar los datos son muy variables y no se cuenta con una medida estándar de licopeno en $100 \mathrm{~g} \mathrm{o} \mathrm{ml} \mathrm{de} \mathrm{los}$ alimentos fuente para poder establecer porciones de alimentos en un régimen de alimentación que asegure su ingesta. El European Food Information Council (EUFIC, 2012) determinó una ingesta diaria admisible (IDA) de 0,5 mg/kg/día incluyendo las fuentes naturales y colorantes de licopeno.

Curiosamente un estudio realizado sólo con hombres demostró que al parecer la cantidad absoluta de licopeno absorbida no parece variar mucho con la dosis. Diwadkar-Navsariwala et al. (2003) sometieron a un grupo de voluntarios a diferentes dosis de jugo de tomate (entre 10 a $120 \mathrm{mg}$ de licopeno) con un porcentaje constante 
de grasa para facilitar su absorción. La gama de licopeno absorbida, independiente de la dosis, fue de entre $1,8 \mathrm{mg}$ y $14,3 \mathrm{mg}$, con un promedio de $4,7 \mathrm{mg}$. La cantidad de licopeno absorbida por los hombres que consumieron $120 \mathrm{mg}$ de licopeno no era significativamente diferente de la absorbida por los que consumieron $10 \mathrm{mg}$ de licopeno. La conclusión del estudio fue que las diferencias individuales tienen mayor impacto que la dosis en la cantidad de licopeno absorbida.

Es necesario entonces, en primer lugar, determinar el contenido de licopeno en los alimentos fuente por cien gramos. Establecer posteriormente las porciones de alimentos que aseguren una ingesta de $50 \mathrm{mg}$ por día y utilizar estas porciones en la planificación de menús que puedan ser utilizados de manera preventiva por personas sanas y específicamente como tratamiento hipolipemiante por las personas que padezcan dislipemias

Además, Shami et al. (2004) consideran que es necesaria la orientación alimentaria para estimular a la población en el consumo de alimentos que son fuentes de licopeno, así como de frutas y verduras que son ricas en antioxidantes a fin de garantizar el consumo de la cantidad diaria recomendada de tal manera que el daño celular y el estrés puedan ser minimizados.

Existe una brecha muy grande entre los niveles recomendados de ingesta diaria de licopeno y los niveles reales de consumo en todo el mundo, lo que representa una gran oportunidad de investigación para los profesionistas de la salud; conocer más sobre su biodisponibilidad, mecanismos de acción, metabolismo y seguridad pues representa un elemento importante en la prevención y tratamiento de las enfermedades y la calidad de vida.

La poca adherencia a la terapia nutricional y farmacológica y al ejercicio en las personas que padecen enfermedades crónicas ha obligado a los profesionistas de la salud a buscar alternativas fáciles, poco costosas y que produczcan resultados a mediano y corto plazo, los alimentos funcionales parecen ser una alternativa viable, que requiere de ensayos clínicos que corroboren su eficacia. 


\section{CAPÍTULO 3.}

OBJETIVOS

\subsection{Pregunta de Investigación}

¿Cuál es el efecto de la dieta rica en licopeno, de la práctica de ejercicio físico o de la asociación entre ambos sobre los niveles de lípidos en sangre y el porcentaje de grasa corporal en adultos con dislipemia?

\subsection{Objetivo General}

Conocer los efectos de una dieta rica en licopeno, de la práctica de ejercicio físico o la asociación entre ambos sobre los niveles de lípidos en sangre y en el porcentaje de grasa corporal en adultos con dislipemia.

\subsection{Objetivos Específicos.}

1. Determinar las raciones de alimentos ricos en licopeno especificando el tipo y la marca comercial.

2. Diseñar la dieta estándar, la dieta rica en licopeno y el programa de ejercicio físico para adultos con dislipemia.

3. Determinar si la dieta rica en licopeno ( $50 \mathrm{mg} / \mathrm{día}$ ) durante 12 semanas tiene efectos sobre los niveles de lípidos en sangre y el porcentaje de grasa corporal en adultos con dislipemia en comparación con la dieta estándar

4. Determinar si la practica del ejercicio físico (mínimo 4 días a la semana) durante 12 semanas tiene efectos sobre los niveles de lípidos en sangre y el porcentaje de grasa corporal en adultos con dislipemia cuando se combina con la dieta estándar como con la dieta rica en licopeno. 


\subsection{Hipótesis}

En concordancia con los objetivos planteados en este estudio y con el diseño experimental utilizado se determinaron las siguientes hipótesis:

$\mathrm{H}$ 1. La ingesta de una dieta rica en licopeno ( $50 \mathrm{mg} /$ dia) durante 12 semanas tiene efecto sobre los niveles de lípidos en sangre y el porcentaje de grasa corporal en adultos con dislipemia en comparación con la dieta estándar.

Ho. La ingesta de una dieta rica en licopeno ( $50 \mathrm{mg} / \mathrm{dia}$ ) durante 12 semanas no tiene efecto sobre los niveles de lípidos en sangre ni el porcentaje de grasa corporal en adultos con dislipemia en comparación con la dieta estándar.

H2. La practica de ejercicio físico (mínimo 4 días a la semana por 60 minutos) durante 12 semanas tiene efecto sobre los niveles de lípidos en sangre y el porcentaje de grasa corporal en adultos con dislipemia cuando se combina con la dieta estándar como con la dieta rica en licopeno.

Ho. La practica de ejercicio físico (mínimo 4 días a la semana por 60 minutos) durante 12 semanas no tiene efecto sobre los niveles de lípidos en sangre ni el porcentaje de grasa corporal en adultos con dislipemia cuando se combina con la dieta estándar como con la dieta rica en licopeno.

\subsection{Definición de variables}

Se definen a continuación las variables del estudio de manera conceptual y operacional.

\section{Variables independientes}

\section{Dieta estándar}

Definición conceptual: se define como el conjunto de alimentos y bebidas que cumple con todos los criterios propuestos por la Norma Oficial Mexicana para la prevención, tratamiento y control de las dislipidemias (NOM-037-SSA2-2002).

Definición operacional: para fines del presente estudio, se definió como dieta estándar al conjunto de alimentos y bebidas que tienen $30 \%$ de grasas totales, calculada mediante el método breve, que cumple con todos los criterios propuestos por la Norma Oficial Mexicana para la prevención, tratamiento y control de las dislipidemias (NOM-037-SSA2-2002) y que será utilizada por el grupo control de la investigación. 


\section{Dieta rica en licopeno}

Definición conceptual: se define como un conjunto de alimentos y bebidas altos en licopeno y que cumple con todos los criterios propuestos por la Norma Oficial Mexicana para la prevención, tratamiento y control de las dislipidemias (NOM-037-SSA2-2002).

Definición operacional: para el presente estudio se definió como un conjunto de alimentos y bebidas que en total proporcionan aproximadamente $50 \mathrm{mg}$ de licopeno al día, obtenido a través del método de extracción con solventes por etapas, que cumple con todos los criterios propuestos por la Norma Oficial Mexicana para la prevención, tratamiento y control de las dislipidemias (NOM-037SSA2-2002) y que será utilizada durante 12 semanas por el grupo experimental de la investigación.

\section{Ejercicio físico}

Definición conceptual: se define como una subclase de la actividad física que se caracteriza por ser un movimiento corporal planeado, estructurado y repetitivo hecho para mejorar o mantener uno de los componentes de la aptitud física (American College of Sports Medicine, 2001)

Definición operacional: para el presente estudio, se entiende por ejercicio físico a la caminata durante 60 minutos a la intensidad de 60-70 \% de la frecuencia cardiaca máxima por lo menos 4 días a la semana, durante 12 semanas que realizarán un grupo de participantes del grupo control y otro del grupo experimental.

\section{Dislipemias}

Definición conceptual: dislipemia es un término que se refiere a las alteraciones en el plasma del colesterol total $(C L)$, de los triglicéridos (TG) o ambos, acompañados generalmente de niveles altos de LDL y bajos niveles de HDL (Liu et al., 2010).

Definición operacional: para el presente estudio la dislipemia se definió como la presencia en sangre de los niveles de $C L>$ a 200 $\mathrm{mg} / \mathrm{dL}, \mathrm{TG}>150 \mathrm{mg} / \mathrm{dL}$, LDL $>130 \mathrm{mg} / \mathrm{dL}$ y $\mathrm{HDL}<60 \mathrm{mg} / \mathrm{DL}$ en los participantes en el estudio.

\section{Porcentaje de grasa corporal}

Definición conceptual: se define como el porcentaje del peso total que es tejido graso. (American College of Sports Medicine, 2001). 
Definición operacional: para el presente estudio, se define como la cantidad de grasa corporal de los participantes en el estudio, que resulta de la medición por bioimpedancia expresada en porcentaje.

\subsection{Justificación}

Las dislipemias se encuentran entre las primeras causas de mortalidad y discapacidad en los adultos en México, cuyos factores de riesgo podrían corregirse mediante estilos de vida saludables. (World Health Organization, 2000)

Los organismos internacionales y nacionales han emitido recomendaciones, normas y pautas concretas para la prevención, la detección y el tratamiento de la dislipemia, que promueven cambios en el régimen de alimentación, específicamente la modificación en el consumo de grasas saturadas, la adopción de una rutina de ejercicio físico, el mantenimiento del peso adecuado, la disminución en el consumo de alcohol, la eliminación del consumo de tabaco y la inclusión de alimentos que contienen antioxidantes y fibra proveniente de las frutas y verduras (Rincón et al., 2010).

Se ha demostrado (Rao, 2002; Kun, et al., 2007; Santosh et al., 2010) que el consumo de antioxidantes como el licopeno puede reducir el riesgo de enfermedades cardiovasculares, protegiendo a los lípidos debido a que evita que las LDL se oxiden y produzcan daños en la membrana celular. Se encuentra principalmente en alimentos como el tomate, la sandía, la toronja rosada, la guayaba rosada y la papaya, y en algunos productos procesados como el puré y jugo de tomate (Vitale, et al., 2010), que a diferencia de otros carotenoides, potencializa su efecto cuando se somete al calor, lo que permite utilizarlo en diferentes preparaciones de uso cotidiano y bajo costo ya que se apegan a la dieta habitual del mexicano.

Sin embargo, son muy pocas las personas con dislipemia que adoptan estas pautas y muchos los que optan por el tratamiento farmacológico, el cual además de resultar de alto costo produce efectos colaterales.

El manejo de las dislipemias mediante modificaciones en el estilo de vida representa un gran reto para los profesionistas de la salud ya que estas enfermedades son generalmente asintomáticas y los efectos del tratamiento no farmacológico no presentan beneficios palpables a corto plazo; por lo tanto, presentan porcentajes bajos de adherencia, lo que ha provocado que la prevalencia e incidencia de estas enfermedades se haya incrementado de manera acelerada en los últimos años, lo que probablemente provoque en el futuro el colapso de las instituciones de salud y no sean capaces de solventar los costos derivados de estas enfermedades y sus complicaciones. 
Por lo anterior, la utilización de estrategias dietéticas y de actividad física de bajo costo y fáciles de seguir que tengan efecto seguro sobre los niveles de lípidos en sangre, podrían contribuir a demostrar la eficacia de intervenciones no farmacológicas en la prevención y el tratramiento de las dislipemias, que podrían significar ahorro de recursos económicos en el tratamiento y control de dichas enfermedades. 


\section{CAPÍTULO 4.}

METODOLOGÍA

\subsection{Tipo de estudio}

El presente estudio es de tipo explicativo, es decir, pretende establecer las causas de la ocurrencia de los fenómenos y cómo se manifiestan. Se utiliza para establecer si existe una relación causaefecto entre las variables (Hernández et al. 2007; Daniel, 2009).

Se orienta a comprobar hipótesis causales mediante la identificación y análisis (variables independientes) de los resultados explicados en hechos verificables (variables independientes).

\subsection{Diseño de la Investigación}

El estudio es experimental con un diseño factorial, que se plantea cuando se quiere someter a contrastación el efecto de dos o más variables independientes y de una posible interacción entre ellas sobre la variable dependiente (Pelegrina et al., 1999; Daniel, 2009).

Este tipo de experimentos permiten el estudio del efecto de cada factor sobre la varible respuesta, así como el efecto de las interacciones entre factores sobre dicha variable.

\subsection{Población de estudio}

El reclutamiento de los participantes en el estudio se realizó utilizando varias estrategias; por invitación a los usuarios del Servicio de Salud y del Laboratorio de Análisis Clínicos de la Facultad de Química de la Universidad Autónoma de Yucatán (UADY); mediante invitación personal en la Feria de la Salud realizada en el Edificio Central de la UADY y otras personas fueron invitados por los propios participantes, siendo un total de 162 personas invitadas. 
Los participantes del Servicio de Salud de la UADY fueron 53 personas identificadas, previo permiso de las autoridades, a través de la base de datos con que cuenta el personal de nutrición recabado mediante las detecciones realizadas en las Facultades de la propia Universidad. La invitación se realizó a través del correo electrónico, explicándoles todo lo referente al estudio y los beneficios para la salud.

Los usuarios del Laboratorio de Análisis Clínicos la Facultad de Química fueron 29 personas invitados mediante tarjetitas que se colocaron en los sobres con los resultados de laboratorio donde se detectó que presentaron cifras alteradas en sus niveles de lípidos.

En las tarjetitas se explicará el objetivo del estudio, los criterios de inclusión y cual sería el beneficio de su participación.

En la Feria de la Salud, se invitó a las personas (53) que acudieron a las detecciones de lípidos en los módulos de la Unidad Cardiometabólica de la Facultad de Medicina y en el de la Facultad de Química de la UADY, ahí se les proporcionó la información de manera verbal, se les entregó una tarjetita con los datos de la responsable de la investigación y se registraron sus generales en un listado. Con los datos obtenidos se elaboró un listado de los posibles participantes y se les contactó por teléfono y correo electrónico.

Algunos de los participantes (27) contactaron a la responsable de la investigación por teléfono o correo electrónico para ser considerados en el estudio.

Se les invitó a todos para asistir a una plática informativa, referente al proyecto, de acuerdo con sus horarios disponibles. Se realizaron ocho sesiones, cuatro en el turno matutino y cuatro en el vespertino de acuerdo con el programa previamente elaborado (Anexo I) donde participaron personal del área de Medicina del Deporte, Cardilología, Medicina General, Psicología y Nutrición con temas relacionados a las dislipemias desde sus diferentes enfoques, su tratamiento integral, el objetivo y la metodología general de la investigación.

Durante las sesiones se presentaron también los criterios de inclusión y eliminación para participar en el proyecto los cuales se presentan en la tabla No. 29

A los participantes que cumplieron con los criterios de inclusión y que aceptaron formar parte del estudio se les solicitó firmen una carta de consentimiento informado (Anexo II) donde se explicita de manera clara y completa los objetivos de la investigación, los procedimientos que van a usarse y su propósito, los beneficios y riesgos (en caso que existan), el compromiso de confidencialidad de los datos y resultados y la libertad de retirarse del estudio cuando lo consideren pertinente como norma el Reglamento de la Ley General 
de Salud en Materia de Investigación para la Salud de los Estados Unidos Mexicanos (Secretaría de Salud, 1987).

Tabla No. 29 Criterios que deben cumplir los participantes en el estudio.

\begin{tabular}{|c|c|}
\hline Inclusión & Eliminación \\
\hline $\begin{array}{l}\text {-Hombres y mujeres entre } 21 \text { y } 64 \text { años } \\
\text {-Que acepten participar en el estudio } \\
\text {-Que padezcan hipercolesterolemia, } \\
\text { hipertrigliceridemia y /o hipoalfalipiproteinemia. } \\
\text {-Que no padezcan diabetes, ni hipertensión arterial } \\
\text { diagnosticada y con tratamiento farmacológico. } \\
\text {-Que no hayan realizado ejercicio físico durante tres } \\
\text { meses antes del estudio } \\
\text {-Que no tengan impedimento para realizar ejercicio } \\
\text { físico. } \\
\text {-Que no consuman tabaco }\end{array}$ & $\begin{array}{l}\text {-Que no completen los } \\
\text { estudios de laboratorio } \\
\text {-Que no realicen el } \\
\text { programa de ejercicio } \\
\text {-Que no cumplan con la } \\
\text { dieta. }\end{array}$ \\
\hline
\end{tabular}

En esta tabla se presentan los criterios que debieron cubrir los participantes en el estudio. En la primera columna se encuentran listados los criterios de inclusión y en la segunda los criterios de eliminación.

El estudio tuvo una duración de 12 semanas; se realizó en la Unidad Cardiometabólica de la Facultad de Medicina de la UADY, ubicada en Av Itzaes No. 486 entre $59^{a}$ y 86 en la ciudad de Mérida, Yucatán, México.

Se realizaron 4 sesiones de trabajo con cada grupo: al inicio del programa una sesión de inducción grupal para proporcionar la información detallada de las actividades a realizar durante la cual se aplicó la pre-prueba del estudio.

Posteriormente se realizaron tres, al término del primero y segundo mes que fueron de monitoreo y una al tercer mes durante la cual se aplicó la pos-prueba, las cuales fueron de manera individual a través de la consulta programada de nutrición; esto permitió asegurar que entre los participantes no existiera comunicación y no supieran a que grupo fueron asigandos.

La pre-prueba y pos-prueba consistieron en la medición del peso y la estatura para determinar el Índice de Masa Corporal (IMC), el porcentaje de grasa corporal (PGC) y la circunferencia abdominal (CA), con el objetivo de conocer a través de dichos indicadores el estado de nutrición; también se registró la tensión arterial (TA).

Además se realizó la determinación del perfil de lípidos para tener el diagnóstico de dislipemias mediante la determinación de sus indicadores ( $C L, T G, L D L$ y $H D L)$ y calcular el índice aterogénico.

Estos datos y los demográficos se incluyeron en la historia clínica (Anexo III), la cual está elaborada siguiendo los lineamientos de la 
Norma Oficial MexicanaNOM-168-SSA1-1998. Del expediente clínico.

A los participantes de los grupos que realizaron ejercicio físico se les sometió previamente a la prueba de esfuerzo.

Para lograr el objetivo se diseñó el estudio dividiendo a la población en cuatro grupos. El grupo uno y el dos fueron tratados con una dieta estándar para el control de las dislipemias elaborada de acuerdo con la NOM-037-SSA2-2002, en la cual se utilizaron alimentos de uso cotidiano (grupo control), donde el grupo uno no realizó ejercicio físico y el grupo dos si lo realizó.

El grupo tres y el cuatro fueron tratados con una dieta rica en licopeno elaborada de acuerdo con la NOM-037-SSA2-2002 (grupo experimental); el grupo tres no participó en el programa de ejercicio físico previamente diseñado, mientras el grupo cuatro si participó.

Los sujetos fueron asignados aleatoriamente a uno de los cuatro grupos de acuerdo con el Artículo 15 del Reglamento de la Ley General de Salud en Materia de Investigación para la Salud de los Estados Unidos Mexicanos (1987), que a la letra dice: "cuando el diseño experimental de una investigación que se realice en seres humanos incluya varios grupos, se usarán métodos aleatorios de selección para obtener una asignación imparcial de los participantes en cada grupo....." además fueron equiparados por edad y sexo.

La metodología utilizada para la aleatorización fué la siguiente:

1. Se seleccionaron los sujetos de acuerdo al cumplimiento de los criterios de inclusión.

2. Se estratificaron por edad y sexo.

3. Se numeraron.

4. De determinaron los cuatro grupos.

5. Se distribuyeron los sujetos a los cuatro grupos utilizando una tabla aleatoria (Hernández et al., 2007).

El número inicial de participantes fue de 84 personas, quienes cumplieron los criterios de inlcusión, que por diferentes razones, como: la falta de tiempo para realizar el ejercicio, problemas económicos, viajar a otras ciudades con frecuencia por cuestiones de trabajo, la dificultad para seguir un régimen de alimentación específico, entre otros, fueron abandonando el estudio.

Finalmente, sólo 48 particiantes completaron el tiempo total de estudio, de los cuales el $35,42 \%$ fueron hombres $(n=17)$ y el $64,58 \%$ fueron mujeres $(n=31)$ los cuales quedaron distribuidos en los cuatro grupos de intervención como puede observarse en tabla No.30. 
Tabla No. 30 Distribución de la población de estudio por intervención

\begin{tabular}{|l|c|c|c|}
\hline \multirow{2}{*}{ Intervención } & \multicolumn{2}{|c|}{ Sexo } & \multirow{2}{*}{ Total \% } \\
\cline { 2 - 3 } & Hombres \% & Mujeres \% & \multirow{2}{*}{$10(20,83)$} \\
\hline $\begin{array}{l}\text { Dieta estándar sin } \\
\text { ejercicio físico }\end{array}$ & $1(2,08)$ & $9(18,75)$ & $13(27,08)$ \\
\hline $\begin{array}{l}\text { Dieta estándar con } \\
\text { ejercicio físico }\end{array}$ & $5(10,42)$ & $8(16,66)$ & $12(25,00)$ \\
\hline $\begin{array}{l}\text { Dieta rica en licopeno sin } \\
\text { ejercicio físico }\end{array}$ & $5(10,42)$ & $7(14,58)$ & $13(27,08)$ \\
\hline $\begin{array}{l}\text { Dieta rica en licopeno } \\
\text { con ejercicio físico }\end{array}$ & $6(12,50)$ & $7(14,58)$ & $48(99.99)$ \\
\hline Total & $17(35,42)$ & $31(64,57)$ & \\
\hline
\end{tabular}

En esta tabla se presenta la distribución de los participantes en los diferentes tipos de intervención, las cuales se presentan en la primera columna; en la segunda columna se presenta la distribución por sexo, cuyos valores estan expresados en numero en frecuencia ( $n$ ) y en porcentajes (\%). y al final de la tabla las sumatorias correspodientes.

En la tabla No. 31 se presenta la media de edad y la desviación estándar de la población de estudio como quedó distribuída después de la deserción de algunos participantes como se comentó anteriormente.

Tabla No. 31 Media de edad y desviación estándar de la población de estudio por grupos de tratamiento.

\begin{tabular}{|l|c|c|c|}
\hline \multicolumn{1}{|c|}{ Grupo } & $\mathbf{n}$ & Media & D.E. \\
\hline $\begin{array}{l}\text { Dieta estándar sin ejercicio } \\
\text { físico }\end{array}$ & 10 & 55,80 & 8,77 \\
\hline $\begin{array}{l}\text { Dieta estándar con ejercicio } \\
\text { físico }\end{array}$ & 13 & 48,00 & 12,29 \\
\hline $\begin{array}{l}\text { Dieta rica en licopeno sin } \\
\text { ejercicio físico }\end{array}$ & 12 & 45,50 & 11,52 \\
\hline $\begin{array}{l}\text { Dieta rica en licopeno con } \\
\text { ejercicio físico }\end{array}$ & 13 & 44,38 & 9,87 \\
\hline
\end{tabular}

D.E. = desviación estándar

Se puede apreciar que los grupos más homogéneos en edad fueron el grupo tratado con dieta estándar que no realizaron ejercicio físico y el grupo tratado con dieta rica en licopeno que si realizaron ejercicio físico.

En la tabla No. 32 se presentan los datos sociodemográficos de la población de estudio, donde se consideraron el estado civil, la escolaridad y la ocupación. 
Respecto al estado civil, la mayoría de los participante refirieron ser casados $(64,58 \%)$ y seguido en porcentaje por los solteros $(28,57 \%)$, los divorciados $(4,16 \%)$ y los viudos $(2,08 \%)$.

En cuanto al nivel de escolaridad de los participantes, la mayoría refirió tener estudios de licenciatura (68,75\%), seguido de preparatoria y/o bachiller $(10,41 \%)$ y maestría $(10,41 \%)$; es curioso observar que el $2,08 \%$ de los participantes poseen estudios de doctorado.

Tabla No. 32 Características sociodemográficas de la población de estudio

\begin{tabular}{|c|c|c|c|}
\hline \multirow{2}{*}{$\begin{array}{c}\text { Características } \\
\text { de la } \\
\text { población }\end{array}$} & \multicolumn{2}{|c|}{ Sexo } & \multirow{2}{*}{$\begin{array}{l}\text { Total } \\
\mathrm{N}(\%)\end{array}$} \\
\hline & $\begin{array}{c}\text { Hombres } \\
\%\end{array}$ & $\begin{array}{c}\text { Mujeres } \\
\%\end{array}$ & \\
\hline \multicolumn{4}{|l|}{ Estado civil } \\
\hline Soltero & $6(12,50)$ & $8(16,67)$ & $14(28,57)$ \\
\hline Casado & $11(22,92)$ & $20(41,66)$ & $31(64,58)$ \\
\hline Divorciado & 0 & $2(4,16)$ & $2(4,16)$ \\
\hline Viudo & 0 & $1(2,08)$ & $1(2,08)$ \\
\hline \multicolumn{4}{|l|}{ Escolaridad } \\
\hline Primaria & $1(2,08)$ & $1(2,08)$ & $2(4,16)$ \\
\hline Secundaria & 0 & $2(4,16)$ & $2(4,16)$ \\
\hline Preparatoria & $2(4,16)$ & $3(6,25)$ & $5(10,41)$ \\
\hline Licenciatura & $13(27,08)$ & $20(41,67)$ & $33(68,75)$ \\
\hline Maestría & $1(2,08)$ & $4(8,33)$ & $5(10,41)$ \\
\hline Doctorado & 0 & $1(2,08)$ & $1(2,08)$ \\
\hline \multicolumn{4}{|l|}{ Ocupación } \\
\hline Ama de casa & 0 & $13(27,08)$ & $13(27,08)$ \\
\hline Estudiante & $1(2,08)$ & 0 & $1(2,08)$ \\
\hline Empleado & $10(20,83)$ & $14(29,17)$ & $24(50,00)$ \\
\hline $\begin{array}{l}\text { Negocio } \\
\text { propio }\end{array}$ & $5(10,41)$ & $1(2,08)$ & $6(12,50)$ \\
\hline Jubilado & $1(2,08)$ & $3(6,25)$ & $4(8,33)$ \\
\hline
\end{tabular}

En esta tabla se presentan las características sociodemográficas de la población de estudio. En la primera columna se especifican las variables, en la segunda corresponde al sexo de los particpantes, cuyos valores estan expresados en numero en frecuencia ( $n$ ) y en porcentajes (\%). y al final de la tabla las sumatorias correspodientes.

En lo que se refiere a la ocupación, el 50,00\% de los participantes son empleados, el $27,08 \%$ amas de casa; el $12,50 \%$ poseen un negocio propio y la minoría jubilados y estudiantes.

\subsection{Diseño general de la investigación}

El diseño general de la investigación se describe a continuación y se representan en el siguiente algoritmo (figura. 11). 


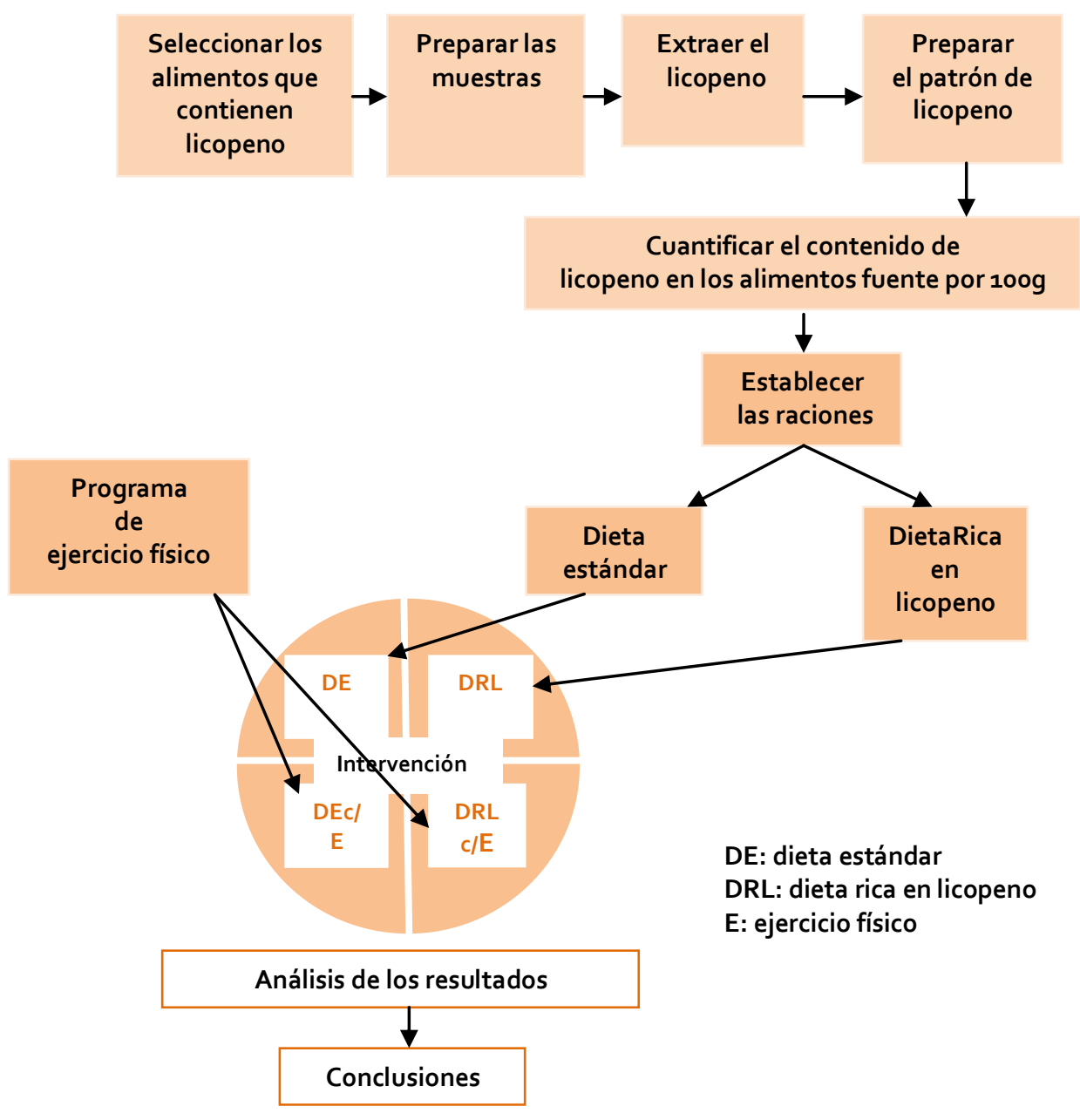

Figura 11. Diseño general de la investigación

\subsubsection{Cuantificación del contenido de licopeno en los alimentos fuente.}

En primer término se hicieron las gestiones pertinentes en la Facultad de Ingeniería Química de la Universidad Autónoma de Yucatán, con la finalidad de contar con el apoyo técnico y científico para realizar el proyecto.

Debido a que el licopeno es un carotenoide lipifílico fácilmente dagradable cuando se expone a factores físicos y químicos como la luz, el oxígeno, condiciones de $\mathrm{pH}$ extremas, temperaturas elevadas y al contacto con superficies activas, fue necesario buscar el método más apropiado que pudiera replicarse en el Laboratorio de Materiales e Instrumental de dicha Facultad. El método de extracción con solventes por etapas fue el más adecuado para el desarrollo del presente trabajo 
Posteriormente se procedió a la compra de los reactivos y el material necesario que junto con el equipo se presentan en la tabla No. 33 .

Tabla No.33 Reactivos, material y equipo utilizados en la extracción de licopeno

\begin{tabular}{|c|c|c|}
\hline Reactivos & Material & Equipo \\
\hline $\begin{array}{l}\text { Acetato de etilo } \\
\text { grado comercial } \\
\text { Acetona G.R } \\
\text { Cloruro de sodio } 10 \\
\% \\
\text { Éter de petróleo } \\
\text { ligero } \\
\text { Hexano G.R } \\
\text { Licopeno Sigma- } \\
\text { Aldrich L9879-10 MG } \\
\text { Sulfato de sodio } \\
\text { anhidro }\end{array}$ & $\begin{array}{l}\text { Embudo de separación } \\
\text { de } 250 \mathrm{ml} \\
\text { Espátula } \\
\text { Mangueras } \\
\text { Matraz balón de } 250 \mathrm{ml} \\
\text { Matraz Erlenmeyer de } \\
250 \mathrm{ml} \\
\text { Matraz volumétrico de } 10 \\
\text { ml. } \\
\text { Matraz volumétrico de } 25 \\
\text { ml. } \\
\text { Microespátula } \\
\text { Mortero con pistilo } \\
\text { Papel filtro } \\
\text { Pipetor de tres vías } \\
\text { Probeta de } 25 \mathrm{ml} \\
\text { Vaso de ppt de } 250 \mathrm{ml} \\
\text { Vaso de ppt de } 500 \mathrm{ml} \\
\text { Vial de } 1.5 \mathrm{ml}\end{array}$ & $\begin{array}{l}\text { Bomba de vacío BÜCHI } \\
\text { labortechnik AG V-700. } \\
\text { Cámara de desarrollo por } \\
\text { espacio TANK } 34104-00 \\
\text { capacidad } 5 \text { platos. } \\
\text { Espectrofotómetro UV-Vis, } \\
\text { THERMO SCIENTIFIC type } \\
\text { evolution } 300 \text { LC. } \\
\text { Estufa Lab-line IMPERIAL-V. } \\
\text { Lámpara model UVGL-25, UV- } \\
254 / 366 \text { nm, } 115 \text { Volts. } \\
\text { Placas de Silicagel 6oGF254 } \\
\text { de } 20 \times 20 \\
\text { Rotavapor BÜCHI switzerland } \\
\text { R-21 }\end{array}$ \\
\hline
\end{tabular}

En esta tabla se presentan los reactivos, el material y el equipo utilizado para la extracción de licopeno en el Laboratorio de Materiales e Instrumental de la Facultad de Ingeniería Química de la Universidad Autónoma de Yucatán.

\section{Selección de los alimentos}

Los alimentos fueron seleccionados por sus características organolépticas y físicas siguiendo los lineamientos de la NOM-251SSA1-2009. Prácticas de higiene para el proceso de alimentos, bebidas o suplementos alimenticios.

En los alimentos frescos se consideró la madurez, integridad de las piezas y la calidad. En los alimentos procesados se consideró además de la integridad de los empaques y la fecha de caducidad, la marca comercial ya que muchas de ellas no cumplen con los requisitos mínimos establecidos por la normatividad vigente.

Los alimentos frescos y procesados se higienizaron con agua y jabón y luego fueron enjuagados a chorro de agua de acuerdo con lo estipulado en la NOM-251-SSA1-2009. Prácticas de higiene para el proceso de alimentos, bebidas o suplementos alimenticios. Posteriormente fueron procesados utilizando los reactivos, material y equipo requeridos. 


\section{Preparación de la muestra}

1.- Se tomaron muestras de $5 \mathrm{~g}$ de cada alimento y se trituraron en un mortero con $25 \mathrm{ml}$ de acetona grado reactivo.; se trataron repetidas veces hasta obtener los extractos homogéneos incoloros.

2.- Estos extractos acetónicos se filtraron con ayuda de un embudo BÚCHNER a vacío utilizando papel filtro del número 5 y evaporaron con ayuda de un rotavapor BÚCHI switzarland R-215 a vacío hasta desecar el homogenado para diluirlo seguidamente en $25 \mathrm{ml}$ acetato de etilo grado comercial.

3.- Posteriormente se transvasaron en un embudo de separación con $25 \mathrm{ml}$ de cloruro de sodio $(\mathrm{NaCl})$ al $10 \%$ y se mezclaron agitando cuidadosamente.

4.- Se separó la fase acuosa y etérea, mediante el lavado sucesivamente hasta que la fase acuosa se haga incolora.

5.- Después se deshidrató la fase etérea utilizando como desecante sulfato de sodio anhidro y se sometió a un proceso de eliminación del solvente utilizando un rotavapor acoplado con una bomba de vacío y una temperatura inferior a los $40^{\circ} \mathrm{C}$ durante 30 minutos; la muestra finalmente seca se diluyó en éter de petróleo ligero con el objetivo de realizar la cromatografía de capa fina. Todo este procedimiento se realizó bajo luz reducida.

\section{Extracción de licopeno}

1.- A través de la cromatografía de capa fina se separaron y purificaron los pigmentos carotenoides; para ello se utilizaron placas de silicagel 60 GF254 de $20 \times 20$ y como solvente de desarrollo se utilizó éter de petróleo ligero.

2.- El extracto de carotenoide se colocó en pequeñas proporciones utilizando la pipeta de Pasteur sobre las placas previamente activadas en la estufa a $120^{\circ} \mathrm{C}$ durante una hora.

3.- Posteriormente se llevaron a la cámara de desarrollo por espacio de 30 minutos; luego se extrajeron las placas, se secaron para colocarlas bajo la luz ultravioleta.

4.- Se utilizó la misma cantidad del patrón de licopeno para posteriormente recoger los pigmentos obtenidos de las muestras junto con el patrón de licopeno y proceder a identificarlos mediante la realización de un barrido por espectrofotometría de UV-Vis UVVis, THERMO SCIENTIFIC type evolution 300 LC, comparando los espectros de los pigmentos obtenidos de las muestras con el espectro del estándar de licopeno. Utilizando una longitud de onda de $450 \mathrm{~nm}$. 


\section{Preparación del patrón de licopeno}

Se preparó una solución madre de $500 \mathrm{ppm}$ diluyendo $5 \mathrm{mg}$ del estándar de licopeno en $10 \mathrm{ml}$ de hexano, para esto se utilizó como patrón licopeno Sigma-AldrichL9879-10 MG; a partir de esta muestra se prepararon distintas diluciones sucesivas, en una atmósfera confinada de nitrógeno, en un rango de 1 a 4,5 ppm y se midió a una longitud de onda de $450 \mathrm{~nm}$ mediante espectroscopia visible utilizando un Spectronic 20.

\section{Cuantificación del contenido de licopeno}

Una vez concluido el desarrollo cromatográfico en capa fina, se raspó la capa de forma individual para cada uno de los componentes, se diluyó con hexano y se determinó la absorbancia a la longitud de onda de máxima absorción, se sustituyó en la ecuación de la recta y se determinó las concentraciones de licopeno en las distintas muestras, la identificación del licopeno se basó en el espectro del estándar o patrón de licopeno, como puede apreciarse en la figura 12.

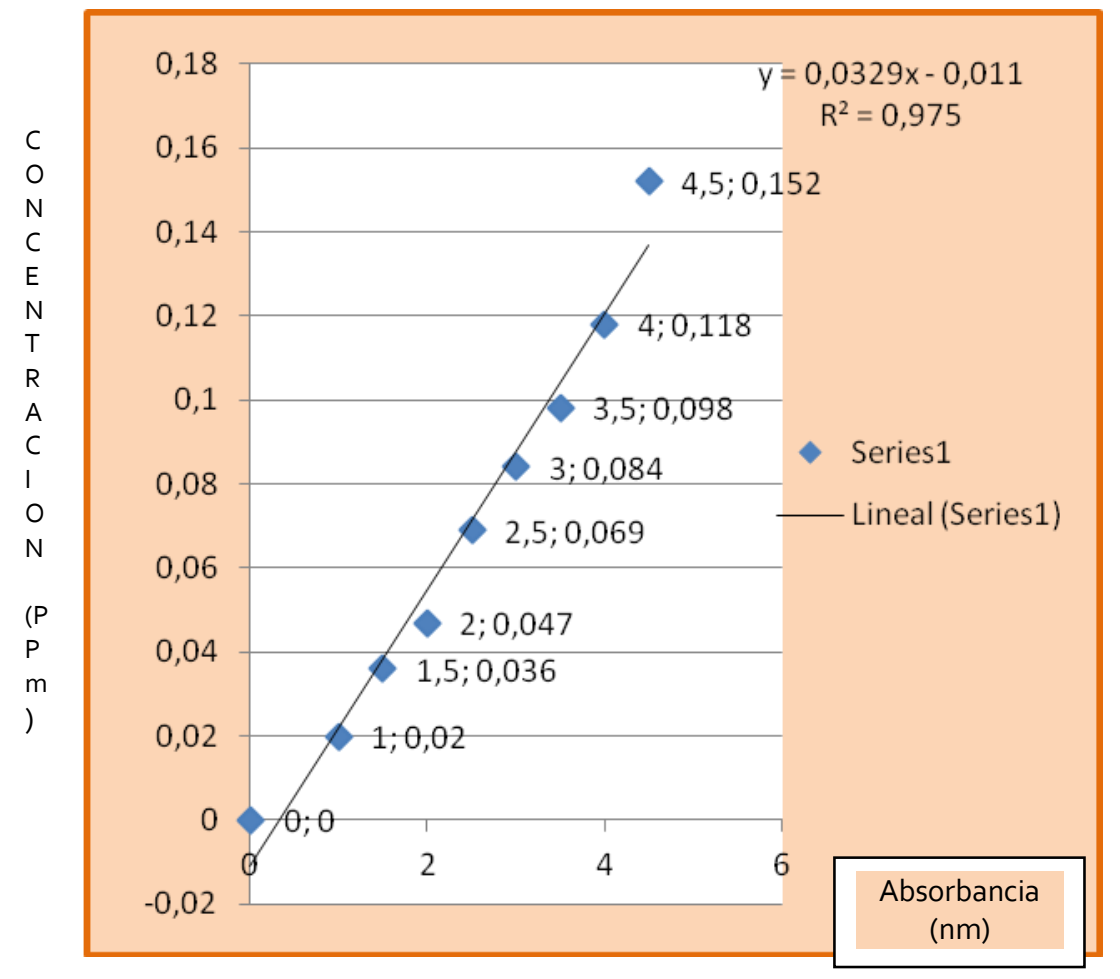

Figura No. 12 Curva de calibración de los estándares de licopeno a diferente concentración 
Después se cuantificó el contenido de licopeno de cada alimento y se expresó en miligramos por cada $100 \mathrm{~g}$ de cada una de las muestras (Tabla No.34).

Tabla No.34 Contenido de licopeno en las muestras de alimentos analizadas

\begin{tabular}{|l|c|}
\hline \multicolumn{1}{|c|}{ Muestra de alimento } & Contenido de licopeno $\mathbf{~ m g / 1 0 0 g}$ \\
\hline Papaya maradol & 2,03 \\
\hline Tomate saladette & 2,11 \\
\hline Toronja rosada & 0,37 \\
\hline Sandía roja & 2,75 \\
\hline Guayaba amarilla & 0,47 \\
\hline Jugo de tomate** & 4,29 \\
\hline Salsa cátsup* & 3,97 \\
\hline Puré de tomate* & 3,29 \\
\hline
\end{tabular}

En esta tabla se presenta el contenido de licopeno de las muestras de alimentos analizadas, especificando el tipo y las marcas y la cantidad de licopeno en mg por $100 \mathrm{~g}$. *Marca la Costeña **Marca Jumex

\subsubsection{Diseño de la dieta estándar}

La dieta estándar se definió como un conjunto de alimentos y bebidas que tienen $30 \%$ de grasas totales y que cumple con todos los criterios propuestos por la Norma Oficial Mexicana para la prevención, tratamiento y control de las dislipidemias (NOM-037SSA2-2002) y que será utilizada por el grupo control de la investigación.

Para su diseño, se calcularon las necesidades de energía (kilocalorías) a través del método breve el cual de acuerdo con el nivel de actividad física (bajo, moderado y alto) establece la cantidad de kilocalorías por kilogramo de peso para los diferentes objetivos: perder peso, mantener el peso o aumentar de peso independientemente del sexo del sujeto como puede apreciarse en la tabla No. 35

Tabla No.35 Métodos breves para calcular las necesidades energéticas.

\begin{tabular}{|l|c|c|c|}
\hline \multirow{2}{*}{ Objetivo } & \multicolumn{3}{c|}{ Nivel de actividad física } \\
\cline { 2 - 4 } & Bajo & Moderado & Alto \\
\hline Perder peso & $15 \mathrm{Kcal} / \mathrm{Kg}$ & $20 \mathrm{Kcal} / \mathrm{Kg}$ & $25 \mathrm{Kcal} / \mathrm{Kg}$ \\
\hline Mantener el peso & $20 \mathrm{Kcal} / \mathrm{Kg}$ & $25 \mathrm{Kcal} / \mathrm{Kg}$ & $30 \mathrm{Kcal} / \mathrm{Kg}$ \\
\hline Aumentar de peso & $25 \mathrm{Kcal} / \mathrm{Kg}$ & $30 \mathrm{Kcal} / \mathrm{Kg}$ & $35 \mathrm{Kcal} / \mathrm{Kg}$ \\
\hline
\end{tabular}

Fuente: Escott-Stump, S. (2010). Nutrición, Diagnóstico y Tratamiento. España: Wolters Kluwer. Lippincott Williams \& Wilkins 
En el caso que nos ocupa, el objetivo es mantener el peso con una actividad moderada e inducir modificaciones en los diferentes indicadores del estado de nutrición (IMC, porcentaje de grasa corporal y circunferencia abdominal) y los niveles de lípidos sanguíneos ( $C L, T G, H D L$ y $L D L$ ) mediante cambios cualitativos en la alimentación a través de la dieta. Por lo anterior se tomo como promedio un hombre de $72 \mathrm{Kg}$ que al multiplicar su peso por 25 $\mathrm{Kcal} / \mathrm{Kg}$ da como resultado 1800 Kilocalorías por día, y una mujer de promedio $60 \mathrm{Kg}$ que al multiplicar su peso por $25 \mathrm{Kcal} / \mathrm{Kg}$ da como resultado 1500 Kilocalorías por día.

Se procedió a la elaboración de la tabla de distribución de macronutrientes, tanto para hombres como para mujeres de acuerdo con los porcentajes normales: $55 \%$ de hidratos de carbono, $15 \%$ de proteínas y $30 \%$ de lípidos. Se incluye también el cálculo del porcentaje de cada uno de los macronutrientes y su equivalente en kilocalorías y gramos, los cuales se utilizaron para el diseño de los menús para hombres (Tabla No.36) y para mujeres (Tabla No.37).

Tabla No.36 Distribución de nutrientes y energía para el diseño de menús para hombres (con base en 1800 kilocalorías)

\begin{tabular}{|l|c|c|c|}
\hline \multicolumn{1}{|c|}{ Nutrientes } & Porcentaje (\%) & Energía (Kcal) & Gramos \\
\hline Hidratos de Carbono & 55 & 990 & 247,5 \\
\hline Proteínas & 15 & 270 & 67,5 \\
\hline Lípidos* & 30 & 540 & 60,0 \\
\hline Total & 100 & 1800 & - \\
\hline
\end{tabular}
Las recomendaciones del porcentaje de lípidos están de acuerdo con la Norma Oficial Mexicana para
la prevención, tratamiento y control de las dislipidemias.NOM-037-SSA2-2002.

Para la elaboración de los menús se utilizaron las porciones de alimentos del Sistema Mexicano de Alimentos Equivalentes ya que su manejo es muy sencillo debido a que se presenta en medidas comúnmente utilizadas en la cocina casera (taza, vaso, cuchara, cucharita, etc.) y sus equivalencias en medidas de peso o de volumen (g. o ml. respectivamente) (Pérez et al., 2008).

Tabla No.37 Distribución de nutrientes y energía para el diseño de menús para mujeres (con base en 1500 kilocalorías)

\begin{tabular}{|l|c|c|c|}
\hline \multicolumn{1}{|c|}{ Nutrientes } & Porcentaje (\%) & Energía (Kcal) & Gramos \\
\hline Hidratos de Carbono & 55 & 825 & 206.25 \\
\hline Proteínas & 15 & 225 & 56.25 \\
\hline Lípidos* & 30 & 450 & 50.00 \\
\hline Total & 100 & 1500 & - \\
\hline
\end{tabular}

* Las recomendaciones del porcentaje de lípidos están de acuerdo con la Norma Oficial Mexicana para la prevención, tratamiento y control de las dislipidemias.NOM-037-SSA2-2002. 
Posteriormente se procedió a la elaboración del cuadro de distribución de equivalentes de alimentos en 24 horas utilizando y el cuadro de distribución por tiempos de comida de cada uno de los menús.

Se diseñaron seis menús: 3 para hombres (Anexo $V$ ) y tres para mujeres (Anexo $\mathrm{VI}$ ) considerados para el grupo tratado con dieta estándar.

Respecto a los lípidos de la dieta, se consideró $30 \%$ en total con $10 \%$ de saturados, $10 \%$ de monoinsaturados y $10 \%$ de poliínsaturados, con menos de $30 \mathrm{mg} /$ día de colesterol, como puede apreciarse en la tabla No. 38 en la sección correspondiente a la primera etapa de las recomendaciones que corresponde a los criterios estblecidos para la población en general.

Tabla No.38 Recomendaciones de la NOM-037-SSA2-2002 referentes al aporte de energía y nutrientes para el tratamiento nutricional de las dislipemias.

\begin{tabular}{|c|c|c|}
\hline Etapas & \multicolumn{2}{|c|}{ Recomendaciones } \\
\hline Etapa I & \multicolumn{2}{|c|}{ Criterios para la población en general } \\
\hline Hidratos de carbono & \multicolumn{2}{|c|}{ De 50-60\% complejos } \\
\hline Proteínas & \multicolumn{2}{|l|}{ Hasta $20 \%$} \\
\hline \multirow{3}{*}{ Lípidos } & \multirow{3}{*}{ De 25 a $35 \%$} & $10 \%$ saturados \\
\hline & & $10 \%$ nomoinsaturados \\
\hline & & $10 \%$ poliinsaturados \\
\hline Colesterol & \multicolumn{2}{|l|}{$>30 \mathrm{mg} / \mathrm{dí}$} \\
\hline Fibra & \multicolumn{2}{|l|}{$<30$ g/día } \\
\hline Etapa II & \multicolumn{2}{|c|}{ Criterios específicos para dislipemias } \\
\hline Hidratos de carbono & \multicolumn{2}{|c|}{ De $50-60 \%$ complejos } \\
\hline Proteínas & \multicolumn{2}{|l|}{ Hasta $20 \%$} \\
\hline \multirow{3}{*}{ Lípidos } & \multirow{3}{*}{ De 25 a $35 \%$} & $7 \%$ saturados \\
\hline & & $10 \%$ nomoinsaturados \\
\hline & & $13 \%$ poliinsaturados \\
\hline Colesterol & \multicolumn{2}{|l|}{$>30 \mathrm{mg} / \mathrm{dí}$} \\
\hline Fibra & \multicolumn{2}{|l|}{$<30 \mathrm{~g} /$ día } \\
\hline
\end{tabular}

Fuente: Norma Oficial Mexicana. NOM-037-SSA2-2002. Para la prevención, tratamiento y control de las dislipidemias.

\subsubsection{Diseño del programa de ejercicio físico}

El American College of Sports Medicine (2001) define el ejercicio como una subclase de la actividad física que se caracteriza por ser un movimiento corporal planeado, estructurado y repetitivo hecho para mejorar o mantener uno de los componentes de la aptitud física. 
Existe mucha evidencia en la literatura de las ventajas de realizar ejercicio físico y de los problemas de salud que causa el sedentarismo, dentro de las cuales las dislipemias ocupan un lugar especial.

En primer término se revisó la literatura relacionada con los efectos del ejercicio en las enfermedades cardiovasculares, específicamente en las dislipemias, encontrando que las recomendaciones se dirigen hacia la práctica del ejercicio aeróbico por su efecto en la reducción de los niveles de TG y el peso corporal, el incremento en los niveles de HDL y en la potencia muscular (Woolf-May, K., 2008).

Se pensó en la selección de varias actividades que no requirieran de la compra de equipo, que pudieran realizarse en lugares cercanos al hogar y que no representan inconvenientes, para lograr una mayor adherencia; se concluyó que caminar, nadar o bicicleta móvil o estática serían las opciones adecuadas porque provocan incremento en el consumo de oxígeno $\left(\mathrm{VO}_{2}\right)$ y de la frecuencia cardíaca $(\mathrm{FC})$ y puede realizarse al aire libre en parques y deportivos.

Se consideraron en primer término los componentes del programa de ejercicio aeróbico para 12 semanas. La frecuencia se planeó de cuatro veces a la semana, preferentemente cinco, de acuerdo con las recomendaciones de la Norma Oficial Mexicana NOM-037-SSA2-2002, para la prevención, tratamiento y control de las dislipidemias, que pueden realizarse en una o varias sesiones dependiendo de la disponibilidad de tiempo.

El tiempo se consideró de 60 minutos y la intensidad de 60-70 \% de la frecuencia cardiaca máxima. Para lograr esa frecuencia se contó con elapoyo del Departamento de Medicina del Deporte de la Facultad de Medicina para capacitar a los participantes en la toma de la frecuencia cardíaca en reposo y después de hacer ejercicio.

Además, se les capacitó en el uso de la Escala de Borg (Figura No. 13) que ha demostrado tener una mejor aceptación que el uso de la frecuencia cardíaca, ya que representa la percepción del esfuerzo al realizar ejercicio físico de manera individual, lo que permite ir avanzando de forma progresiva sin forzar al individuo, de acuerdo con llarraza, (2002) quien mediante un estudio donde participaron 105 pacientes de edades entre 30 y 85 años que fueron sometidos a 4 semanas de ejercicio controlado, pudo concluir que el uso de la Escala de Borg es tan segura como la frecuencia cardíaca, provocando efectos de entrenamiento a 4 semanas de su utilización.

Posteriormente se diseñó el programa de ejercicio considerando cada una de sus etapas y la duración en minutos. 
La implementación del programa fue de manera progresiva ya que la mayoría de los participantes eran sedentarios o no habían realizado ejercicio al menos tres meses antes del estudio.

\begin{tabular}{|c|l|}
\hline 0 & Nada \\
\hline 1 & Muy muy ligero \\
\hline 2 & Muy ligero \\
\hline 3 & Ligero \\
\hline 4 & Moderado \\
\hline 5 & Un poco pesado \\
\hline 6 & Pesado \\
\hline 7 & \\
\hline 8 & Muy pesado \\
\hline 9 & \\
\hline 10 & Extremadamente pesado \\
\hline
\end{tabular}

Figura 13. Escala de Borg

Fuente: Borg, G. (1982). Psychophysical bases of perceived exertion. Medicine and Science in Sports and Exercise, 14 (5), 377-381

Se elaboró el ejemplo de una sesión completa de ejercicio, en este caso en particular de caminata (Anexo IV). Se inició con el calentamiento, que consiste en el movimiento y estiramiento de todas las partes del cuerpo, que incrementan de forma gradual la temperatura muscular; tiene la finalidad de conseguir que el cuerpo alcance un nivel óptimo de manera paulatina para enfrentar las exigencias del ejercicio y prevenir lesiones.

Los beneficios del calentamiento son el incremento de la temperatura corporal; incremento de la irrigación de los músculos con el consecuente aumento en el aporte de oxígeno y eliminación de dióxido de carbono; el mejoramiento de la utilización del oxígeno al incrementarse la actividad pulmonar; mejoramiento de la transmisión de los impulsos nerviosos, la contracción muscular; incremento de los niveles de fuerza, de la elasticidad muscular, entre otros.

Se inicia con la parte superior y concluyendo con la parte inferior, durante aproximadamente 3 minutos. Posteriormente se continuó con el calentamiento específico que consta de movimientos y estiramientos de las partes del cuerpo que se van a utilizar más durante la sesión de ejercicio, esta etapa tiene una duración aproximada de 7 minutos. 
La fase de ejercicio principal como se comentó anteriormente consiste en caminar a intensidad moderada (60-70 \% de la frecuencia cardiaca máxima) durante aproximadamente 40 minutos.

La fase de enfriamiento incluye movimientos de estiramiento de todas las partes del cuerpo iniciando con el cuello y de ahí se va avanzando hacia abajo hasta las piernas y los pies que son los más utilizados en la caminata.

El enfriamiento ayuda a recuperar progresivamente la frecuencia cardíaca, la tensión arterial y la respiración; con el estiramiento aumenta la flexibilidad y reduce el riesgo de lesiones. Además, ayuda a eliminar los productos de desecho del tejido muscular como el ácido láctico, lo cual reduce el riesgo de dolores.

\section{Prueba de esfuerzo}

La prueba de esfuerzo es un procedimiento ampliamente utilizado para valorar la capacidad física de la persona con el propósito de estratificar el riesgo cardiovascular y prescribir el nivel de esfuerzo físico que debe desarrollar durante la práctica de ejercicio. Frecuenteme, sin embargo, también se utiliza en personas sanas para obtener un diagnóstico de salud (confirmando la ausencia de enfermedades, principalmente cardiacas) y para la valoración de la capacidad funcional del deportista (la capacidad para hacer ejercicio) (Arós et al., 2000).

La manera más útil para conocer la capacidad funcional de un individuo es determinando de su consumo máximo de oxígeno $\left(\mathrm{VO}_{2}\right)$ durante la ergonometría. El $\mathrm{VO}_{2}$ máximo se refiere a la máxima captación de oxígeno por un individuo sometido a ejercicio, de tal manera que, aunque siga haciendo ejercicio, el $\mathrm{VO}_{2}$ ya no sigue incrementándose sino que se estabiliza porque ha llegado a su límite fisológico. Una manera práctica para determinar el $\mathrm{VO}_{2}$ de manera indirecta es a través de las diferentes tablas que permiten realizar el cálculo a partir de otros datos como son la edad, el sexo, el nivel de entrenamiento y la etapa alcanzada de un determinado protocolo.

Los protocolos son esquemas de sistematización del ejercicio que se llevan a cabo en cada uno de los tipos de prueba de esfuerzo. Un determinado tipo de prueba de esfuerzo puede utilizar uno o diferentes protocolos (Castellano et al. 2009).

Otra forma utilizada para conocer la capacidad funcional es conociendo el gasto energético durante el ejercicio medido en equivalentes metabólicos (MET). 1 MET esquivale a $3,5 \mathrm{ml} \mathrm{O}_{2}$ $/ \mathrm{Kg} /$ minuto. Al conocer los METs consumidos en cada etapa del protocolo, el total de METs alcanzados da una idea de la capacidad de trabajo lograda por el individuo, lo que permite clasificarlo desde el punto de vista funcional de acuerdo con la tabla No. 39 
Tabla No.38 Clasificación de los niveles de funcionalidad de las prueba de esfuerzo de acuerdo con el gasto energético.

\begin{tabular}{|c|c|}
\hline Grado & METs \\
\hline I & De 7 a 16 \\
\hline II & De 5 a 6 \\
\hline II & De 2 a 4 \\
\hline IV & De 1 a 2 \\
\hline
\end{tabular}

Fuente: Castellano et al. (2009). Electrocardiografía Clínica. España: Elsevier.

Los datos obtenidos permiten un asesoramiento médico específico si se encuentran patologías o del entrenamiento, determinando las intensidades de ejercicio recomendables para iniciar o mejorar el rendimiento deportivo.

Pueden realizarse en diversos equipos, los más utilizados son la banda sin fin y la bicicleta ergométrica.

La banda sin fin es el método más utilizado, la banda, es activada por un motor eléctrico sobre la cual la persona debe caminar a distintas velocidades y pendiente de acuerdo con el protocolo establecido.

\section{Condiciones para la prueba de esfuerzo}

El área destinada para realizar las pruebas de esfuerzo debe estar accesible, con buena ventilación y que no sea húmeda, para favorecer la dispersión del calor y el sudor que provoca el ejercicio (aproximadamente 21 grados centígrados).

En este caso en particular, las pruebas de esfuerzo de realizaron en el área específica para dichas pruebas de la Unidad Cardiometabólica de la Facultad de Medicina que cuenta con un equipo con sistema computarizado de banda sin fin, baumanómetro, estetoscopio, un banco de altura, una camilla y una toma de oxigeno, carro de emergencia y desfibrilador, por si se presentan complicaciones, multímetro, glucómetro con tiras reactivas, torundas con alcohol, fibra verde y electrodos, así como los medicamentos necesarios y el material para atender correctamente la reanimación cardiopulmonar, crisis hipertensivas, arritmias, angina, etc.(Antúnez et al., 2004).

Las pruebas de esfuerzo fueron realizadas por un médico capacitado que conoce los procedimientos y que además interpretó y supervisó los datos clínicos del ecocardiograma durante la prueba y posterior a ella y que puede atender las complicaciones. 


\section{Preparación de los participantes}

Se informó a los participantes el procedimiento, el objetivo que se persigue y las posibles complicaciones.

Se les solicitó que no consuman café, alcohol y tabaco tres horas antes de la prueba; además, que no realice actividad física doce horas antes de la prueba. Deben haber realizado una comida ligera y portar zapatos deportivos y ropa cómoda.

Para colocar los electrodos correctamente se limpió la piel con alcohol y con la fibra verde para eliminar las células muertas; en el caso de los participantes del sexo masculino se les solicitó que se realizaran previo al procedimiento la tricotomía en la cara anterior del tórax.

Se realizó un electrocardiograma antes de la prueba y se colocó posteriormente una bata o camiseta para asegurar los electrodos y los cables se sujetaron en la ropa del participante (Arós et al. 2000).

\section{Durante la prueba de esfuerzo}

Se observó al paciente y se le interrogó para identificar cualquier malestar, se observaron también los cambios en el ritmo cardíaco.

El médico decide de acuerdo a los cambios observados en el paciente durante el procedimiento el momento de dar por terminada la prueba de esfuerzo, es decir, cuando el participante presente síntomas o signos clínicos o electrocardiográficos que aconsejen su suspensión o haya alcanzado la frecuencia cardiaca máxima para la edad o frecuencia cardiaca blanco.

De acuerdo con la frecuencia cardíaca alcanzada, las pruebas de esfuerzo pueden ser máximas y submáximas; en las pruebas máximas la frecuencia cardiaca supera el $85 \%$ de la frecuencia cardíaca blanco, mientras que en las submáximas el resultado de la prueba es inferior.

Para el presente estudio se utilizó el protocolo de Bruce, el cual consiste en hacer etapas de tres minutos con una velocidad $y$ pendiente creciente, empezando con una velocidad de 1,7 millas por hora ( $\mathrm{mph}$ ), donde una milla equivale a 1,609 $\mathrm{m}$ y una pendiente del 10\% como puede observarse en la tabla No. 40.

Este es uno de los protocolos mejor tolerados, siendo apto tanto para personas con enfermedades cardíacas, para personas sanas, sedentarias que desean realizar ejercicio como para personas entrenadas (Castellano et al., 2009). 
Tabla No. 40 Protocolo de Bruce para prueba de esfuerzo

\begin{tabular}{|c|c|c|c|c|}
\hline Etapa & Velocidad & Inclinación & Minutos & Mets \\
\hline 1 & 1,7 & 10 & 3 & 4,6 \\
\hline 2 & 2,5 & 12 & 3 & 7,0 \\
\hline 3 & 3,4 & 14 & 3 & 10,1 \\
\hline 4 & 4,2 & 16 & 3 & 12,9 \\
\hline 5 & 5,0 & 18 & 3 & 15,0 \\
\hline 6 & 5,5 & 20 & 3 & 16,9 \\
\hline 7 & 6,0 & 22 & 3 & 19,1 \\
\hline
\end{tabular}

Fuente: Guidelines for exercise testing Journal of the American College of Cardiology (JACC) (1997) 30 (1), 260. En: M. Antúnez et al. (2004). Valoración inicial con prueba de esfuerzo al paciente cardiópata para ingresar al programa de rehabilitación cardiaca. Revista Mexicana de Enfermería Cardiológica 12 (1), $34-37$.

\section{Posterior a la prueba de esfuerzo}

Se registró la tensión arterial y la frecuencia cardíaca del participante al término de la prueba y a los 5,7 y 10 minutos si la prueba resultó negativa para isquemia o arritmias; en caso contrario continuará monitoréandolo hasta su recuperación.

\section{Interpretación de la prueba de esfuerzo}

Una prueba de esfuerzo resulta negativa cuando no resenta datos clínicos ni eléctricos de positividad. Se considera positiva ligera, cuando la sintomatología o las alteraciones eléctricas aparecen a partir del estadío III del protocolo de Bruce y el segmento ST no disminuya más de $2 \mathrm{~mm}$.

Si las alteraciones clínicas o eléctricas aparecen en el estadío I del protocolo de Bruce y se incrementan con el esfuerzo, persistiendo por más de 8 minutos en la recuperación o el segmento ST disminuya más de $3 \mathrm{~mm}$, se considera positiva precoz.

Se considera moderadamente positiva cuando las alteraciones aparezcan entre las dos situaciones anteriores y no concluyentes, cuando no se presenten datos clínicos ni eléctricos de positividad, pero no se alcance la frecuencia cardiaca submáxima.

Se considera positiva para isquemia miocárdica cuando se presentan los siguientes indicadores estándar: 0,1 mm de desviación horizontal o descendente del segmento ST a 6o-80 mseg del punto J.

Otras alteraciones inducidas por el esfuerzo que indican una prueba anormal y la necesidad de mayor evaluación son angina, arritmias y caída de la tensión arterial (Castellano et al., 2009). 


\subsubsection{Disgnóstico de dislipemia, índice aterogénico de Castelli tipo I, indicadores del estado de nutrición y tensión arterial.}

\section{Diagnóstico de dislipemia}

En esta etapa se realizó la determinación del perfil de lípidos al inicio del estudio (pre-prueba) para obtener el diagnóstico de dislipemias mediante la determinación de sus indicadores $(C L, T G$, $\mathrm{LDL}$ y $\mathrm{HDL}$ ) y al final (post-prueba) para conocer el efecto del tratamiento en dichos indicadores. Además la determinación de los indicadores del estado de nutrición como el porcentaje de grasa corporal (PGC), el Índice de Masa Corporal (IMC)y la circunferenca abdominal (CA), así como la tensión arterial (TA).

El perfil de lípidos se realizó en el Laboratorio de Análisis Clínicos de la Facultad de Quimica, utilizando técnicas, equipos y procedimientos que se encuentran certificados por ISO 9001, a continuación se describe la técnica, antes y después de la intervención. Además se calculó el Índice aterogénico de Castelli.

\section{Toma de las muestras}

Las condiciones para la toma de las muestras son: el día previo evitar comer alimentos grasosos y lácteos; procurar tomar la cena a las 19:00 horas como máximo; la cena debe consistir en alimentos ligeros como jugos, frutas y verduras y no consumir alcohol. El día de la toma de la muestra acudir al laboratorio entre las 7 y 9 de la mañana con 12 horas de ayuno y sin haber realizado ejercicio físico.

Las muestras fueron obtenidas de los participantes en posición cómodamente sentados durante cinco minutos antes de la toma, por medio de la punción de la vena media cubital mediante la siguiente técnica (Céspedes, 1999).

\section{Técnica}

1.- Colocar al paciente de manera que se tenga mejor acceso a la fosa radial

2.- Aplicar un torniquete durante un minuto, solicitando al paciente que cierre el puño y bombee para que las venas resulten más palpables.

3.- Seleccionar la vena (preferentemente la cubital interna), se limpia la zona de venopunción con un algodón con solución de alcohol al 70\%, con movimientos en espiral hacia fuera del punto de punción y se deja secar.

4.- Realizar la venopunción penetrando a través de la piel con la aguja de calibre 0.8 .

5.- Soltar el torniquete cuando la sangre empiece a fluir. 
6.- Indicar al paciente que relaje el puño y no bombee con la mano una vez que se ha extraído toda la muestra.

7.- Extraer la aguja colocando un algodón sobre el punto de punción presionando la zona.

Las muestras se centrifugaron a $4000 \mathrm{rpm}$ durante 15 minutos y se procesaron por métodos enzimáticos en un equipo RA 50 Express Plus Bayer semiautomático con los reactivos para colesterol (serapack plus 6273) con un coeficiente de variación dentro del 3\%; para triglicéridos (serapack plus 4543) y para HDL colesterol directo (serapack plus B01457701), ambos con un coeficiente de variación dentro del $5 \%$ y para LDL deshidrogenasa láctica (Bayer 720729).

Los valores deseables de lípidos en sangre fueron comparados con los resultados de cada participante para clasificarlos con los criterios para diagnosticar las dislipidemias de acuerdo con la NOM037-SSA2-2002. Para la prevención, tratamiento y control de las dislipidemias que se describen a continuación:

1. Hipercolesterolemia: $\mathrm{CT}$ mayor de $200 \mathrm{mg} / \mathrm{dL}, \mathrm{Tg}$ menor a 200 $\mathrm{mg} / \mathrm{dL}$ y LDL igual o mayor a $130 \mathrm{mg} / \mathrm{dL}$.

a) Hipercolesterolemia leve: CT 200-239 mg/dL.

b) Hipercolesterolemia moderada: CT 240-300 mg/dL.

c) Hipercolesterolemia severa: CT mayor de $300 \mathrm{mg} / \mathrm{dL}$.

2. Hipertrigliceridemia: $T G$ mayor de $200 \mathrm{mg} / \mathrm{dL}, C T$ menor de $200 \mathrm{mg} / \mathrm{dL}$ y LDL menor de $130 \mathrm{mg} / \mathrm{dL}$.

3. Dislipidemia mixta: CT mayor de $300 \mathrm{mg} / \mathrm{dL}, \mathrm{Tg}$ mayor de 200 $\mathrm{mg} / \mathrm{dL}$ y LDL igual o mayor de $130 \mathrm{mg} / \mathrm{dL}$.

4. Cabe aclarar que para el diagnóstico de hipoalfalipoproteinemia se utilizó el criterio de la NCEP, que tiene como límite inferior $\geq 40 \mathrm{mg} / \mathrm{dl}$ y superior $\geq 60 \mathrm{mg} / \mathrm{dl}$.

En la tabla No.41 se presentan los criterios de la NOM-037-SSA2-2002 y de la NCEP, de donde se tomaron dichos criterios.

Tabla No. 41 Valores normales de los niveles de lípidos en sangre

\begin{tabular}{|c|c|c|c|}
\hline \multirow[t]{2}{*}{ Indicador } & \multicolumn{3}{|c|}{ Deseable } \\
\hline & \multicolumn{2}{|c|}{ NOM-037-SSA2-2002 } & NCEP \\
\hline Colesterol mg/dl & \multicolumn{2}{|c|}{$<200$} & $<200$ \\
\hline \multirow[t]{2}{*}{ HDL mg/dl } & \multirow[t]{2}{*}{$>35$} & $>40$ hombres & \multirow[t]{2}{*}{$\geq 60$} \\
\hline & & $>50$ mujeres & \\
\hline LDL mg/dl & \multicolumn{2}{|c|}{$<130$} & $<100$ \\
\hline Triglicéridos mg/dl & \multicolumn{2}{|c|}{$<150$} & $<150$ \\
\hline
\end{tabular}

Fuente: Modificada de la Norma Oficial Mexicana. Para la prevención, tratamiento y control de las dislipidemias. NOM-037-SSA2-2002 y de Expert Panel on Detection, evaluation and treatment of high blood colesterol in adults. Executive summary of the third report of the National Cholesterol Education Program (NCEP) (2001) Expert Panel on Detection, evaluation and treatment of high blood cholesterol in adults (Adult Treatment Panel.II). Journal of the American Medical Association (JAMA), $1,627-633$ 


\section{Índice aterogénico de Castelli}

El índice aterogénico de Castelli (1988) es un método rápido y sencillo para determinar el riesgo de enfermedad cardiovascular en el que se encuentran los individuos en función de sus niveles de $\mathrm{CL}$. Se considera un predictor más potentede riesgo coronario que el $\mathrm{CL}$, LDL y HDL utilizados de forma independiente.

Se calcula de dos maneras, para el tipo I, dividiendo el valor de CL total entre el valor de las HDL, con la fórmula siguiente:

\section{Índice Aterogénico Tipo I = Colesterol Total / HDL}

Para el tipo II, se divide el valor de las LDL entre el valor de las HDL con la fórmula siguiente:

Índice Aterogénico Tipo $/ /=L D L / H D L$

Para interpretar el riesgo aterogénico se utilizan los valores para hombres y mujeres que se presentan en la tabla No. 42.

Tabla No.42 Clasificación del índice aterogénico de Castelli por sexo y sus valores de referencia

\begin{tabular}{|l|c|c|}
\hline Riesgo aterogénico & Hombres & Mujeres \\
\hline Tipo I & $>5$ & $>4,5$ \\
\hline Tipo II & $>3,5$ & $>3,5$ \\
\hline
\end{tabular}

Fuente: Castelli W.P. (1988). Cholesterol and lipids in the risk of coronary artery disease.the Framinaham Heart Studv. Canadian Journal of Cardioloav, 4, 5A-10A.

Porcentaje de grasa corporal, indicadores del estado de nutrición (Índice de Masa Corporal, circunferencia abdominal) y tensión arterial.

Se realizó la toma de las mediciones corporales de peso, estatura, porcentaje de grasa corporal (PGC) y circunferencia abdominal (CA) a los participantes para determinar su estado de nutrición, utilizando el Índice de Masa Corporal (IMC) y el riesgo de padecer enfermedades crónicas.

Para la toma de peso, PGC y el IMC se utilizó una báscula marca TANITA TBF-621.

Para medir la estatura, se usó un estadímetro marca SECA modelo 2222081 y para la CA una cinta flexible marcada en centímetros, utilizando las técnicas de medición específicas para cada caso que deben ser aplicadas por dos personas. 


\section{Medición de la estatura}

1. Se solicitó a la persona que se presente sin adornos en la cabeza que dificulten la medición y se descalce.

2. Se colocó a la persona en posición erecta, con los brazos cayendo a los costados, los talones juntos y las puntas ligeramente separadas en un ángulo de 45 grados, y la cabeza en plano de Frankfort.

3. Se colocó la barra del estadímetro en la parte posterior del cuerpo, se aplicó la maniobra de Tanner para corregir la postura de la cabeza y se baja lentamente la plataforma móvil hasta tocar el vértex.

4. Se tomó el dato, se repitió la operación y se colocó la medición en la hoja de registro del expediente clínico del participante (Pérez et al., 2000).

\section{Medición del peso y el porcentaje de grasa corporal}

El porcentaje de grasa corporal se define como el porcentaje del peso total que es tejido graso. (American College of Sports Medicine, 2001) y se midió utilizando la siguiente técnica:

1. Se solicitó a la persona que se presente a la medición con ropa ligera, que se quite los zapatos y calcetines.

2. De preferencia después de haber defecado y orinado y sin tomar alimentos.

3. Se ingresaron los datos de edad, sexo y estatura al procesador de la báscula y cuando la máquina lo indicó se procedió a la medición.

4. Se solicitó a la persona que se coloque sobre la plataforma en posición erecta, con los brazos cayendo a los costados.

4. La báscula marcó el peso y el PGC, los cuales fueron anotados en la hoja de registro del expediente clínico correspondiente (Pérez et al., 2000).

Los resultados de la medición pueden compararse con los rangos normales por edad y sexo que se encuentran en la tabla No.43.

Tabla No.43 Rangos normales de porcentaje de grasa en el cuerpo

\begin{tabular}{|c|r|r|r|r|r|}
\hline $\begin{array}{c}\text { Edad en } \\
\text { años }\end{array}$ & $0-30$ & $31-40$ & $41-50$ & $51-60$ & $61-100$ \\
\hline Hombres & $12-18 \%$ & $13-19 \%$ & $14-20 \%$ & $16-20 \%$ & $17-21 \%$ \\
\hline Mujeres & $20-26 \%$ & $21-27 \%$ & $22-28 \%$ & $22-30 \%$ & $22-31 \%$ \\
\hline
\end{tabular}

Fuente: Pérez et al. (2000). Manual de Dietas Normales y Terapéuticas. (4ạ. Ed.). México: La

Prensa Médica Mexicana. 


\section{Determinación del Índice de Masa Corporal (IMC)}

El equipo para medir el peso y el PGC es el de impedancia bioeléctrica que proporciona también los datos de IMC de los participantes; el dato es posteriormente comparado con los puntos de corte que se presentan en la tabla No. 44.

Tabla No. 44 Puntos de corte para el IMC $\left(\mathrm{Kg} / \mathrm{m}^{2}\right)$

\begin{tabular}{|l|l|}
\hline Obesidad: & mayor a 40 \\
\hline Tercer grado & entre 30 y 40 \\
\hline Segundo grado & entre 25 y 29,9 \\
\hline Primer grado & entre 18,5 y 25 \\
\hline Peso normal & \multicolumn{2}{|l|}{} \\
\hline Desnutrición: & 17 a 18,4 \\
\hline Primer grado & 16 a 16,9 \\
\hline Segundo grado & menor a 16 \\
\hline Tercer grado &
\end{tabular}

Fuente: Pérez et al. (2000). Manual de Dietas Normales y Terapéuticas. (4ª Ed.). México: La Prensa Médica Mexicana.

\section{Medición de la circunferencia abdominal}

La medición se realizó utilizando la siguiente técnica:

1. Se solicitó a las personas presentarse preferentemente en ayuno, con ropa muy delgada o sin ella en el área.

2. Colocadas de pie con los pies juntos y el abdomen relajado; los brazos a los lados y el peso repartido en forma equitativa entre ambos pies.

3. Se identificó la parte más baja de las costillas, así como las crestas ilíacas a nivel de la línea axilar media y se realizó la medición del perímetro entre estos dos puntos, a la altura de la cicatriz umbilical.

4. La medición se hizo con una cinta de fibra de vidrio flexible cuyo rango de medición en centímetros es de o a 143. (World Health Organization (WHO), 2000)

El riesgo de padecer enfermedades crónicas se obtuvo comparando los resultados obtenidos de la medición con los parámetros de normalidad y de riesgo moderado y elevado que se presentan el la tabla No. 45 . 
Tabla No.45 Puntos de corte para la circunferencia abdominal

\begin{tabular}{|c|c|c|c|}
\hline Sexo & Normal & $\begin{array}{c}\text { Riesgo } \\
\text { Moderado }\end{array}$ & $\begin{array}{c}\text { Riesgo } \\
\text { Significativamente } \\
\text { Elevado }\end{array}$ \\
\hline Hombres & $<94 \mathrm{~cm}$ & $94-102 \mathrm{~cm}$ & $>102$ \\
\hline Mujeres & $<80 \mathrm{~cm}$ & $80-88 \mathrm{~cm}$ & $>88 \mathrm{~cm}$ \\
\hline
\end{tabular}

Fuente: adaptado de World Health Organization. (2000). Technical Report series 894: Obesity: Preventing and Managing the global epidemic: report of WHO consultation. Geneva

\section{Medición de la tensión arterial}

Para determinar la tensión arterial su utilizó el baumanómetro de aneroide marca WelchAllyn. El Instituto Nacional del corazón, los Pulmones y la Sangre y la Organización Panamericana de la Salud (OPS), han establecido los siguientes lineamientos para la toma de la presión arterial:

1. Se solicitó evitar comer, consumir bebidas alcohólicas, fumar o hacer ejercicio por lo menos treinta minutos antes de hacer la medición.

2. Tratar de estar relajado y evitar usar prendas de vestir ajustadas del antebrazo derecho y además evitar hablar durante la medición.

3. El participante debe sentarse cómodamente con ambos pies apoyados sobre el piso y la espalda contra un respaldo.

4. La habitación debe ser cómoda y poco ruidosa.

5. El brazo derecho debe colocarse sobre una mesa al nivel del corazón, ligeramente flexionado y con la palma de la mano hacia arriba.

6. El borde inferior del mango debe estar a $2,5 \mathrm{~cm}$. por encima de la articulación del codo.

7. Se realiza la medición y se levanta el brazo del participante por arriba del nivel del corazón durante 15 segundos, se descansa un minuto y puede proceder a realizar la medición de nuevo (World Health Organization (WHO), 2000).

Los resultados obtenidos de cada participante se comparan con los parámetros establecidos que se encuentran en la tabla No.46 y se anotan las cifras y la categoría resultante en el espacio correspondiente del expediente clínico. 
Tabla No.46 Clasificación de la tensión arterial

\begin{tabular}{|l|c|c|}
\hline \multicolumn{1}{|c|}{ Categoría } & Sistólica $(\mathrm{mm} / \mathrm{Hg})$ & Diastólica $(\mathrm{mm} / \mathrm{Hg})$ \\
\hline Óptima & Menor a 120 & Menor a 80 \\
\hline Normal & $120-129$ & $80-84$ \\
\hline Normal Alta & $130-139$ & $85-89$ \\
\hline \multicolumn{3}{|c|}{ Hipertensión: } \\
\hline Grado I: leve & $140-159$ & $90-99$ \\
\hline $\begin{array}{l}\text { Grado II: } \\
\text { moderada }\end{array}$ & $160-179$ & Mayor o igual a 110 \\
\hline Grado III: severa & Mayor o igual a 180 & 90 \\
\hline Sistólica aislada & Mayor o igual a 140 &
\end{tabular}

Fuente: Casanueva et al. (2000). Nutriología Médica. 2a . Ed. México: Editorial Panamericana.

\subsection{Diseño estadístico y análisis de los datos:}

Los datos obtenidos en las distintas mediciones (pre-test y posttest) fueron incorporados a una base elaborada en en el programa Statistical Package for Social Sciencies (SPSS) versión 17 en español. Se codificaron las mediciones de cada individuo y con base en esta codificación se obtuvieron los cuadros con respecto a los datos demográficos y posteriormente se calcularon los estadísticos descriptivos de cada uno de los aspectos recabados.

Para obtener los resultados generales del estudio y para los niveles de lípidos en sangre y porcentaje de grasa corporal se utilizó los valores expresados en media aritmética y desviación típica para la muestra total.

Posteriormente se presentan las gráficas para la demostración del comportamiento de cada indicador con respecto a cada grupo, más adelante se exponen los valores del análisis de varianza (ANOVA) para demostrar la significación y por último los resultados de la prueba Post Hoc de Tukey

Al igual que la estadística descriptiva, el procesamiento de datos para el cálculo todas esta prueba se realizó por medio del programa Statistical Package for Social Sciencies (SPSS) versión 17 en español. 


\section{CAPÍTULO 5.}

RESULTADOS

En el presente capítulo se describen los resultados de la investigación siguiendo el orden de los objetivos propuestos. En primer término se presentan los resultados de la determinación del contenido de licopeno en los alimentos fuente en miligramos por cien gramos.

En segundo término el diseño de la dieta estándar y la dieta rica en licopeno utilizando las raciones de alimentos que proporcionan 50 $\mathrm{mg}$ de licopeno en 24 horas y el diseño del programa de ejercicio físico. Posteriormente se abordan los factores de riesgo, el estado de nutrición y el índice aterogénico de la población de estudio.

Por último, los resultados del efecto de los cuatro tipos de tratamientos en los adultos que padecen dislipemia utilizando los menús elaborados y el programa de ejercicio físico, de acuerdo con la metodología descrita con anterioridad.

\subsection{Determinación de las raciones de alimentos ricos en licopeno.}

Utilizando el método de extracción con solventes por etapas y siguiendo el procedimiento descrito en la metodología, se procesaron los siguientes alimentos: tomate saladette, toronja rosada, papaya maradol, guayaba amarilla y sandía roja.

Los alimentos procesados fueron: puré de tomate marca La Costeña ${ }^{\circledR}$, salsa catsup marca La Costeña ${ }^{\circledR}$ y jugo de tomate marca Jumex ${ }^{\circledR}$. Posteriormente se cuantificó el contenido de licopeno y se expresó en miligramos por cada $100 \mathrm{~g}$ de muestra.

Los resultados muestran que el mayor contenido de licopeno se encontró en los alimentos industrializados derivados del tomate, el jugo de tomate, la salsa cátsup y el puré de tomate, mientras que en los alimentos frescos se observó que el contenido de licopeno fue 
semejante entre la papaya maradol, el tomate saladette y la sandía roja y en menor cantidad la guayaba amarilla y la toronja rosada.

Utilizando las raciones del Sistema Mexicano de Alimentos Equivalentes (Pérez et al., 2008) expresadas en medidas caseras y gramos, se establecieron las raciones de alimentos ricos en licopeno con su contenido de licopeno en miligramos.

Se utilizó una operación matemática de proporcionalidad entre tres valores y una incógnita con la finalidad de calcular la cantidad de licopeno.

La ración de cada uno de los alimentos en medidas caseras y gramos con su repectiva cantidad en $\mathrm{mg}$ de licopeno, se puede apreciar en la tabla No. 47.

Tabla No.47 Raciones de alimentos ricos en licopeno en medidas caseras y gramos.

\begin{tabular}{|l|l|c|c|}
\hline \multirow{2}{*}{ Alimento } & \multicolumn{2}{c|}{ Ración } & $\begin{array}{c}\text { Cantidad de } \\
\text { licopeno en } \mathbf{~ m g} .\end{array}$ \\
\cline { 2 - 3 } & \multicolumn{1}{|c|}{ Medidas Caseras } & Gramos & 5,23 \\
\hline Jugo de tomate** & 1/2 taza & 122 & 0,59 \\
\hline Salsa catsup* & 1 cucharada & 15 & 2,07 \\
\hline Puré de tomate* & 1/4 de taza & 63 & 4,40 \\
\hline Sandía roja & 1 taza (picada) & 160 & 2,84 \\
\hline Papaya maradol & 1 taza (picada) & 140 & 2,53 \\
\hline Tomate saladette & ---------- & 120 & 0,63 \\
\hline Gayaba amarilla & 3 piezas & 135 & 0,60 \\
\hline $\begin{array}{l}\text { Toronja rosada en } \\
\text { gajos }\end{array}$ & 1 taza & 150 & \\
\hline
\end{tabular}

En esta tabla se presentan las raciones de alimentos ricos en licopeno espeificando el tipo y la marca comercial, medidas caseras, en equivalente en gramos y en $\mathrm{mg}$.

*Marca La Costeña $\quad * *$ Marca Jumex

Al contar con las raciones de alimentos ricos en licopeno se consigue el primer objetivo específico de la investigación.

Se procedió a continuación a establecer las raciones con alimentos que contengan aproximadamente $50 \mathrm{mg}$ de licopeno, utilizando recomendaciones de diferenes autores (Willcox et al., 2003; Shi et al., 2004; Waliszewsky et al., 2010) encaminadas a obtener un efecto terapéutico hipolipemiante, como se puede observar en la tabla No.48.

Cabe señalar que se incluyó la variedad de las frutas utilizadas y la marca comercial de los alimentos industrializados con el propósito de asegurar la cantidad especificada y poder realizarcomparaciones con estudios posteriores que utilicen las mismas variedades $y$ marcas. 
Tabla No.48 Raciones de alimentos que aportan $50 \mathrm{mg}$ de licopeno

\begin{tabular}{|l|l|c|c|}
\hline \multicolumn{1}{|c|}{ Alimento } & Medidas Caseras & $\begin{array}{c}\text { Peso o } \\
\text { volumen }\end{array}$ & $\begin{array}{c}\text { Contenido de } \\
\text { licopeno }(\mathbf{m g})\end{array}$ \\
\hline Jugo de tomate** & 2 tazas & $488 \mathrm{ml}$ & 20,92 \\
\hline Puré de tomate* & 1 taza & $252 \mathrm{~g}$ & 8,28 \\
\hline Salsa Catsup* & 3 cucharadas & $45 \mathrm{~g}$ & 1,77 \\
\hline Sandía roja & 2 tazas & $320 \mathrm{~g}$ & 8,80 \\
\hline Papaya maradol & 2 tazas & $280 \mathrm{~g}$ & 5,68 \\
\hline Tomate saladette & 2 piezas & $240 \mathrm{~g}$ & 5,06 \\
\hline Toronja rosada & 1 taza & $150 \mathrm{~g}$ & 0,60 \\
\hline & & Total & 51,11 \\
\hline
\end{tabular}

En esta tabla se presentan las raciones de alimentos que aportan aproximadamente $50 \mathrm{mg}$ de licopeno, especificando tipo y marca comercial, las raciones en medidas casereras, su correspondencia en peso o volumen y la cantidad de licopeno de cada ración expresada en mg. *Marca La Costeña **Marca Jumex

\subsection{Diseño de la dieta rica en licopeno}

Las dietas bajas en frutas y verduras son un factor causal importante de 2,7 millones de muertes por enfermedades cardiovasculares y ciertos tipos de cáncer al año. Las frutas y verduras y sus jugos continen fitoquímicos, algunos de los cuales, como es el caso del licopeno, ejercen protección sobre las macromoléculas biológicas contra el daño oxidativo al incrementar la actividad de el óxido nítrico sintetasa endotelial (eNOS) (George et al., 2012). Se ha demostrado que su consumo puede reducir la incidencia de estas enfermedades, sin embargo, es difícil establecer pautas para su inclusión en la dieta habitual debido a que no existe una ingesta diaria recomendada (IDR). Sin embargo, el contar con las raciones de alimentos que aportan $50 \mathrm{mg}$ de licopeno facilita la inclusión de este antioxidante en la dieta cotidiana lo que puede coadyuvar a la prevención y control de las enfermedades cardiovasculares por su ya conocido efecto hipolipemiante.

Se diseñó la dieta rica en licopeno, con la inclusión de estas raciones de alimentos, utilizando los mismos menús diseñados para la dieta estándar, los cuales fueron utilizados para el grupo experimental, tanto para hombres (Anexo VII) como para mujeres (Anexo VIII). Sólo se modificaron cambiando algunos alimentos programados por aquellos que contienen licopeno, es decir, para el grupo control se utilizaron alimentos como melón, plátano, manzana, pera y jugos como naranja, zanahoria, etc. Para el grupo experimental se incluyeron los alimentos ricos en licopeno que se encuentran en la tabla No.47, como sandía roja, toronja, papaya, puré de tomate, jugo de tomate, etc.

\subsection{Diseño del programa de ejercicio físico}

Con base en las recomendaciones de la Norma Oficial Mexicana 
NOM-037-SSA2-2002, para la prevención, tratamiento y control de las dislipidemias y siguiendo la metodología descrita previamente, se diseñó el programa de ejercicio físico (Tabla No. 49) con el objetivo de disminuir los niveles séricos de $C L$, TG y LDL, el PGC el IMC y la CA, así como incrementar el HDL.

Tabla No. 49. Progarama de ejercicio físico

\begin{tabular}{|c|c|c|c|}
\hline \multicolumn{4}{|c|}{ Fases de Progresión de un programa de ejercicio } \\
\hline Fases & Inicial & Mejoría & Mantenimiento \\
\hline Intensidad & $30-40 \% \mathrm{FC}$ & $40-70 \% \mathrm{FC}$ & $50-70 \% \mathrm{FC}$ \\
\hline Duración & $10-30 \mathrm{~min}$ & $30-90 \mathrm{~min}$ & $60-90 \mathrm{~min}$ \\
\hline Semanas & $1-4$ & 4-6 & $6-10$ \\
\hline Frecuencia & $\begin{array}{l}\text { 2-4 veces por } \\
\text { semana }\end{array}$ & $\begin{array}{c}\text { 4-6 veces por } \\
\text { semana }\end{array}$ & $\begin{array}{l}\text { 5-7 veces por } \\
\text { semana }\end{array}$ \\
\hline Progresión & Lenta & Más rápida & Lenta \\
\hline $\begin{array}{l}\text { Recomendaciones } \\
\text { para iniciar el } \\
\text { programa de } \\
\text { ejercicio. }\end{array}$ & $\begin{array}{l}\text { Personas } \\
\text { sedentarias que } \\
\text { nunca han hecho } \\
\text { ejercicio o las } \\
\text { que hace más de } \\
\text { seis meses que } \\
\text { no lo hacen }\end{array}$ & $\begin{array}{l}\text { Personas que } \\
\text { ya han hecho } \\
\text { ejercicio por lo } \\
\text { menos durante } \\
\text { tres meses }\end{array}$ & $\begin{array}{l}\text { Personas que hace } \\
\text { más de seis meses } \\
\text { que hacen ejercicio }\end{array}$ \\
\hline
\end{tabular}

Se presenta el programa de ejercicio con sus fases de progresión y las recomendaciones de su utilización. $\mathrm{FC}=$ Frecuencia cardiaca

También se elaboró el ejemplo de una sesión completa de ejercicio, en este caso en particular de caminata, que puede consultarse en el Anexo VII.

Con el diseño de las dietas estándar y rica en licopeno y el programa de ejercicio se logra el segundo objetivo específico de la investigación.

\section{Resultados de la prueba de esfuerzo}

Como se comentó anteriormente, la prueba de esfuerzo en el presente proyecto se utilizó para obtener un diagnóstico de salud (confirmando la ausencia de enfermedades, principalmente cardiacas) de los participantes antes de someterlos a un programa de ejercicio físico y además para valorar de la capacidad funcional de los paticipantes para establecer su rutina de ejercicio. 
Es importante observar que el mayor porcentaje de las personas que realizaron ejercicio físico corresponde a la franja de edad comprendida entre 41 a 60 años y el menor entre 60 y más.

El gasto energético durante la prueba en promedio global fue de 10,3 METs, siendo de 10,9 el promedio para hombres y 9,8 el promedio para mujeres.

El cuanto a las etapas de la prueba de esfuerzo de acuerdo con el Protocolo de Bruce, el mayor porcentaje de los participantes $(58,1 \%)$ llegaron a la etapa 3 , de los cuales el $38,7 \%$ fueron mujeres y $19,3 \%$ hombres, seguido de la etapa $4(25,8 \%)$, en la que el $22,6 \%$ fueron hombres y sólo el 3,2\% mujeres.

El 12,9\% llegó a la etapa 2, la mitad de las mujeres y la mitad los hombres. Y sólo el 3,2\% alcanzó la etapa 1, del sexo femenino. Cabe aclarar que el $100 \%$ de las pruebas fueron negativas para cardiopatía isquémica.

\subsection{Dislipemia, indicadores del estado de nutrición e hipertensión arterial}

\subsubsection{Dislipemias}

En la tabla No. 50 se presenta la distribución de los participantes de acuerdo a sus niveles de lípidos en sangre como resultado de la muestra tomada antes de inciar las intervenciones del estudio.

Tabla No.50 Clasificación de la población de estudio de acuerdo con el tipo de dislipemia (NCEP-III)

\begin{tabular}{|l|c|c|c|}
\hline \multirow{2}{*}{ Dislipemias } & \multicolumn{2}{c|}{ Sexo (\%) } & \multirow{2}{*}{$\begin{array}{c}\text { Total } \\
\text { (\%) }\end{array}$} \\
\cline { 2 - 3 } & Hombres & Mujeres & \\
\hline Hipercolesterolemia $(<200 \mathrm{mg} / \mathrm{dL})$ & $1(2,08)$ & $11(22,92)$ & $12(25,00)$ \\
\hline Hipertrigliceridemia $(<150 \mathrm{mg} / \mathrm{dL})$ & $3(6,25)$ & $3(6,25)$ & $6(12,50)$ \\
\hline $\begin{array}{l}\text { Dislipemia mixta } \\
(C L<200 \text { y TG }<150 \mathrm{mg} / \mathrm{dL})\end{array}$ & $\begin{array}{c}10 \\
(20,83)\end{array}$ & $13(27,08)$ & $23(47,91)$ \\
\hline $\begin{array}{l}\text { Hipoalfalipoproteinemia } \\
(\geq 60 \mathrm{mg} / \mathrm{dL})\end{array}$ & $3(6,25)$ & $4(8,33)$ & $7(14,58)$ \\
\hline
\end{tabular}

En esta tabla se presenta la clasificaciópn de la población de estudio de acuerdo con el tipo de dislipidemia que padecen, se presentan los datos por sexo expresados en frecuencias $(n)$ y porcentaje (\%) y en la tercera las sumatorias correspondientes.

Se puede apreciar que el mayor porcentaje de los participantes padecen dislipemia mixta, es decir alteración de ambas familias de lípidos sanguíneos, seguido de hipercolesterolemia aislada y de hipoalfalipoproteinemia; la menor proporción fue de hipertrigliceridemia. 
5.4.2. Indicadores del estado de nutrición: porcentaje de grasa corporal, Índice de Masa Corporal, circunferencia abdominal y tensión arterial.

Para identificar el estado de nutrición de los participantes se utilizaron tres indicadores: el porcentaje de grasa corporal (PGC), el índice de masa corporal (IMC) y la circunferencia abdominal (CA).

El porcentaje de grasa del cuerpo es un indicador de la composición corporal; de acuerdo con la tabla No.51, la población de estudio presentó un alto porcentaje de riesgo a padecer enfermedades cardiovasculares ya que el $97,9 \%$ se encuentra por arriba del parámetro normal para su edad y sexo.

En este indicador, hasta los 40 años, los hombres presentaron mayores niveles de grasa corporal que las mujeres, pero después de los 40 años, sucede lo contrario. La mayor presencia de grasa corporal en las mujeres puede estar relacionada con la edad y con los niveles hormonales.

Tabla No.51. Clasificación de la población de estudio con el indicador porcentaje de grasa corporal

\begin{tabular}{|c|c|c|c|c|c|c|c|}
\hline \multirow{2}{*}{$\begin{array}{c}\text { Grupos } \\
\text { de } \\
\text { edad }\end{array}$} & \multirow{2}{*}{$\begin{array}{c}\text { Porcentaje } \\
\text { Grasa } \\
\text { Normal }\end{array}$} & \multicolumn{2}{|c|}{ Hombres (\%) } & \multirow{2}{*}{$\begin{array}{c}\text { Porcentaje } \\
\text { Grasa } \\
\text { Normal }\end{array}$} & \multicolumn{2}{|c|}{ Mujeres (\%) } & \multirow{2}{*}{$\begin{array}{c}\text { Total } \\
(\%)\end{array}$} \\
\hline & & $\mathbf{N}$ & $A$ & & $\mathbf{N}$ & $A$ & \\
\hline $0-30$ & $12-18$ & 0 & $\begin{array}{c}2 \\
(4,17) \\
\end{array}$ & $20-26$ & 0 & $\begin{array}{c}1 \\
(2,08) \\
\end{array}$ & $\begin{array}{c}3 \\
(6,25) \\
\end{array}$ \\
\hline $31-40$ & $13-19$ & 0 & $\begin{array}{c}7 \\
(14,58) \\
\end{array}$ & $21-27$ & 0 & $\begin{array}{c}3 \\
(6,25) \\
\end{array}$ & $\begin{array}{c}10 \\
(20,83) \\
\end{array}$ \\
\hline 41-50 & $14-20$ & $\begin{array}{c}1 \\
(2,08) \\
\end{array}$ & $\begin{array}{c}4 \\
(8,33)\end{array}$ & $22-28$ & 0 & $\begin{array}{c}6 \\
(12,51)\end{array}$ & $\begin{array}{c}11 \\
(22,92) \\
\end{array}$ \\
\hline $51-60$ & $16-20$ & 0 & $\begin{array}{c}1 \\
(2,08)\end{array}$ & $22-30$ & 0 & $\begin{array}{c}14 \\
(29,17)\end{array}$ & $\begin{array}{c}15 \\
(31,25) \\
\end{array}$ \\
\hline $61-100$ & $17-21$ & 0 & $\begin{array}{c}2 \\
(4,17)\end{array}$ & $22-31$ & 0 & $\begin{array}{c}7 \\
(14,58)\end{array}$ & $\begin{array}{c}9 \\
(18,75)\end{array}$ \\
\hline
\end{tabular}

Se presenta la clasificación de la población de estudio de acuerdo con su porcentaje de grasa corporal por grupos de edad y sexo, expresado en frecuencias ( $n$ ) y porcentajes (\%).y en la última columna las respectivas sumatorias.

$\mathrm{N}=$ Normal $\quad A=$ Alto

Con respecto al IMC, en la tabla No.52 se puede observar que sólo el $20,8 \%$ de la población del estudio clasificó con IMC normal, el $79,2 \%$ de la población clasificó con obesidad en diferentes grados, siendo la obesidad tipo I la que se presentó con mayor frecuencia.

En cuanto a la distribución por sexo, las mujeres superaron a los hombres en el punto de corte de normalidad de IMC y obesidad tipo I; mientras que los hombres superaron a las mujeres en obesidad tipo II y III. 
Tabla No.52 Clasificación de la población de estudio con el indicador IMC

\begin{tabular}{|l|c|c|c|}
\hline \multirow{2}{*}{$\begin{array}{c}\text { Puntos de Corte } \\
\mathrm{Kg} / \mathrm{m}^{\mathbf{2}}\end{array}$} & \multicolumn{2}{|c|}{ Sexo (\%) } & \multirow{2}{*}{$\begin{array}{c}\text { Total } \\
\text { (\%) }\end{array}$} \\
\cline { 2 - 3 } & Hombres & Mujeres & \\
\hline Obesidad III (mayor a 40) & $3(6,25)$ & $1(2,08)$ & $4(8,33)$ \\
\hline Obesidad II (entre 30 y 40) & $8(16,67)$ & $7(14,58)$ & $15(31,25)$ \\
\hline Obesidad I (entre 25 y 29,9) & $4(8,33)$ & $15(31,25)$ & $19(39,58)$ \\
\hline Normal (entre 18,5 y 25) & $2(4,17)$ & $8(16,67)$ & $10(20,84)$ \\
\hline
\end{tabular}

Se presenta la clasificación de la población de estudio con el indicador IMC. En la primera columna se presenta los puntos de corte del IMC que presentó la población de estudio. Cabe aclarar que nadie se encontró en desnutrición. En la segunda columna la subclasificación por sexo expresado en frecuencias $(n)$ y porcentajes (\%) y la tercera fila las sumatorias correspondientes.

En los hombres cifras de IMC pueden estar elevadas a expensas de la masa magra y no de grasa que es el componente patógenico de las enfermedades cardiovasculares.

Los participantes que se encuentran en el rango normal de IMC y en obesidad I pertenecen a los grupos de edad entre 41 y 60 años; los que se encuentran en obesidad II entre 31 y 60 años. Llama la atención que aquellos que presentaban obesidad III son los más jóvenes, entre 20 y 40 años.

La medición de la circunferencia del abdomen se ha convertido en un indicador para determinar el riesgo de padecer enfermedades cardiovasculares y es muy utilizado por la sencillez de su aplicación y por su precisión (Ver tabla No. 53).

Tabla No.53 Clasificación de la población de estudio con el indicador circunferencia abdominal

\begin{tabular}{|c|c|c|c|c|}
\hline Sexo & $\begin{array}{c}\text { Normal } \\
(\%)\end{array}$ & $\begin{array}{c}\text { Riesgo } \\
\text { moderado } \\
(\%)\end{array}$ & $\begin{array}{c}\text { Riesgo } \\
\text { elevado } \\
(\%)\end{array}$ & $\begin{array}{c}\text { Total } \\
(\%)\end{array}$ \\
\hline \multirow{2}{*}{$\begin{array}{l}\text { Hombres } \\
n=17\end{array}$} & $<94 \mathrm{~cm}$ & $94-102 \mathrm{~cm}$ & $>102 \mathrm{~cm}$ & \multirow[b]{2}{*}{$17(35,42)$} \\
\hline & $2(4,17)$ & $4(8,34)$ & $11(22,91)$ & \\
\hline \multirow{2}{*}{$\begin{array}{l}\text { Mujeres } \\
n=31\end{array}$} & $<80 \mathrm{~cm}$ & $80-88 \mathrm{~cm}$ & $>88 \mathrm{~cm}$ & \multirow[b]{2}{*}{$31(64,58)$} \\
\hline & $2(4,17)$ & $11(22,91)$ & $18(37,50)$ & \\
\hline
\end{tabular}

En esta tabla se presenta la clasificación de la población de estudio de acuerdo con el indicador CA por sexo. Se presentan los puntos de corte en frecuencias (n) y porcentajes (\%).

Se puede observar que el mayor porcentaje de la población $(91,6 \%)$, se encuentra por encima de los parámetros de normalidad ( $<94 \mathrm{~cm}$ en los hombres y $<80 \mathrm{~cm}$ en mujeres). En el $31,2 \%$ de los participantes el riesgo fue clasificado como moderado y $60,4 \%$ presentaron un riego elevado. Los participantes que presentaron 
riesgo moderado se encuentran entre las edades de 41 a 50 años y los de riesgo alto entre 51 a 60 .

Aunque el perimétro abdominal fue clasificado como de riesgo para desarollar enfermedades cardiovasculares tanto en hombres como en mujeres, esté índice fue más alto en las mujeres.

Se realizó también la medición de la tensión arterial (TA). Se presenta el la tabla No.54 la clasificación de los participantes de acuerdo con el indicador tensión arterial.

Se puede observar en esta tabla que la mayor parte de los participantes en el estudio presentaron tensión arterial normal y óptima, siendo sólo el $14,6 \%$ de la población quienes presentaron hipertensión grado I (leve), la cual fue diagnosticada al momento del estudio.

Tabla No.54 Clasificación de la población de estudio de acuerdo con su tensión arterial.

\begin{tabular}{|c|c|c|c|}
\hline \multirow[t]{2}{*}{ Tensión arterial } & \multicolumn{2}{|c|}{ Valores en (\%) } & \multirow{2}{*}{$\begin{array}{c}\text { Total } \\
(\%)\end{array}$} \\
\hline & Hombres & Mujeres & \\
\hline $\begin{array}{l}\text { Óptima } \\
(<120 / 80)\end{array}$ & $\begin{array}{c}2 \\
(4,17) \\
\end{array}$ & $\begin{array}{c}15 \\
(31,25)\end{array}$ & $\begin{array}{c}17 \\
(35,42)\end{array}$ \\
\hline $\begin{array}{l}\text { Normal } \\
(120-129 / 80-84)\end{array}$ & $\begin{array}{c}11 \\
(22.92) \\
\end{array}$ & $\begin{array}{c}7 \\
(14,58) \\
\end{array}$ & $\begin{array}{c}18 \\
(37,50) \\
\end{array}$ \\
\hline $\begin{array}{l}\text { Normal alta } \\
(130-139 / 85-89)\end{array}$ & $\begin{array}{c}1 \\
(2,08) \\
\end{array}$ & $\begin{array}{c}5 \\
(10,42) \\
\end{array}$ & $\begin{array}{c}6 \\
(12,50) \\
\end{array}$ \\
\hline $\begin{array}{l}\text { Hipertensión grado I leve } \\
(140-149 / 90-99)\end{array}$ & $\begin{array}{c}3 \\
(6,25) \\
\end{array}$ & $\begin{array}{c}4 \\
(8,33) \\
\end{array}$ & $\begin{array}{c}7 \\
(14,58) \\
\end{array}$ \\
\hline $\begin{array}{l}\text { Hipertensión grado II moderada } \\
(160-179 / 100-109)\end{array}$ & 0 & 0 & 0 \\
\hline $\begin{array}{l}\text { Hipertensión grado III severa } \\
(\geq 180 / 110)\end{array}$ & 0 & 0 & 0 \\
\hline $\begin{array}{l}\text { Sistólica aislada } \\
(\geq 140 / 90)\end{array}$ & 0 & 0 & 0 \\
\hline
\end{tabular}

En esta tabla se presenta la clasificación de la población de acuerdo con sus niveles de tensión arterial con sus respectivos puntos de referencia (tensión arterial sistólica/diastólica). Se presenta la subdivisión por sexo expresada en frecuencias ( $n$ ) y porcentaje (\%) y la sumatorias correspondientes.

\subsection{Factores de riesgo de la población de estudio}

\subsubsection{Factores de riesgo no modificables}

En la tabla No.55 se presentan los antecedentes heredofamiliares de los participantes, los cuales fueron considerados como factores de riesgo no modificables en la génesis de las enfermedades cardiometabólicas.

Se puede observar que la población de estudio, refirió antecedentes heredofamiliares de padecimientos crónico- 
degenerativos presentes o como causa de muerte en los padres, abuelos y tíos, destacando en las mujeres, en orden de mayor frecuencia la HTA, la obesidad, la diabetes mellitus, la hipercolesterolemia y la hipertrigliceridemia.

En los hombres, la hipercolesterolemia, la HTA, la hipertrigliceridemia, la diabetes mellitus y la obesidad.

Tabla No.55 Antecedentes heredofamiliares de la población de estudio

\begin{tabular}{|c|c|c|c|c|c|c|}
\hline \multirow{2}{*}{$\begin{array}{c}\text { Antecedentes } \\
\text { Heredo- } \\
\text { Familiares }\end{array}$} & \multicolumn{3}{|c|}{ Sí (\%) } & \multicolumn{3}{|c|}{ No (\%) } \\
\hline & $\mathrm{H}$ & $M$ & Total & $\mathrm{H}$ & $M$ & Total \\
\hline Obesidad & $\begin{array}{c}9 \\
(18,74)\end{array}$ & $\begin{array}{c}17 \\
(35,42)\end{array}$ & $\begin{array}{c}26 \\
(54,16)\end{array}$ & $\begin{array}{c}9 \\
(18,75)\end{array}$ & $\begin{array}{c}14 \\
(29,16)\end{array}$ & $\begin{array}{c}23 \\
(47,91)\end{array}$ \\
\hline Diabetes mellitus & $\begin{array}{c}10 \\
(20,83)\end{array}$ & $\begin{array}{c}16 \\
(33,33)\end{array}$ & $\begin{array}{c}26 \\
(54,16)\end{array}$ & $\begin{array}{c}9 \\
(18,75)\end{array}$ & $\begin{array}{c}14 \\
(29,16)\end{array}$ & $\begin{array}{c}23 \\
(47,91) \\
\end{array}$ \\
\hline HTA & $\begin{array}{c}11 \\
(22,92) \\
\end{array}$ & $\begin{array}{c}20 \\
(41,66) \\
\end{array}$ & $\begin{array}{c}31 \\
(64,58) \\
\end{array}$ & $\begin{array}{c}7 \\
(14,58) \\
\end{array}$ & $\begin{array}{c}11 \\
(22,92) \\
\end{array}$ & $\begin{array}{c}18 \\
(37,50) \\
\end{array}$ \\
\hline $\begin{array}{l}\text { Hiper- } \\
\text { colesterolemia }\end{array}$ & $\begin{array}{c}11 \\
(22,92) \\
\end{array}$ & $\begin{array}{c}16 \\
(33,33) \\
\end{array}$ & $\begin{array}{c}27 \\
(56,25) \\
\end{array}$ & $\begin{array}{c}6 \\
(12,50) \\
\end{array}$ & $\begin{array}{c}15 \\
(31,25) \\
\end{array}$ & $\begin{array}{c}21 \\
(43,74) \\
\end{array}$ \\
\hline $\begin{array}{l}\text { Hipe- } \\
\text { rtrigliceridemia }\end{array}$ & $\begin{array}{c}10 \\
(20,83) \\
\end{array}$ & $\begin{array}{c}15 \\
(31,25) \\
\end{array}$ & $\begin{array}{c}25 \\
(52,08) \\
\end{array}$ & $\begin{array}{c}7 \\
(14,58) \\
\end{array}$ & $\begin{array}{c}16 \\
(33,33) \\
\end{array}$ & $\begin{array}{c}23 \\
(47,91) \\
\end{array}$ \\
\hline Cáncer & $\begin{array}{c}7 \\
(14,58)\end{array}$ & $\begin{array}{c}15 \\
(31,25)\end{array}$ & $\begin{array}{c}22 \\
(45,83)\end{array}$ & $\begin{array}{c}10 \\
(20,83)\end{array}$ & $\begin{array}{c}16 \\
(33,33)\end{array}$ & $\begin{array}{c}26 \\
(54,16)\end{array}$ \\
\hline Nefropatías & $\begin{array}{c}1 \\
(2,08) \\
\end{array}$ & $\begin{array}{c}8 \\
(16,66) \\
\end{array}$ & $\begin{array}{c}9 \\
(18,75) \\
\end{array}$ & $\begin{array}{c}16 \\
(33,33)\end{array}$ & $\begin{array}{c}23 \\
(47,92) \\
\end{array}$ & $\begin{array}{c}39 \\
(81,25) \\
\end{array}$ \\
\hline Cardiopatías & $\begin{array}{c}7 \\
(14,58) \\
\end{array}$ & $\begin{array}{c}14 \\
(29,17) \\
\end{array}$ & $\begin{array}{c}21 \\
(43,74) \\
\end{array}$ & $\begin{array}{c}11 \\
(22,92) \\
\end{array}$ & $\begin{array}{c}17 \\
(35,41) \\
\end{array}$ & $\begin{array}{c}28 \\
(58,33) \\
\end{array}$ \\
\hline Epilepsia & $\begin{array}{c}1 \\
(2,08)\end{array}$ & $\begin{array}{c}1 \\
(2,08)\end{array}$ & $\begin{array}{c}2 \\
(4,16)\end{array}$ & $\begin{array}{c}17 \\
(35,42)\end{array}$ & $\begin{array}{c}30 \\
(62,50)\end{array}$ & $\begin{array}{c}47 \\
(97,92) \\
\end{array}$ \\
\hline
\end{tabular}

En esta tabla se presentan los antecedentes heredofamiliares referidos por los participantes del estudio subdivididos por sexo. Los valores estan expresados cuantitativamente en frecuencias $(n)$ y en porcentajes (\%).

$\mathrm{H}=$ hombres, $\mathrm{M}=$ mujeres

\subsubsection{Factores de riesgo modificables}

Dentro de los factores de riesgo cardiovascular modificables que refirieron los participantes en el estudio se encuentran el consumo de tabaco o de alcohol y la falta de ejercicio físico (Tabla No.56).

Con respecto al consumo de tabaco, se puede observar que sólo el $16,7 \%$ de los participantes lo consumieron en algún momento antes de iniciar el estudio y abandonaron el hábito por motivos de salud, es decir, siguiendo las recomendaciones de su médico para disminiur el riesgo de enfermedad pulmonar; de los participantes que fumaban el $10,3 \%$ fueron hombres y el $6,4 \%$ mujeres.

En lo referente al consumo de alcohol, el $20,8 \%$ de los participantes $(12,5 \%$ hombres y $8,3 \%$ mujeres $)$ mencionaron 
consumir alcohol de manera moderada, una copa de vino con las comidas la mayor parte de los días de la semana o una o dos cervezas los fines de semana.

Es importante recalcar que estos datos fueron referidos por los participantes como antecedente ya que entre los criterios de inclusión no se aceptaba tabaquismo y alcoholismo activo, para evitar sesgos en la interpretación de los resultados de las interevenciones dietéticas y deportivas del estudio.

Tabla No.56 Consumo de tabaco y alcohol y práctica de ejercicio físico de la población de estudio por intervención

\begin{tabular}{|c|c|c|c|c|c|c|}
\hline \multirow[b]{2}{*}{ Intervención } & \multicolumn{2}{|c|}{ Tabaco (\%) } & \multicolumn{2}{|c|}{ Alcohol (\%) } & \multicolumn{2}{|c|}{ Ejercicio físico (\%) } \\
\hline & Sí & No & Sí & No & Sí & No \\
\hline $\begin{array}{l}\text { Dieta estándar } \\
\text { sin ejercicio } \\
\text { físico }\end{array}$ & 0 & $\begin{array}{c}10 \\
(20,83)\end{array}$ & $\begin{array}{c}2 \\
(4,16)\end{array}$ & $\begin{array}{c}8 \\
(16,66)\end{array}$ & $\begin{array}{c}3 \\
(6,25)\end{array}$ & $\begin{array}{c}7 \\
\left(14,5^{8}\right)\end{array}$ \\
\hline $\begin{array}{l}\text { Dieta estándar } \\
\text { con ejercicio } \\
\text { físico }\end{array}$ & $\begin{array}{c}5 \\
(10,42 \\
)\end{array}$ & $\begin{array}{c}8 \\
(16,66)\end{array}$ & $\begin{array}{c}3 \\
(6,25)\end{array}$ & $\begin{array}{c}10 \\
(20.83)\end{array}$ & $\begin{array}{c}7 \\
(14,58)\end{array}$ & $\begin{array}{c}7 \\
\left(14,5^{8}\right)\end{array}$ \\
\hline $\begin{array}{l}\text { Dieta rica en } \\
\text { licopeno sin } \\
\text { ejercicio físico }\end{array}$ & $\begin{array}{c}1 \\
(2,08)\end{array}$ & $\begin{array}{c}11 \\
(22,92)\end{array}$ & $\begin{array}{c}2 \\
(4,16)\end{array}$ & $\begin{array}{c}10 \\
(20,83)\end{array}$ & $\begin{array}{c}2 \\
(4,16)\end{array}$ & $\begin{array}{c}10 \\
(20,83)\end{array}$ \\
\hline $\begin{array}{l}\text { Dieta rica en } \\
\text { licopeno con } \\
\text { ejercicio físico }\end{array}$ & $\begin{array}{c}2 \\
(4,16)\end{array}$ & $\begin{array}{c}11 \\
(22,92)\end{array}$ & $\begin{array}{c}3 \\
(6,25)\end{array}$ & $\begin{array}{c}10 \\
(20,83)\end{array}$ & $\begin{array}{c}3 \\
(6,25)\end{array}$ & $\begin{array}{c}10 \\
(20,83)\end{array}$ \\
\hline
\end{tabular}

En esta tabla se muestran los factores de riego modificable por intervención, expresados en frecuencias $(n)$ y porcentajes (\%).

Otro importante factor de riesgo para el desarrollo de las enfermedades cardiometabolicas es la falta de práctica de ejercicio físico; pese a que existe mucha información sobre los efectos benéficos del ejercicio físico en la salud cardiovascular, y el empeño de los profesionistas de las instituciones de salud por prescribirlo, sólo un porcentaje reducido de la población que participó en la investigación (31,2\%), afirmó durante la aplicación de la historia clínica, que realizaba ejercicio en algún momento antes del estudio. Las actividades que mencionaron haber realizado son caminar, realizar una rutina de ejercicio en el gimnasio, realizar una rutina de pesas, zumba, natación y futbol.

\section{5·5.3. Padecimientos de la población de estudio}

A través de la historia clínica, se identificaron también los padecimientos que los participantes en el estudio han presentado, algunas enfermedades son crónicas y se encuentran ya diagnosticados y con tratamiento como gastritis, estreñimiento, obesidad, colon irritable; mientras que otras, fueron hallazgos 
encontrados a través de los estudios de laboratorio y gabinete que se realizaron como parte de la metodología de la investigación como sucedió con la hipoalfalipoproteinemia y la HTA.

Además de hipercolesterolemia $(60,4 \%)$ e hipertrigliceridemia $(54,2 \%)$, que eran condición para ingresar al estudio, se encontraron en mayor porcentaje otros padecimientos como fueron gastritis, alergia a medicamentos, colon irritable y obesidad en los hombres y gastritis, estreñimiento, colon irritable e intolerancia a los alimentos en las mujeres (Tabla No.57).

Tabla No.57 Padecimientos de la población de estudio

\begin{tabular}{|c|c|c|c|c|c|c|}
\hline \multirow[b]{2}{*}{ Padecimientos } & \multicolumn{3}{|c|}{ Sí(\%) } & \multicolumn{3}{|c|}{ No (\%) } \\
\hline & $\mathrm{H}$ & M & Total & $\mathrm{H}$ & M & Total \\
\hline Gastritis & $\begin{array}{c}5 \\
(10,42) \\
\end{array}$ & $\begin{array}{c}11 \\
(22,92) \\
\end{array}$ & $\begin{array}{c}16 \\
(33,33)\end{array}$ & $\begin{array}{c}13 \\
(27,08) \\
\end{array}$ & $\begin{array}{c}20 \\
(41,67) \\
\end{array}$ & $\begin{array}{c}33 \\
(68,75)\end{array}$ \\
\hline Hipertrigliceridemia & $\begin{array}{c}12 \\
(25,00) \\
\end{array}$ & $\begin{array}{c}14 \\
(29,17) \\
\end{array}$ & $\begin{array}{c}26 \\
(54,16)\end{array}$ & $\begin{array}{c}6 \\
(12,50) \\
\end{array}$ & $\begin{array}{c}17 \\
(35,42)\end{array}$ & $\begin{array}{c}23 \\
(47,92) \\
\end{array}$ \\
\hline Cáncer & 0 & $\begin{array}{c}1 \\
(2,08)\end{array}$ & $\begin{array}{c}1 \\
(2,08)\end{array}$ & $\begin{array}{c}18 \\
(37,50)\end{array}$ & $\begin{array}{c}30 \\
(62,50) \\
\end{array}$ & $\begin{array}{c}48 \\
(100) \\
\end{array}$ \\
\hline Colon irritable & $\begin{array}{c}4 \\
(8,33) \\
\end{array}$ & $\begin{array}{c}9 \\
(18,75)\end{array}$ & $\begin{array}{c}13 \\
(27,08) \\
\end{array}$ & $\begin{array}{c}14 \\
(29,16) \\
\end{array}$ & $\begin{array}{c}22 \\
(45,83) \\
\end{array}$ & $\begin{array}{c}36 \\
(75,00) \\
\end{array}$ \\
\hline Obesidad & $\begin{array}{c}3 \\
(6,25) \\
\end{array}$ & $\begin{array}{c}2 \\
(4,16) \\
\end{array}$ & $\begin{array}{c}5 \\
(10,42) \\
\end{array}$ & $\begin{array}{c}15 \\
(31,25)\end{array}$ & $\begin{array}{c}29 \\
(60,42) \\
\end{array}$ & $\begin{array}{c}44 \\
(91,66) \\
\end{array}$ \\
\hline Estreñimiento & $\begin{array}{c}2 \\
(4,16)\end{array}$ & $\begin{array}{c}11 \\
(22,92)\end{array}$ & $\begin{array}{c}13 \\
(27,08)\end{array}$ & $\begin{array}{c}16 \\
(33,33)\end{array}$ & $\begin{array}{c}20 \\
(41,67) \\
\end{array}$ & $\begin{array}{c}36 \\
(75,00)\end{array}$ \\
\hline HTA & $\begin{array}{c}3 \\
(6,25) \\
\end{array}$ & $\begin{array}{c}4 \\
(8,33) \\
\end{array}$ & $\begin{array}{c}7 \\
(14,58) \\
\end{array}$ & $\begin{array}{c}15 \\
(31,25) \\
\end{array}$ & $\begin{array}{c}27 \\
(56,25) \\
\end{array}$ & $\begin{array}{c}42 \\
(87,50)\end{array}$ \\
\hline Hipercolesterolemia & $\begin{array}{c}9 \\
(18,75)\end{array}$ & $\begin{array}{c}20 \\
(41,67)\end{array}$ & $\begin{array}{c}29 \\
(60,42)\end{array}$ & $\begin{array}{c}9 \\
(18,75)\end{array}$ & $\begin{array}{c}11 \\
(22,92)\end{array}$ & $\begin{array}{c}20 \\
(41,67)\end{array}$ \\
\hline Alergia a alimentos & $\begin{array}{c}2 \\
(4,16) \\
\end{array}$ & 0 & $\begin{array}{c}2 \\
(4,16) \\
\end{array}$ & $\begin{array}{c}16 \\
(33,33) \\
\end{array}$ & $\begin{array}{c}31 \\
(64,58) \\
\end{array}$ & $\begin{array}{c}47 \\
(97,92) \\
\end{array}$ \\
\hline $\begin{array}{l}\text { Alergia a } \\
\text { medicamentos }\end{array}$ & $\begin{array}{c}5 \\
(10,42)\end{array}$ & $\begin{array}{c}6 \\
(12,50)\end{array}$ & $\begin{array}{c}11 \\
(22,92)\end{array}$ & $\begin{array}{c}13 \\
(27,08)\end{array}$ & $\begin{array}{c}25 \\
(52,08)\end{array}$ & $\begin{array}{c}38 \\
(79,17)\end{array}$ \\
\hline $\begin{array}{l}\text { Intolerancia a } \\
\text { alimentos }\end{array}$ & $\begin{array}{c}2 \\
(4,16)\end{array}$ & $\begin{array}{c}8 \\
(16,66)\end{array}$ & $\begin{array}{c}10 \\
(20,83)\end{array}$ & $\begin{array}{c}16 \\
(33,33)\end{array}$ & $\begin{array}{c}23 \\
(47,92)\end{array}$ & $\begin{array}{c}39 \\
(81,25)\end{array}$ \\
\hline
\end{tabular}

$\mathrm{H}=$ hombres, $\mathrm{M}=$ mujeres

\subsection{Efecto de la intervención}

A continuación se presentan los estadísticos descriptivos de cada indicador del perfil de lípidos asociado a la dislipemia y el porcentaje de grasa corporal de acuerdo a los grupos de estudio después de 12 semanas de intervención. Se presentan primero los valores estadísticos descriptivos de la media y la desviación estándar. Después se presentan las gráficas para la demostración del comportamiento de cada indicador con respecto a cada grupo; posteriormente se exponen los valores del análisis de varianza (ANOVA) para demostrar la significación y por último los resultados 
de la prueba post hoc deTukey para identificar las diferencias entre grupos.

\subsubsection{Colesterol (CL)}

El CL es uno de los indicadores del perfil de lípidos que tiene más repercusiones sobre las dislipemias y junto con las LDL es uno de los blancos tanto del tratamiento farmacológico como del no farmacológico.

Se puede destacar (Tabla No.58) que en el presente estudio se encontró mayor diminución de las medias de $\mathrm{CL}$ entre la determinación previa y posterior a la intervención en los participantes tratados con dieta rica en licopeno en comparación con los participantes tratados con dieta estándar.

Tabla No.58 Medias de los niveles de colesterol ( $\mathrm{mg} / \mathrm{dL}$ ) de la población previa y posterior a la intervención por grupos de tratamiento y sus diferencias post-pre

\begin{tabular}{|c|c|c|c|c|}
\hline Grupo & & $\begin{array}{c}\text { Colesterol } \\
\text { Pre } \\
(\mathrm{mg} / \mathrm{dL})\end{array}$ & $\begin{array}{c}\text { Colesterol } \\
\text { Post } \\
(\mathrm{mg} / \mathrm{dL})\end{array}$ & $\begin{array}{c}\text { Diferencia } \\
\text { Post-pre } \\
\text { (mg/dL) }\end{array}$ \\
\hline $\begin{array}{l}\text { Dieta estándar sin } \\
\text { ejercicio físico }\end{array}$ & $\begin{array}{l}\text { Media } \\
\mathrm{n} \\
D . E .\end{array}$ & $\begin{array}{c}210,67 \\
10 \\
39,01\end{array}$ & $\begin{array}{c}204,10 \\
10 \\
44,67\end{array}$ & $-6,57$ \\
\hline $\begin{array}{l}\text { Dieta estándar con } \\
\text { ejercicio físico }\end{array}$ & $\begin{array}{l}\text { Media } \\
\mathrm{n} \\
D . E .\end{array}$ & $\begin{array}{c}230,19 \\
13 \\
37,44 \\
\end{array}$ & $\begin{array}{c}232,89 \\
13 \\
37,14 \\
\end{array}$ & $+2,70$ \\
\hline $\begin{array}{l}\text { Dieta rica en } \\
\text { licopeno } \\
\text { sin ejercicio físico }\end{array}$ & $\begin{array}{l}\text { Media } \\
\mathrm{n} \\
D . E .\end{array}$ & $\begin{array}{c}224,31 \\
12 \\
42,60\end{array}$ & $\begin{array}{c}213,94 \\
12 \\
33,13\end{array}$ & $-10,37$ \\
\hline $\begin{array}{l}\text { Dieta rica en } \\
\text { licopeno } \\
\text { con ejercicio físico }\end{array}$ & $\begin{array}{l}\text { Media } \\
\mathrm{n} \\
D . E\end{array}$ & $\begin{array}{c}221,30 \\
13 \\
33,68\end{array}$ & $\begin{array}{c}198,40 \\
13 \\
28,59\end{array}$ & $-22,90$ \\
\hline
\end{tabular}

D.E.= desviación estándar

El grupo tratado con dieta estándar sin ejercicio físico disminuyó sus valores un $3,1 \%(6,57 \mathrm{mg} / \mathrm{dL})$ entre la primera y la segunda determinación de $\mathrm{CL}$, mientra que el grupo con dieta estándar que si realizó ejercicio presentó un incremento de 1,2\% (2,70 mg/dL).

El grupo tratado con dieta rica en licopeno sin ejercicio físico presentó disminución en la media de $C \mathrm{~L}$ del 4,6\% (10,37 mg/dL), mientras el grupo tratado con dieta rica en licopeno con ejercicio físico fue el que presentó la mayor disminución entre las medias post 
y pre intervención con un $10,4 \%(22,90 \mathrm{mg} / \mathrm{dL})$ de reducción en los valores de CL. (Ver figura No.15).

\subsubsection{Lipoproteínas de alta densidad (HDL)}

La tabla No.59 muestra los niveles de HDL que presentó la población del estudio en las determinaciones previa y posterior a la intervención.

Tabla No.59 Medias de los niveles de HDL $(\mathrm{mg} / \mathrm{dL}$ ) de la población previa y posterior a la intervención por grupos de tratamiento y sus diferencias post-

$$
\text { pre }
$$

\begin{tabular}{|c|c|c|c|c|}
\hline \multicolumn{2}{|l|}{ Grupo } & $\begin{array}{c}\text { HDL } \\
\text { Pre } \\
\text { (mg/dL) }\end{array}$ & $\begin{array}{c}\text { HDL } \\
\text { Post } \\
\text { (mg/dL) }\end{array}$ & $\begin{array}{c}\text { Diferencia } \\
\text { Post-pre } \\
\text { (mg/dL) }\end{array}$ \\
\hline $\begin{array}{l}\text { Dieta estándar sin } \\
\text { ejercicio físico }\end{array}$ & $\begin{array}{l}\text { Media } \\
\mathrm{n} \\
\text { D.E. }\end{array}$ & $\begin{array}{c}44,55 \\
10 \\
14,30 \\
\end{array}$ & $\begin{array}{c}46,39 \\
10 \\
13,97 \\
\end{array}$ & $+1,84$ \\
\hline $\begin{array}{l}\text { Dieta estándar con } \\
\text { ejercicio físico }\end{array}$ & $\begin{array}{l}\text { Media } \\
\mathrm{n} \\
\text { D.E. }\end{array}$ & $\begin{array}{c}46,73 \\
13 \\
18,92\end{array}$ & $\begin{array}{c}47,60 \\
13 \\
17,28\end{array}$ & $+0,87$ \\
\hline $\begin{array}{l}\text { Dieta rica en } \\
\text { licopeno } \\
\text { sin ejercicio físico }\end{array}$ & $\begin{array}{l}\text { Media } \\
\mathrm{n} \\
\text { D.E. }\end{array}$ & $\begin{array}{c}49,46 \\
12 \\
18,51\end{array}$ & $\begin{array}{c}53,29 \\
12 \\
18,20\end{array}$ & $+3,83$ \\
\hline $\begin{array}{l}\text { Dieta rica en } \\
\text { licopeno } \\
\text { con ejercicio físico }\end{array}$ & $\begin{array}{l}\text { Media } \\
\mathrm{n} \\
D . E .\end{array}$ & $\begin{array}{c}49,39 \\
13 \\
16,04\end{array}$ & $\begin{array}{c}52,01 \\
13 \\
13,88\end{array}$ & $+2,62$ \\
\hline
\end{tabular}

D.E.= desviación estándar.

Estudios epidemiológicos han demostrado que las concentraciones altas de HDL (superiores a $60 \mathrm{mg} / \mathrm{dL}$ ) tienen un efecto protector contra las enfermedades cardiovasculares, debido a que puede retirar el $C L$ de las arterias y trasportarlo de regreso al hígado para ser reutilizado, pero cuando los niveles de HDL se encuentran por debajo de $35 \mathrm{mg} / \mathrm{dL}$ se presenta riesgo a padecer dichas enfermedades, sobre todo en las mujeres.

En la presente investigación se detectó un leve incremento en las medias de HDL en los cuatro grupos de estudio, mayor en los dos grupos tratados con dieta rica en licopeno.

En los grupos tratados con dieta estándar, cuando los participantes no realizaron ejercicio físico se encontró un incremento del $4,1 \%(1,84 \mathrm{mg} / \mathrm{dL})$ de HDL. En el grupo con dieta estándar que realizó ejercicio físico, el incremento de HDL fue menor, de un 1,9\% $(0,87 \mathrm{mg} / \mathrm{dL})$. En los grupos tratados con dieta rica en licopeno sin 
ejercicio, el incremento de HDL fue de $7,7 \%(3,83 \mathrm{mg} / \mathrm{dL})$, mientras en el grupo tratado con dieta rica en licopeno que si realizó ejercicio incrementó sus valores un 5,3\% (2,62 mg/dL).

En la figura No. 14 se puede apreciar las diferencias entre los cuatro grupos de tratamiento.

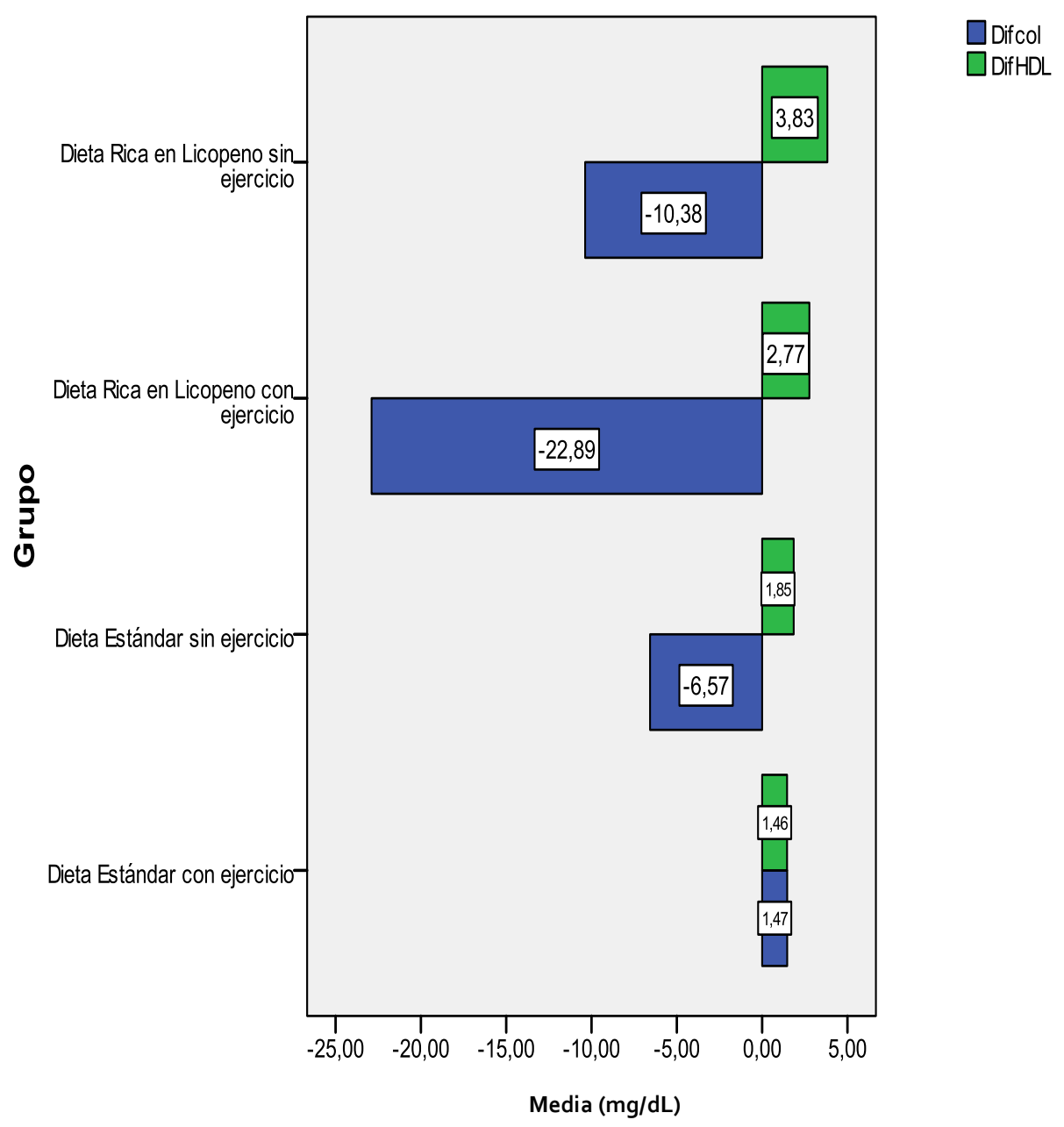

Figura No.14 Diferencia post-pre de las medias de los niveles de colesterol y HDL $(\mathrm{mg} / \mathrm{dL})$ de la población de estudio por grupos de tratamiento

Es interesante observar que en los grupos con dieta estándar y con dieta rica en licopeno cuando los participantes no realizaron ejercicio físico, el incremento en los niveles de HDL fue mayor en comparación con los participantes que hicieron ejercicio físico. 


\subsubsection{Triglicéridos (TG)}

En cuanto al indicador TG, en la tabla No.6o se presenta el comportamiento de este lípido en los cuatro grupos tratamiento previo y posterior a la intervención en la población de estudio.

Tabla No.6o Medias de los niveles de triglicéridos $(\mathrm{mg} / \mathrm{dL}$ ) de la población previa y posterior a la intervención por grupos de tratamiento y sus diferencias post-pre

\begin{tabular}{|c|c|c|c|c|}
\hline Grupo & & $\begin{array}{c}\text { Triglicéridos } \\
\text { Pre } \\
\text { (mg/dL) }\end{array}$ & $\begin{array}{c}\text { Triglicéridos } \\
\text { Post } \\
\text { (mg/dL) }\end{array}$ & $\begin{array}{c}\text { Diferencia } \\
\text { Post-pre } \\
(\mathrm{mg} / \mathrm{dL})\end{array}$ \\
\hline $\begin{array}{l}\text { Dieta estándar sin } \\
\text { ejercicio físico }\end{array}$ & $\begin{array}{l}\text { Media } \\
\mathrm{n} \\
D . E .\end{array}$ & $\begin{array}{c}166,77 \\
10 \\
50,31\end{array}$ & $\begin{array}{c}157,5^{8} \\
10 \\
51,76\end{array}$ & $-9,19$ \\
\hline $\begin{array}{l}\text { Dieta estándar con } \\
\text { ejercicio físico }\end{array}$ & $\begin{array}{l}\text { Media } \\
\mathrm{n} \\
D . E .\end{array}$ & $\begin{array}{c}213,42 \\
13 \\
135,26\end{array}$ & $\begin{array}{c}200,98 \\
13 \\
112,79\end{array}$ & $-12,44$ \\
\hline $\begin{array}{l}\text { Dieta rica en } \\
\text { licopeno } \\
\text { sin ejercicio físico }\end{array}$ & $\begin{array}{l}\text { Media } \\
\mathrm{n} \\
D . E .\end{array}$ & $\begin{array}{c}187,72 \\
12 \\
79,96 \\
\end{array}$ & $\begin{array}{c}169,07 \\
12 \\
70,18 \\
\end{array}$ & $-18,65$ \\
\hline $\begin{array}{l}\text { Dieta rica en } \\
\text { licopeno } \\
\text { con ejercicio físico }\end{array}$ & $\begin{array}{l}\text { Media } \\
\mathrm{n} \\
D . E \text {. }\end{array}$ & $\begin{array}{c}183,87 \\
13 \\
86,76\end{array}$ & $\begin{array}{c}163,90 \\
13 \\
76,10\end{array}$ & $-19,97$ \\
\hline
\end{tabular}

D.E.= desviación estándar.

De acuerdo con los resultados los valores de TG fueron más reducidos en la determinación posterior a la intervención en los participantes de los cuatro grupos; sin embargo, la reducción fue mayor en aquellos que fueron tratados con dieta rica en licopeno en comparación con los participantes tratados con dieta estándar.

El grupo que fue tratado con dieta estándar sin ejercicio físico disminuyó un $5,5 \%(9,19 \mathrm{mg} / \mathrm{dL})$ los niveles de TG entre la segunda y primera determinación, mientras que el grupo tratado con dieta estándar que si realizó ejercicio disminuyó sus valores un 5,8\% (12,44 $\mathrm{mg} / \mathrm{dL}$ ). Se podría decir que el efecto de la dieta estándar se incrementó con la inclusión del ejercicio físico en el tratamiento.

Los grupos tratados con dieta rica en licopeno presentaron disminuciones similares: el grupo sin ejercicio físico mostró una reducción del $9,9 \%(18,65 \mathrm{mg} / \mathrm{dL})$ y el grupo tratado con dieta rica en licopeno con ejercicio físico fue el que presentó la mayor disminución, de un 10,9\% (19,97 mg/dL) de TG. (Ver figura No.15). 


\subsubsection{Lipoproteínas de baja densidad (LDL)}

En la tabla No. 61 se presenta el comportamiento de las LDL antes y después de la intervención.

Tabla No.61 Medias de los niveles de LDL $(\mathrm{mg} / \mathrm{dL})$ de la población previa y posterior a la intervención por grupos de tratamiento y sus diferencias post-

$$
\text { pre }
$$

\begin{tabular}{|c|c|c|c|c|}
\hline Grupo & & $\begin{array}{c}\text { LDL } \\
\text { Pre } \\
\text { (mg/dL) }\end{array}$ & $\begin{array}{c}\text { LDL } \\
\text { Post } \\
\text { (mg/dL) }\end{array}$ & $\begin{array}{c}\text { Diferencia } \\
\text { Post-pre } \\
\text { (mg/dL) }\end{array}$ \\
\hline $\begin{array}{l}\text { Dieta estándar sin } \\
\text { ejercicio físico }\end{array}$ & $\begin{array}{l}\text { Media } \\
\mathrm{n} \\
\text { D.E. }\end{array}$ & $\begin{array}{c}134,61 \\
10 \\
26,46 \\
\end{array}$ & $\begin{array}{c}127,54 \\
10 \\
30,46\end{array}$ & $-7,07$ \\
\hline $\begin{array}{l}\text { Dieta estándar con } \\
\text { ejercicio físico }\end{array}$ & $\begin{array}{l}\text { Media } \\
\mathrm{n} \\
\text { D.E. }\end{array}$ & $\begin{array}{c}135,75 \\
13 \\
35,62\end{array}$ & $\begin{array}{c}152,23 \\
13 \\
42,85\end{array}$ & 16,48 \\
\hline $\begin{array}{l}\text { Dieta rica en } \\
\text { licopeno } \\
\text { sin ejercicio físico }\end{array}$ & $\begin{array}{l}\text { Media } \\
\mathrm{n} \\
\text { D.E. }\end{array}$ & $\begin{array}{c}128,54 \\
12 \\
30,30 \\
\end{array}$ & $\begin{array}{c}122,83 \\
12 \\
22,55 \\
\end{array}$ & $-5,71$ \\
\hline $\begin{array}{l}\text { Dieta rica en } \\
\text { licopeno } \\
\text { con ejercicio físico }\end{array}$ & $\begin{array}{l}\text { Media } \\
\mathrm{n} \\
D . E .\end{array}$ & $\begin{array}{c}136,09 \\
13 \\
33,58\end{array}$ & $\begin{array}{c}124,02 \\
13 \\
26,96\end{array}$ & $-12,07$ \\
\hline
\end{tabular}

D.E. = desviación estándar

Las lipoproteínas de baja densidad son las que más efectos nocivos producen en el sistema circulatorio cuando se encuentran aumentadas, debido a que se depositan en la capa íntima de las arterias donde son detenidas para ser oxidadas, favoreciendo los procesos inflamatorios y transformándose gracias a la acción de los macrófagos en la placa aterosclerótica causante de eventos cardiovasculares.

La dietoterapia y la farmacoterapia consideran a las LDL como uno de los factores de las dilipemias más difíciles de modificar, de ahí la importancia de buscar alternativas para su adecuado manejo.

Los resultados muestran que el grupo tratado con dieta estándar sin ejercicio físico presentó una disminución del 5,3\% (7,07 mg/dL); en contraste, el grupo tratado con dieta estándar con ejercicio presentó un incremento importante del 12,4\% (16,48 mg/dL).

En los grupos tratados con dieta rica en licopeno, cuando los participantes no realizaron ejercicio físico, se encontró una disminución del 4,4\% (5,71 mg/dL). 
En el grupo tratado con dieta rica en licopeno y ejercicio físico, la disminución de LDL fue mayor, de un $8,9 \%(12,07 \mathrm{mg} / \mathrm{dL})$, como se puede observar en la figura No. 15.

\subsubsection{Porcentaje de grasa corporal (PGC)}

El porcentaje de grasa corporal se utiliza para conocer la composición corporal de los individuos y el estado de nutrición y es un predictor de riesgo de padecer enfermedades cardiometabólicas. Se puede apreciar tras la intervención (Tabla No.62) una disminución en los valores de los cuatro grupos de estudio, mayor en los grupos tratados con dieta rica en licopeno.

Tabla No.62 Medias de porcentaje de grasa corporal (puntos porcentuales) de la población previa y posterior a la intervención por grupos de tratamiento y sus diferencias post-pre

\begin{tabular}{|c|c|c|c|c|}
\hline Grupo & & $\begin{array}{c}\text { Porcentaje de } \\
\text { grasa corporal } \\
\text { Pre } \\
\text { (Puntos } \\
\text { porcentuales) }\end{array}$ & $\begin{array}{c}\text { Porcentaje de } \\
\text { grasa corporal } \\
\text { Post } \\
\text { (Puntos } \\
\text { porcentuales) }\end{array}$ & \begin{tabular}{|c|} 
Diferencia \\
Post-pre \\
(Puntos \\
porcentuales)
\end{tabular} \\
\hline $\begin{array}{l}\text { Dieta estándar sin } \\
\text { ejercicio físico }\end{array}$ & $\begin{array}{l}\text { Media } \\
\mathrm{n} \\
D . E .\end{array}$ & $\begin{array}{c}35,91 \\
10 \\
4,75 \\
\end{array}$ & $\begin{array}{c}37,03 \\
10 \\
4,72 \\
\end{array}$ & $-1,12$ \\
\hline $\begin{array}{l}\text { Dieta estándar con } \\
\text { ejercicio físico }\end{array}$ & $\begin{array}{l}\text { Media } \\
\mathrm{n} \\
D . E .\end{array}$ & $\begin{array}{c}33,56 \\
13 \\
5,87 \\
\end{array}$ & $\begin{array}{c}35,12 \\
13 \\
6,51 \\
\end{array}$ & $-1,56$ \\
\hline $\begin{array}{l}\text { Dieta rica en } \\
\text { licopeno } \\
\text { sin ejercicio físico }\end{array}$ & $\begin{array}{l}\text { Media } \\
\mathrm{n} \\
D . E .\end{array}$ & $\begin{array}{c}34,76 \\
12 \\
11,29 \\
\end{array}$ & $\begin{array}{c}36,21 \\
12 \\
11,47 \\
\end{array}$ & $-1,45$ \\
\hline $\begin{array}{l}\text { Dieta rica en } \\
\text { licopeno } \\
\text { con ejercicio físico }\end{array}$ & $\begin{array}{l}\text { Media } \\
\mathrm{n} \\
D . E .\end{array}$ & $\begin{array}{c}32,80 \\
13 \\
6,49\end{array}$ & $\begin{array}{c}35,18 \\
13 \\
6,72\end{array}$ & $-2,38$ \\
\hline
\end{tabular}

D.E.= desviación estándar.

Cuando los participantes no realizaron ejercicio, la disminución de PGC fue del $4,0 \%$ ( 1,45 puntos porcentuales), a diferencia del 6,8\% (2,38 puntos porcentuales) con ejercicio físico. 


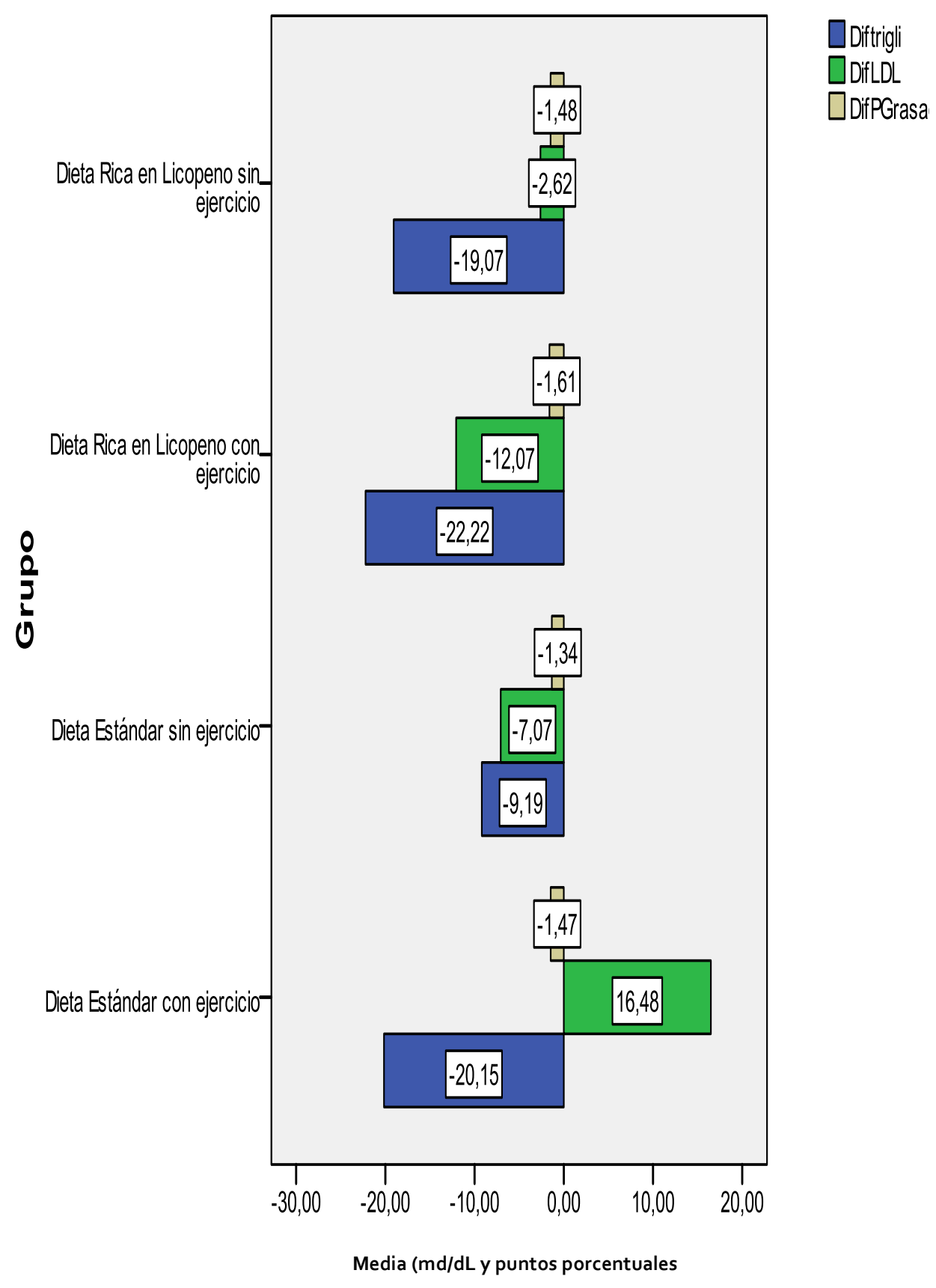

Figura No.15 Diferencia post-pre de las medias de los niveles de triglicéridos, LDL (mg/dL) y porcentaje de grasa corporal (puntos porcentuales) de la población de estudio por grupos de tratamiento 
En la tabla No. 63 se presentan los resultados del análisis de varianza (ANOVA) para las diferencias de medias post-pre de todas las variables del estudio.

Se puede observar que existen diferencias significativas en las medias de las variables CL y LDL.

Tabla No. 63 Resultado del análisis de varianza (ANOVA) para las difererencias de medias post-pre de las variables del estudio.

\begin{tabular}{|l|c|c|c|}
\hline \multicolumn{1}{|c|}{ Variable } & $\begin{array}{c}\text { Diferencia de } \\
\text { medias }\end{array}$ & $\boldsymbol{F}$ & $\boldsymbol{p}$ \\
\hline Colesterol (mg/dL) & 1563,78 & 5,150 & 0,004 \\
\hline Triglicéridos (mg/dL) & 360,25 & 0,268 & 0,848 \\
\hline $\mathrm{HDL}(\mathrm{mg} / \mathrm{dL})$ & 13,41 & 0,533 & 0,662 \\
\hline LDL (mg/dL) & 1988,90 & 8,219 & 0,001 \\
\hline $\begin{array}{l}\text { Porcentaje de grasa } \\
\text { corporal (puntos } \\
\text { porcentuales) }\end{array}$ & 0,136 & 0,032 & 0,992 \\
\hline
\end{tabular}

$\mathrm{F}=$ estadístico de prueba de Fisher

Para identificar entre que grupos se han producido las diferencias entre las medias se utilizó la prueba post hoc de Tukey para las variables colesterol y LDL.

En la tabla No. 64 se observa que los grupos que fueron tratados con dieta estándar sin ejercicio físico y con dieta rica en licopeno sin ejercicio físico no presentaron diferencias en sus medias con los demás grupos en la variable $\mathrm{CL}$.

Sin embargo, los grupos que fueron tratados con dieta estándar con ejercicio físico y dieta rica en licopeno con ejercicio físico presentaron diferencia significativa en sus medias de CL entre ellos.

Los resultados ponen en evidencia el efecto significativo de la dieta rica en licopeno sobre los niveles de colesterol cuando se combina con la práctica de ejercicio físico. 
Tabla No. 64 Comparación de las difererencias de medias entre grupos para la variable CL (post hoc de Tukey)

\begin{tabular}{|c|c|c|c|}
\hline Grupo & $\begin{array}{c}\text { Grupos de } \\
\text { comparación }\end{array}$ & $\begin{array}{c}\text { Media de la } \\
\text { diferencia } \\
\text { entre grupos }\end{array}$ & $p$ \\
\hline \multirow[t]{3}{*}{$\begin{array}{l}\text { Dieta estándar sin } \\
\text { ejercicio físico }\end{array}$} & $\begin{array}{l}\text { Dieta estándar con } \\
\text { ejercicio físico }\end{array}$ & $-10,28$ & 0,504 \\
\hline & $\begin{array}{l}\text { Dieta rica en licopeno } \\
\text { sin ejercicio físico }\end{array}$ & 3,80 & 0,132 \\
\hline & $\begin{array}{l}\text { Dieta rica en licopeno } \\
\text { con ejercicio físico }\end{array}$ & 16,32 & 0,956 \\
\hline \multirow[t]{3}{*}{$\begin{array}{l}\text { Dieta estándar con } \\
\text { ejercicio físico }\end{array}$} & $\begin{array}{l}\text { Dieta estándar sin } \\
\text { ejercicio físico }\end{array}$ & 10,28 & 0,504 \\
\hline & $\begin{array}{l}\text { Dieta rica en licopeno } \\
\text { sin ejercicio físico }\end{array}$ & 14,09 & 0,196 \\
\hline & $\begin{array}{l}\text { Dieta rica en licopeno } \\
\text { con ejercicio físico }\end{array}$ & 26,60 & 0,002 \\
\hline \multirow{3}{*}{$\begin{array}{l}\text { Dieta rica en } \\
\text { licopeno sin } \\
\text { ejercicio físico }\end{array}$} & $\begin{array}{l}\text { Dieta estándar sin } \\
\text { ejercicio físico }\end{array}$ & $-3,80$ & 0,956 \\
\hline & $\begin{array}{l}\text { Dieta estándar con } \\
\text { ejercicio físico }\end{array}$ & $-14,09$ & 0,196 \\
\hline & $\begin{array}{l}\text { Dieta rica en licopeno } \\
\text { con ejercicio físico }\end{array}$ & 12,51 & 0,290 \\
\hline \multirow{3}{*}{$\begin{array}{l}\text { Dieta rica en } \\
\text { licopeno con } \\
\text { ejercicio físico }\end{array}$} & $\begin{array}{l}\text { Dieta estándar sin } \\
\text { ejercicio físico }\end{array}$ & $-16,32$ & 0,132 \\
\hline & $\begin{array}{l}\text { Dieta estándar con } \\
\text { ejercicio físico }\end{array}$ & $-26,60$ & 0,002 \\
\hline & $\begin{array}{l}\text { Dieta rica en licopeno } \\
\text { sin ejercicio físico }\end{array}$ & $-12,51$ & 0,290 \\
\hline
\end{tabular}

En lo que se refiere a la variable LDL, la Tabla No.65 se puede observar que existen diferencias significativas entre el grupo tratado con dieta estándar con ejercico físico y todos los demás grupos: dieta estándar sin ejercicio físico dieta rica en licopeno sin ejercicio físico y dieta rica en licopeno con ejercicio físico.

Los resultados dan cuenta de que la dieta estándar tuvo efecto significativo en los niveles de LDL en el grupo que realizó ejercicio físico.

Por otro lado la dieta rica en licopeno presentó efectos significativos sobre los niveles de LDL cuando los participantes no practicaron ejercicio físico y cuando sí practicaron ejercicio físico. 
Tabla No. 65 Comparación de las difererencias de medias entre grupos para la variable LDL (post hoc de Tukey)

\begin{tabular}{|c|c|c|c|}
\hline Grupo & $\begin{array}{c}\text { Grupos de } \\
\text { comparación }\end{array}$ & $\begin{array}{c}\text { Media de la } \\
\text { diferencia } \\
\text { entre grupos }\end{array}$ & $p$ \\
\hline \multirow[t]{3}{*}{$\begin{array}{l}\text { Dieta estándar sin } \\
\text { ejercicio físico }\end{array}$} & $\begin{array}{l}\text { Dieta estándar con } \\
\text { ejercicio físico }\end{array}$ & $-23,55$ & 0,004 \\
\hline & $\begin{array}{l}\text { Dieta rica en licopeno } \\
\text { sin ejercicio físico }\end{array}$ & $-4,45$ & 0,908 \\
\hline & $\begin{array}{l}\text { Dieta rica en licopeno } \\
\text { con ejercicio físico }\end{array}$ & 4,99 & 0,870 \\
\hline \multirow[t]{3}{*}{$\begin{array}{l}\text { Dieta estándar con } \\
\text { ejercicio físico }\end{array}$} & $\begin{array}{l}\text { Dieta estándar sin } \\
\text { ejercicio físico }\end{array}$ & 23,55 & 0,004 \\
\hline & $\begin{array}{l}\text { Dieta rica en licopeno } \\
\text { sin ejercicio físico }\end{array}$ & 19,10 & 0,019 \\
\hline & $\begin{array}{l}\text { Dieta rica en licopeno } \\
\text { con ejercicio físico }\end{array}$ & 28,55 & 0,001 \\
\hline \multirow{3}{*}{$\begin{array}{l}\text { Dieta rica en } \\
\text { licopeno sin } \\
\text { ejercicio físico }\end{array}$} & $\begin{array}{l}\text { Dieta estándar sin } \\
\text { ejercicio físico }\end{array}$ & 4,45 & 0,908 \\
\hline & $\begin{array}{l}\text { Dieta estándar con } \\
\text { ejercicio físico }\end{array}$ & $-19,10$ & 0,019 \\
\hline & $\begin{array}{l}\text { Dieta rica en licopeno } \\
\text { con ejercicio físico }\end{array}$ & 9,45 & 0,436 \\
\hline \multirow{3}{*}{$\begin{array}{l}\text { Dieta rica en } \\
\text { licopeno con } \\
\text { ejercicio físico }\end{array}$} & $\begin{array}{l}\text { Dieta estándar sin } \\
\text { ejercicio físico }\end{array}$ & $-4,99$ & 0,870 \\
\hline & $\begin{array}{l}\text { Dieta estándar con } \\
\text { ejercicio físico }\end{array}$ & $-28,55$ & 0,001 \\
\hline & $\begin{array}{l}\text { Dieta rica en licopeno } \\
\text { sin ejercicio físico }\end{array}$ & $-9,45$ & 0,436 \\
\hline
\end{tabular}

$P \leq 0,05$

\subsection{6. Índice aterogénico de Castelli}

Con el propósito de determinar el riesgo de enfermedad cardiovascular de la población de estudio se calculó el índice aterogénico de Castelli tipo I utilizando como indicadores los niveles de $C L$ y HDL que presentaron los participantes antes y después de la intervención.

En la tabla No.66 se presentan la media y la desviación estándar del índice aterogénico tipo I (CL/HDL) pre y post de cada uno de los grupos de intervención de la población de estudio.

Se puede observar que las medias del índice aterogénico disminuyeron después de la intervención en los cuatro grupos de tratamiento, pero fue mayor en los que fueron tratados con dieta rica en licopeno, sin ejercicio físico y con ejercicio físico, en comparación con los grupos tratados con dieta estándar. 
Tabla No.66 Medias del índice aterogénico de Castelli tipo I de la población, previa y posterior a la intervención, por grupos de tratamiento y sus diferencias post-pre

\begin{tabular}{|c|c|c|c|c|}
\hline \multicolumn{2}{|l|}{ Grupo } & $\begin{array}{c}\text { Índice } \\
\text { Aterogénico } \\
\text { Pre } \\
\text { (CL/HDL) } \\
\end{array}$ & $\begin{array}{c}\text { Índice } \\
\text { Aterogénico } \\
\text { Post } \\
\text { (CL/HDL) }\end{array}$ & $\begin{array}{c}\text { Diferencia } \\
\text { Pos-pre } \\
\text { (CL/HDL) }\end{array}$ \\
\hline $\begin{array}{l}\text { Dieta estándar sin } \\
\text { ejercicio } \\
\text { físico }\end{array}$ & $\begin{array}{l}\text { Media } \\
\mathrm{n} \\
\text { D.E. }\end{array}$ & $\begin{array}{c}5,00 \\
10 \\
1,16\end{array}$ & $\begin{array}{c}4,60 \\
10 \\
1,13\end{array}$ & $-0,40$ \\
\hline $\begin{array}{l}\text { Dieta estándar con } \\
\text { ejercicio físico }\end{array}$ & $\begin{array}{l}\text { Media } \\
\mathrm{n} \\
\text { D.E. }\end{array}$ & $\begin{array}{c}5,38 \\
13 \\
1,57\end{array}$ & $\begin{array}{c}5,36 \\
13 \\
1,15\end{array}$ & $-0,02$ \\
\hline $\begin{array}{l}\text { Dieta rica en } \\
\text { licopeno sin } \\
\text { ejercicio físico }\end{array}$ & $\begin{array}{l}\text { Media } \\
\mathrm{n} \\
\text { D.E. }\end{array}$ & $\begin{array}{c}5,38 \\
12 \\
2,58\end{array}$ & $\begin{array}{c}, 45 \\
12 \\
1,48\end{array}$ & $-0,93$ \\
\hline $\begin{array}{l}\text { Dieta rica en } \\
\text { licopeno con } \\
\text { ejercicio físico }\end{array}$ & $\begin{array}{l}\text { Media } \\
\mathrm{n} \\
\text { D.E. }\end{array}$ & $\begin{array}{c}4,92 \\
13 \\
1,65\end{array}$ & $\begin{array}{c}4,09 \\
13 \\
1,29\end{array}$ & $-0,83$ \\
\hline
\end{tabular}

D.E. Desviación estándar

Valores del índice aterogénico de Castelli tipo I > 5 en hombres y >4.5 en mujeres.

En la figura No. 16 se puede observar el efecto de la dieta rica en licopeno sobre el índice aterogénico en los cuatro diferentes grupos de tratamiento antes y despúes de la intervención.

En la tabla No. 67 se presentan los resultados del análisis de varianza (ANOVA) para las diferencias de medias post-pre del índice aterogénico de Castelli tipo I.

Tabla No. 67 Resultado del análisis de varianza (ANOVA) para las difererencias de medias post-pre del índice aterogénico de Castelli tipo I

\begin{tabular}{|l|c|c|c|}
\hline \multicolumn{1}{|c|}{ Diferencias } & Media & $\boldsymbol{F}$ & $\boldsymbol{p}$ \\
\hline Inter grupos & 1,784 & 1,972 & 0,132 \\
\hline Intragrupos & 0,905 & & \\
\hline
\end{tabular}

$\mathrm{F}=$ estadístico de prueba de Fisher 
Se puede observar que no existen diferencias significativas en las medias de esta variable.

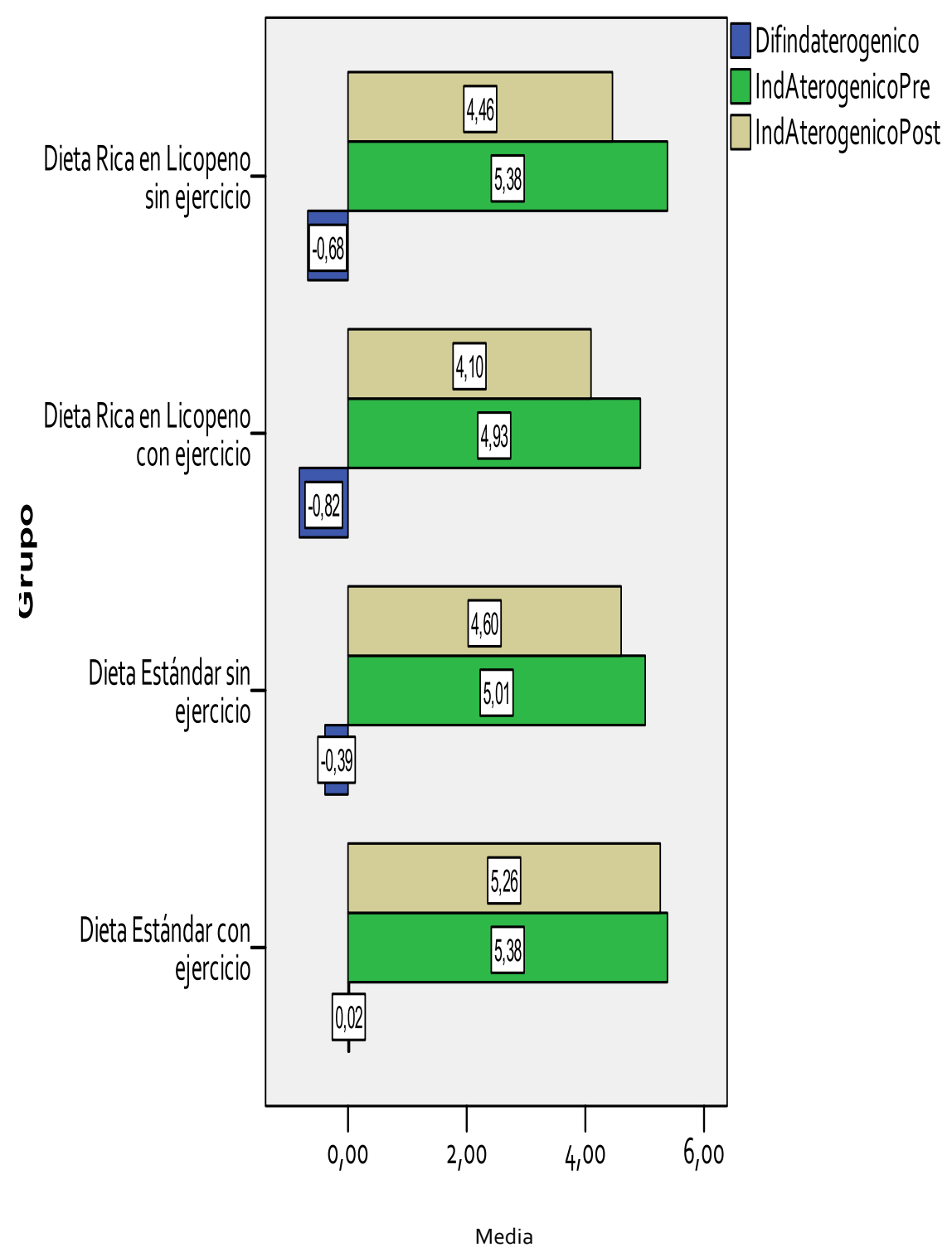

Figura No.16 Diferencia post-pre de las medias del índice aterogénico de Castelli tipo I de la población de estudio por grupos de tratamiento

Este apartado final permite dar respuesta a los dos últimos objetivos particulares del estudio; a manera de resumen se concluye afirmando que:

a) después de 12 semanas de tratamiento, la dieta rica en licopeno (50 mg/día) disminuyó significativamente los niveles de CL en sangre 
cuando se combinó con la práctica de ejercicio físico, en comparación con la dieta estándar.

b) después de 12 semanas de tratamiento, la dieta rica en licopeno (50 mg/día) disminuyó significativamente los niveles de LDL en sangre independientemente de la práctica ejercicio físico.

c) después de 12 semanas de tratamiento, la dieta rica en licopeno (50 mg/día) no tuvo efecto significativo sobre los niveles de HDL, TG en sangre y el PGC.

d) La práctica de ejercicio físico (mínimo 4 días a la semana) durante 12 semanas tuvo efecto sigificativo sobre los niveles de LDL en sangre cuando se combinó con dieta estándar. 


\section{CAPÍTULO 6.}

DISCUSIÓN

\subsection{Determinación de las raciones de alimentos ricos en licopeno}

Como se mencionó en los antecedentes, existe gran controversia en cuanto a la cantidad de licopeno necesaria para beneficiarse de sus propiedades funcionales, ya que los estudios presentan grandes diferencias en sus resultados, lo que dificulta el consenso y la generalización de las cantidades necesarias para el establecimiento de recomendaciones del consumo de dietas ricas en licopeno.

La falta de concordancia entre los resultados de distintas investigaciones, así como su falta de actividad provitamina $A$, pueden ser aspectos por los que el licopeno no sea considerado como un nutriente "esencial" y por lo tanto no se haya establecido la ingesta diaria recomendada (IDR) de manera oficial por los comités de expertos y los organismos internacionales (Story et al., 2010).

Algunos autores, como Waliszewski et al. (2010) han realizado la determinación del contenido de licopeno en la mayoría de sus alimentos fuente que generalmente son expresados en rangos de miligramos por gramo de la muestra húmeda, por lo cual no eran factibles de ser usados como parámetro de regencia en el presente estudio.

Vitale et al. (2010) y Martín et al. (2002) presentan sus resultados en miligramos por gramo de alimento, en porciones y su correspondiente aporte de licopeno por porción pero no especifican la marca comercial de los productos, por lo cual tampoco podían ser referencia para la elaboración de los menús del proyecto.

No hemos encontrado estudios en la literatura en los que se especificen estos datos, por lo que las recomendaciones de consumo se hacen más complicadas (Periago et al., 2001) debido a que cuando se trata de alimentos frescos, existen factores como el tipo, la variedad, el grado de madurez, o las condiciones estacionales, entre 
otras, que influyen en su contenido de licopeno. Cuando se trata de productos procesados (salsas, purés, jugo, conservas) la marca comercial es importante, puesto que no todas las marcas tienen las mismas características nutrimentales.

Debido a estas situaciones se propuso como primer objetivo del presente proyecto determinar las raciones de alimentos ricos en licopeno, especificando el tipo de alimento fresco y la marca comercial en los industrializados para que puedan ser utilizados por la población en general.

Por lo anterior, fue necesario cuantificar el contenido de licopeno en los alimentos fuente por 100 gramos, ya que a partir de estos valores se pueden establecer las raciones de alimentos ricos en licopeno.

Existen varios métodos para esta determinación, sin embargo los más factibles encontrados en la revisión de la literatura que pudieran realizarse en el laboratorio de la Facultad de Ingeniería Química de la UADY fueron: la extracción soxhlet y la extracción con solventes por etapas (Guash, 2002).

El método de extracción soxhlet consiste en someter a la muestra del alimento a procesos de troceado, secado, molienda y posteriormente la extracción de la oleorresina de licopeno.

Con el método de extracción con solventes por etapas, la muestra del alimento se somete a licuado, a filtración y eliminación del jugo (aproximadamente el 60\%); el extracto que se obtiene se somete a un proceso de eliminación del solvente y la oleorresina resultante se analiza mediante espectometría visible UV, determinando el contenido de licopeno de acuerdo a la absorvancia de la solución diulida.

Cardona et al., (2006) realizaron un estudio en el que compararon los métodos de extracción soxhlet y la extracción con solventes por etapas para identificar el mejor solvente para la extracción de licopeno con el método soxhlet, el método de extracción más adecuado y establecer las condiciones más apropiadas de temperatura, relación pulpa de tomate/volumen de solvente, tiempo de extracción y número de etapas para la obtención de la oleorresina con alto contenido de licopeno a escala de planta piloto.

Los resultados mostraron que el método de extracción con solventes por etapas requiere de condiciones menos exigentes de operación que el método de extracción con soxhlet, con un ahorro en la cantidad de energía y solvente y de tiempo de extracción.

Fernández et al. (2007), utilizaron el método de extracción con solventes por etapas para evaluar el contenido de licopeno y algunas propiedades fisicoquímicas y microbiológicas en cuatro pastas de tomate, motivados por la falta de información nutrimental en las 
etiquetas con respecto al nivel de otros carotenoides y de licopeno que contienen. Estas dos evidencias permitieron elegir el método de extracción con solventes para el desarrollo del presente trabajo.

La selección de los alimentos industrializados para realizar la cuantificación de licopeno se realizó considerando los criterios establecidos en la Norma Oficial Mexicana NMX-F-033-1982. Alimentos para humanos: puré de tomate envasado, que estipula a los fabricantes que los purés deben contener un mínimo de $10 \%$ de sólidos solubles de tomate, no excederse del $2 \%$ de contenido de sal y no contener conservadores, colorantes ni espesantes, pues podrían disfrazar la falta de tomate en el producto.

Al no encontrar estos datos en las diferentes etiquetas se consultó un estudio realizado en 2010 por la Procuraduría Federal del Consumidor (Profeco) en el que se realizaron 1,262 pruebas a 18 productos denominados en el mercado como "puré de tomate"; se verificó en cada producto el contenido de sólidos de tomate, el contenido de sal, la adición de colorantes, espesantes y conservadores y la calidad sanitaria. Los resultados muestran que sólo el $16,6 \%$ de los productos analizados cumplen con el porcentaje de contenido normado de sólidos del tomate. Con respecto al contenido de sal y a la calidad sanitaria todos cumplieron; sin embargo, en el $44,4 \%$ de los productos se encontró espesantes y colorantes y en el 38,9\% conservadores.La Profeco consideró a la marca comercial La Costeña ${ }^{\circledR}$ como el mejor puré de tomate que aunque es condimentado, cumple con el contenido de sólidos de tomate, contiene poca sal, no contiene conservadores, espesantes ni colorantes y su precio es accesible (\$1,80 por 100g.)

En el mismo periodo, la Profeco realizó el análisis de 12 marcas de salsa cátsup y 9 de salsa de tomate "tipo cátsup" con un total de 1,290 pruebas basándose en la Norma Oficial Mexicana NMX-F-346S-1980 Salsa de Tomate Catsup, que establece que este tipo de salsa debe estar conformada por tomate (no menos de $12 \%$ de sólidos), vinagre, azúcar y sal, sin conservadores, espesantes ni colorantes. Se evaluó el contenido de: tomate, azúcar, sal, colorantes, conservadores y espesantes, así como la calidad sanitaria. Los resultados dan cuenta de que desde el punto de vista sanitario todas las marcas tanto de salsa cátsup como de salsa de tomate "tipo cátsup" cumplen con la normatividad, al igual que en lo que respecta al contenido de sal; sin embargo, ninguno de estos productos cumple con el contenido de sólidos de tomate y están rebasadas en el contenido de azúcar.

En cuanto al contenido de colorantes sólo el $25 \%$ de las marcas de salsa cátsup y el $22,2 \%$ de las salsas "tipo cátsup" cumplieron con la normatividad. El $58 \%$ de las salsas cátsup no presentó colorantes y el 
$66,7 \%$ no presentó conservadores. De las salsas de tomate "tipo cátsup" todas las marcas presentaron colorantes y conservadores.

Bajo esa perspectiva la Profeco consideró las tres marcas de salsa catsup que contienen mayor cantidad de sólidos de tomate que son: Heinz $^{\circledR}(11,1 \%)$, Santiveri ${ }^{\circledR}(10,4 \%)$ y La Costeña ${ }^{\circledR}(9,4 \%)$.

Considerando los resultados anteriores, los alimentos procesados que se analizaron fueron: puré de tomate marca la $\operatorname{COSTEÑA}^{\circledR}$, salsa catsup marca La Costeña jugo de tomate marca Jumex ${ }^{\circledR}$, todos ellos fueron adquiridos en el supermercado ubicado en la ciudad de Mérida, Yucatán. Los alimentos frescos analizados fueron: tomate saladette, toronja rosada, papaya maradol, guayaba amarilla y sandía roja.

Se seleccionó el tomate tipo saladette porque es la variedad que más se produce en México, representando el $56 \%$ de la producción total del país, principalmente en los Estados de Sinaloa (50\%), Michoacán (15\%) y San Luis Potosí (10\%). Su producción mayor es en los meses de enero, febrero y marzo y la menor en junio y julio (Gobierno del Estado.Sagarpa, 2010).

Coincidiendo con varios autores (Waliszewsky et al., 2010; Vitale et al., 2010; Story et al., 2010; Shukla et al., 2010), en el presente estudio se concluyó que el mayor contenido de licopeno se encontró en los alimentos industrializados derivados del tomate: el jugo de tomate $(4,29 \mathrm{mg} / 100 \mathrm{~g})$, la salsa cátsup $(3,97 \mathrm{mg} / 100 \mathrm{~g})$ y el puré de tomate $(3,29 \mathrm{mg} / 100 \mathrm{~g})$, y en menor proporción en los alimentos frescos.

Esto puede ser resultado de que en los alimentos procesados en su preparación se utilizan piezas con mayor grado de madurez, lo que incrementa el contenido de licopeno. Además, durante el proceso de industrialización, el calor utilizado produce la liberación celular del licopeno, incrementando su biodisponibilidad.

Se establecieron las raciones de alimentos ricos en licopeno considerando $50 \mathrm{mg} /$ día al día ya que su máxima absorción es del 30\%, la biodisponibilidad sería de $15 \mathrm{mg}$ al día. Esta cantidad difiere de las recomendaciones de diferentes autores las cuales presentan mucha variabilidad: Rao et al. (2000) sugirieron 35 mg/día; Rao et al. (2002) entre 5 y 10 mg/día; Sesso et al. (2003) y Rao et al. (2007) entre 30 y $60 \mathrm{mg} / \mathrm{dí}$ de licopeno. $\mathrm{Y}$ es superior también a las recomendaciones de la ingesta diaria admisible (IDA) de 0,5 $\mathrm{mg} / \mathrm{Kg} / \mathrm{dí}$ de la European Food Information Council (EUFIC), las cuales no consideran el porcentaje máximo de absorción.

Por tanto, respondiendo al primer objetivo específico de este estudio, las raciones de alimentos ricos en licopeno (50 mg/día) utilizadas en el diseño de menús que pueden proporcionar efectos terapéuticos hipolipemiantes en 24 horas son: 2 tazas de jugo de 
tomate marca Jumex ${ }^{\circledR}, 1$ taza de puré de tomate marca La Costeña ${ }^{\circledR}, 3$ cucharadas de salsa cátsup marca La Costeña ${ }^{\circledR}$, dos tazas de sandía roja, dos tazas de papaya maradol, 2 piezas de tomate saladette y 1 pieza de toronja rosada, los cuales podrán ser utilizados por los profesionistas de la nutrición para el diseño de menús ricos en éste carotenoide y por las personas en general para incrementar el contenido de mismo en su dieta.

\subsection{Datos generales de la población de estudio}

La población de estudio estuvo formada por mayor proporción de mujeres que hombres, con un promedio de edad de 48 años. Si bien es cierto que las mujeres son más participativas en este tipo de proyectos, también podría entenderse que tanto en el nivel nacional como estatal la población femenina es ligeramente mayor $(50,7 \%)$ que la masculina $(49,3 \%)$ con una mediana de 26 años, como se reportó en el Censo de Población y Vivienda del INEGI (2010) para el Estado de Yucatán.

Dentro de los datos socio-demográficos se encontró que la mayor parte de los participantes en el estudio refirieron ser casados y en segundo término solteros; estos datos siguen el comportamiento reportado por el INEGI en el Estado de Yucatán derivado del Censo de Población y Vivienda (2010) donde se pudo observar que el 48\% de los habitantes de la entidad son casados y el $34,7 \%$ son solteros, cifras que han descendido respecto al censo de 1990 (53,4\% y $37,8 \%$ respectivamente), mientras que las personas que viven en unión libre se han incrementado más del doble, de 2,9\% a 7,9\%.

Con respecto al nivel de escolaridad, en el presente estudio más de la mitad de los participantes comentaron contar con estudios de licenciatura, seguido de preparatoria y maestría. Esta situación llama la atención debido a que el promedio de escolaridad (número de años aprobados) de los yucatecos de acuerdo con el último censo (2010) fue de 8,2 años, es decir, segundo año de secundaria (INEGI, 2010).

El que el nivel de escolaridad sea alto en la población de estudio puede deberse a que se invitó a participar en primer término a personal docente de la Universidad Autónoma de Yucatán, quienes representaron el $40 \%$ de la población, además algunos participantes invitaron a su vez a sus parejas que también son profesionistas. El resto de la población fueron personas de nivel escolar más bajo, lo que pudo causar la deserción, quedando en el estudio mayor cantidad de profesionistas, situación que coincide con otras investigaciones (Merino et al., 2010; Arrossi et al., 2011) que muestran que cuando se tiene menor nivel académico, las personas desertan más de las acciones para mejorar la salud. 
En cuanto al empleo, la tasa de participación económica de la población de 12 años y más, se ha incrementado del 2000 al 2010 de 51,4 a 52,5\% en el Estado de Yucatán.

Es importante resaltar que disminuyó en los hombres de 72,8 a $72,7 \%$ y se incrementó en las mujeres de 30,9 a 32,2\%. El 62,2\% de la población activa se desarrolla como empleados en el sector comercio y servicios; el $25 \%$ en el sector industrial y el $12,2 \%$ en el agropecuario. Situación que coincide con el presente estudio donde se encontró que el porcentaje más alto de los participantes son empleados (INEGI, 2010).

\subsection{Dislipemia, indicadores del estado de nutrición e hipertensión arterial}

El mayor porcentaje de los participantes en el estudio presentaron dislipemia mixta, es decir alteración de dos o más de los lípidos sanguíneos. Este tipo de dislipemia (ya sea combinando hipercolesterolemia con hipertrigliceridemia o hipertrigliceridemia con hipoalfalipoproteinemia) tiene un alto riesgo aterogénico y es directamente proporcional a la edad, alcanzando su máximo entre los 40 y 49 años. Su frecuencia fue mayor en las mujeres que en los hombres.

En segundo lugar se encontró la hipercolesterolemia, también con mayor frecuencia en las mujeres $y$ en tercero la hipoalfalipoproteinemia, coincidiendo que las mujeres fueron más afectadas que los hombres; la menor proporción fue de hipertrigliceridemia, con la misma frecuencia en los hombres y en las mujeres.

Querales et al. (2013) en un estudio realizado en Venezuela con población similar, encontraron baja frecuencia de hiperlipemia mixta (18\%), sin embargo, la dislipemia más común encontrada fue la hipercolesterolemia (43\%), seguida de hipertrigliceridemia (32\%) e hipoalfalipoproteinemia (31\%). Datos muy diferentes a los encontrados en población mexicana.

Aguilar et al. (2010) encontraron en los resultados de la ENSANUT 2006 que la hipoalfalipoproteinemia fue la dislipemia más común en la población mexicana (60\%), seguida de la hiperocolesterolemia $(43,6 \%)$, la hipertrigliceridemia (30\%) y por último la dislipemia mixta (18\%). Estos datos coinciden con el presente estudio sólo en cuanto a la hipercolesterolemia pero difieren en las demás dislipemias. Resultados tan diferentes pueden deberse a que la ENSANUT 2006 presenta los datos de dislipemias encontrados a nivel nacional, mientras que en el nivel local, el consumo de una dieta rica en grasa saturadas como es característica de la comida regional yucateca junto con el consumo alto de refrescos embotellados pueden ser las 
causas de la presencia de la dislipemia mixta en la población de estudio.

Así mismo, los hallazgos encontrados en la ENSANUT 2006, específicamente en el Estado de Yucatán, muestran que la hipercolesterolemia en esta población $(9,1 \%)$ se encuentra por encima de la media nacional $(8,6 \%)$.

Con estos resultados, se consideró importante determinar el riesgo de enfermedad cardiovascular de la población de estudio mediante el cálculo del índice aterogénico de Castelli tipo I previo y posterior al tratamiento por grupos de intervención.

Antes de la intervención en torno a la mitad de la población se encontraba con índice aterogénico con valores alterados (cociente $>5$ en hombres $y>4,5$ en mujeres), y una proporción similar de hombres y mujeres. Después de la intervención el 47,9\% presentó índice aterogénico alterado, siendo el 60,9\% hombres y el 39,2\% mujeres. Aunque se observa disminución, estos datos son preocupantes debido a que el valor elevado en el cociente CL/HDL se encuentra asociado a alteraciones relacionadas con la isquemia cardíaca y la resistencia a la insulina (Arsenault et al., 2010).

Respecto al estado de nutrición de los participantes en el estudio se utilizaron tres indicadores: el PGC, el IMC y la CA.

EI PGC, en un indicador del estado de nutrición cuyo incremento se convierte en riesgo de padecer enfermedades cardiovasculares. Se encontró que un alto porcentaje de participantes resultaron con cifras por encima del parámetro normal para su edad y sexo, siendo mayor en las mujeres que en los hombres.

El indicador IMC, sirvió para clasificar a los participantes, encontrándose que el 79,2\% de la población del estudio clasificó con obesidad en diferentes grados. Con obesidad tipo I (IMC entre 25 y $29,9 \mathrm{Kg} / \mathrm{m} 2$ ) las mujeres superaron a los hombres. Esto difiere con lo reportado en la ENSANUT 2006, donde se encontró que a nivel nacional, el IMC $>25 \mathrm{Kg} / \mathrm{m} 2$ (de acuerdo con la OMS) fue mayor en los hombres $(42,5 \%)$ que en las mujeres $(37,4 \%)$. Respecto a la obesidad II (IMC entre 30 y $40 \mathrm{Kg} / \mathrm{m} 2)$, los hombres $(16,7 \%)$ superaron a las mujeres $(14,6 \%)$, situación contraria a lo reportado en la ENSANUT 2006, en que las mujeres (34,5\%) superaron a los hombres (24,2\%). En este aspecto, como el IMC sólo relaciona el peso y la estatura, posiblemente, en caso de los hombres que generalmente presentan menor cantidad de grasa corporal, el dato esté representado por mayor cantidad de masa muscular, lo que hace que difiera de lo encontrado a nivel nacional. En el presente estudio se encontró que el 6,3\% de los hombres y el 2,1\% de las mujeres presentaron obesidad tipo III (IMC >40) o mórbida. 
El IMC es un indicador útil para valorar el riesgo de enfermedades cardio-metabólicas, sin embargo debe considerarse con precaución debido a que dichas enfermedades pueden presentarse a niveles promedio menores (IMC de $22.23 \mathrm{Kg} / \mathrm{m}^{2}$ ) como es el caso de Asia y México. En Asia debido a que los riesgos para enfermedades crónicas como diabetes mellitus e HTA ocurrían con IMC menores a los propuestos por lo OMS, redefinieron sobrepeso y obesidad. En México el riesgo de padecer diabetes mellitus e hipertensión arterial aumentó a partir de IMC de 22 a $24 \mathrm{~kg} / \mathrm{m}^{2}$ tanto en hombres como en mujeres. Para predecir diabetes mellitus e HTA los umbrales de corte óptimos de IMC variaron entre 26,3 a $27,4 \mathrm{Kg} / \mathrm{m} 2$ en hombres y de 27,7 a $28,9 \mathrm{Kg} / \mathrm{m}^{2}$ en mujeres (Sánchez et al., 2004).

Con respecto a la edad, los participantes que presentaron obesidad I y II se encontraron en los rangos de edad entre 31 y 60 años, mientras que la obesidad III o mórbida se presentó en los participantes más jóvenes (entre 20 y 24 años), lo que resulta interesante debido a que el comportamiento de la obesidad es incrementarse con la edad, por lo que resulta importante establecer medidas terapéuticas inmediatas.

La CA ha sido relacionada con alteraciones metabólicas como la resistencia a la insulina, las dislipemias y ambas son factores que predisponen a un mayor riesgo de enfermedades cardiovasculares.

En el presente estudio la práctica totalidad de los participantes presentaron riesgo, moderado o elevado de acuerdo con la CA y fueron las mujeres las más afectadas en ambos. Existe coincidencia con los datos reportados en la ENSANUT 2006 donde el 83,3\% de los encuestados a nivel nacional presentaron alto riesgo, siendo mayor en las mujeres $(61,9 \%)$ que en los hombres $(21,4 \%)$. En la misma encuesta a nivel estatal, la prevalencia de alto riesgo fue de $73,4 \%$, más alta en mujeres $(81,1 \%)$ que en los hombres $(61,4 \%)$.

Aun cuando los puntos de corte para determinar el riesgo mediante este indicador han sido muy útiles, tanto en hombres $(<94$ $\mathrm{cm}$ ) como en mujeres ( $<80 \mathrm{~cm}$ ), Rodríguez et al., 2009, postulan que en la población mexicana, el riesgo a padecer diabetes mellitus e HTA se incrementó a partir de 75 a $80 \mathrm{~cm}$ en hombres y de 70 a $80 \mathrm{~cm}$ en mujeres. Los análisis de prevalencia mostraron que $90 \mathrm{~cm}$ en uno y otro sexo permite identificar $80 \%$ de los casos de diabetes e HTA a nivel nacional. Estos valores ( $90 \mathrm{~cm}$ en hombres y $83 \mathrm{~cm}$ en mujeres) podrían ser utilizados como prueba tamiz para iniciar las acciones de detección y en la prevención de las enfermedades crónicas (Rodríguez et al., 2009; Pimentel et al., 2011).

La mayor parte de los participantes en el estudio presentaron tensión arterial sistólica óptima, normal y normal alta, siendo sólo el $14,6 \%$ de la población quienes presentaron hipertensión grado I (leve), con nivles más altos en las mujeres respecto a los hombres. 
Datos reportados en la ENSANUT, 2006 muestran que una parte importante de la población no cuenta con diagnóstico médico de HTA, por lo tanto no se encuentra con tratamiento por lo que su situación es de constante riesgo. Los porcentajes de HTA detectados mediante dicha encuesta, fueron de $20,1 \%$ en hombre y $12,1 \%$ en mujeres, datos que no concuerdan con lo encontrado en el presente estudio.

Es evidente que con el avance de la edad, las mujeres presentan disminución en el metabolismo, que induce el incremento en el peso y en la distribución de la grasa corporal. El sobrepeso da lugar a una mayor predisposición para la insulinorresistencia e hiperinsulinismo, lo que estimula la liberación de testosterona por el ovario, que a su vez incrementa la aparición del tejido graso y de la producción de ácidos grasos libres (AGL) que son responsables a nivel hepático de la producción de VLDL ricos en TG. El incremento de los TG en sangre contribuye por mecanismos indirectos a la producción de LDL densas y al descenso de las HDL lo que produce el síndrome metabólico (Monge et al., 2012). Las mujeres presentan una incidencia más alta que los hombres de morbilidad y de discapacidades a lo largo de la vida, debido a que acumulan más enfermedades crónicas que los varones.

\subsection{Factores de riesgo de la población de estudio}

Los antecedentes heredofamiliares se consideran factores de riesgo no modificables que pueden generar enfermedades cardiovasculares; los participantes en el estudio refirieron tener antecedentes de HTA, diabetes mellitus, hipercolesterolemia, hipertrigliceridemia $(52,08 \%)$, obesidad y cáncer; esta situación tiene un contraste con lo reportado en las últimas encuestas de salud y nutrición realizadas en México, en las que la población adulta presenta altas prevalencias de estas enfermedades que además se incrementan con la edad.

En la ENSANUT 2006, se reportó prevalencia nacional de HTA de $30,8 \%$, mayor en hombres $(20,1 \%)$ que en mujeres $(12,1 \%)$, siendo los estados del norte del país los más afectados; respecto a la diabetes mellitus, sólo se reportaron los datos de las personas que tenían diagnóstico previo a la encuesta realizado por un médico, que fue de $7 \%$, mayor en las mujeres $(7,3 \%)$ que en los hombres $(6,5 \%)$, la cual se incrementó a $9,1 \%$, de acuerdo a la reportado en la ENSANUT 2012 (Gutiérrez et al.,2012).

La hipercolesterolemia presentó una prevalencia del 26,5\% también mayor en mujeres que en hombres y la obesidad presento una prevalencia del 30\%, igualmente mayor en las mujeres que en los hombres. 
También se consideraron los factores de riesgo modificables que se mencionaron como antecedentes y que fueron abandonados mucho tiempo antes del estudio, destacando el consumo de tabaco y alcohol, junto con la falta de ejercicio. Los datos encontrados en el presente trabajo pueden relacionarse con los resultados reportados en la Encuesta Nacional de Salud y Nutrición 2012 (ENSANUT, 2012) donde la media de consumo de tabaco general en el Estado de Yucatán (12,8\%) se encuentra por debajo de la media nacional (19\%), mientras en el consumo de alcohol sucede lo contrario, la media estatal de consumo $(18,1 \%)$ sobrepasa a la media nacional $(15,7 \%)$. Esta situación es preocupante, ya que el consumo de alcohol tiene repercusiones en el metabolismo de los lípidos sobre todo de los TG.

Con relación a la práctica de ejercicio físico, en la presente investigación sólo el $31,24 \%$ de los participantes realizaban ejercicio físico antes del estudio y lo abandonaron por diferentes causas como son: el exceso de trabajo, no contar con tiempo, el cuidado de los hijos o disgusto por los gimnasios, entre otros. Existen muchas barreras para iniciar, mantener o abandonar el ejercicio físico; Rodríguez et al. (2009) señalan que en los adultos contribuyen la falta de tiempo, la carencia de instalaciones, no tener compañero con quien ir, no tener dinero, pobre salud, dolores, el cuidado de los hijos y experiencias negativas en el pasado. Por otro lado, los adultos mayores argumentan más a menudo razones relacionadas con su salud como son: no tener las condiciones físicas, incapacidad, presencia de dolores y miedo a sufrir caídas.

\subsection{Efecto de la intervención}

En el tratamiento de las enfermedades crónicas el plan de alimentación adecuado y el ejercicio físico son los puntos fundamentales que sostienen a largo plazo los efectos, aun cuando sea necesario el tratamiento farmacológico.

De los componentes de la dieta, la grasa es el que tiene más influencia sobre el perfil de lípidos debido a su efecto sobre las concentraciones de las lipoproteínas y ese efecto depende más del tipo de ácidos grasos que la componen que de su cantidad; debido a esto, el tratamiento dietético para las dislipemias ha estado orientado al control en el consumo de colesterol y los ácidos grasos saturados y trans así como en una reducción de la energía proveniente de hidratos de carbono simples, con el incremento de hidratos de carbono complejos y fibra.

Una revisión de ensayos clínicos aleatorizados en la que se compararon diferentes tipos de dietas para reducir el peso pone de manifiesto los efectos de la dieta modificada en el tipo de grasas con beneficios adicionales en la tensión arterial, el perfil lipídico y la glucemia basal, por lo que dicho tipo de dieta se con sidera la más 
recomendada en los problemas relacionados con los lípidos sanguíneos. (Avenell et al., 2004; Mozaffarian et al., 2010). Sin embargo, el impacto de esta estrategia no ha sido del todo alentador, debido a que la mayoría de las personas no se ciñe al tratamiento por largo tiempo y lo abandona, situación que se comprueba al observar las prevalencias de estas enfermedades en todo el mundo, las cuales se han ido incrementando con el paso del tiempo.

En la búsqueda de nuevas estrategias para potenciar el efecto del tratamiento nutricional en las dislipemias se propuso en el presente trabajo el incluir en la dieta alimentos que proporcionen componentes funcionales que tienen efecto sobre los niveles de los lípidos sanguíneos. En el caso específico del licopeno, una de las ventajas de su inclusión en la dieta es que se encuentra en alimentos de uso cotidiano y a diferencia de otros carotenoides, en lugar de perderse por efectos del calor, presenta mayor biodisponibilidad, por lo que su uso en la alimentación cotidiana podría verse como una estrategia del tratamiento no farmacológico para el manejo de las dislipemias e incluso potenciar el efecto del tratamiento farmacológico (Willcox et al., 2003; Shi et al., 2004; Jones, 2007; Capanoglu et al., 2010).

Por otro lado, el ejercicio físico se observa como un elemento importante para la mejora de las alteraciones de los lípidos sanguíneos y también para el riesgo cardiovascular (Elosua, 2005; Jacobs et al., 2006; Dancy et al., 2008), reduciendo los TG e incrementando el $\mathrm{HDL}$, así como reduciendo algunos indicadores del estado de nutrición como son el PGC, el IMC y la CA.

El objetivo del tratamiento dietético de las dislipemias es disminuir la tendencia hacia la ateriosclerosis y limitar su progresión en personas que ya se encuentran afectadas; se fundamenta en la reducción del $\mathrm{CL}$ y de las LDL mediante la sustitución en el consumo de ácidos grasos saturados por monoinsaturados en un período de 6 a 12 semanas, haciendo una evaluación del efecto antes de utilizar el tratamiento farmacológico (NOM-043-SSA 2-2005).

Las dietas modificadas en grasas (estándar) como la que se utilizó en el presente estudio para el tratamiento del grupo control se han asociado a la reducción en el peso corporal, el IMC y la CA, como se puede constatar en el estudio realizado por Paoli et al. (2011) quienes encontraron reducción significativa $(p<0,001)$ en el IMC $\left(31,45 \mathrm{Kg} / \mathrm{m}^{2}\right.$ a $\left.29,01 \mathrm{Kg} / \mathrm{m}^{2}\right)$, el peso corporal $(86,15 \mathrm{~kg}$ a $79,43 \mathrm{~kg}$ ) y la circunferencia de cintura $(106.56 \mathrm{~cm}$ a $97,10 \mathrm{~cm})$ en 106 empleados del Consejo de Roma quienes fueron tratados con una dieta cetogénica durante 6 semanas.

Se ha demostrado que la dieta modificada en grasas ha producido diminución en el CL, TG y las LDL. Los ácidos grasos 
monoinsaturados como los que se encuentran en el aceite de oliva (oleico) son los que producen el perfil de lípidos más saludable para prevenir las enfermedades cardiovasculares, incrementando las HDL y las apolipoproteínas A-1.

Los ácidos grasos poliínsaturados por su lado, reducen el CL total y las LDL. Entre ellos se encuentra el ácido linoléico (omega-6) que se encuentra principalmente en las semillas de girasol, maíz, entre otras.

El ácido linolénico (omega-3) se encuentra en los pescados y mariscos y su efecto principal está demostrado sobre los TG y las VLDL. Pero el efecto de estos ácidos grasos depende del tipo de dislipemia que padece la persona; por ejemplo, en pacientes con el $\mathrm{CL}$ total elevado, los omega-3 disminuyen las LDL si se diminuye al mismo tiempo el consumo de grasas saturadas. Pero en personas con TG elevados, los omega-3 pueden causar una ligera disminución o un ligero incremento.

Algunos estudios (Estruch et al., 2006; Feliciano et al., 2008) han demostrado que las dietas bajas en grasas saturadas tiene efectos sobre los niveles de CL y LDL; sin embargo, en el presente estudio la dieta estándar sólo tuvo efecto significativo en la disminución de LDL del perfil de lípidos cuando el tratamiento se combinó con ejercicio físico. No produjo efecto en los demás componentes del perfil de lípidos ( $C L, T G$ y $H D L)$, ni en el PGC.

Dentro de las estrategias efectivas para reducir los niveles de LDL, se encuentran la combinación de los ácidos grasos monoinsaturados y poliínsaturados en la dieta; esta combinación también incrementa los niveles de HDL. Los resultados del presente estudio sólo coinciden en la reducción de los niveles de LDL, ya que el incremento en los niveles de HDL no presentó significación estadística. Esto puede tener relación con lo mencionado por Castellanos et al. (2003) quienes afirman que las dietas ricas en ácidos grasos poliínsaturados pueden tener efectos adversos sobre los niveles de HDL, reduciéndose también su papel protector contra las enfermedades cardiovasculares al disminuir la concentración de las apolipoproteínas A-1 responsables de la acción antiaterogénica. Estudios recientes han demostrado que al sustituir las grasas saturadas por monoinsaturadas las HDL aumentan. También se ha comprobado que se aumenta la concentración de apolipoproteína AI, a la que se le atribuye un papel antiaterogénico importante.

Varady et al. (2010) encontraron que las dietas bajas en grasas tienen efecto en los niveles de CL y LDL y la práctica de ejercicio físico sobre las HDL y TG y afirman que la combinación de los dos tratamientos produce efectos importantes en los pacientes con dislipemia. Cuando estos autores redujeron la grasa total de la dieta entre 20 y $30 \%$ de la energía total y la grasa saturada entre 6 y $10 \%$ 
con un programa de ejercicio de 30 a 60 minutos por día de 3 a 7 veces por semana, los niveles de $C L$ redujeron entre 7 y $18 \%$ y las LDL entre 7 y $15 \%$. Los niveles de TG se redujeron entre 4 a $18 \%$, sin embargo los niveles de HDL presentaron incremento no significativo, incluso podría disminuir en algunos casos como resultados de la combinación de los dos tratamientos como sucede en el presente estudio.

Es importante considerar que con respecto a los niveles bajos de HDL el NCEP-ATPIII no ha establecido un tratamiento farmacológico específico, aun cuando las personas no presenten otro trastorno lipídico o riesgo aterosclerótico; se utilizan generalmente medicamentos como los fibratos y el ácido nicotínico empleados para otras dislipemias y que incrementan el transporte reverso del colesterol y la estimulación de los efectos pleiotrópicos obtenidos con el incremento de los niveles de HDL.

Para su manejo siempre se han utilizado recomendaciones generales como disminuir el peso corporal, suspender el consumo de tabaco y realizar ejercicio físico aeróbico y la inclusión en la dieta de ácidos grasos omega-3. Sin embargo, muchas veces la falta de efecto del tratamiento no farmacológico sobre los niveles de HDL puede deberse a factores genéticos, a trastornos del metabolismo (alteraciones en los receptores, en las enzímas y los transportadores) y también al consumo de algunos medicamentos que reducen el HDL como los betabloqueadores, anabólicos, progestágenos y corticoides.

Por otra parte, se han demostrado ampliamente en los diferentes estudios in vitro e in vivo las propiedades del licopeno. Los resultados de las investigaciones (Burri et al., 2010; Kim et al., 2010; Story et al., 2010; Burton et al., 2012; García et al., 2012; Lorenz et al., 2012) han enfatizado las propiedades antioxidantes del licopeno como coadyuvante importante del sistema de defensa endógeno contra el daño oxidativo durante las condiciones pro-oxidantes como las resultantes de estrés oxidativo postprandial, que tiene efectos inhibitorios en la oxidación de las $L D L$, la reducción del $C L$ e incremento de las HDL.

Por lo anterior en esta investigación se esperaba encontrar efectos contundentes del efecto de la dieta rica en licopeno sobre los niveles de todos los lípidos en sangre y el PGC. Sin embargo, los participantes que fueron tratados con dieta rica en licopeno sin ejercicio físico, presentaron diferencias significativas entre sus medias sólo en la variable $L D L$; en las variables $C L, T G, H D L$ y PGC no se encontraron efectos significativos.

Nuestro resultado difiere con el estudio de Blum et al. (2006), en el que se pudo comprobar que el consumo de $300 \mathrm{~g}$ de tomates al día durante un mes incrementó el nivel de HDL en un $15 \%$ y de Vitale et 
al. (2010) quienes coinciden en que una dieta rica en licopeno (300 g de tomate al día) incrementa significativamente $(15,2 \%)$ los niveles de HDL.

Tambien Madrid et al. (2006) coinciden con el incremento de los niveles de HDL, al suplementar a los participantes de su estudio con jugo concentrado de tomate durante 7 días. Lo interesante fue que al dejar de suplementarlos, los niveles de HDL volvieron a su estado inicial, lo que deja evidencia de la susceptibilidad del organismo al efecto del licopeno. Los niveles de $C L$, TG y $L D L$ no sufrieron modificaciones, que es otra diferencia encontrada con la presente investigación.

Se ha demostrado (Rao, 2002; Kun et al., 2007; Santosh et al., 2010) que el consumo de antioxidantes como el licopeno protegen las biomoléculas crtíticas como las LDL, pues debido a su función antioxidante evita que se oxiden y produzcan daños en la membrana celular. La susceptibilidad de las LDL del plasma sanguíneo al daño oxidativo se redujo significativamente con el consumo diario durante 8 semanas de una bebida de soya y tomate ( $21 \mathrm{mg} / \mathrm{dia}$ de licopeno) en un estudio realizado por Bohn et al., (2013).

Fuhrman et al. (2000), en un estudio donde suplementaron a seis hombres sanos durante 3 meses con $60 \mathrm{mg}$ de licopeno al día, encontraron al final del tratamiento una reducción del $14 \%$ de los niveles de $\mathrm{CL}$ plasmático.

Story et al. (2010) reportaron una disminución significativa en los niveles de $C L$ después de 2 semanas de intervención con $20 \mathrm{mg}$ de licopeno al día a través del consumo de jugo de tomate.

Por otro lado, se encontraron resultados diferentes al presente estudio en la investigación de García et al. (2012), que con el objetivo de evaluar el efecto del jugo de tomate enriquecido con ácidos grasos poliinsaturados omega-3 en el perfil de lípidos, los niveles de biomarcadores del estado oxidante y el riesgo de ECV, lo compararon con el jugo de tomate sin adicionar. No se encontraron efectos en el perfil de lípidos con ninguna de las intervenciones posiblemente debido a la corta duración del estudio (2 semanas), ya que en otras investigaciones similares pero de tiempo más prolongado se han encontrado efectos positivos en los componentes del perfil de lípidos.

Cuando la dieta rica en licopeno fue combinada con ejercicio físico, los participantes presentaron diferencias significactivas en las medias de los indicadores CL y LDL del perfil de lípidos. El efecto de la inclusión de la práctica de ejercicio físico se observó incrementando la magnitud del efecto en dichos indicadores. No se encontró efecto significativo sobre los niveles de HDL aun cuando si hubo una tendencia al incremento y tampoco en los niveles de TG y el PGC, aunque los valores tendían a dsiminuir. 
Es importante resaltar que aunque los resultados sólo con la dieta han sido atractivos, la inclusión en el estudio de la práctica de ejercicio físico, potencia el efecto de aquella (Castellanos et al., 2003; Mora, 2005).

Llama la atención que en los grupos con dieta estándar y con dieta rica en licopeno cuando los participantes no realizaron ejercicio físico, el incremento en los niveles de HDL fue mayor en comparación con los participantes que hicieron ejercicio físico, lo que podría interpretarse como indicativo de un escaso efecto del ejercicio físico sobre los niveles de HDL independientemente de la dieta. Este resultado coincide con un estudio de intervención con niños y adolescentes obesos realizado por Watts et al. (2005) en el que no se encontró efecto significativo sobre los niveles de HDL y TG después de la intervención con 60 minutos de ejercicio.

Con respecto al PGC, aunque las modificaciones no fueron significativas se puede observar que en los grupos que fueron tratados con dieta estándar y dieta rica en licopeno sin ejercicio físico, la disminución en los puntos porcentuales tendía a ser menor que en los grupos que si realizaron ejercicio físico. El grupo que presentó mayor tendencia a la reducción fue el tratado con dieta rica en licopeno y ejercicio físico. Esto puede deberse a que las intervenciones dietéticas producen cambios en el peso y en la distribución de la grasa corporal que se potencian con la inclusión del ejercicio físico (Kraus et al., 2002; Torres et al., 2009).

Varios estudios transversales y longitudinales afirman que la dieta, combinada con el ejercicio físico representa una estrategia efcaz para mejorar el perfil de lípidos. (Jacob et al., 2008; Palomo et al., 2010).

Grandjean et al. (2000) realizaron un estudio con hombres que padecía y que no padecían hipercolesterolemia y encontraron que no existe diferencia en los cambios inducidos por el ejercicio físico en los niveles de HDL, situación que coincide con la presente investigación.

Por otro lado, se ha demostrado que el ejercicio físico aeróbico disminuye los niveles plasmáticos de TG y LDL e incrementa los de HDL (Kraus et al., 2002). Esto coincide con lo encontrado por Obisesan et al. (2009) y Varady et al. (2011) que sustentan que la modificación en las HDL se consigue con una pérdida de peso corporal inducida por ejercicio a partir del $6 \%$ y del 10 al $15 \%$ respectivamente.

Coincidiendo también con el presente estudio, Torresani (2010) encontró asociación estadística entre los valores de LDL y el consumo de licopeno, pero no con HDL y CA en un estudio realizado sólo con mujeres pre y post menopáusicas. 
Es importante considerar que además del licopeno existen otros factores presentes en la dieta que han podido afectar los niveles de $\mathrm{HDL}$ en los participantes del presente estudio; por ejemplo, es conocido que la presencia de grasas saturadas, monoinsaturadas, de colesterol y de alcohol en la dieta elevan la concentracion de HDL en sangre, mientras que la presencia de los ácidos grasos poliinsaturados, los hidratos de carbono y el exceso de kilocalorías la disminuyen (Ashen, 2005).

Por otro lado, también la práctica regular de ejercicio físico produce la disminución de la grasa corporal y a su vez tiene efecto en el incremento de la masa magra; esta situación tiene como consecuencia efectos positivos en las alteraciones de los lípidos plasmáticos, reduciendo el riesgo cardiovascular (Elosua, 2005; Jacobs et al., 2006; Dancy et al., 2008).

Grundy et al. (1999) afirman que para ver efectos sobre los niveles de LDL con un tratamiento, es necesario combinar la dieta con ejercicio físico porque reduce la grasa epicárdica, el peso corporal, el IMC, la circunferencia de cintura y la grasa visceral independientemente de la edad y el sexo del individuo. Por lo tanto, el incremento de la actividad física reduce la secreción de adipocinas pro-inflamatorias.

Es de llamar la atención que algunos autores (Kraus et al., 2002; Torres et al., 2009) afirman que el ejercicio físico produce disminución de los niveles de TG, lo que reduce la formación de partículas de LDL pequeñas y densas las cuales se asocian a un mayor potencial aterogénico; que la práctica de ejercicio físico produce mayor actividad de la lipoproteinlipasa (LPL) tanto en el músculo como en el tejido adiposo al catabolizar las partículas de VLDL ricas en TG, proporcionando más elementos para la síntesis hepática de HDL. Aquí se ven involucrados también debido al efecto del ejercicio físico, la disminución de la actividad de la lipasa hepática (LH) reduciendo el paso de $\mathrm{HDL}_{2}$ a $\mathrm{HDL}_{3}$ y el incremento de la actividad de la lecitina colesterol acetiltransferasa (LCAT) que cataliza la transferencia de ácidos grasos desde lecitina y $\mathrm{CL}$ estratificado.

Roselló et al. (2001) encontraron diferencias significativas en los niveles de $C L$, $L D L$ e IMC después de un programa de ejercicio.Otros estudios ofrecen evidencias diversas, Shen et al. (2007), en un ensayo clínico con 24 sujetos tratados con tres diferentes tratamientos: tomate fresco, jugo de tomate, o una bebida con licopeno (todas con $40 \mathrm{mg} /$ día) durante seis semanas, encontraron que los niveles de TG y de LDL se redujeron, mientras las HDL y el $C L$ aumentaron en los participantes que consumieron tomate fresco y jugo de tomate.

Stefanick et al. (1998) distribuyeron aleatoriamente a los sujetos de estudio en cuatro intervenciones: dieta sola (30\% de grasa total y 
$7 \%$ de grasa saturada), ejercicio solo (6o minutos, tres veces a la semana bajo supervisión), la combinación de dieta y ejercicio y el control. Los resultados mostraron que en el grupo de dieta los niveles de $C L$ y LDL disminuyeron, el grupo de ejercicio incrementó significativamente el HDL y disminuyó TG, mientras al grupo de combinación experimentó cambios favorables en los cuatro indicadores del perfil de lípidos, situación que difiere del presente estudio. Esta situación puede deberse a que la duración del estudio no fue suficiente para producir los resultados arriba mencionados. Miller et al. (2002), hicieron evidente que los estudios en los que se logran mayores efectos en los niveles de lípidos, fueron estudios a largo plazo (entre 16 semanas a 1 año).

Existen estudios que postulan que el ejercicio físico (Kraus et al., 2002) y el licopeno (Palomo et al., 2010) tienen poco efecto sobre los niveles de TG; por otro lado Grundy et al. (1999) afirman que para que los TG se modifiquen mediante el ejercicio físico es necesaria la disminución de por lo menos $4,5 \mathrm{Kg}$ de peso corporal, situación que coincide con el presente estudio ya que la dieta baja en grasas, la dieta rica en licopeno y la combinación de ambas con el ejercicio físico no tuvieron efecto en la disminución de los niveles de TG en los participantes.

También se han encontrado resultados de estudios contradictorios respecto a ciertos tipos de ejercicio que conllevan un esfuerzo físico importante, particularmente en relación con los valores de la lipoproteína A (LpA). Estudios experimentales no mostraron diferencias en los valores plasmáticos de LpA entre sujetos entrenados y sedentarios, mientras otros estudios mostraron valores mayores de LpA en sujetos entrenados. (Ruíz et al., 2004).

Por otro lado, Roldan et al. (2008) observaron en un estudio que las personas con niveles más bajos de LDL fueron las físicamente más activas, y a diferencia de lo encontrado en la literatura, los que no realizaron ejercicio presentaron $\mathrm{HDL}$ altos, dato que coincide con el presente estudio. Las causas que pueden dar explicación a estas discrepancias son muy diversas: los métodos de análisis de los lípidos y las lipoproteínas, la condición física de los sujetos, el historial de entrenamiento, el tipo, el volumen y la intensidad del ejercicio, el componente genético hasta la etnia de los sujetos.

Willcox et al.(2003) aseguran que la dieta juega un papel importante en el desarrollo, la prevención y el control de las enfermedades cardiovasculares y que modificaciones sencillas como la inclusión de fuentes de carotenoides pueden inducir cambios sustanciales en la oxidación de los lípidos insaturados de las LDL; el licopeno sobre todo, actúa reduciendo la expresión de moléculas de adhesión y la adhesión de los monocitos a la pared de las arterias 
previniendo la generación de la placa aterosclerótica disminuyendo de esta manera el riesgo de eventos cardiovasculares.

Respecto al índice aterogénico de Castelli tipo I, que fue realizado con el objetivo de identificar el efecto de la intervención, por su alto poder diferenciador de enfermedad cardíaca coronaria, se puede decir que no presentó significación estadística, en contraposición con el estudio realizado por Querales et al. (2013) donde se encontró una menor frecuencia en el índice de Castelli tipo I (23\%) tanto en hombres $(28,2 \%)$ como en mujeres $(19,7 \%)$.

Se puede concluir entonces que existe suficiente evidencia para aceptar las hipótesis de investigación, puesto que la ingesta de una dieta rica en licopeno ( $50 \mathrm{mg} /$ día) durante 12 semanas disminuyó los niveles sanguíneos de $C L$ y $L D L$ en adultos con dilipemia en comparación con la dieta estándar.

Así mismo, la práctica de ejercicio físico (mínimo 4 días a la semana por 60 minutos) durante 12 semanas disminuyó los niveles de LDL en adultos con dislipemia cuando se combinó con dieta estándar y cuando se combinó con dieta rica en licopeno disminuyó los niveles de CL y LDL

\subsection{Limitaciones del estudio}

Las principales limitaciones del presente estudio que pudieran influir en los resultados y que deben ser consideradas para investigaciones ulteriores fueron las siguientes:

En primer lugar el rango amplio de edades de los parrticipantes, hombres y mujeres entre 20 y 65 años, y el tamaño final de la muestra, en la que se produjeron abandonos por razones diversas, tales como la falta de tiempo para acudir al seguimiento, la dificultad para seguir el régimen de alimentación o el programa de ejercicio.

Por otra parte, al no ser factible una seguimiento continuo de la adherencia al programa de ejercicio por parte de los participantes, la escala de Borg y la frecuencia cardíaca fueron los datos utilizados para apoyar la realización regular de dicha actividad.

De forma semejante, y en relación con la dieta, se hizo entrega de los menús y se insistió en el compromiso por parte de los participantes de consumirla; sin embargo, al no ser factible una verificación directa de dicho consumo, hubo de inferirse su reflejo en los indicadores del estado de nutrición.

Otros aspectos que pudieron haber influído en los resultados fueron la duración de la intervención dietética y el tipo, duración e intensidad del ejercicio, que pudieron ser insuficientes para producir los cambios esperados después del tratamiento. 
A pesar de dichas limitaciones, los datos obtenidos apuntan hacia un efecto beneficioso tanto del consumo de la dieta rica en licopeno como de la práctica de ejercicio sobre la salud cardiovascular de los participantes en el estudio. 


\section{CAPÍTULO 7}

CONCLUSIONES

Considerando los resultados obtenidos en la investigación desarrollada se ha llegado a las siguientes conclusiones:

\section{CONCLUSIÓN PRIMERA}

Los alimentos con mayor contenido de licopeno en el presente estudio fueron los alimentos industrializados derivados del tomate: jugo de tomate, salsa catsup y puré de tomate.

\section{CONCLUSIÓN SEGUNDA}

Las raciones de alimentos ricos en licopeno (50 mg/día) que pueden proporcionar efectos terapéuticos hipolipemiantes son: 2 tazas de jugo de tomate marca Jumex ${ }^{\circledR}, 1$ taza de puré de tomate marca La Costeña ${ }^{\circledR}, 3$ cucharadas de salsa cátsup marca La Costeña ${ }^{\circledR}$, dos tazas de sandía roja, dos tazas de papaya maradol, 2 piezas de tomate saladette y 1 pieza de toronja rosada.

\section{CONCLUSIÓN TERCERA}

La ingesta de una dieta rica en licopeno ( $50 \mathrm{mg} / \mathrm{día}$ ) durante 12 semanas indujo una reducción de los niveles sanguíneos de colesterol y lipoproteínas de baja densidad en adultos con dislipemia.

\section{CONCLUSIÓN CUARTA}

La práctica de ejercicio físico (mínimo 4 días a la semana, 60 minutos) durante 12 semanas disminuyó los niveles de las lipoproteínas de baja densidad (LDL) cuando se combinó con la dieta 
estándar y los niveles de colesterol $(C L)$ y lipoproteínas de baja densidad (LDL) al asociarse con la dieta rica en licopeno.

\section{CONCLUSION FINAL}

Los datos obtenidos en el presente estudio dan apoyo a la utilidad potencial del licopeno en la prevención y tratamiento de las dislipemias, e indican que el consumo de dietas enriquecidas con este carotenoide podrían representar una alternativa más de tratamiento no farmacológico para la mejora de las condiciones clínicas y bioquímicas de las personas que padecen estas enfermedades, sobre todo cuando se combina con un programa de ejercicio físico.

Contar con las raciones de alimentos ricos en licopeno en medidas caseras, tipo y marcas comerciales facilita la inclusión de este carotenoide en la dieta habitual, lo que podría mejorar las condiciones cardiovasculares de los pacientes y contribuir a la reducción de la morbimortalidad por estas enfermedades. 


\section{CAPÍTULO 8. BIBLIOGRAFÍA}

- Aguilar, C., Gómez, F., Lerman, I., Vázqudoez, C., Pérez, O., Posadas, C. (2004). Diagnóstico y tratamiento de las dislipidemias: posición de la Sociedad Mexicana de Nutrición y Endocrinología. Revista de Endocrinología y Nutrición, 12 (1), 1-41.

- Aguilar, C., Rojas, R., Gómez-Pérez, F., Valles, V., Franco, A., Oláiz, G. et al. (2002). Características de los casos con dislipidemias mixtas en un estudio de población: resultados de la Encuesta Nacional de Enfermedades Crónicas. Salud Pública de México, 44(6), 546-553.

- Aguilar, C., Gómez, F., Rull, J., Villalpando, S., Barquera, S., Rojas, R. (2010). Prevalenceof dyslipidemia in the Mexican National Health and Nutrition Survey 2006. Salud Pública de México. 52(S1), S 44-S53.

- Anderson, G., Chu, E. (2007). Expanding priorities-confronting chronic disease in countries with low income. The New England Journal of Medicine, 356(3), 209-211.

- Antúnez, M., Jiménez, M., Cortés, G. (2004). Valoración inicial con prueba de esfuerzo al paciente cardiópata para Ingresar al programa de rehabilitación cardiaca. Revista Mexicana de Enfermería Cardiológica, $12(1), 34-37$.

- American College of Sports Medicine (ACSM) (2001). Position stand: appropriate intervention strategies for weight loss and prevention for weight regain for adults. Medicine and Science in Sports and Exercise, 33, 2145-2156.

- American Heart Association. (2001). Heart and Stroke Statistical Update. Dallas, Tx.

- American Heart Association. (2006). Heart Disease and Stroke Statistics2006 Update. Dallas, Tx.

- Arós, F., Boraita, A., Alegría, E., Alonso A., Bardaji, A., Lamiel, R. et al. (2000). Guías de práctica clínica de la Sociedad Española de Cardiología en pruebas de esfuerzo. Sociedad Española de Cardiología. Revista Española de Cardiología, 53, 1063-1094. 
- Arrossi, S., Herrero, M., Greco, A., Ramos, S. (2011). Factores asociados a la no-adherencia al tratamiento de la tuberculosis: revisión de la literatura. Centro de Estudios de Estado y Sociedad (CEDES), Área Salud, Economía y Sociedad: 1-37.

- Arsenault, B., Rana, J., Stroes, E., Després, J., Shah, P., Kastelein, J. (2010). Beyond low-density lipoprotein cholesterol respective contributions of non-high-density lipoprotein cholesterol levels, triglycerides, and the total cholesterol/high-density lipoprotein cholesterol ratio to coronary heart disease risk in apparently healthy men and women. Journal of the American College Cardiology, 55, 35-41

- Ascaso, J., González, P., Hernández, A., Mangas, A., Masana, L., Millán, J. et al. (2007). Management of dyslipidemia in the metabolic syndrome. Recomendations of the Spanish HDL forum. American Journal of Cardiovascular Drugs, 7 (1), 39-58.

- Ashen, M., Blumenthal, R. (2005). Low HDL cholesterol level. The New England Journal of Medicine, Clinical practice, 353, 1252-1260.

- Autoridad Europea de Seguridad Alimentaria EFSA (2010). EU Menu. Recuperado el 15 de marzo de 2012 en: http://www.efsa.europa.eu/en/datex/datexeumenu.htm.

- Avenell, A., Brown, T., McGee, M., Campbell, M., Grant, A., Broom, J. et al. (2004). What are the long-term benefits of weight reducing diets in adults? A systematic review of randomized controlled trials. Journal of Human Nutrition and Dietetics, 17, 317-335.

- Backer, G., Ambrosioni, E., Borch-Johnsen, K., Brotons, C., Cifkova, R., Dallongeville, J. et al. (2004). Guía europea para la prevención cardiovascular en la práctica clínica. Tercer grupo de trabajo de las sociedades europeas y otras sociedades sobre prevención cardiovascular en la práctica clínica (constituido por representantes de ocho sociedades y expertos invitados) Hipertensión, 21(8), 405-417.

- Barquera, S., Campos, I., Aguilar, C. (2009). Epidemiología de las dislipidemias en México. En: S. Barquera, I.Campos. Dislipidemias, epidemiología, evaluación, adherencia y tratamiento (pp.19-32). México: Instituto Nacional de Salud Pública.

- Beers, M.H., Porter, R.S., Jones, T.V., Kaplan, J.L., Berkwits. M. (Eds.). (2007). El Manual Merck de Diagnóstico y Tratamiento. (11 a. Ed.). España: Elsevier.

- Belardinelli, R., Goergiou, D., Ginzton, L., Ciani, G., Purcaro, A., (1998). Effects of moderate exercise training on thallium uptake and contractile response lo low-dose dobutamine of dysfunctional myocardiumin patients with ischemic cardiomyopathy. Circulation, 97 (6), 553-561.

- Belser, C., Lüscher, T., Landmesser, U. (2012). Molecular mechanism of vascular effects of high-density lipoprotein: alterations in cardiovascular disease. EMBO Molecular Medicine, 4, 251-268.

- Biesalski, H., Grimm, P. (2007). Nutrición: Texto y Atlas. España: Editorial. Médica Panamericana. 
- Blanco, M., Trujillo, A. (2010). Dislipoproteinemias. Recuperado el 27 de octubre de 2010 en: http://es.scribd.com/doc/45283524/dislipoproteinemias.

- Blum, A., Merei, M., Karem, A., Blum, N., Ben-Arzi, S., Wirsansky, I. (2006). Effects of tomatoes on the lipid profile. Clinical and Investigative Medicine, 29 (5), 298-300.

- Böhm, V. (2012). Lycopene and heart health. Molecular Nutrition \& Food Research, 56, 296-303.

- Bohn, T., Blackwood, M., Francis, D., Tian, Q., Schwartz, S., Clinton, S. (2013). Bioavailability of phytochemical constituents from a novel soy fortified lycopene rich tomato juice developed for targeted cancer prevention trials. Nutrition and Cancer, 65 (6), 919-929.

- Borg, G. (1982). Psychophysical bases of perceived exertion. Medicine and Science in Sports and Exercise, 14 (5), 377-381.

- Burri, B., Nguyen, T., Neidlinger, T. (2010). Absorption estimates improve the validity of the relationship between dietary and serum lycopene. Nutrition; 26, 82-89.

- Burton, B., Talbot, J., Park, E., Krishnankutti, S., Eridisinghe, I. (2012). Protective activity of prosessed tomato products on postprandial oxidation and inflammation: a clinical trial in healthy weight men and women. Molecular Nutrition \& Food Research, 56, 622-631.

- Cáez, G., Casas, N. (2007). Formar en un estilo de vida saludable: otro reto para la ingeniería y la industria. Educación y Educadores, 10 (2), 103-117.

- Calderón Montero, F. J. (2007). Fisiología Aplicada al Deporte. España: Tebar.

- Campos, I., Aguilar, C., Barquera, S. (2009). Diagnóstico de las Dislipidemias. En: S.Barquera, I, Campos. Dislipidemias, epidemiología, evaluación, adherencia y tratamiento, (pp.81-104).México: Instituto Nacional de Salud Pública.

- Capanoglu, E., Beekwilder, J., Boyacioglu, D., De Vos, R., Hall, R. (2010). The effect of industrial food prosessing on potentially health-beneficial tomato antioxidants. Clinical Reviews in Food Science and Nutrition, 50, 919-930.

- Cardona, E., Ríos, L., Restrepo, G. (2006). Extracción del carotenoide licopeno del tomate chonto (Lycopersicum esculentum). Vitae, 13 (2), 4453 .

- Carrero, J., Mertín, E., Baró, L., Fonollá, J., Jiménez, J., Boza, J. et al. (2005). Efectos cardiovasculares de los ácidos grasos omega-3 y alternativas para incrementar su ingesta. Nutrición Hospitalaria, 20(1), 6369.

- Casales, G., Hernández, J. (2008). Protocolo de enfermería para la atención de pacientes con enfermedades crónicas: sobrepeso, riesgo cardiovascular y diabetes. México: Secretaría de Salud. 
- Casanueva, E., Kaufer, M., Pérez, A., Arroyo, P. (2000). Nutriología Médica. (2 ${ }^{a}$. Ed.) México: Editorial Panamericana.

- Casso, D., White, E., Patterson, R., Agurs-Collins, T., Kooperberg, C., Haines, P. (2000). Correlates of serum lycopene in older women. Nutrition and Cáncer, 36(2), 163-169.

- Castellano, C., Pérez de Juan, M.A., Attie, F. (2009). Electrocardiografía Clínica.España: Elsevier.

- Castellanos, A., Rosado, G. (2003). Las grasa saturadas en la alimentación, realidades y mitos. Revista de la Universidad Autónoma de Yucatán. $227,14-23$.

- Castelli W.P. (1988). Cholesterol and lipids in the risk of coronary artery disease the Framingham Heart Study. Canadian Journal of Cardiology, 4, $5 \mathrm{~A}-10 \mathrm{~A}$.

- Céspedes, M.C., Edward, S. (1999). Preparación del paciente y colección de muestras para análisis de laboratorio clínico. Medisan, 3 (1), 31-35.

- Ciurana, R., Brotons, C. (2005). Actividades de prevención y promoción de la salud en el adulto. En: A, Martín. y J.F. Cano, Compendio de atención primaria. Conceptos, organización y práctica clínica (pp.202-220). (2a.Ed.). España: Elsevier.

- Colegio Mexicano de Nutriólogos. (2006).Postura del colegio Mexicano de Nutriólogos sobre orientación en actividad física para la prevención y manejo de las enfermedades crónicas en el ciclo de la vida asociadas con la nutrición. México.

- Dancy, C., Lohsoonthorn, V., Williams, M. (2008).Risk of dyslipidemia in relation to level of physical activity among Thai professional and office workers. Southeast Asian Journal of Tropical Medicine and Public Health, 39 (5), 932-941.

- Daniel, W. (2009). Bioestadística. Base para el análisis de las ciencias de la salud. (4 ${ }^{\mathrm{a}}$. Ed.). México: Limusa Wiley.

- De Souza, L.J., Souto, J., De Souza, T.F., Reis, A.F., Gicovate, N.C., Bastos, D.A. et al. (2003). Prevalence of Dyslipidemia and risk Factors in Campos dos Goytacazes, in the Brazilian State of Rio de Janeiro. Arquivos Brasileiros de Cardiologia, 81 (3), 249-264.

- Diwadkar-Navsariwala, V., Novotny, J., Gustin, D., Sosman, J., Rodvold, K., Crowell, J. et al. (2003) A physiological pharmacokinetic model describing the disposition of lycopene in healthy men. Journal of Lipid Research, 44, 1927-1939.

- Ekelund, U., Brage, S., Franks, P., Hennings, S., Emms, S., Wareham, N. (2005). Physical activity energy expenditure predicts progression toward the metabolic syndrome independently of aerobic fitness in middle-aged healthy Caucasians. Diabetes Care, 28(5), 1195-1200.

- Eliot, A., Brinton, MD. (2009). Clinical decision making: improving outcomes for patients with mixed dyslipidemia. Supplement to journal of Managed Care Pharmacy, 15 (1 S-c), 14-19. 
- Elosua, R. (2005). Actividad física. Un eficiente y olvidado elemento de la prevención cardiovascular, desde la infancia hasta la vejez. Revista Española de Cardiología, 58(8), 887-89o.

- Escott-Stump, S. (2010). Nutrición, Diagnóstico y Tratamiento. España: Wolters Kluwer. Lippincott Williams \& Wilkins.

- Escribano, A., Vega, A., Lozano, J., Álamo, R., Castrodeza, J., Lelras, S., en nombre de los participantes en el Estudio del Riesgo de Enfermedad Cardiovascular en Castilla y León. (2010). Gaceta Sanitaria, 24, (4), 282287.

- Espeitx, E. (2006). Práctica deportiva, alimentación y construcción del cuerpo. Revista Pueblos y Frontera digital. Universidad Nacional Autónoma de México, 2, 1-22.

- Estruch, R., Martínez-González, M., Corella, D., Salas-Salvadó, J., RuízGutiérrez, V., Covas, M.I. et al. (2006). Effects of a Mediterranean style diet on cardivascular risk factors. Annals of Internal Medicine, 145, 1-11.

- European Food Information Council (EUFIC) Consumo de frutas y verdura en Europa. Recuperado el 3 de agosto de 1012 en: http:// www.eufic.org/article/es/expid/Consumo-frutas-verduras-Europa.

- Expert panel on detection, evaluation and treatment of high blood cholesterol in adults. Executive summary of the third report of the National Cholesterol Education Program (NCEP) (2001). Expert panel on detection, evaluation and treatment of high cholesterol. Journal of the American Medical Association (JAMA), 285, 2486-2497.

- Fan, A., Ham, S., Reddy, S., Mokdad, A. (2009). Validation of reported physical activity for cholesterol control using two diferent physical activity instruments. Vascular Health and Risk Management, 5, 649-661.

- Feliciano, J., Sierra, I. (2008). Elevendo el colesterol HDL. ¿Cuál es la mejor estrategia? Revista de la Asocciación Médica Brasileña, 54(4), 369-376.

- Fernández, C., Pitre, A., Llobregat, M., Rondón, Y. (2007). Evaluación del Contenido de Licopeno en Pastas de Tomate Comerciales Información Tecnológica, 18 (3), 31-38.

- Flores, M., Macías, N., Barquera, S. (2009). Dislipidemia e inflamación crónica de baja intensidad. En: S. Barquera e I. Campos, Dislipidemias, epidemiología, evaluación, adherencia y tratamiento (pp.70-78). México: Instituto Nacional de Salud Pública.

- Foster, C., Hillsdon, M., Thorogood, M., Kaur, A., Wedatilake, T. (2005) Interventions for promoting physical activity. Cochrane Database System Review. Jan 25;(1): CDoo3180

- Fuhrman, B., Volkova, N., Rosemblat, M., Aviram, M. (2000). Original research communication: lycopene synergistically inhibits LDL oxidation in combination with vitamin E, glabridin, rosmarinic acid, or garlic. Antioxidants \& Redox Signaling, 2, 494-506. 
- Galhardo, R., Ferraz Da Silva, E. (2009). Tomatoes and tomato products as dietary sources of antioxidants. Food Reviews International, 25, 313325.

- García-Alonso, F., Jorge-Vidal, V., Ros, G., Periago, M. (2012). Effect of consumtion of tomato juice enriched with $n-3$ polyunsaturated fatty acidson the lipid profile, antioxidant biomarker status, and cardiovascular disease risk in healthy women. Europen Journal of Nutrition. 51, 415-424.

- Genest, J., Libby, P., Gotto, A. (2005). Dyslipoproteinemias/ Atheroesclerosis. Cardiovascular therapeutics. A companion to Braunwald heart disease. W.B. Saunders Company, 1013-1053.

- George, T.W., Waroonphan, S., Niwat, C., Gordon, M.H., Lovegrove, J.A. (2012). The Glu298Asp single nucleotide polymorphism in the endothelial nitric oxide synthase gene differentially affects the vascular response to acute consumption of fruit and vegetable puree based drinks. Molecular Nutrition \& Food Research. 56 (7), 1014-1024.

- Giovannucci, E., Ascherio, A., Rimm, E., Stampfer, M., Colitz, G., Willett, W. (1994). Intake of carotenoids and retinol in relation to risk of prostate cancer. Journal of the National Cencer Institute, 87, 1767-1776.

- Gobierno Federal (2008). Segundo informe de ejecución del plan nacional de desarrollo 2007-2012. México. Recuperado el 3 de noviembre de 2011 en http://pnd.calderon.presidencia.gob.mx/pdf/Segundolnforme Ejecucion/3_2.pdf.

- Gobierno Federal (2008), b. Tercer informe de ejecución del plan nacional de desarrollo 2007-2012. México. Recuperado el 3 de noviembre de 2011 en http://pnd.calderon.presidencia.gob.mx/pdf/TercerInformeEjecucion/3_2. pdf.

- Gobierno Federal. (2010). Secretaría de Agriculatura, Ganadería, Desarrollo rural, Pesca y Alimentación (SAGARPA). Subsecretaría de fomento a los Agronegocios. Monografía de cultivos. Jitomate. Recuperado el 13 de febrero de 2013 en: http://www.sagarpa. gob.mx/agronegocios/Documents/pablo/Documentos/Monografias/Jitom ate.pdf.

- Golbidi, S., Laher, I. (2012) Exercise and the cardiovascular system, Cardiology Reseach and Practice, 2012; 2012:210852.

- Gomes, E., Veiga, G. (2004). Physical exercise and metabolic síndrome. Revista Brasileira de Medicina do Esporte, 10 (4), 325-330.

- González, C., Pavía, A., Redding, F., Zacarías, J., Ramírez, M., Alpízar, M. et al. (2009). Encuesta sobre el manejo de dislipidemia con estatinas en México: porcentaje de pacientes que alcanzan las metas establecidas por el Programa Nacional de Educación en Colesterol (National Cholesterol Education Program [NCAP]). Revista Mexicana de Cardiología, 20 (1), 1822. 
- González, J., Sánchez, P., Matix, J. (2006). Nutrición en el deporte. Ayudas ergogénicas y dopaje. España. Fundación Universitaria Iberoamericana y Ediciones Díaz de Santos.

- Grandes, G., Sánchez, A., Ortega, R., Torcal, J., Montoya, I. Lizarraga, K. et al. (Grupo PEPAF) (2009). Effectiviness of physical activity advice and prescription by physicians in routine primary care. A cluster randomized trial. Archives of Internal Medicine, 169, 694-701.

- Grandjean, P., Crouse, S., Rohack, J. (2000). Influence of choresterol status on blood lipid and lipoprotein enzyme responses to aerobic exercise. Journal of Applied Physiology, 89 (2), 472-480.

- Grundy, S., Blackburn, G., Higgins, M., Lauer, R., Perri, M., Ryan, D. (1999) Physical activity in the treatment of obesity and comorbilities. Medicine \& Science in Sport \& Exercise. 11 (Suppl), $\mathrm{S}_{502}-\mathrm{S}_{508 .}$

- Guash, L. CSIC AGROo17- Supercritical fluid extraction and selective fractionation of lycopene and other carotenoids from natural sources. Oficina de patentes Venezolanas 200201310.2002.Junio 6.

- Guidelines for exercise testing Journal of the American College of Cardiology (JACC) (1997) 30 (1), 26o. En: M, Antúnez, M, Jiménez, G, Cortés, G. (2004). Valoración inicial con prueba de esfuerzo al paciente cardiópata para ingresar al programa de rehabilitación cardiaca. Revista Mexicana de Enfermería Cardiológica 12(1), 34-37.

- Gurría, A. (2011). Conferencia "Los retos de la salud en México". México: UNAM. Recuperado el 3 de noviembre de 2011 en http://www.oecd.org/document/41/o,3746,es_36288966_36288553_4688 8233_1_1_1_1,00.html.

- Gutiérrez, G. B., Acosta, H., Reyes, I., Fernández, S., Flores, G., Martínez, M. (2003). Programas Integrados de Salud. Encuesta Nacional de Coberturas ENCOPREVENIMSS 2003. México: IMSS.

- Gutiérrez, J., Rivera-Dommarco, J., Shamah-Levy, T., VillalpandoHernández, S., Franco, A., Cuevas-Nasu, L. et al. (2012). Encuesta Nacional de Salud y Nutrición 2012. Resultados Nacionales. Cuernevaca, México: Instituto Nacional de Salud Pública (MX).

- Gutiérrez, E., Romero, J.J. (2010). Dislipidemia y niveles de lípidos sanguíneos en pacientes tratados en centros de atención primaria de la zona este de San José, Costa Rica, año 2006. Revista en Ciencias del Movimiento Humano y Salud, 7,2, 1-13.

- Hernández, R., Fernández, C., Baptista P. (2007). Metodología de la Investigación. (4 $4^{\mathrm{a}}$. Ed.). México: McGraw Hill.

- Henson, S., Masakure, O., Cranfield, J. (2008). The propensity for consumers to offset health risks through the use of functional foods and nutraceuticals: The case of lycopene. Food Quality and Preference, 19, 395406.

- Hodge, A., Cunningham, .J, Maple-Brown, L., Dunbar, T., O’Dea, K. (2011). Plasma carotenoids are associated with socioeconomic status in an urban Indigenous population: an observational study. BMC Public 
Health, 11, 76 .

- llarraza, H. (2002). Conceptos Actuales sobre la Escala de Borg. II Congreso Iberoamericano de Rehabilitación Cardíaca, Palma de Mallorca, España.

- International Lipid Information Bureau (ILIB)(1998). Enfoque escalonado para la evaluación y el tratamiento de la dislipidemia en adultos. Manual ILIB sobre lípidos para la práctica clínica. Walverly Hispánica S.A.

- Institute for Clinical Systems Improvement (2001). Health Care Guideline: Preventive Counseling and Education. Recuperado el 5 de septiembre de 2011 en http:// www.icsi.org.

- Instituto Nacional de Economía, Geografía e Informática (INEGI) (2010). Mujeres y hombres en México 2010. México. [Revisado el 21 de febrero de 2013]

en: www.inegi.org.mx/prod_serv/contenidos/espanol/bvinegizproductos/cen sos/población/2010/princi_result/yuc/31-1.

- Instituto Nacional de Salud Pública (2012) Estadísticas de mortalidad en México: muertes registradas en el año 2002. México. Recuperado el 20 de octubre de 2011 en: http:// www.mendeley.com/research/estadisticasmortalidad-en-mexico-muertes-registradas-en-el-año-2003.

- Jacob, K., Periago, M., Böhm, V., Banuezo, G. (2008). Influence of lycopene and vitamin $C$ from tomato juice on biomarkers of oxidative stress and inflammation. British Journal of Nutrititon. 99, 137-146.

- Jacobs, K., Krauss, R., Fattor, J., Horning, M., Friedlander, A., Bauer, T. et al. (2006). Endurance training has little effect on active muscle free fatty acid, lipoprotein cholesterol, or triglyceride net balance. American Journal of Physiology Endocrinol and Metabolism, 291(3), 656-665.

- Jacoby, E., Keller, I. (2006). La promoción del consumo de frutas y verduras en América Latina: buena oportunidad de acción intersectorial por una alimentación saludable. Revista Chilena de Nutrición, 33, 226-231.

- Jiménez, E., Tortós, J., Vinocour, M., Angulo, J.M., Jiménez, M., Del Río, L. et al. (2004). Guías para la detección, el diagnóstico y el tratamiento de las dislipidemias para el primer nivel de atención. Costa Rica. Caja Costarricense de Seguro Social.

- Jiménez, M., Martínez, P., Miró, E., Sánchez, A. (2008). Bienestar psicológico y hábitos saludables: ¿están asociados a la práctica de ejercicio físico? International Journal of Clinical and Health Psychology, 8 (1), 185-202.

- Jones, R. (2007). Effects of postharvest handling conditions and cooking on anthocyanin, lycopene and glucosinolate content and bioavailability in fruits and vegetables. New Zeland Journal of Crop and Horticultural Sciences, 35, 219-22.

- Kim, M.K., Tomita, T., Kim, M.J., Sasai, H., Maeda, S., Tanaka, K. (2009). Aerobic exercise training reduces epicardial fatin obese men. Journal of Applied Physiology, 106 (1), 5-11. 
- Kim, O., Yoe, H., Kim, H., Park, J., Kim, J., Lee, S. et al. (2010). Independent inverse relationship between serum lycopene concentration and arterial stiffness. Atherosclerosis, 208, 581-586.

- Klipstein-Grobusch, K., Launer, L., Geleijnse, J., Boeing, H., Hofman, A., Witteman, J. (2000). Serum carotenoids and atherosclerosis The Rotterdam Study. Atherosclerosis, 148, 49-56

- Kodama, S., Tanaka, S., Saito, K., Shu, M., Sone, Y. (2007). Effect of aerobic exercise training on serum levels of high-density lipoprotein cholesterol: a metaanalysis. Archives of Internal Medicine, 167, 999-1008.

- Kun, Y., Lule, U., Xiao-Lin, D. (2007). Lycopene: its properties and relationship to human health. Food Reviews International, 22, 309-333.

- Kurl, S., Laukkanen, J., Rauramaa, R., Lakka, T., Sivenius, J., Salonen, T. (2001). Systolic blood pressure response to exercise stress test and rosk of stroke. Stroke, 32, 2036-2041.

- Kraus, W., Houmard, J., Duscha, B., Knetzger, K., Wharton, M., McCartney, J. et al. (2002). Effects on the amount and intensity of exercise on plasma lipoproteins. The New England Journal of Medicine, $347,1483-1492$.

- Kristenson, M., Zeiden, B., Kucinskiene, Z., Elinder, L., Bargdahl, B., Elwing, B. et al. (1997). Antioxidant state and mortality from coronary heart disease in Lithuanian and Swedish men: concomitant cross sectional study of men aged 50. British Medical Journal, 314, 629-633.

- Lee, I., Skerret, J. (2001) Physical activity and all-cause mortality: what is the dose-response relation? Medicine and Science in Sports and Exercise, 33 (6), S459-S471.

- Lim, S., Garaziano, T., Gakidou, E., Reddy, K., Farzadfar, F., Lozano, R. et al. (2007). Prevention of cardiovascular disease in highrisk individuals in low-income and middle-income countries: health effects and costs. Lancet, 370 (9604), 2054-2062.

- Liu, Y., Zhang, P., Wang, W., Wang, H., Zhang, L., Wu, W. et al. (2010). The characteristics of dyslipidemia patients with different durations in Beijing: a cross-sectional study. Lipids in Health and Disease, 9 (1), 115.

- Lorenz, M., Fechner, M., Kalkowsky, J., Fröhlich, K., Trautmann, A., Böhm, V. et al. (2012). Effect of lycopene on the initial state of atherosclerosis in New Zealand White (NZW) rabbits. PLoS On; 7, e30808.

- Mackinnon, E.S., Rao, A.V., Josse, R.G., Rao, L.G. (2011). Supplementation with the antioxidant lycopene significantly decreases oxidative stress parameters and the bone resorption marker $\mathrm{N}$ telopeptide of tipe I collagen in postmenopausal women. Osteoporos International, 22, 1091-1101.

- Madden, K., Lockhart, C., Cuff, D., Potter, T., Meneilly, G. (2009). Shortterm aerobic exercise reduces arterial stiffness in older adults with type 2 diabetes, hypertension, and hypercholesterolemia. Diabetes Care, 32(8), 1531-1535. 
- Madrid, E., Vásquez, D., Leyton, F., Mandiola, C., Escobar, J. (2006). El consumo de Lycopersicum esculentum podría aumentar lipoproteínas de alta densidad (HDL) y disminuir es estrés oxidativo a corto plazo. Revista Médica de Chile, 134(7), 855-862

- Magbanua, M., Roy, R., Sosa, E., Weinberg, V., Federman, S., Mattie, M. et al. (2011). Gene expression and biological pathways in tissue of men with prostate cancer in a randomized clinical trial and lycopene and fish oil supplementation. PLoS One, 6: e24004.

- Martín, J.M., Gorgojo, L. (2002) Licopeno y salud. A propósito del tomate y de algunas de las virtudes del gazpacho, del "paambtomàquet" y otros productos de nuestra gastronomía. Alimentación, Nutrición y Salud, 9 (1) 17-26.

- Martínez, A., Chávez, R. (2007). Prevalencia y comorbilidad de dislipidemias en el primer nivel de atención. Revista Médica del Instituto Mexicano del Seguro Social. 45 (5), 469-475.

- Mataix, J., Ramírez, J.A., Solá, R. (2009). Enfermedad del Sistema Circulatorio. En: J. Mataix. Tratado de Alimentación y Nutrición. Tomo 2 situaciones Fisiológicas y Patológicas (pp.1471-1517). España: Editorial Oceano/Ergon.

- Mataix, J. Pérez, F. (2009). Aterosclerosis y Trombosis En: J. Mataix. Tratado de Alimentación y Nutrición. Tomo 2 situaciones Fisiológicas y Patológicas (pp. 1110-1144). España: Editorial Oceano/Ergon.

- Matthew, I., Mckenney, J., Brinton, E. (2009). Maintaining Cardiovascular Health in Patients with mixed Dyslipidemia: Optimizing the Management of hypertriglyveridemia and Non-HDL Choresterol. Supplement to Journal of Managed Care Pharmacy, 15 (1 S-c), 3-7.

- Matulka, R., Hood, A., Griffiths, J. (2004). Safety evaluation of a natural tomato oleoresin extract derived from food-processing tomatoes. Regulatory Toxicology and Pharmacoogy, 39, 390-402.

- McClain, R., Bausch, J. (2003). Summary of safety studies conducted with synthetic lycopene. Regulatory Toxicology and Pharmacology. 37, 274-285.

- McKenney, J. (2009). Making Informed Choices: Assesing Efficacy and cost-Benefit of therapeutic Options for the Management of mixed Dyslipidemia. Supplement to Journal of Managed Care Pharmacy, 15 (1 Sc), 8-13.

- McPherson, R., Frohlich, J., Fodor, G., Genest, J. (2006). Canada Cardiovascular Society position statement -Recommendations for the diagnosis and treatment of dyslipidemia and prevention of cardiovascular disease. Canadian Journal of Cardiology, 22(11), 913-927.

- Meaney, E., Vela, A., Ramos, A., Alemao, E., Yin, D. (2004). Cumplimiento de las metas con reductores del colesterol en pacientes mexicanos. El estudio COMETA México. Gaceta Medica de México, 140(5), 493-501.

- Meaney, E., Lara, A., Ceballos G.M., Asbun, J., Vela, A., Martínez, Y. et al (2007). Cardiovascular risk factors in the urban Mexican population: the FRIMEX study. Public Health, 121(5), 378-384. 
- Merchán, A., Merchán, J. (2010). Estratificación del riesgo de enfermedad coronaria, metas del perfil lipídico y tratamiento de acuerdo con el riesgo.En: M. Blanco, A, Trujillo. (2012). Dislipoproteinemias.Recuperado de: http://es.scribd.com/doc/45283524/dislipoproteinemias.

- Merino, V., Lozano, D., Torrico, F. (2010). Factores que influyen en la adherencia a la suplementación con sulfato ferroso durante el embarazo. Gaceta Médica Boliviana, 2010, 33 (2), 21-25.

- Miguel, F., Maderuelo, J., García, A. (2008). Riesgo cardiovascular: concepto, estimación, usos y limitaciones. Actualización en Medicina de Familia, 4(8), 423-433.

- Miguel, P. (2009) Dislipidemias. Revista Cubana de Información en Ciencias de la Salud (ACIMED), 20(6), 265-273.

- Millán, J., Alegría, E., Álvarez, L., Ascaso, J., Lahoz, C., Mantilla, T. et al. (2012). Documento abordaje de la dislipidemia. Sociedad Española de Ateriosclerosis (parte III), Clinica e Investigación en Arterioesclerosis, 24, (2), 102-107.

- Miller, E., Erlinger, T., Young, D., Jehn, M., Chaleston, J., Rhodes, D. et al. (2002). Results of the diet, exercise and weight loss intervention trial (DEW-IT). Hypertension, 4, 612-618.

- Mills, L., Wilson, H., Thies, F. (2012). Lycopene inhibits lynphocyte proliferation through mechanisms dependent on early cell activation. Molecular Nutrition \& Food Research, 56, 1034-1042.

- Ministerio de Sanidad y Consumo de España. (2000). Control de la colesterolemia en España, un instrumento para la prevención cardiovascular Parte B. Revista Española de Salud Pública. Madrid, España, $74(3), 234-253$

- Monge, B., Saban, J. (2012). La menopausia como "status" de alto riesgo cardiovascular. Capítulo 29 en: Control global del riesgo cardiovascular. P. 583-590. Saban (Editor) Ediciones Díaz de Santos, Madrid.

- Mooradian, A. (2009). Dyslipidemia in type 2 diabetes mellitus. Endocrinology \& Metabolism, 5(3), 150-159.

- Mora, G. (2005). Diet and coronary health disease. Revista de la Facultad de Medicina de Colombial [online], 53 (2), 98-106.

- Mozaffarian, D., Micha, R., Wallace, S. (2010). Effects on Coronary Heart Disease of Increasing Polyunsaturated Fat in Place of Saturated Fat: A Systematic Review and Meta-Analysis of Randomized Controlled Trials.Consultado el 11-04-2011 de: www.plosmedicine.org.

- Munguia, C., Sánchez, R., Hernández, D., Cruz, M. (2008). Prevalencia de dislipidemias en una población de sujetos en apariencia sanos y su relación con la resistencia a la insulina. Salud Pública de Mexico, 50 (5), 375-382.

- Neuhouser, M., Miller, D., Kristal, Alan Barnett, M., Cheskin, L. (2002). Diet and Exercise Habits of Patients with diabetes, Dyslipidemia, 
Cardiovascular Disease or hypertension. Journal of American College of Nutrition, 21(5), 394-401.

- Norma Oficial Mexicana NMX-F-346-S-1980 Salsa de Tomate Catsup. Recuperado el 18 de mayo de 2012 de www.colpos.mx/bancodenormas/nmexicanas/NMX-F-346-S-1980.PDF.

- Norma Oficial Mexicana NMX-F-033-1982. Alimentos para humanos. Puré de tomate envasado. Recuperado el 18 de mayo de 2012 de: http://www.colpos.mx/bancodenormas/mexicanas/NMX-F-033-1982.PDF.

- Norma Oficial Mexicana NOM-168-SSA1-1998. Del expediente clínico. Recuperado el 14 de diciembre de 2011 de: http://www.salud. gob.mx/unidades/cdi/nom/168ssa18.html.

- Norma Oficial Mexicana NOM-251-SSA1-2009. Prácticas de higiene para el proceso de alimentos, bebidas o suplementos alimenticios.Disponible en http:www.salud.gob.mx/unidades/cdi/nom/og3ssa14.html.

- Norma Oficial Mexicana. NOM-037-SSA2-2002. Para la prevención, tratamiento y control de las dislipidemias. Recuperado el 14 de diciembre de 2011 en: http://www.salud.gob.mx/unidades/cdi/nom/037ssa202.html.

- Norma Oficial Mexicana. Servicios básicos de salud. Promoción y educación para la salud en materia alimentaria. Criterios para brindar orientación. NOM-043-SSA2-2005. Recuperado el 14 de diciembre de 2011 en: http://www.salud.gob.mx/unidades/cdi/nomssa.html.

- Obisesan, T., Farrell, R., Goldberg, A., Phares, D., Ellis, T., Hagberg, J. (2008). APOE Genotype effect black-white responses of high-density lipoprotein cholesterol subspecies to aerobic exercise training. Metabolism; 57(12), 1669-1676.

- Oláiz, G., Rivera, J., Shamah, T., Rojas, R., Villalpando, S., Henández, M. et al. (2006). Encuesta Nacional de Salud y Nutrición 2006. México: Instituto Nacional de Salud Pública.

- Omoni, A., Aluko, R. (2005). The anti-carcenogenic and anti-atherogenic effects of lycopene: a review. Trens in Food Science \& Technology, 16, 344350.

- Ordóñez, A., Balanza, M., Martín, F., Flores, C. (2009). Estabilidad del carotenoide licopeno en tomates en conserva. Inform Technologies, 20, 31-37.

- Organización de las Naciones Unidas para la Alimentación y la Agricultura (FAO) Statistical Database, Food Balance Sheets. Recuperado el 21 de junio de 2012 en: http://faostat.fao.org/faostat/form?collection=FBSDomain=FBSservlet=1 hasbulk= version $=$ extlanguage $=\mathrm{E}$.

- Organización Mundial de la Salud. (2001). 48.a Asamblea Mundial de la Salud Geneva. Recuperado el 30 de diciembre de 2011 en: http://www.who.imt/gb.

- Organización Mundial de la Salud (2004). Estrategia mundial sobre régimen 
alimentario, actividad física y salud. Fomento del consumo mundial de frutas y verduras. Recuperado el 13 de julio de 2012.Disponible en: http://who.int/dietfisicalactivity/fruit/.

- Palatini, P. (2012). Cardiovascular effectsof exercise in Young hypertensives. International Journal of Sports Medicine.33(9):683-69o

- Palomo, I., Fuentes, E., Carrasco, G., González, D., Moore-Carrasco, R. (2010). Actividad antioxidante, hipolipemiante y antiplaquetaria del tomate (Solanum lycopersicum L.) y el efecto de su procesamiento y almacenaje. Revista Chilena de Nutrición; 37 (4), 524-533.

- Paoli, A., Marcoli, G., Zonin, F., Neri, M., Sivieri, A., Pacelli, Q.F. (2011). Exercicing fasting or fed to enhence fat loss?. Influence of food intake on respiratory ratio and excess postexercise oxygen consumption after a boot of endurance training. International Journal of Sport Nutrition and Exercise Metabolism. 21(1), 48-54.

- Pelegrina, M. y Salvador, F. (1999). La investigación experimental en psicología. Málaga: Aljibe.

- Pennathur, S., Maitra, D., Byun, J., Sliskovic, I., Abdulhamid, I., Saed, G. et al. (2010). Potent antioxidative activity of lycopene: a potential role in scavenging hypoclorous acid. Free Radical Biology and Medicine, 49, 205213.

- Pérez, A., Marván, L. (2000). Manual de Dietas Normales y Terapéuticas. ( $4^{\mathrm{a}}$. Ed.). México: La Prensa Médica Mexicana, S.A. de C.V.

- Pérez, A., Palacios, B., Castro, A. (2008). Sistema Mexicano se Alimentos Equivalentes. ( $3^{\mathrm{a}}$. Ed.). México: Fomento de Nutrición y Salud A.C. y Ogali.

- Pérez, A., Rigla, M. (2004). Ejercicio físico en diversos trastornos metabólicos: diabetes, dilipemia y obesidad. En: R, Serra, C. Bagur, Prescripción de Ejercicio Físico para la Salud (pp.341-374). España: Ed. Paidotribo.

- Pérez, O. (2009). Anormalidades de las lipoproteínas que contienen ApoB. En: S, Barquera, e I. Campos, Dislipidemias, epidemiología, evaluación, adherencia y tratamiento (pp.33-51). México. Instituto Nacional de Salud Pública.

- Pérez, O. (2009) b. Alteraciones de las lipoproteínas de alta densidad (HDL) En: S, Barquera e I, Campos, Dislipidemias, epidemiología, evaluación, adherencia y tratamiento (pp.53-68). México: Instituto Nacional de Salud Pública.

- Periago, M.J., Martínez-Valverde, I., Ros, G., Martínez, C., López, G. (2001). Propiedades químicas, biológicas y valor nutritivo del licopeno. Anales de Veterinaria de Murcia, 17, 51-66.

- Pértregas, S., Pita, S. (2003). Cálculo del poder estadístico de un estudio. Cadernos de Atención Primaria; 1, 59-63.

- Pimentel, G., Moreto, F., Takahashi, M., Portero-Maclellan, K., Burini, R. (2011). Sagital abdominal diameter, but no waist circumference is 
strongly associated with glycemia, triacilglycerols and HDL-c levels in overweight adults. Nutrición Hospitalaria. 26(5), 1225-1229.

- Pontes, L.M., Pinheiro, S.S., Zemolín, C.M., Araújo, T.K.C., Silva, R.L., Kumamoto, F.I.D. et al. (2008). Standard of physical activity and influence of sedentarism in the occurrence of dyslipidemias in adults. Fitness \& Performance Journal, 7 (4), 245-250.

- Procuraduría Federal del Consumidor. Revista del Consumidor. (2011), 407,44-53.Disponible en: revistadelconsumidor.gob.mx.

- Querales, M., Sánchez, C., Querales, M. (2013). Dislipidemias en un grupo de adultos. Salus online, 7-14.

- Ramírez, J., Ortega R., Gallegos, M., Ruíz J., Brito, E., Albadalejo, M. (2011). El ejercicio físico. La actuación no farmacológica con mayor impacto en la prevención cardiovascular. En: D. San Román Sánchez., J.A. Ruíz Caballero (Edit.), Deporte y corazón (pp.303-320). España: Wanceulen Médica.

- Rao, A., Agarwal, S. (2000). Role of oxidant lycopene in cancer and heart disease. Journal of American College of Nutrition, 19, 563-569.

- Rao, A., Shen, H. (2002). Effect of low dose lycopene intake on lycopene bioavailability and oxidative stress. Nutrition Research, 22, 1125-1131.

- Rao, A. (2002). Lycopene, tomatoes and prevention of coronary heart disease. Experimental Biology and Medicine, 227, 908-913.

- Rao, L., Krishnadev, N., Banasikowska, K., Rao, A. (2003). Lycopene I. Effect on osteoclasts; lycopene inhibits basal and Parathyroid Hormone (PTH)-Simulated osteoclast formation and mineral resorption medianted by Reactive Oxygen Species (ROS) in a Rat Bone Marrow Cultures. Journal of Medicinal Food, 6 (2), 69-78.

- Rao, A., Amanat, A. (2007). Biologically active phytochemicals in human health: Lycopene. International Journal of Food Properties, 10, 279-288.

- Rincón, M., Sarmiento, J. (2010). Manejo no farmacológico de las dislipidemias. En: Blanco, M., Trujillo, A. Dislipoproteinemia, (pp.329-334).

- Rissanen, T., Voutilainen, S., Salonen, R., Kaplan, G., Salonen, J. (2000). Serum lycopene concentration and carotid atherosclerosis: the Kupio Ischaemic Heart Disease Risk Factor Study. American Journal of Clinical Nutrition, 77, 133-138.

- Rodas, G., Garrido, E. (2006). Valoración funcional y cardiologico previa al entrenamiento físico. En: R. Serra, C. Bagur. Prescripción de Ejercicio Físico para la Salud. (pp. 27-55). España. Ed. Paidotribo.

- Rodríguez, G., Boned, C., Garrido, M. (2009). Motivos y barreras para hacer ejercicio y practicar deportes en Madrid. Revista Panamericana de Salud Pública. 26(3), 244-254.

- Roldán, E., Lopera, M., Londoño F., Cardeño, J., Zapata, S. (2008). Análisis descriptivo de las variables: nivel de actividad física, depresión y riesgos cardiovasculares en empleados y docentes de una institución 
universitaria en Medellín (Colombia). Apunts Medicina de L'Esport, 158, $55-61$.

- Roselló, M., Guzmán, S., Bolaños, M. (2001). Efecto de un programa de rehabilitación cardiaca en la alimentación, peso corporal, perfil lipídico y ejercicio físico de pacientes con enfermedad corornaria. Revista Costarricense de Cardiología; 3(2), 15-20.

- Ruiz, J., Mesa, J., Mingorance, I., Rodríguez-Cuartero, A., Castillo, M. (2004). Deportes con alto grado de estrés físico afectan negativamente al perfil lipídico plasmático. Revista Española de Cardiología, 57(6), 495-498.

- Saha, S.A., Kizhakepunnur, L.G., Bahekar, A., Arora, R.R. (2007). The role of fibrates in the prevention of cardiovascular disease a pooled metaanalysis of long term randomized placebo-controlled clinical trials. American Heart Journal, 154,943-53.

- Sánchez, C., Pichardo, E., López, P. (2004). Epidemiología de la Obesidad. Gaceta Médica de México. 140(S2): S3-S20.

- Santosh, K., Shipra, G., Shreesh, O., Suman, S. (2010). Cardiovascular friendly natural products: a promising approach in the management of CVD. Natural Product Research, 24 (9), 873-898.

- Secretaría de Salud. (1987) Reglamento de la Ley General de Salud en Materia de Investigación para la Salud de los Estados Unidos Mexicanos. Recuperado el 3 de mayo de 2012 en: http://www.salud. gob.mx/unidades/cdi/nom/compi/rlgsmis.html.

- Secretaría de Salud. (1993). Encuesta Nacional de Enfermedades Crónicas. Dirección General de Epidemiología México.

- Secretaría de Salud (2006). Boletín de Información Estadística No. 23, Volumen IV. Dirección General de Información en Salud. México.

- Secretaría de Salud. Subsecretaría de Prevención y Promoción de la Salud. (2008) Anuarios de mortalidad SEED/DGESS/INEGI, 2000-2006. Recuperado el 20 de octubre de 2011 en http://www.cenave.gob.mx/prograccion/cardio.pdf.

- Secretaría de Salud. Subsecretaría de Prevención y Promoción de la Salud. (2008). Programa de Acción Específico 2007-2012. Riesgo Cardiovascular. Recuperado el 20 de octubre de 2011 en: http://www.cenave.gob.mx/prograccion/cardio.pdf.

- Secretaría de Salud (2009). Unidad de Análisis Económico: Gasto catastrófico por motivos de Salud en México 2009. México.

- Secretaría de Salud. Dirección General de Información en Salud (DGIS). Sistema Nacional de Información en Salud (SINAIS) (2012). Estadísticas de Mortalidad 2008. Recuperado el 12 de junio de 2011 en: http://www.sinais.salud.gob.mx.

- Secretaría de Salud/Dirección General de Información en Salud. Sistema Nacional de Información en Salud. (2012). Principales causas de mortalidad en México 2008. Elaborado a partir de la base de datos de defunciones 19792008 INEGI/SS y de las Proyecciones de la Población de México 2005-2050, 
y proyección retrospectiva 1990-2004. CONAPO 2006. Recuperado el 20 de octubre de 2011 en: http:// www.sinais.salud.gob.mx.

- Secretaría de Salud/Dirección General de Información en Salud. Sistema Nacional de Información en Salud. (SINAIS)(2012). Principales causas de mortalidad en Yucatán, 2008. Elaborado a partir de la base de datos de defunciones 1979-2008 INEGI/SS y de las Proyecciones de la Población de México 2005-2050, y proyección retrospectiva 1990-2004. CONAPO 2006. Recuperado el 20 de octubre de 2011 en: http:// www.sinais.salud.gob.mx.

- Secretaría de Salud/ Subsecretaría de Integración y Desarrollo del Sector Salud/Dirección General de Evaluación del Desempeño. Rendición de cuentas en Salud 2010. Recuperado el 13 de septiembre de 2012 en: http: www.dged.salud.gov.ma/contenidos/dedss/descargas/res/RCS2010.pdf.

- Sesso, H., Lui, S., Gaziano, J., Buring, J. (2003). Dietary lycopene, tomatobased food products and cardiovascular disease in women. Journal of Nutrition, 133, 2336-2341.

- Shami, N. J. I. E., Moreira, E. A. M. (2004). Licopeno como agente antioxidante. Revista de Nutrição Campinas, 17 (2), 227-236.

- Shen, Y., Chen, S., Wang, C. (2007). Contribution of tomato phenolics to antioxidation and down-regulation of blood lipids. Journal of Agricultural and Food Chemistry, Ss (16), 6475-6481.

- Shi, J., Qu, Q., Kakùda, Y., Yeung, D., Jiang, Y. (2004). Stability and synergistic of antioxidative properties of lycopene and other active components. Critical Reviews in Food Science and Nutrition, 44, 559-573.

- Shixian, Q., Dai, Y., Kakuda, Y., Shi, J., Mittal, G., Yeung, D. et al. (2007). Synergistic anti-oxidative effects of lycopene with other bioactive compounds. Food Reviews International, 21, 295-311.

- Shukla, S., Gupta, S., Ojha, S., Sharma, S. (2010). Cardiovascular friendly natural products: a promising approach in the management of CVD. Natural Product Reserch, 24:873-898.

- Silaste, M., Alfthan, G., Aro, A., Kesäniemi, Y., Hörkkö, S. (2007).Tomato juice decreases LDL cholesterol levels and increases LDL resistance to oxidation. British Journal of Nutrition, 98 (6), 1251-1258.

- Stahl, W., Sies, H. (1996). Lycopene: a biologically important carotenoid for humans? Archives of Biochemistry and Biophysics, 336(1), 1-9.

- Stefanick, M., Mackey, S., Sheehan, M., Ellsworth, N., Haskell, W., Wood, P. (1998). Effects of diet and exercise in men and postmenopuasal womwn with low levels of HDL cholesterol and high levels of LDL cholesterol. The New England Journal of Medicine, 339, 12-20.

- Stevens, G., Díaz, R.H., Thomas, K.J.A., Rivera, J.A, Carvalho, N. et al. (2008). Characterizing the Epidemiological Transition in México: National and Subnational Burden of Diseases, Injuries and Risk Factors. PLoS Medicine, 5(6), e 125 .

- Story, E., Kopec, R., Schwartz, S., Harris, G. (2010). An update on the health effects of tomato lycopene. Annual Review of Food Science 
Technology, 1, 189-210.

- Tapia, C., Gutiérrez, G., Sepúlveda, J. (1992). Metodología de la Encuesta Nacional Seroepidemiológica. Salud Pública de México, 34, 124-135.

- Torres, F., Dutilh, M., Tirapegui, J. (2009). The effect of physical exercise and caloric restriction on the components of metabolic syndrome. Brazilian Journal of Pharmaceutical Sciences, 45 (3), 379-399.

- Torresani, M. (2009) Asociación entre riesgo cardiovascular y consumo de licopeno en mujeres pre y post menopáusicas. Archivos Latinoamericanos de Nutrición, 59, 120-127.

- Valdespino, J., Olaiz, G., López, M., Mendoza, L., Palma, O., Velázques, O. et al. (2003). Encuesta Nacional de Salud 2000. Instituto Nacional de Salud Pública. México.

- Van Breemen, R., Pajkovic, N. (2008). Multitargeted theraphy of cáncer by lycopene. Cancer Letters, 269, 339-351.

- Van Breemen, R, Sharifi, R., Viana, M., Pajkovic, N., Zhu, D., Yuan, L. et al. (2011). Antioxidant effects of lycopene in african-american men with prostate cancer or benign prostate hyperplasia: a randomized controlled trial. Cancer Prevention Research, 4(5), 711-718.

- Varady, K., Jones, P. (2005). Combination Diet and Exercise Interventions for the Treatment of Dyslipidemia: an Effective Preliminary Strategy to Lower Cholesterol Levels? The Journal of Nutrition, 135 (8), 1829-1835.

- Varady, K., Bhutani, S., Klempel, M., Kroeger, C. (2011) Comparison of effects of diet versus exercise weight loss regimens on LDL and HDL particle size in obese adults. Lipids in Health and Disease. 10, 119.

- Varo, J., Martínez, A., Martínez, M. (2003). Beneficios de la actividad física y riesgos del sedentarismo. Medicina Clínica (Barc), 121(17), 665-672.

- Vasconcelos, A. (2005). Planificación y organización del entrenamiento deportivo. España: Editorial Paidotribo.

- Villar, F., Maiques, A., Brotons, C., Torcal, J., Lorenzo, A., Vilaseca, J. et al. (2001). Prevención cardiovacular en prevención primaria. Atención Primaria, 28(2), 23-36.

- Villalobos, A., Rojas, R. (2007).Consumo de tabaco en México.Resultados de las Encuestas Nacionales de Salud 2000 y 2006. Salud Pública de México, 49 (S2), S147-154.

- Vitale, A., Bernatene, E., Pomilio, A. (2010). Carotenoides en quimioprevención: licopeno. Acta Bioquímica Clínica Latinoamericana, $44(2), 195-238$.

- Voeghtly, L., Neatrour, D., Decewicz, D., Burke, A., Haberkorn, M., Lechak, F. et al. (2012). Cardiometabolic risk reduction in an intensive cardiovascular health program. Nutrition, Metabolism \& Cardiovascular Diseases, 23(7):662-669. 
- Waliszewki, K., Blasco, G. (2010). Propiedades nutracéuticas del licopeno. Salud Pública de México, 52 (3), 254-265.

- Watts, K., Jones, T.W., Davis, E.A., Green, D. (2005). Exercise training in obese children and adolescents: curren concepts. Sports Medicine, 35 (5), 375-392.

- Willcox, J., Catignani, G., Lazarus, S. (2003). Tomatoes and cardiovascular health. Critical Reviews in Food and Science and Nutrition, 43 (1), 1-18.

- Woolf-May, K. (2008). Prescripción del ejercicio. Fundamentos fisiológicos. España: Elsevier.Masson.

- Wooten, J., Biggerstaff, K., Ben-Ezra, V. (2009). Responses of LDL and HDL particle size and distribution to omega-3 fatty acid supplementation and aerobic exercise. Journal of Applied Physiology, 107 (3), 794-800.

- World Health Organization. (2000). Technical Report series894: Obesity: Preventing and Mannaging the global epidemic: report of WHO consultation. Geneva.

- World Health Organization. (2002). World Health Report 2002. Geneva.

- World Health Organization. (2005). Preventing Chronic Diseases: a Vital Investment. Geneva: WHO. Recuperado en: http://www.who.int/chp/chronic_disease_report/contents/foreword.pdf

- Yeo, H., Kim, O., Lim, H., Kim, J., Lee, J. (2010). Association of serum lycopene and brachial-ankle pulse wave velocity with metabolic syndrome. Metabolism Clininical and Experimental, 6o, 537-543.

- Yusuf, S., Hawen, S., Ounpuu, S., Dans, T., Avezum, A., Lanas, F. et al. (2004). Effect of potentially modifiable risk factors associated with myocardial infarction in 52 countries (the INTERHEART study): casecontrol study. Lancet, 364(9438), 937-52.

- Zerceño, E., Rodríguez, J., Cantón, E. (2009). La Psicología de la Salud y la Psicología del Deporte. FACAD, 2, 3-20 


\title{
ANEXO.I
}

\section{PROGRAMA DE ACTIVIDADES}

\author{
UNIVERSIDAD AUTÓNOMA DE YUCATÁN \\ FACULTAD DE MEDICINA \\ UNIDAD CARDIOMETABÓLICA
}

\section{SESIONES DEL GRUPO DE TRABAJO DEL PROYECTO DE DISLIPIDEMIAS}

\begin{tabular}{|c|c|c|}
\hline Sesiones Grupales & Consultas de Nutrición & $\begin{array}{l}\text { Pruebas de } \\
\text { laboratorio y } \\
\text { gabinete }\end{array}$ \\
\hline \multirow{2}{*}{$\begin{array}{l}1 \text { de inicio informativa } \\
\text { con duración de máximo } \\
\text { dos horas entre el } 12 \text { y } 15 \\
\text { de diciembre de } 2011\end{array}$} & $\begin{array}{l}1 \text { en enero inicial con } \\
\text { duración máxima de una } \\
\text { hora }\end{array}$ & \multirow{2}{*}{$\begin{array}{l}1 \text { perfil de lípidos } \\
\text { al inicio } \\
1 \text { prueba de } \\
\text { esfuerzo l inicio }\end{array}$} \\
\hline & $\begin{array}{l}1 \text { en febrero de control con } \\
\text { duración de } 20 \text { minutos }\end{array}$ & \\
\hline $\begin{array}{l}1 \text { final para compartir los } \\
\text { resultados entre el } 28 \text { y } \\
30 \text { de marzo de } 2012 \text { con } \\
\text { duración de una hora }\end{array}$ & $\begin{array}{l}1 \text { en marzo final con } \\
\text { duración de } 40 \text { minutos }\end{array}$ & $\begin{array}{l}\text { 1 perfil de lípidos } \\
\text { al final }\end{array}$ \\
\hline
\end{tabular}

Para las sesiones grupales de inicio y final se tendrán dos turnos matutino ( 8 a 10 horas) y vespertino (17:30 a 19:30 horas).

Las consultas de nutrición se calendarizarán con fechas programadas de acuerdo con su disponibilidad de horario.

El perfil de lípidos será realizado en la Facultad de Química de la UADY en horario de 7:00 a 11:00 h. de lunes a viernes. Las sesiones como las consultas de nutrición y la prueba de esfuerzo se realizarán en la Unidad Cardiomatabólica cuya dirección es: Av. Itzaes No. 486 entre 59 A y 86, Col. Centro (frente a la Facultad de Medicina) no tendrán costo. Teléfono 9237396. 


\section{PROGRAMA DE ACTIVIDADES PREVIAS A LA INTERVENCIÓN}

\begin{tabular}{|c|c|}
\hline \multicolumn{2}{|c|}{ Del 28 de noviembre al 2 de diciembre de 2011} \\
\hline Actividades & Para \\
\hline \multirow[t]{3}{*}{$\begin{array}{l}\text { 1.- Invitar a los participantes } \\
\text { al programa de intervención }\end{array}$} & $\begin{array}{l}\text { 1. Realizar un listado con el nombre } \\
\text { completo, domicilio, teléfono, edad, sexo, } \\
\text { consumo de medicamentos, si realiza } \\
\text { ejercicio y la disponibilidad de horario de } \\
\text { los participantes para asistir a las sesiones } \\
\text { y las consultas. }\end{array}$ \\
\hline & $\begin{array}{l}\text { 2. Elaborar de acuerdo con la } \\
\text { disponibilidad de horario de los } \\
\text { participantes, las listas de los grupos que } \\
\text { acudirán por la mañana y los que lo harán } \\
\text { por la tarde tanto a las sesiones como a la } \\
\text { consulta, así como las listas de los que } \\
\text { harán ejercicio y los que no. } \\
\text { (Independientemente de su distribución en } \\
\text { los grupos control y experimental). }\end{array}$ \\
\hline & $\begin{array}{l}\text { 3. Distribuir a los participantes por rangos } \\
\text { de edad y sexo para luego repartirlos } \\
\text { aleatoriamente en los dos grupos control y } \\
\text { experimentales. }\end{array}$ \\
\hline \multirow[t]{2}{*}{$\begin{array}{l}\text { 2. Elaborar todos los } \\
\text { formatos para obtener los } \\
\text { datos de los participantes }\end{array}$} & $\begin{array}{l}\text { 1. Contar con los juegos de fotocopias de la } \\
\text { carta de consentimiento informado, así } \\
\text { como las hojas de registro de datos } \\
\text { antropométricos y bioquímicos. }\end{array}$ \\
\hline & $\begin{array}{l}\text { 2. Contar con los formatos de solicitud de } \\
\text { perfil de lípidos firmados por el médico. }\end{array}$ \\
\hline \multirow[t]{2}{*}{$\begin{array}{l}\text { 3. Elaborar los materiales } \\
\text { para las sesiones educativas }\end{array}$} & $\begin{array}{l}\text { 1. Contar con las presentaciones para el } \\
\text { taller: del psicólogo, del médico, del } \\
\text { nutriólogo y del médico del deporte. }\end{array}$ \\
\hline & $\begin{array}{l}\text { 2. Contar con el material educativo para } \\
\text { los participantes }\end{array}$ \\
\hline
\end{tabular}

\begin{tabular}{|l|l|}
\hline \multicolumn{2}{|c|}{ Del $\mathbf{5}$ al $\mathbf{9}$ de diciembre de 2011} \\
\hline \multicolumn{1}{|c|}{ Actividades } & \multicolumn{1}{|c|}{ Para } \\
\hline $\begin{array}{l}\text { 1.- Diseñar el programa de } \\
\text { ejercicio aeróbico adecuado } \\
\text { para personas con } \\
\text { dislipemias }\end{array}$ & $\begin{array}{l}\text { 1. Capacitar a los investigadores en la } \\
\text { metodología para realizar ejercicio físico } \\
\text { dislipemias para las personas con }\end{array}$ \\
\hline
\end{tabular}




\begin{tabular}{|c|c|}
\hline \multicolumn{2}{|r|}{ Del 12 al 15 de diciembre de 2011} \\
\hline Actividades & Para \\
\hline \multirow[t]{7}{*}{$\begin{array}{l}\text { 1. Realizar el taller } \\
\text { con los } \\
\text { participantes. } \\
(1: 30-2: 00 \mathrm{~h})\end{array}$} & $\begin{array}{l}\text { 1. Proporcionar información sobre las dislipemias, } \\
\text { sus complicaciones, el tratamiento farmacológico y } \\
\text { sus efectos, el tratamiento no farmacológico y sus } \\
\text { beneficios a largo plazo. }\end{array}$ \\
\hline & $\begin{array}{l}\text { 2. Proporcionar información sobre el programa de } \\
\text { intervención y su metodología. }\end{array}$ \\
\hline & $\begin{array}{l}\text { 3. Realizar las mediciones corporales de peso, } \\
\text { estatura, IMC, porcentaje de grasa corporal, tensión } \\
\text { arterial, circunferencia abdominal. }\end{array}$ \\
\hline & $\begin{array}{l}\text { 4. Obtener la firma de la carta de consentimiento } \\
\text { informado. }\end{array}$ \\
\hline & $\begin{array}{l}\text { 5. Entrega de la orden para la realización de la } \\
\text { primera toma de laboratorio de perfil de lípidos } \\
\text { (para entregar resultados el día de su primera } \\
\text { consulta) y de su calendario de consultas de } \\
\text { nutrición. }\end{array}$ \\
\hline & $\begin{array}{l}\text { 6. Distribuir en forma aleatoria a los participantes en } \\
\text { el grupo control y experimental. }\end{array}$ \\
\hline & $\begin{array}{l}\text { 7. Entregar la orden de la prueba de esfuerzo a los } \\
\text { participantes que realizarán ejercicio. }\end{array}$ \\
\hline
\end{tabular}

\begin{tabular}{|c|c|}
\hline \multicolumn{2}{|c|}{ Del 16 y 19 de diciembre de 2011} \\
\hline Actividades & Para \\
\hline \multirow[t]{2}{*}{$\begin{array}{l}\text { 1. Capacitar a los } \\
\text { participantes que realizarán } \\
\text { ejercicio físico }(1: 00-1: 30 \mathrm{~h})\end{array}$} & $\begin{array}{l}\text { 1. Presentar el programa de ejercicio físico } \\
\text { a los participantes y las opciones para } \\
\text { realizarlo. }\end{array}$ \\
\hline & 2. Capacitar a los participantes \\
\hline
\end{tabular}

\section{DURANTE LA INTERVENCIÓN}

\begin{tabular}{|c|c|}
\hline \multicolumn{2}{|c|}{ Del 4 de enero al 27 de marzo de 2012} \\
\hline Actividades & Para \\
\hline \multirow{5}{*}{$\begin{array}{l}\text { 1. Proporcionar } \\
\text { consulta de nutrición } \\
\text { de acuerdo con su } \\
\text { calendario personal } \\
\text { previamente } \\
\text { entregado }\end{array}$} & $\begin{array}{l}\text { 1. Elaboración de expediente clínico con todas sus } \\
\text { evaluaciones (antropométrica, bioquímica, clínica } \\
\text { y dietética) de cada participante. }\end{array}$ \\
\hline & $\begin{array}{l}\text { 2. Entregar el menú (control o experimental) a } \\
\text { cada participante }\end{array}$ \\
\hline & $\begin{array}{l}\text { 3. Acordar con cada participante (control o } \\
\text { experimental) su plan de ejercicio físico }\end{array}$ \\
\hline & 4. Recordar la cita subsecuente \\
\hline & $\begin{array}{l}\text { 5. Entregar en la penúltima cita la orden para la } \\
\text { realización de la segunda toma de laboratorio de } \\
\text { perfil de lípidos (para entregar resultados el día de } \\
\text { su última consulta) }\end{array}$ \\
\hline
\end{tabular}


DESPUÉS DE LA INTERVENCIÓN

Del 28 al 30 de marzo de 2012

Actividades Para

1. Elaborar un informe de 1. Presentar a los participantes y agradecer resultados. su apoyo.

2. Clausurar el programa 


\title{
ANEXO.II
}

\author{
CARTA DE CONSENTIMIENTO \\ INFORMADO PARA LOS \\ PARTICIPANTES EN EL ESTUDIO
}

\section{UNIVERSIDAD AUTÓNOMA DE YUCATÁN \\ FACULTAD DE MEDICINA \\ UNIDAD CARDIOMETABÓLICA}

CARTA DE CONSENTIMIENTO INFORMADO PARA PARTICIPAR EN UN ESTUDIO DE INVESTIGACIÓN MÉDICA

"Efecto de una dieta rica en licopeno y de la práctica de ejercicio físico sobre los niveles de lípidos y el porcentaje de grasa corporal en adultos con dislipemia"

Usted está invitando a participar en este estudio de investigación. Antes de decidir su participación debe conocer y comprender cada uno de los siguientes apartados. Este proceso se conoce como consentimiento informado. Siéntase con absoluta libertad para preguntar sobre cualquier aspecto que le ayude a aclarar sus dudas al respecto.

Una vez que haya comprendido el estudio y si usted desea participar, entonces se le pedirá que firme este formato, del cual se le entregará una copia firmada y fechada.

1. JUSTIFICACIÓN DEL ESTUDIO. Los niveles altos en sangre de colesterol, triglicéridos, lipoproteínas de baja densidad (LDL) y niveles bajos de lipoproteínas de alta densidad (HDL), son los factores que provocan problemas de salud más graves como el infarto del miocardio y el infarto cerebral que producen discapacidad, gastos de atención médica elevados y pueden causar la muerte. En Yucatán las enfermedades cardiovasculares en los adultos son la segunda y tercera causas de muerte y a nivel nacional ocupan el cuarto lugar. 
Existen recomendaciones de organismos nacionales e internacionales para prevenir y controlar estas enfermedades que se concretan en tres puntos principales: el control de los factores de riesgo (dejar el tabaco; adoptar una dieta baja en grasas saturadas y alta en antioxidantes; disminuir el peso y el porcentaje de grasa corporal y en caso necesario la utilización de fármacos); la adopción de un programa de ejercicio físico supervisado y el apoyo psicológico (cambios en el comportamiento y motivación).

2. OBJETIVO DEL ESTUDIO. Por lo anterior el objetivo del presente estudio es conocer el efecto del ejercicio y la dieta rica en antioxidantes sobre los niveles en sangre de colesterol, triglicéridos, LDL y HDL y sobre el porcentaje de grasa corporal.

3. BENEFICIOS DEL ESTUDIO. Existen estudios que confirman que el ejercicio y la dieta que incluya sustancias antioxidantes que se encuentran en los vegetales tienen un efecto en la reducción de los niveles de lípidos en sangre. El ejercicio físico mejora la función cardiovascular y tiene efectos sobre los triglicéridos y las HDL, mientras que la dieta rica en antioxidantes disminuye el colesterol y las LDL.

4. PROCEDIMIENTO DEL ESTUDIO. El estudio tiene una duración de 12 semanas y se llevará a efecto en la Unidad Cardiometabólica de la Facultad de Medicina de la Universidad Autónoma de Yucatán (Av. Itzáez No. 486 entre 59ª y 86, Col. Centro en Mérida, Yucatán).

En caso que acepte participar en el estudio se le harán algunas preguntas relacionadas con sus antecedentes de salud, las mediciones corporales de peso, estatura, circunferencia abdominal y porcentaje de grasa corporal, como parte de la historia clínica. Se le realizará un perfil de lípidos para conocer sus niveles de colesterol, triglicéridos LDL y HDL al inicio y al final del procedimiento. Se someterán a una dieta que será monitoreada cada mes en la consulta de nutrición y a las personas que realizarán ejercicio se les someterá previamente una prueba de esfuerzo.

5. RIESGOS ASOCIADOS CON EL ESTUDIO. Para todo el procedimiento del estudio se le darán previamente las instrucciones y la capacitación necesaria con el objeto de evitarle algún riesgo, sin embargo existen algunas situaciones que pueden causarle alarma.

1. Posterior a la toma de la muestra de sangre para el perfil de lípidos puede aparecerle un moretón en la zona donde se introdujo la aguja que desaparece sin problemas.

2. Durante la prueba de esfuerzo puede presentar dolor en el pecho $u$ otros síntomas que serán tratados por el médico responsable de acuerdo con los procedimientos de seguridad y utilizando el equipo recomendado. 
2. Al inicio de un programa de ejercicio puede sentir dolor muscular que desaparecerá conforme se vaya acostumbrando a la actividad.

6. ACLARACIONES. Debe saber que su participación es voluntaria y puede retirarse del estudio en caso que así lo considere, en el momento en que lo desee, no recibirá pago por su participación, ni le generará gastos y la información obtenida será guardada en estricta confidencialidad.

\section{ACEPTACIÓN}

Yo,

he leído y comprendido la información anterior y entiendo que los datos obtenidos en el estudio pueden ser publicados o difundidos con fines científicos. Estoy de acuerdo en participar en este estudio de investigación. Recibiré una copia firmada y fechada de esta forma de consentimiento.

Firma del participante

Fecha

Esta parte debe ser completada por el Investigador:

He explicado al Sr(a).

el

objetivo y los procedimientos de la investigación, así como los beneficios y riesgos que implica su participación. He respondido sus dudas. Acepto que he leído y conozco la normatividad correspondiente para realizar investigación con seres humanos y me apego a ella.

Nombre y firma del investigador

Fecha 


\section{ANEXO.III}

\section{HISTORIA CLÍNICA \\ UNIVERSIDAD AUTÓNOMA DE YUCATÁN \\ FACULTAD DE MEDICINA \\ UNIDAD CARDIOMETABÓLICA}

Av. Itzáes No. 486 x 59 A y 86

Tel: 9-23-73-96

HISTORIA CLÍNICA

DATOS SOCIO-DEMOGRÁFICOS

Fecha

Nombre

Edad Sexo

Estado civil

Email:

Escolaridad

Ocupación

Dirección

$---$

Teléfonos: domicilio

celular trabajo

¿Cómo se entero del servicio?

ANTECEDENTES HEREDOFAMILIARES

\begin{tabular}{|l|l|l|l|l|l|l|l|l|}
\hline \multicolumn{1}{|c|}{ PATOLOGÍAS } & $\mathrm{Ma}$ & $\mathrm{Pa}$ & $\begin{array}{l}\mathrm{Ab} / \\
\mathrm{m}\end{array}$ & $\begin{array}{l}\mathrm{Abo} \\
\mathrm{Im}\end{array}$ & $\begin{array}{l}\mathrm{Ab} / \\
\mathrm{p}\end{array}$ & $\begin{array}{l}\mathrm{Abo} / \\
\mathrm{p}\end{array}$ & $\begin{array}{l}\mathrm{T} / \\
\mathrm{m}\end{array}$ & $\mathrm{T} / \mathrm{p}$ \\
\hline Obesidad & & & & & & & & \\
\hline Diabetes mellitus & & & & & & & & \\
\hline $\begin{array}{l}\text { Hipertensión } \\
\text { arterial }\end{array}$ & & & & & & & & \\
\hline Hipercolesterolemia & & & & & & & & \\
\hline Hipertrigliceridemia & & & & & & & & \\
\hline Cáncer & & & & & & & & \\
\hline Nefropatías & & & & & & & & \\
\hline Cardiopatías & & & & & & & & \\
\hline Epilepsia & & & & & & & & \\
\hline
\end{tabular}

Ma-madre; Pa-padre; Ab/m-abuela materna; Abo/m-abuelo materno; Ab/p-abuela paterna; Abo/p-abuelo paterno; $\mathrm{T} / \mathrm{m}$-tíos maternos y $\mathrm{T} / \mathrm{p}$-tíos paternos. 
ANTECEDENTES PERSONALES NO PATOLÓGICOS

\begin{tabular}{|l|c|l|c|c|}
\hline CONSUME & $\begin{array}{c}\text { VECES/ } \\
\text { SEMANA }\end{array}$ & CANTIDAD & $\begin{array}{c}\text { DESDE } \\
\text { CUANDO LO } \\
\text { CONSUME }\end{array}$ & $\begin{array}{c}\text { DESDE } \\
\text { CUANDO LO } \\
\text { DEJÓ }\end{array}$ \\
\hline Tabaco & & & & \\
\hline Alcohol & & & & \\
\hline Drogas & & & & ¿CUÁL? \\
\hline REALIZA & $\begin{array}{c}\text { VECES/ } \\
\text { SEMANA }\end{array}$ & TIEMPO & $\begin{array}{c}\text { DESDE CUNDO } \\
\text { LO REALIZA }\end{array}$ & ¿CEN \\
\hline Ejercicio & & & & \\
\hline
\end{tabular}

\begin{tabular}{|l|l|l|l|}
\hline \multicolumn{3}{|c|}{ ANTECEDENTES GINECOBSTÉTRICOS } \\
\hline Inicio menarquía & & Inicio menopausia & \\
\hline Fecha último período & & Duración del período & \\
\hline Embarazos & & Abortos & \\
\hline Partos & & Cesáreas & \\
\hline Método anticonceptivo & \multicolumn{3}{|l}{} \\
\hline
\end{tabular}

ANTECEDENTES PERSONALES PATOLÓGICOS

\begin{tabular}{|l|l|l|l|l|l|}
\hline \multicolumn{1}{|c|}{ PADECIMIENTOS SÍ } & TIEMPO & PADECIMIENTOS SÍ & TIEMPO \\
\hline EVC previo cerebral & & & Nefropatías & & \\
\hline $\begin{array}{l}\text { ISO } \\
\text { transitoria }\end{array}$ & & Cardiopatías & & \\
\hline $\begin{array}{l}\text { Enfermedad vascular } \\
\text { periférica }\end{array}$ & & & Angiopatías & & \\
\hline Gastritis & & Hipotensión & & \\
\hline Trombosis arterial & & Hipoglicemia & & \\
\hline Úlcera & & Artritis & & \\
\hline Trombosis Venosa & & Anemia & & \\
\hline Hipertrigliceridemia & & Epilepsia & & \\
\hline Cáncer & & $\begin{array}{l}\text { Intolerancia a } \\
\text { alimentos }\end{array}$ & & \\
\hline Colon irritable & & $\begin{array}{l}\text { Alergia } \\
\text { alimentos a }\end{array}$ & & \\
\hline Obesidad & & $\begin{array}{l}\text { Alergia } \\
\text { medicamentos }\end{array}$ & & \\
\hline Diabetes mellitus & & & Estreñimiento & & \\
\hline Hipertensión arterial & & & Otras: & & \\
\hline Hipercolesterolemia & & & & & \\
\hline $\begin{array}{l}\text { Enfermedades } \\
\text { respiratorias }\end{array}$ & & & & & \\
\hline $\begin{array}{l}\text { Enfermedades de la } \\
\text { tiroides }\end{array}$ & & & & \\
\hline
\end{tabular}


INTERROGATORIO POR APARATOS Y SISTEMAS

\begin{tabular}{|l|l|}
\hline APARATOS Y SISTEMAS & \multicolumn{1}{|c|}{ CONDICIONES } \\
\hline Respiratorio & \\
\hline Cardiovascular & \\
\hline Urinario & \\
\hline Digestivo & \\
\hline Neurológico & \\
\hline Osteo-muscular & \\
\hline
\end{tabular}

\begin{tabular}{|c|c|}
\hline \multicolumn{2}{|c|}{ TRATAMIENTOS PREVIOS } \\
\hline CIRUGÍAS & \\
\hline & \\
\hline & \\
\hline & TIEMPO \\
\hline MEDICAMENTOS & \\
\hline & \\
\hline & \\
\hline & \\
\hline & \\
\hline & \\
\hline
\end{tabular}

EXPLORACIÓN FÍSICA

SIGNOS VITALES

\begin{tabular}{|c|c|c|c|}
\hline FECHA & $\begin{array}{c}\text { TENSIÓN } \\
\text { ARTERIAL }\end{array}$ & $\begin{array}{c}\text { FRECUENCIA } \\
\text { CARDIACA }\end{array}$ & $\begin{array}{c}\text { RIESGO } \\
\text { CARDIOVASCULAR }\end{array}$ \\
\hline & & & \\
\hline & & & \\
\hline & & & \\
\hline & & & \\
\hline
\end{tabular}

EVALUACIÓN BIOQUÍMICA

\begin{tabular}{|c|c|c|c|c|}
\hline FECHA & CT & TG & HDL & LDL \\
\hline & & & & \\
\hline & & & & \\
\hline & & & & \\
\hline & & & & \\
\hline
\end{tabular}


EVALUACIÓN DIETÉTICA

\begin{tabular}{|l|l|}
\hline ALIMENTOS QUE LE GUSTAN & \\
\hline $\begin{array}{l}\text { ALIMENTOS OUE NO LE } \\
\text { GUSTAN O NO CONSUME }\end{array}$ & \\
\hline CANTIDAD DE AGUA AL DÍA & \\
\hline
\end{tabular}

\begin{tabular}{|l|l|l|l|}
\hline \multicolumn{3}{|c|}{ FRECUENCIA DE CONSUMO DE ALIMENTOS } \\
\hline Alimento & Frecuencia & \multicolumn{1}{c|}{ Alimento } & Frecuencia \\
\hline Pollo & & Pan dulce & \\
\hline Res & & Pan francés & \\
\hline Cerdo & & Tortillas de maíz & \\
\hline Pescado & Tortillas de harina & \\
\hline Atún & & Frutas & \\
\hline Mariscos & Verduras & \\
\hline Huevo & & Manteca & \\
\hline Jamón & & Mantequilla & \\
\hline Salchicha & & Mermelada & \\
\hline Leche & & Miel & \\
\hline Yogurt & Jugos naturales & \\
\hline Crema & $\begin{array}{l}\text { Refrescos } \\
\text { embotellados }\end{array}$ & \\
\hline Queso & Jugos industrializados & \\
\hline Leguminosas & & Refrescos naturales & \\
\hline Pan de caja blanco & & Café/té & \\
\hline Pan de caja integral & & Dulces y helados & \\
\hline Pastelitos/galletas & & Productos light & \\
\hline
\end{tabular}

EVALUACIÓN ANTROPOMÉTRICA

\begin{tabular}{|c|l|l|l|l|l|l|l|c|}
\hline Fecha & Peso & Estatura & IMC & $\begin{array}{c}\text { \% de } \\
\text { grasa }\end{array}$ & C.A. & $\begin{array}{c}\text { Kg. } \\
\text { grasa }\end{array}$ & $\begin{array}{c}\text { Kg. } \\
\text { magra }\end{array}$ & $\begin{array}{c}\text { Kg. } \\
\text { Agua }\end{array}$ \\
\hline & & & & & & & & \\
\hline & & & & & & & & \\
\hline & & & & & & & & \\
\hline & & & & & & & & \\
\hline
\end{tabular}

DIAGNÓSTICO NUTRICIONAL

TRATAMIENTO NUTRICIONAL 
NOTA DE EVOLUCIÓN

HOJA

\begin{tabular}{|c|l|}
\hline $\begin{array}{c}\text { UNIVERSIDAD AUTÓNOMA DE } \\
\text { YUCATÁN }\end{array}$ & Nombre: \\
\cline { 2 - 2 } $\begin{array}{c}\text { FACULTAD DE MEDICINA } \\
\text { UNIDAD CARDIOMETABÓLICA }\end{array}$ & Folio: \\
\hline
\end{tabular}

\begin{tabular}{|c|c|}
\hline $\begin{array}{c}\text { FECHAY } \\
\text { HORA }\end{array}$ & EVOLUCIÓN \\
\hline . & \\
& \\
& \\
& \\
& \\
& \\
& \\
\end{tabular}




\section{ANEXO.IV}

\section{EJEMPLO DE PROGRAMA DE EJERCICIO FÍSICO}

Objetivo: disminuir los niveles séricos de colesterol total, triglicérido y LDL, el porcentaje de grasa corporal, la circunferencia abdominal y el IMC, así como incrementar el HDL.

\begin{tabular}{|c|c|c|}
\hline \multicolumn{3}{|c|}{ Etapas de una sesión de ejercicio } \\
\hline Etapas & Características & Tiempo \\
\hline $\begin{array}{l}\text { Preparatoria o } \\
\text { de } \\
\text { calentamiento }\end{array}$ & $\begin{array}{l}\text { El calentamiento y estiramiento de los } \\
\text { músculos incrementa la elasticidad y } \\
\text { disminuye la posibilidad de tirones y } \\
\text { desgarros musculares. Primero se aceleran } \\
\text { los latidos del corazón y la frecuencia } \\
\text { respiratoria, activados por la demanda de } \\
\text { sangre, nutrimentos y oxígeno y por la } \\
\text { necesidad de la eliminación del Coz y los } \\
\text { metabolitos de desecho, lo que se traduce } \\
\text { en un incremento de la vascularización } \\
\text { periférica y la transpiración. }\end{array}$ & 10 minutos \\
\hline Principal & $\begin{array}{l}\text { Es donde se logra la máxima eficiencia del } \\
\text { ejercicio o deporte practicado. } \\
\text { Psicológicamente, nos ayuda a controlar la } \\
\text { ansiedad y sirve como mecanismo de } \\
\text { desviación del estrés, además de mejora la } \\
\text { disposición psíquica, la percepción sensorial } \\
\text { y la atención, así como la activación de } \\
\text { determinadas estructuras centrales. A nivel } \\
\text { fisiológico, no solo mejora la musculatura, } \\
\text { sino también el sistema cardiorrespiratorio y } \\
\text { neuromuscular. }\end{array}$ & $\begin{array}{c}20-40 \\
\text { minutos }\end{array}$ \\
\hline $\begin{array}{l}\text { Final } o \text { de } \\
\text { enfriamiento }\end{array}$ & $\begin{array}{l}\text { Es cuando la persona pasa de un estado de } \\
\text { activación a uno de laxitud, la frecuencia } \\
\text { cardiaca y la demanda de oxigeno vuelven } \\
\text { paulatinamente a la normalidad. Es } \\
\text { necesario la realización de estiramiento y } \\
\text { ejercicios de relajación para concluir }\end{array}$ & 10 minutos \\
\hline
\end{tabular}




\section{Ejemplo de una sesión de ejercicio}

Calentamiento general: actividades de mediana intensidad y de carácter general con duración de 3 minutos

1. Iniciar con movimientos ligeros del cuello

2. Luego ligeros movimientos y balanceos de brazos con los codos por debajo de los hombros.

3. Después movimientos más amplios de brazos solicitando mayor musculatura por subir los codos por encima de los hombros

4. Después un grupo de ejercicios por musculatura, pectorales, bíceps, hombros y tríceps.

5. Intensifica el calentamiento de los brazos con ejercicios de mayor intensidad, como elevaciones laterales completas.

6. Ampliamos la amplitud de movimiento articular de los hombros mediante rotaciones forzando los límites de la flexibilidad.

7. Empezamos el calentamiento de la zona abdominal y la cadera con elevaciones de los muslos y rotaciones de la cadera.

8. Realizan aperturas de las piernas calienta abductores.

9. Mediante pequeños saltos con y sin flexión, calentamos: glúteos y cuádriceps.

10. Mediante medias sentadillas y sentadillas se calienta más intensamente el tren inferior.

11. Para terminar unos saltos hacen que aumente las pulsaciones y la temperatura corporal.

Calentamiento específico: ejercicios y movimientos directamente relacionados con las habilidades o capacidades físicas propias de la actividad a realizar con duración de 7 minutos

1. Movilizar los tobillos con movimientos circulares de los pies hacia un lado y hacia el otro.

2. Movilizar las rodillas flexionándolas hacia arriba o doblando las piernas hacia atrás

3. Movilizar las caderas en forma circular ya que son las articulaciones que más intervienen en la caminata.

4. Realizar pequeños saltos para activar los músculos de las piernas.

5. Estiramiento de las piernas estirándolas hacia el frente alternadas, hacia los lados y hacia atrás.

Ejercicio principal, duración entre 20 y 40 minutos

1. Caminata moderada intensidad

\section{Enfriamiento, duración 10 minutos}

1. Iniciar con movimientos ligeros del cuello

2. Luego ligeros movimientos y balanceos de brazos con los codos por debajo de los hombros.

3. Después movimientos más amplios de brazos solicitando mayor musculatura por subir los codos por encima de los hombros

4. Después un grupo de ejercicios por musculatura, pectorales, bíceps, hombros y tríceps.

5. Intensifica el calentamiento de los brazos con ejercicios de mayor intensidad, como elevaciones laterales completas.

6. Ampliamos la amplitud de movimiento articular de los hombros mediante rotaciones forzando los límites de la flexibilidad.

7. Empezamos el calentamiento de la zona abdominal y la cadera 
con elevaciones de los muslos y rotaciones de la cadera.

8. Estiramiento de la pantorrilla levantando y bajando los talones del piso.

9. Estiramiento de cuádriceps, doblando la pierna hacia atrás hasta tocar el glúteo con el pie, mantenerlo unos segundos y cambiar a la otra pierna.

10. Estiramiento de la ingle, agáchese hacia el piso y ponga ambas manos en el piso delante suyo. Estire su pierna izquierda hacia atrás. Mantenga su pie derecho completamente en el piso, e inclínese hacia adelante con el pecho hacia su rodilla derecha, luego gradualmente dirija su peso hacia su pierna izquierda manteniéndola lo más derecho posible. Mantenga este estiramiento durante 20 segundos. Repita el ejercicio de estiramiento con su pierna derecha hacia atrás 


\section{ANEXO.V}

\section{MENUS PARA HOMBRES TRATADOS CON DIETA ESTÁNDAR (GRUPO CONTROL)}

Fórmula dieto-sintética

\begin{tabular}{|c|c|c|c|}
\hline Nutrimentos & Porcentaje & $\begin{array}{c}\text { Energía } \\
\text { (Kcal) }\end{array}$ & Gramos \\
\hline $\begin{array}{c}\text { Hidratos de } \\
\text { Carbono }\end{array}$ & $55 \%$ & 990 & 247.5 \\
\hline Proteínas & $15 \%$ & 270 & 67.5 \\
\hline Lípidos* & $30 \%$ & 540 & 60.0 \\
\hline Total & $100 \%$ & 1800 & - \\
\hline
\end{tabular}

* Las recomendaciones del porcentaje de lípidos están de acuerdo con la Norma Oficial Mexicana para la prevención, tratamiento y control de las dislipidemias.NOM-037-SSA2-2002. 


\section{Distribución de Equivalentes}

\begin{tabular}{|c|c|c|c|c|c|c|}
\hline \multirow[b]{2}{*}{$\begin{array}{l}\text { Grupo de } \\
\text { Alimentos }\end{array}$} & \multirow[b]{2}{*}{ Subgrupo } & \multirow{2}{*}{$\begin{array}{l}\text { No. de } \\
\text { Equiv. }\end{array}$} & \multicolumn{4}{|c|}{ Aporte Nutrimental Promedio } \\
\hline & & & $\begin{array}{c}\text { Energía } \\
\text { Kcal }\end{array}$ & $\begin{array}{l}\text { Proteínas } \\
\text { g. }\end{array}$ & $\begin{array}{l}\text { Lípidos } \\
\text { g. }\end{array}$ & $\begin{array}{c}\text { Hidratos } \\
\text { de } \\
\text { Carbono } \\
\text { g. }\end{array}$ \\
\hline Verduras & & 6 & 150 & 12 & 0 & 24 \\
\hline Frutas & & 6 & 360 & 0 & 0 & 90 \\
\hline \multirow{2}{*}{$\begin{array}{ll}\text { Cereales } & y \\
\text { tubérculos } & \end{array}$} & a) sin grasa & 4 & 280 & 8 & 0 & 60 \\
\hline & b) con grasa & 2 & 230 & 4 & 10 & 30 \\
\hline Leguminosas & & 1 & 120 & 8 & 1 & 20 \\
\hline \multirow{4}{*}{$\begin{array}{l}\text { Alimentos de } \\
\text { origen animal }\end{array}$} & $\begin{array}{l}\text { a) muy bajo aporte } \\
\text { de grasa }\end{array}$ & & & & & \\
\hline & $\begin{array}{l}\text { b) bajo aporte de } \\
\text { grasa }\end{array}$ & & & & & \\
\hline & $\begin{array}{l}\text { c) moderado } \\
\text { aporte de grasa }\end{array}$ & 3 & 225 & 21 & 15 & 0 \\
\hline & $\begin{array}{l}\text { d) alto aporte de } \\
\text { grasa }\end{array}$ & & & & & \\
\hline \multirow{4}{*}{ Leche } & a) descremada & 1 & 95 & 9 & 2 & 12 \\
\hline & b) semidescremada & & & & & \\
\hline & c) entera & & & & & \\
\hline & d) con azúcar & & & & & \\
\hline \multirow{2}{*}{$\begin{array}{l}\text { Aceites } \quad y \\
\text { grasas }\end{array}$} & a) sin proteínas & 4 & 180 & 0 & 20 & 0 \\
\hline & b) con proteínas & 1 & 70 & 3 & 5 & 3 \\
\hline \multirow[t]{2}{*}{ Azúcares } & a) sin grasa & 2 & 80 & 0 & 0 & 20 \\
\hline & b) con grasa & & & & & \\
\hline \multicolumn{7}{|l|}{$\begin{array}{l}\text { Alimentos } \\
\text { libres en } \\
\text { energía }\end{array}$} \\
\hline $\begin{array}{l}\text { Bebidas } \\
\text { alcohólicas }\end{array}$ & & & & & & \\
\hline
\end{tabular}




\section{Distribución de equivalentes en los tiempos de comida del menú 1}

\begin{tabular}{|c|c|c|c|c|c|c|c|}
\hline \multirow[b]{2}{*}{$\begin{array}{l}\text { Grupo de } \\
\text { Alimentos }\end{array}$} & \multirow[b]{2}{*}{ Subgrupo } & \multirow{2}{*}{$\begin{array}{l}\text { No. de } \\
\text { Equiv. }\end{array}$} & \multicolumn{5}{|c|}{ Tiempos de Comida } \\
\hline & & & Des & Col & Com & Col & Cena \\
\hline Verduras & & 6 & & 2 & 2 & & 2 \\
\hline Frutas & & 6 & 1 & 1 & 2 & 1 & 1 \\
\hline \multirow{2}{*}{$\begin{array}{l}\text { Cereales } \\
\text { tubérculos }\end{array}$} & a) sin grasa & 4 & 2 & & 1 & 1 & \\
\hline & b) con grasa & 2 & & 1 & & & 1 \\
\hline Leguminosas & & 1 & & & 1 & & \\
\hline \multirow{4}{*}{$\begin{array}{l}\text { Alimentos de } \\
\text { origen animal }\end{array}$} & $\begin{array}{l}\text { a) muy bajo aporte } \\
\text { de grasa }\end{array}$ & & & & & & \\
\hline & $\begin{array}{l}\text { b) bajo aporte de } \\
\text { grasa }\end{array}$ & & & & & & \\
\hline & $\begin{array}{l}\text { c) moderado } \\
\text { aporte de grasa }\end{array}$ & 3 & & & 2 & & 1 \\
\hline & $\begin{array}{l}\text { d) alto aporte de } \\
\text { grasa }\end{array}$ & & & & & & \\
\hline \multirow{4}{*}{ Leche } & a) descremada & 1 & 1 & & & & \\
\hline & b) semidescremada & & & & & & \\
\hline & c) entera & & & & & & \\
\hline & d) con azúcar & & & & & & \\
\hline \multirow{2}{*}{$\begin{array}{ll}\text { Aceites } & y \\
\text { grasas } & \end{array}$} & a) sin proteínas & 4 & & & 3 & & 1 \\
\hline & b) con proteínas & 1 & 1 & & & & \\
\hline \multirow[t]{2}{*}{ Azúcares } & a) sin grasa & 2 & 1 & & 1 & & \\
\hline & b) con grasa & & & & & & \\
\hline \multicolumn{8}{|l|}{$\begin{array}{l}\text { Alimentos } \\
\text { libres en } \\
\text { energía }\end{array}$} \\
\hline $\begin{array}{l}\text { Bebidas } \\
\text { alcohólicas }\end{array}$ & & & & & & & \\
\hline
\end{tabular}




\section{Menú 1}

\begin{tabular}{|c|c|c|c|c|c|c|}
\hline Lunes & Martes & Miércoles & Jueves & Viernes & Sábado & Domingo \\
\hline \multicolumn{7}{|c|}{ Desayuno } \\
\hline $\begin{array}{l}1 \text { taza de } \\
\text { leche } \\
\text { descremada } \\
\text { con } \\
\text { cucharadita } \\
\text { de azúcar } \\
1 \text { taza de } \\
\text { cereal integral } \\
\text { de arroz } \\
1 / 2 \text { plátano } \\
10 \text { almendras } \\
\text { picadas } 0 \text { 14 } \\
\text { cacahuates }\end{array}$ & $\begin{array}{l}1 \text { taza de } \\
\text { licuado con } 1 \\
\text { taza de leche } \\
\text { descremada, } \\
1 / 2 \text { plátano } \\
\text { endulzado } \\
\text { con } 1 \\
\text { cucharadita } \\
\text { de azúcar } \\
2 \text { rebanadas } \\
\text { de pan } \\
\text { integral } \\
\text { tostado con } 1 \\
\text { cucharita de } \\
\text { mantequilla } \\
\text { de cacahuate }\end{array}$ & $\begin{array}{l}1 \text { taza de } \\
\text { leche } \\
\text { descremada } \\
\text { con } \\
\text { cucharadita } \\
\text { de azúcar } \\
1 \text { taza de } \\
\text { cereal integral } \\
\text { de arroz } \\
1 / 2 \text { plátano } \\
10 \text { almendras } \\
\text { picadas o } 14 \\
\text { cacahuates }\end{array}$ & $\begin{array}{l}1 \text { taza de café } \\
\text { con leche } \\
\text { descremada } \\
\text { con splenda } \\
2 \text { hot cakes } \\
\text { pequeños con } \\
\text { dos } \\
\text { cucharaditas } \\
\text { de miel de } \\
\text { abeja } \\
1 \text { cucharadita } \\
\text { de } \\
\text { mantequilla } \\
1 \text { taza de } \\
\text { melón picado }\end{array}$ & $\begin{array}{l}1 \text { taza de } \\
\text { leche } \\
\text { descremada } \\
\text { con } 1 \\
\text { cucharadita } \\
\text { de azúcar } \\
1 \text { taza de } \\
\text { cereal } \\
\text { integral de } \\
\text { arroz } \\
1 / 2 \text { plátano } \\
10 \\
\text { almendras } \\
\text { picadas } 014 \\
\text { cacahuates }\end{array}$ & $\begin{array}{l}1 \text { taza de } \\
\text { licuado con } \\
1 \text { taza de } \\
\text { leche } \\
\text { descremada } \\
1 / 2 \text { plátano } \\
1 \\
\text { cucharadita } \\
\text { de azúcar } \\
1 \text { barrita de } \\
\text { granola } \\
\text { sabor } \\
\text { manzana } \\
10 \\
\text { almendras } 0 \\
14 \\
\text { cacahuates }\end{array}$ & $\begin{array}{l}3 / 4 \text { de taza de } \\
\text { yogurt light } \\
1 \text { taza de } \\
\text { melón } \\
\text { picado con } 1 \\
\text { cucharadita } \\
\text { de miel } \\
10 \\
\text { almendras } \\
\text { picadas o } 14 \\
\text { cacahuates } \\
6 \\
\text { cucharadas } \\
\text { de granola }\end{array}$ \\
\hline \multicolumn{7}{|c|}{ Colación } \\
\hline $\begin{array}{l}1 \text { taza de jugo } \\
\text { de melón } \\
1 \text { galleta de } \\
\text { avena y } \\
\text { manzana } \\
1 \text { taza de kiwi } \\
\text { picado }\end{array}$ & $\begin{array}{lr}1 / 2 \text { taza } & \text { de } \\
\text { jugo } & \text { de } \\
\text { naranja } & \\
1 \text { galleta } & \text { de } \\
\text { avena } & y \\
\text { manzana } & \\
\text { 1 pera } & \end{array}$ & $\begin{array}{lr}1 / 2 \text { taza } & \text { de } \\
\text { jugo } & \text { de } \\
\text { mandarina } & \\
1 \text { galleta } & \text { de } \\
\text { avena } & y \\
\text { manzana } & \\
\text { 1/2 manzana } & \end{array}$ & $\begin{array}{l}1 \text { taza de jugo } \\
\text { de melón } \\
1 \text { galleta de } \\
\text { avena y } \\
\text { manzana } \\
\text { 1 naranja }\end{array}$ & $\begin{array}{l}1 / 2 \text { taza } \text { de } \\
\text { jugo de } \\
\text { naranja } \\
1 \text { galleta de } \\
\text { avena y } \\
\text { manzana } \\
\text { 1/2 manzana }\end{array}$ & $\begin{array}{l}1 / 2 \text { taza de } \\
\text { jugo de } \\
\text { mandarina } \\
1 \text { galleta de } \\
\text { avena y } \\
\text { manzana } \\
1 \text { taza de } \\
\text { kiwi picado }\end{array}$ & $\begin{array}{l}1 / 2 \text { de taza } \\
\text { de jugo de } \\
\text { naranja } \\
\text { 1 galleta de } \\
\text { avena y } \\
\text { manzana } \\
\text { 1 pera }\end{array}$ \\
\hline \multicolumn{7}{|c|}{ Comida } \\
\hline $\begin{array}{l}1 \text { taza de } \\
\text { consomé de } \\
\text { pollo con } 1 / 4 \text { de } \\
\text { taza de arroz } \\
1 \text { bisteck de } \\
\text { bola de res a } \\
\text { la plancha } \\
1 / 2 \text { taza de } \\
\text { chayote } \\
\text { cocido con } \\
\text { mantequilla y } \\
\text { sal. } \\
1 / 2 \text { taza de } \\
\text { frijoles } \\
\text { Agua de limón } \\
\text { con azúcar } \\
1 \text { taza de kiwi } \\
\text { picada }\end{array}$ & $\begin{array}{l}\text { 1 taza de sopa } \\
\text { de verduras } \\
1 / 2 \text { taza de } \\
\text { espagueti con } \\
\text { aceite de oliva } \\
\text { y especias } \\
\text { Fajitas de } \\
\text { pollo (con } \\
\text { chile pimiento } \\
\text { verde y rojo, } \\
\text { cebolla, } \\
\text { tomate y salsa } \\
\text { inglesa) } \\
1 \text { taza de } \\
\text { frijoles } \\
\text { Agua de } \\
\text { jamaica con } \\
\text { azúcar } \\
1 \text { pera }\end{array}$ & 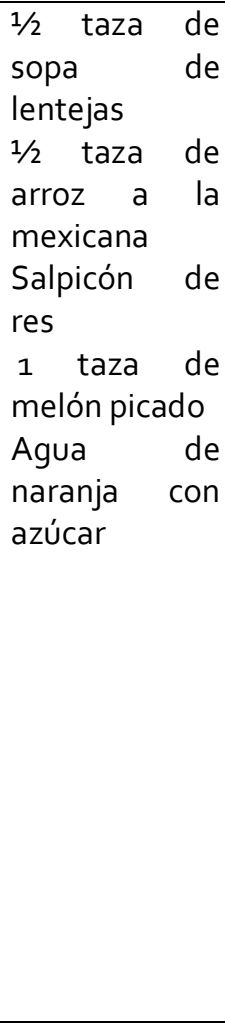 & $\begin{array}{l}1 / 2 \text { taza de } \\
\text { arroz blanco } \\
\text { Tinga de res } \\
1 / 3 \text { taza de } \\
\text { frijol refrito } \\
\text { Agua de limón } \\
\text { con azúcar } \\
1 \text { naranja }\end{array}$ & $\begin{array}{l}1 / 2 \text { taza de } \\
\text { frijol colado } \\
\text { Cerdo a la } \\
\text { plancha } \\
\text { con media } \\
\text { papa cocida } \\
3 \text { tazas de } \\
\text { lechuga, } \\
\text { aceite de } \\
\text { oliva,limón y } \\
\text { sal } \\
\text { Agua de } \\
\text { jamaica con } \\
\text { azúcar } \\
\text { 1 pera }\end{array}$ & $\begin{array}{l}\text { Ensalada: } 3 \\
\text { tazas de } \\
\text { lechuga, } 2 \\
\text { piezas de } \\
\text { tomate } \\
\text { saladet, } 1 / 2 \\
\text { taza de } \\
\text { chícharos } \\
\text { con aderezo } \\
\text { de aceite de } \\
\text { oliva, limón } \\
\text { y sal. } \\
\text { Espagueti a } \\
\text { la boloñesa } \\
\text { (1/2 taza de } \\
\text { espagueti } \\
\text { cocido con } \\
\text { carne } \\
\text { molida de } \\
\text { res y salsa } \\
\text { de tomate } \\
\text { Agua de } \\
\text { mandarina } \\
\text { con azúcar }\end{array}$ & $\begin{array}{l}1 \text { taza de } \\
\text { sopa de } \\
\text { coditos con } \\
\text { tomate } \\
2 \text { tostadas } \\
\text { con frijoles } \\
\text { refritos, } \\
\text { pollo } \\
\text { deshebrado, } \\
\text { lechuga, } \\
\text { tomate, } \\
\text { cebolla, } \\
\text { aguacate, } \\
\text { salsa verde y } \\
\text { queso } \\
\text { Agua de } \\
\text { limón con } \\
\text { azúcar } \\
\text { 1/2 manzana }\end{array}$ \\
\hline
\end{tabular}




\begin{tabular}{|c|c|c|c|c|c|c|}
\hline & & & & & $\begin{array}{l}1 \text { taza de } \\
\text { melón } \\
\text { picado }\end{array}$ & \\
\hline \multicolumn{7}{|c|}{ Colación } \\
\hline $\begin{array}{l}1 \text { taza de } \\
\text { melón picado } \\
21 / 2 \text { tazas de } \\
\text { palomitas con }\end{array}$ & $\begin{array}{l}1 / 2 \text { manzana } \\
21 / 2 \text { tazas de } \\
\text { palomitas }\end{array}$ & $\begin{array}{l}1 \text { pero } \\
21 / 2 \text { tazas de } \\
\text { palomitas }\end{array}$ & $\begin{array}{l}1 \text { taza de kiwi } \\
\text { picado } \\
21 / 2 \text { tazas de } \\
\text { palomitas }\end{array}$ & $\begin{array}{l}\text { 1 naranja } \\
2 \quad 1 / 2 \text { tazas } \\
\text { de palomitas }\end{array}$ & $\begin{array}{l}1 \text { taza de } \\
\text { malón } \\
\text { picado } \\
21 / 2 \text { tazas } \\
\text { de } \\
\text { palomitas }\end{array}$ & $\begin{array}{l}\text { I naranja } \\
21 / 2 \text { tazas } \\
\text { de } \\
\text { palomitas }\end{array}$ \\
\hline \multicolumn{7}{|c|}{ Cena } \\
\hline $\begin{array}{l}1 / 2 \text { taza de } \\
\text { jugo de } \\
\text { mandarina } \\
1 \text { rebanada de } \\
\text { pan integral } \\
\text { con queso } \\
\text { mozarela y } \\
\text { mayonesa. } \\
1 \text { taza de kiwi } \\
\text { picado }\end{array}$ & $\begin{array}{l}1 \text { taza de jugo } \\
\text { de melón } \\
1 \quad \text { salchicha } \\
\text { asada } \\
7 \quad \text { galletas } \\
\text { saladas } \\
\text { cremosas } \\
1 \text { pera }\end{array}$ & $\begin{array}{l}1 / 2 \text { taza de } \\
\text { jugo de } \\
\text { naranja } \\
1 \text { bisquet con } \\
\text { queso } \\
\text { manchego } \\
\text { gratinado } \\
1 / 2 \text { manzana }\end{array}$ & $\begin{array}{l}1 \text { taza de jugo } \\
\text { de melón } \\
1 \text { hot dog con } \\
\text { mayonesa } \\
1 \text { pera }\end{array}$ & $\begin{array}{l}1 / 2 \text { taza de } \\
\text { jugo de } \\
\text { naranja } \\
2 \text { piezas de } \\
\text { pan de ajo } \\
\text { con jamón } \\
1 \text { taza de } \\
\text { kiwi picado }\end{array}$ & $\begin{array}{l}1 / 2 \text { taza de } \\
\text { jugo de } \\
\text { mandarina } \\
1 \text { rebanadas } \\
\text { de pan } \\
\text { integral, con } \\
\text { pollo } \\
\text { deshebrado, } \\
\text { mayonesa. } \\
\text { I pera }\end{array}$ & $\begin{array}{l}1 \text { taza de } \\
\text { jugo de } \\
\text { melón } \\
1 \text { huevo a la } \\
\text { mexicana } \\
1 \text { bisquet }\end{array}$ \\
\hline
\end{tabular}


Distribución de equivalentes en los tiempos de comida del menú 2

\begin{tabular}{|c|c|c|c|c|c|c|c|}
\hline \multirow[b]{2}{*}{ Grupo de Alimentos } & \multirow[b]{2}{*}{ Subgrupo } & \multirow{2}{*}{$\begin{array}{l}\text { No. de } \\
\text { Equiv. }\end{array}$} & \multicolumn{5}{|c|}{ Tiempos de Comida } \\
\hline & & & Des & Col & Com & Col & Cena \\
\hline Verduras & & 6 & 2 & & 2 & 2 & \\
\hline Frutas & & 6 & 1 & 1 & 2 & 1 & 1 \\
\hline \multirow{2}{*}{$\begin{array}{ll}\begin{array}{l}\text { Cereales } \\
\text { tubérculos }\end{array} & y \\
\end{array}$} & a) sin grasa & 4 & 2 & & 1 & 1 & \\
\hline & b) con grasa & 2 & & 1 & & & 1 \\
\hline Leguminosas & & 1 & & & 1 & & \\
\hline \multirow[t]{4}{*}{$\begin{array}{l}\text { Alimentos de origen } \\
\text { animal }\end{array}$} & $\begin{array}{l}\text { a) muy bajo } \\
\text { aporte } \\
\text { grasa }\end{array}$ & & & & & & \\
\hline & $\begin{array}{l}\text { b) bajo aporte } \\
\text { de grasa }\end{array}$ & & & & & & \\
\hline & $\begin{array}{l}\text { c) moderado } \\
\text { aporte de } \\
\text { grasa }\end{array}$ & 3 & 1 & & 2 & & \\
\hline & $\begin{array}{l}\text { d) alto aporte } \\
\text { de grasa }\end{array}$ & & & & & & \\
\hline \multirow[t]{4}{*}{ Leche } & $\begin{array}{l}\text { a) } \\
\text { descremada }\end{array}$ & 1 & & & & & 1 \\
\hline & $\begin{array}{l}\text { b) } \\
\text { semidescrema } \\
\text { da }\end{array}$ & & & & & & \\
\hline & c) entera & & & & & & \\
\hline & d) con azúcar & & & & & & \\
\hline \multirow[t]{2}{*}{ Aceites y grasas } & $\begin{array}{ll}\text { a) } & \sin \\
\text { proteínas } & \\
\end{array}$ & 4 & 1 & & 2 & & 1 \\
\hline & $\begin{array}{l}\text { b) con } \\
\text { proteínas }\end{array}$ & 1 & & 1 & & & \\
\hline \multirow[t]{2}{*}{ Azúcares } & a) sin grasa & 2 & & & 1 & & 1 \\
\hline & b) con grasa & & & & & & \\
\hline \multicolumn{8}{|l|}{$\begin{array}{l}\text { Alimentos libres en } \\
\text { energía }\end{array}$} \\
\hline Bebidas alcohólicas & & & & & & & \\
\hline
\end{tabular}




\section{Menú 2}

\begin{tabular}{|c|c|c|c|c|c|c|}
\hline Lunes & Martes & Miércoles & Jueves & Viernes & Sábado & Domingo \\
\hline \multicolumn{7}{|c|}{ Desayuno } \\
\hline $\begin{array}{l}\text { Omelette } \\
\text { papa de } \\
\text { huevo y } 1 / 2 \\
\text { taza de papa } \\
\text { cocida) } \\
1 / 2 \text { taza de } \\
\text { jugo de } \\
\text { naranja } \\
1 \text { taza de } \\
\text { melón picado } \\
1 \text { rebanada de } \\
\text { pan integral }\end{array}$ & $\begin{array}{l}2 \text { quesadillas } \\
\text { de tortilla de } \\
\text { maíz y } \\
\text { queso } \\
\text { mozzarella } \\
\text { semi- } \\
\text { descremado } \\
\text { 1 taza de } \\
\text { jugo de } \\
\text { mango } \\
1 \text { taza de } \\
\text { kiwi con una } \\
\text { cucharada } \\
\text { de crema } \\
\text { ligera }\end{array}$ & $\begin{array}{l}\text { 1 sandwich de } \\
\text { pan integral } \\
\text { con pollo } \\
\text { deshebrado, } \\
\text { y } 1 \\
\text { cucharadita } \\
\text { de mayonesa } \\
1 / 2 \text { taza de } \\
\text { jugo de } \\
\text { mandarina } \\
1 \text { pera }\end{array}$ & $\begin{array}{l}1 \text { huevo } \\
\text { estrellado } \\
2 \text { rebanadas } \\
\text { de pan } \\
\text { integral } \\
1 / 2 \text { vaso de } \\
\text { jugo de } \\
\text { naranja } \\
1 / 2 \text { manzana }\end{array}$ & $\begin{array}{l}2 \text { rebanadas } \\
\text { de pan } \\
\text { integral con } \\
\text { queso } \\
\text { mozzarella } \\
\text { semi- } \\
\text { descemado } \\
\text { gratinado } \\
1 \text { taza de jugo } \\
\text { de melón } \\
\text { 1/2 plátano } \\
\text { picado con } 1 \\
\text { cucharada de } \\
\text { crema ligera }\end{array}$ & $\begin{array}{l}2 \text { tacos de } \\
\text { pollo } \\
1 / 2 \text { taza de } \\
\text { jugo de } \\
\text { mandarina } \\
1 \text { taza de } \\
\text { melón picada } \\
\text { con } \\
\text { cucharada de } \\
\text { crema ligera }\end{array}$ & $\begin{array}{l}\text { 1 sandwich de } \\
\text { jamón y queso } \\
1 / 2 \text { taza de } \\
\text { jugo de } \\
\text { naranja } \\
1 \text { taza de } \\
\text { mango picado }\end{array}$ \\
\hline \multicolumn{7}{|c|}{ Colación } \\
\hline $\begin{array}{l}\text { l pera } \\
10 \text { almendras } \\
0 \\
\text { cacahuates } \\
5 \quad \text { galletas } \\
\text { marías }\end{array}$ & $\begin{array}{l}1 / 2 \text { manzana } \\
10 \\
\text { almendras o } \\
14 \\
\text { cacahuates } \\
4 \quad \text { galletas } \\
\text { saladas }\end{array}$ & $\begin{array}{l}\text { 1/2 plátano } \\
10 \text { almendras } \\
0 \\
\text { cacahuates } \\
21 / 2 \text { tazas de } \\
\text { palomitas de } \\
\text { maíz }\end{array}$ & $\begin{array}{l}\text { 1 taza de kiwi } \\
\text { picado, } 3 \\
\text { cucharadas de } \\
\text { granola y } 10 \\
\text { almendras } \\
\text { picadas o } 14 \\
\text { cacahuates }\end{array}$ & $\begin{array}{l}\text { taza de } \\
\text { melón picado } \\
3 \text { palitos } \\
\text { integrales } \\
14 \text { cacahuates }\end{array}$ & $\begin{array}{l}\text { I naranja } \\
10 \text { almendras } \\
0 \\
\text { cacahuates } \\
5 \quad \text { galletas } \\
\text { marías }\end{array}$ & $\begin{array}{l}2 \text { mandarinas } \\
2 \text { galletas } \\
\text { dulces sin } \\
\text { relleno } \\
14 \text { cacahuates }\end{array}$ \\
\hline \multicolumn{7}{|c|}{ Comida } \\
\hline $\begin{array}{l}\text { 1 taza de sopa } \\
\text { poblana: } \\
\text { calabaza local, } \\
\text { chile poblano, } \\
\text { elote en grano } \\
\text { en caldo de } \\
\text { pollo } \\
1 / 2 \text { taza de } \\
\text { arroz blanco } \\
2 \text { albóndigas } \\
\text { de carne } \\
\text { molida de res } \\
\text { en salsa roja } \\
1 / 2 \text { taza de } \\
\text { frijoles } \\
\text { Agua de limón } \\
\text { con azúcar } \\
1 \text { taza de } \\
\text { melón picado }\end{array}$ & $\begin{array}{l}\text { 1 taza sopa } \\
\text { de papa con } \\
\text { chícharos } \\
1 / 2 \text { taza de } \\
\text { macarrones } \\
\text { a la } \\
\text { mantequilla } \\
\text { con hierbas } \\
1 \text { filete de } \\
\text { pescado a la } \\
\text { plancha } \\
\text { Ensalada de } \\
\text { aguacate } \\
\text { con aceite } \\
\text { de oliva, } \\
\text { limóny sal } \\
\text { 1/2 taza de } \\
\text { frijoles } \\
\text { Agua de } \\
\text { jamaica con } \\
\text { azúcar taza de } \\
1 \text { tajos de } \\
\text { mandarina }\end{array}$ & $\begin{array}{l}\text { 1 taza de sopa } \\
\text { de verduras } \\
1 / 2 \text { taza de } \\
\text { arroz amarillo } \\
1 \text { porción de } \\
\text { bisteck a la } \\
\text { plancha } \\
1 / 2 \text { taza de } \\
\text { frijoles } \\
\text { Agua } \\
\text { pitahaya con } \\
\text { azúcar } \\
1 \text { pera }\end{array}$ & $\begin{array}{l}1 \text { taza de sopa } \\
\text { de codito con } \\
\text { espinacas } \\
1 \text { porción de } \\
\text { arrachera } \\
\text { Ensalada de } \\
\text { lechuga con } \\
\text { aceite de } \\
\text { oliva, limón y } \\
\text { sal } \\
1 / 2 \text { taza de } \\
\text { frijoles } \\
\text { Agua de limón } \\
\text { con azúcar } \\
18 \text { uvas }\end{array}$ & $\begin{array}{l}\text { 1 taza de } \\
\text { tallarines con } \\
\text { especias } \\
1 \text { milanesa de } \\
\text { pollo a la } \\
\text { plancha } \\
\text { Ensalada con } \\
3 \text { tazas } \\
\text { delechuga } \\
\text { con aceite de } \\
\text { oliva, limón y } \\
\text { sal de } \\
1 / 2 \text { taza de } \\
\text { frijoles } \\
\text { Agua de } \\
\text { jamaica con } \\
\text { azúcar } \\
1 / 2 \text { manzana }\end{array}$ & $\begin{array}{l}1 \text { taza de sopa } \\
\text { de fideos } \\
1 \text { milanesa de } \\
\text { cerdo a la } \\
\text { plancha } \\
3 \text { tazas de } \\
\text { lechuga con } \\
\text { aceite de } \\
\text { oliva, sal, } \\
\text { limón } \\
\text { pimienta } \\
1 / 2 \text { taza de } \\
\text { frijoles } \\
\text { Agua de lima } \\
\text { con azúcar } \\
1 \text { taza de } \\
\text { melón picado }\end{array}$ & 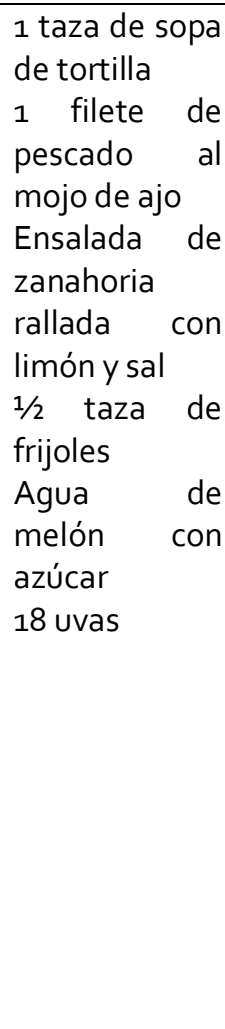 \\
\hline
\end{tabular}




\begin{tabular}{|c|c|c|c|c|c|c|}
\hline $\begin{array}{l}1 \text { taza de jugo } \\
\text { de melón } \\
21 / 2 \text { tazas de } \\
\text { palomitas } \\
1 \text { taza de } \\
\text { pitahaya } \\
\text { picada }\end{array}$ & $\begin{array}{l}1 / 2 \text { taza de } \\
\text { jugo de } \\
\text { naranja } \\
21 / 2 \text { tazas de } \\
\text { palomitas } \\
1 \text { taza de } \\
\text { melón } \\
\text { picado }\end{array}$ & $\begin{array}{l}1 / 2 \text { taza de } \\
\text { jugo de } \\
\text { mandarina } \\
21 / 2 \text { tazas de } \\
\text { palomitas con } \\
1 \text { pera }\end{array}$ & $\begin{array}{l}1 / 2 \text { taza de } \\
\text { jugo de } \\
\text { naranja } \\
21 / 2 \text { tazas de } \\
\text { palomitas con } \\
1 / 2 \text { manzana }\end{array}$ & $\begin{array}{l}1 \text { taza de jugo } \\
\text { de melón } \\
21 / 2 \text { tazas de } \\
\text { palomitas con } \\
1 \text { taza de } \\
\text { gajos de } \\
\text { mandarina }\end{array}$ & $\begin{array}{l}1 / 2 \text { taza de } \\
\text { jugo de } \\
\text { mandarina } \\
21 / 2 \text { tazas de } \\
\text { palomitas con } \\
1 \text { taza de } \\
\text { pitahaya } \\
\text { picada }\end{array}$ & $\begin{array}{ll}1 / 2 \text { taza } & \text { de } \\
\text { jugo } & \text { de } \\
\text { naranja } & \\
21 / 2 \text { tazas de } \\
\text { palomitas con } \\
18 \text { uvas }\end{array}$ \\
\hline \multicolumn{7}{|c|}{ Cena } \\
\hline $\begin{array}{l}\text { 1 taza de café } \\
\text { con leche } \\
\text { descremada } \\
\text { con azúcar } \\
4 \text { galletas } \\
\text { integrales con } \\
1 \text { cucharada } \\
\text { de queso } \\
\text { crema } \\
1 \text { taza de } \\
\text { mango picado }\end{array}$ & $\begin{array}{l}\text { Licuado: } 1 \\
\text { taza de } \\
\text { leche } \\
\text { descremada } \\
1 / 2 \text { plátano, } \\
\text { vainilla } \\
4 \quad \text { galletas } \\
\text { integrales } \\
\text { con } 1 \\
\text { cucharada } \\
\text { de } \\
\text { mantequilla } \\
\text { y } \\
\text { mermelada }\end{array}$ & $\begin{array}{l}1 \text { taza de café } \\
\text { con leche } \\
\text { descremada } \\
\text { con azúcar } \\
1 / 2 \text { plátano } \\
1 \text { barrita de } \\
\text { granola con } \\
\text { chocochip }\end{array}$ & $\begin{array}{l}3 / 4 \text { de taza de } \\
\text { yogurt } \\
1 / 2 \text { manzana } \\
\text { picada } \\
3 \text { cucharadas } \\
\text { de granola } \\
1 \text { cucharada } \\
\text { de azúcar }\end{array}$ & $\begin{array}{l}1 \text { taza de café } \\
\text { con leche } \\
\text { descremada } \\
\text { con azúcar } \\
1 / 2 \text { plátano } \\
1 \text { barrita de } \\
\text { granola con } \\
\text { chocochip }\end{array}$ & $\begin{array}{l}\text { 1 taza de café } \\
\text { con leche } \\
\text { descremada } \\
\text { con azúcar } \\
5 \text { galletas } \\
\text { marías con } \\
\text { cajeta } \\
18 \text { uvas }\end{array}$ & $\begin{array}{l}\text { Licuado: } \\
\text { taza de leche } \\
\text { descremada } \\
1 / 2 \text { plátano, } \\
\text { vainilla } \\
4 \quad \text { galletas } \\
\text { integrales con } \\
1 \text { cucharada } \\
\text { de } \\
\text { mantequilla y } \\
\text { mermelada }\end{array}$ \\
\hline
\end{tabular}




\section{Distribución de equivalentes en los tiempos de comida del menú 3}

\begin{tabular}{|c|c|c|c|c|c|c|c|}
\hline \multirow[b]{2}{*}{$\begin{array}{l}\text { Grupo de } \\
\text { Alimentos }\end{array}$} & \multirow[b]{2}{*}{ Subgrupo } & \multirow{2}{*}{$\begin{array}{l}\text { No. de } \\
\text { Equiv. }\end{array}$} & \multicolumn{5}{|c|}{ Tiempos de Comida } \\
\hline & & & Des & Col & Com & Col & Cena \\
\hline Verduras & & 6 & 2 & & 2 & 2 & \\
\hline Frutas & & 6 & 1 & 1 & 2 & & 2 \\
\hline \multirow{2}{*}{$\begin{array}{ll}\text { Cereales } & y \\
\text { tubérculos } & \end{array}$} & a) sin grasa & 4 & 1 & & 2 & 1 & \\
\hline & b) con grasa & 2 & & & & & 2 \\
\hline Leguminosas & & 1 & 1 & & & & \\
\hline \multirow{4}{*}{$\begin{array}{l}\text { Alimentos de } \\
\text { origen animal }\end{array}$} & $\begin{array}{l}\text { a) muy bajo aporte } \\
\text { de grasa }\end{array}$ & & & & & & \\
\hline & $\begin{array}{l}\text { b) bajo aporte de } \\
\text { grasa }\end{array}$ & & & & & & \\
\hline & $\begin{array}{l}\text { c) moderado } \\
\text { aporte de grasa }\end{array}$ & 3 & 1 & & 2 & & \\
\hline & $\begin{array}{l}\text { d) alto aporte de } \\
\text { grasa }\end{array}$ & & & & & & \\
\hline \multirow{4}{*}{ Leche } & a) descremada & 1 & & & & & 1 \\
\hline & b) semidescremada & & & & & & \\
\hline & c) entera & & & & & & \\
\hline & d) con azúcar & & & & & & \\
\hline \multirow{2}{*}{$\begin{array}{l}\text { Aceites } \\
\text { grasas }\end{array}$} & a) sin proteínas & 4 & 1 & & 3 & & \\
\hline & b) con proteínas & 1 & & 1 & & & \\
\hline \multirow[t]{2}{*}{ Azúcares } & a) sin grasa & 2 & & & 2 & & \\
\hline & b) con grasa & & & & & & \\
\hline \multicolumn{8}{|c|}{\begin{tabular}{ll|l} 
Alimentos & \\
libres en & \\
energía
\end{tabular}} \\
\hline $\begin{array}{l}\text { Bebidas } \\
\text { alcohólicas }\end{array}$ & & & & & & & \\
\hline
\end{tabular}




\section{Menú 3}

\begin{tabular}{|c|c|c|c|c|c|c|}
\hline Lunes & Martes & Miércoles & Jueves & Viernes & Sábado & Domingo \\
\hline \multicolumn{7}{|c|}{ Desayuno } \\
\hline $\begin{array}{l}\text { 1/2 taza de } \\
\text { jugo de } \\
\text { naranja } \\
1 \text { huevo } \\
\text { estrellado } \\
1 \text { rebanada de } \\
\text { pan integral } \\
1 / 2 \text { taza de } \\
\text { frijoles } \\
1 \text { taza de } \\
\text { malón picado }\end{array}$ & $\begin{array}{l}1 / 2 \text { taza de } \\
\text { jugo de } \\
\text { mandarina } \\
1 \text { salchicha de } \\
\text { pavo frita } \\
1 \text { rebanada de } \\
\text { pan integral } \\
1 / 2 \text { taza de } \\
\text { frijoles } \\
1 \text { pera }\end{array}$ & $\begin{array}{l}\text { 1/2 taza de } \\
\text { jugo de } \\
\text { naranja } \\
1 \text { enfrijolada } \\
\text { rellena de } \\
\text { jamón con } \\
\text { crema ligera y } \\
\text { queso } \\
1 \text { taza de piña } \\
\text { picada }\end{array}$ & $\begin{array}{l}1 / 2 \text { taza de } \\
\text { jugo de } \\
\text { mandarina } \\
1 \text { quesadilla } \\
\text { con queso } \\
\text { panela con } 1 \\
\text { cucharada de } \\
\text { crema ligera } \\
1 / 2 \text { taza de } \\
\text { frijoles } \\
1 / 2 \text { manzana }\end{array}$ & $\begin{array}{l}\text { 1/2 taza de } \\
\text { jugo de } \\
\text { naranja } \\
1 \text { sandwich } \\
\text { abierto de } \\
\text { pollo con } \\
\text { mayonesa y } \\
\text { mostaza } \\
1 / 2 \text { taza de } \\
\text { frijoles } \\
1 \text { taza de } \\
\text { melón picado }\end{array}$ & $\begin{array}{l}1 / 2 \text { taza de } \\
\text { jugo de } \\
\text { mandarina } \\
1 \text { huevo } \\
\text { revuelto con } \\
\text { papa cocida } \\
1 / 2 \text { taza de } \\
\text { frijoles } \\
1 \text { taza de piña } \\
\text { picada }\end{array}$ & $\begin{array}{l}\text { 1/2 taza de } \\
\text { jugo de } \\
\text { naranja } \\
1 / 2 \text { de papa } \\
\text { al horno con } \\
\text { cáscara } \\
\text { rellena de } \\
\text { queso y } 1 \\
\text { cucharada } \\
\text { de crema } \\
\text { ligera } \\
1 / 2 \text { taza de } \\
\text { frijoles } \\
1 \text { pera }\end{array}$ \\
\hline \multicolumn{7}{|c|}{ Colación } \\
\hline $\begin{array}{l}1 \text { taza de piña } \\
\text { picada } \\
10 \text { almendras }\end{array}$ & $\begin{array}{l}1 \text { taza de } \\
\text { melón picado } \\
10 \text { almendras }\end{array}$ & $\begin{array}{l}1 \text { pera } \\
10 \text { almendras }\end{array}$ & $\begin{array}{l}1 / 2 \text { manzana } \\
10 \text { almendras }\end{array}$ & $\begin{array}{l}1 \text { taza de piña } \\
\text { picada } \\
10 \text { almendras }\end{array}$ & $\begin{array}{l}1 \text { taza de } \\
\text { melón picado } \\
10 \text { almendras }\end{array}$ & $\begin{array}{l}1 / 2 \text { manzana } \\
10 \\
\text { almendras }\end{array}$ \\
\hline \multicolumn{7}{|c|}{ Comida } \\
\hline $\begin{array}{l}\text { 1 taza de sopa } \\
\text { verduras } \\
\text { Milanesa de } \\
\text { pollo a la } \\
\text { plancha } \\
\text { Ensalada de } \\
\text { aguacate con } \\
\text { aceite de } \\
\text { olive, limón y } \\
\text { sal } \\
1 \text { tortilla } \\
\text { Agua de limón } \\
\text { con azúcar } \\
\text { 1/2 manzana }\end{array}$ & $\begin{array}{l}\text { 1 taza de sopa } \\
\text { de codito con } \\
\text { especias } \\
1 \text { bisteck de } \\
\text { res a la } \\
\text { plancha } \\
\text { Ensalada: } 2 \text { 1/2 } \\
\text { tazas de } \\
\text { delechuga, } 2 \\
\text { tomates, } \\
\text { aceite de oliva } \\
\text { sal y limón } \\
1 \text { tortilla } \\
\text { Agua } \\
\text { jamaica de } \\
1 \text { taza de piña } \\
\text { picada }\end{array}$ & $\begin{array}{l}\text { taza de } \\
\text { consomé de } \\
\text { pollo con pico } \\
\text { de gallo } \\
1 / 2 \text { taza de } \\
\text { arroz blanco } \\
1 \text { taza de } \\
\text { picadillo con } \\
\text { verduras } \\
2 \text { tortillas } \\
\text { Agua de piña } \\
\text { con azúcar } \\
1 \text { taza de } \\
\text { melón picado }\end{array}$ & $\begin{array}{l}\text { Ensalada: } 2 \frac{1 / 2}{2} \\
\text { tazas de } \\
\text { delechuga, } 2 \\
\text { tomates, } \\
\text { aceite de oliva } \\
\text { sal y limón } \\
1 \text { taza de } \\
\text { spaguetti a la } \\
\text { boloñesa } \\
\text { Agua de limón } \\
\text { con azúcar } \\
\text { 1 pera }\end{array}$ & $\begin{array}{l}\text { 1 taza de sopa } \\
\text { de letras } \\
1 \text { filete de } \\
\text { pescado a la } \\
\text { plancha } \\
1 / 2 \text { taza de } \\
\text { zanahoria } \\
\text { rallada y dos } \\
\text { tomates con } \\
\text { aceite de oliva } \\
\text { limóny sal } \\
1 \text { tortilla } \\
\text { Agua de } \\
\text { jamaica con } \\
\text { azúcar } \\
1 / 2 \text { manzana }\end{array}$ & $\begin{array}{l}\text { 1/2 taza de } \\
\text { arroz amarillo } \\
2 \text { rebanadas } \\
\text { de albóndigón } \\
\text { de res an salsa } \\
\text { roja } \\
\text { Ensalada: } 2 \text { 1/2 } \\
\text { tazas de } \\
\text { delechuga y } \\
\text { aguacate } \\
\text { aceite de oliva } \\
\text { sal y limón } \\
2 \text { tortillas } \\
\text { Agua de piña } \\
\text { con azúcar } \\
1 \text { taza de } \\
\text { melón picado }\end{array}$ & $\begin{array}{l}\text { Ensalada: } 2 \\
1 / 2 \\
\text { tazas de } \\
\text { delechuga y } \\
\text { aguacate, } \\
\text { aceite de } \\
\text { oliva sal y } \\
\text { limón } \\
\text { Lasagna de } \\
\text { carne de res } \\
\text { Agua de } \\
\text { melón con } \\
\text { azúcar } \\
\text { 1 pera }\end{array}$ \\
\hline \multicolumn{7}{|c|}{ Colación } \\
\hline $\begin{array}{l}1 \text { mandarina } \\
21 / 2 \text { tazas de } \\
\text { palomitas con } \\
3 \text { cucharadas } \\
\text { de salsa } \\
\text { catsup }\end{array}$ & $\begin{array}{l}1 \text { taza de } \\
\text { melón picado } \\
2 \text { 1/2 tazas de } \\
\text { palomitas con } \\
3 \text { cucharadas } \\
\text { de salsa } \\
\text { cátsup }\end{array}$ & $\begin{array}{l}\text { 1 pera } \\
21 / 2 \text { tazas de } \\
\text { palomitas con } \\
3 \text { cucharadas } \\
\text { de salsa } \\
\text { catsup }\end{array}$ & $\begin{array}{l}1 / 2 \text { manzana } \\
21 / 2 \text { tazas de } \\
\text { palomitas con } \\
3 \text { cucharadas } \\
\text { de salsa } \\
\text { catsup }\end{array}$ & $\begin{array}{l}1 \text { taza de } \\
\text { mango picado } \\
21 / 2 \text { tazas de } \\
\text { palomitas con } \\
3 \text { cucharadas } \\
\text { de salsa } \\
\text { cátsup }\end{array}$ & $\begin{array}{l}1 \text { mandarina } \\
21 / 2 \text { tazas de } \\
\text { palomitas con } \\
3 \text { cucharadas } \\
\text { de salsa } \\
\text { catsup }\end{array}$ & $\begin{array}{l}1 \text { taza de } \\
\text { mango } \\
\text { picado } \\
21 / 2 \text { tazas de } \\
\text { palomitas } \\
\text { con } 3 \\
\text { cucharadas } \\
\text { de salsa } \\
\text { cátsup }\end{array}$ \\
\hline
\end{tabular}




\begin{tabular}{|c|c|c|c|c|c|c|}
\hline \multicolumn{7}{|c|}{ Cena } \\
\hline $\begin{array}{l}1 \text { vaso de } \\
\text { licuado con } 1 / 2 \\
\text { plátano, } 1 \\
\text { taza de leche } \\
\text { descremada, } \\
\text { splenda y } 1 \\
\text { cucharadita } \\
\text { de vainilla } \\
3 \text { galletas de } \\
\text { nuez } \\
1 \text { pera }\end{array}$ & $\begin{array}{l}\text { 1 taza de } \\
\text { leche } \\
\text { descremada } \\
3 / 4 \text { taza de } \\
\text { cereal } \\
1 / 2 \text { plátano y } 1 \\
\text { taza de piña } \\
\text { picada } \\
1 \text { galleta de } \\
\text { avana } \\
\text { manzana }\end{array}$ & $\begin{array}{l}1 / 2 \text { taza de } \\
\text { yogurt } \\
1 \text { taza de } \\
\text { melón picado } \\
1 \text { taza de } \\
\text { mango picada } \\
\text { y } 6 \\
\text { cucharadas de } \\
\text { granola }\end{array}$ & $\begin{array}{l}\text { vaso de } \\
\text { licuado con } 1 / 2 \\
\text { plátano, } 1 \\
\text { taza de leche } \\
\text { descremada, } \\
\text { splenda y } 1 \\
\text { cucharadita } \\
\text { de vainilla } \\
3 \text { galletas de } \\
\text { nuez } \\
1 / 2 \text { manzana }\end{array}$ & $\begin{array}{l}\text { 1 taza de } \\
\text { leche } \\
\text { descremada } \\
2 / 6 \text { taza de } \\
\text { cereal de } \\
\text { almendras } \\
\text { con pasas } \\
1 / 2 \text { plátano y } 1 \\
\text { taza de } \\
\text { mango picado }\end{array}$ & $\begin{array}{l}\text { vaso de } \\
\text { licuado con } 1 / 2 \\
\text { plátano, } 1 \\
\text { taza de leche } \\
\text { descremada, } \\
\text { splenda y } 1 \\
\text { cucharadita } \\
\text { de vainilla } \\
3 \text { galletas de } \\
\text { nuez } \\
1 \text { pera }\end{array}$ & $\begin{array}{l}\text { 1 taza de } \\
\text { leche } \\
\text { descremada } \\
2 / 6 \text { taza de } \\
\text { cereal con } \\
\text { almendras y } \\
\text { pasas } \\
1 \text { taza de } \\
\text { fresas } \\
\text { picadas }\end{array}$ \\
\hline
\end{tabular}




\section{ANEXO.VI}

\section{MENUS PARA MUJERES TRATADAS CON DIETA ESTÁNDAR (GRUPO CONTROL)}

Fórmula dieto-sintética

\begin{tabular}{|c|c|c|c|}
\hline Nutrimentos & Porcentaje & $\begin{array}{c}\text { Energía } \\
\text { (Kcal) }\end{array}$ & Gramos \\
\hline Hidratos de Carbono & $55 \%$ & 825 & 206.2 \\
\hline Proteínas & $15 \%$ & 225 & 56.2 \\
\hline Lípidos* & $30 \%$ & 450 & 50.0 \\
\hline Total & $100 \%$ & 1500 & - \\
\hline
\end{tabular}

* Las recomendaciones del porcentaje de lípidos están de acuerdo con la Norma Oficial Mexicana para la prevención, tratamiento y control de las dislipidemias.NOM-037-SSA2-2002 


\section{Distribución de Equivalentes}

\begin{tabular}{|c|c|c|c|c|c|c|}
\hline \multirow[b]{2}{*}{$\begin{array}{l}\text { Grupo de } \\
\text { Alimentos }\end{array}$} & \multirow[b]{2}{*}{ Subgrupo } & \multirow{2}{*}{$\begin{array}{l}\text { No. de } \\
\text { Equiv. }\end{array}$} & \multicolumn{4}{|c|}{ Aporte Nutrimental Promedio } \\
\hline & & & $\begin{array}{c}\text { Energía } \\
\text { Kcal }\end{array}$ & $\begin{array}{c}\text { Proteínas } \\
\mathrm{g} .\end{array}$ & $\begin{array}{l}\text { Lípidos } \\
\text { g. }\end{array}$ & $\begin{array}{c}\text { Hidratos } \\
\text { de } \\
\text { Carbono } \\
\text { g. }\end{array}$ \\
\hline Verduras & & 6 & 150 & 12 & 0 & 24 \\
\hline Frutas & & 6 & 360 & 0 & 0 & 90 \\
\hline \multirow{2}{*}{$\begin{array}{ll}\text { Cereales } & \text { y } \\
\text { tubérculos } & \end{array}$} & a) sin grasa & 4 & 280 & 8 & 0 & 60 \\
\hline & b) con grasa & & & & & \\
\hline Leguminosas & & 1 & 120 & 8 & 1 & 20 \\
\hline \multirow{4}{*}{$\begin{array}{l}\text { Alimentos de } \\
\text { origen animal }\end{array}$} & $\begin{array}{l}\text { a) muy bajo aporte } \\
\text { de grasa }\end{array}$ & & & & & \\
\hline & $\begin{array}{l}\text { b) bajo aporte de } \\
\text { grasa }\end{array}$ & & & & & \\
\hline & $\begin{array}{l}\text { c) moderado aporte } \\
\text { de grasa }\end{array}$ & 3 & 225 & 21 & 15 & 0 \\
\hline & $\begin{array}{l}\text { d) alto aporte de } \\
\text { grasa }\end{array}$ & & & & & \\
\hline \multirow{4}{*}{ Leche } & a) descremada & 1 & 95 & 9 & 2 & 12 \\
\hline & b) semidescremada & & & & & \\
\hline & c) entera & & & & & \\
\hline & d) con azúcar & & & & & \\
\hline \multirow{2}{*}{$\begin{array}{l}\text { Aceites } \quad y \\
\text { grasas }\end{array}$} & a) sin proteínas & 4 & 180 & o & 20 & 0 \\
\hline & b) con proteínas & 1 & 70 & 3 & 5 & 3 \\
\hline \multirow[t]{2}{*}{ Azúcares } & a) sin grasa & 1 & 40 & 0 & 0 & 10 \\
\hline & b) con grasa & & & & & \\
\hline \multicolumn{7}{|l|}{$\begin{array}{l}\text { Alimentos } \\
\text { libres en } \\
\text { energía }\end{array}$} \\
\hline $\begin{array}{l}\text { Bebidas } \\
\text { alcohólicas }\end{array}$ & & & & & & \\
\hline
\end{tabular}




\section{Distribución de equivalentes en los tiempos de comida del menú 1}

\begin{tabular}{|c|c|c|c|c|c|c|c|}
\hline \multirow[b]{2}{*}{$\begin{array}{l}\text { Grupo de } \\
\text { Alimentos }\end{array}$} & \multirow[b]{2}{*}{ Subgrupo } & \multirow{2}{*}{$\begin{array}{l}\text { No. de } \\
\text { Equiv. }\end{array}$} & \multicolumn{5}{|c|}{ Tiempos de Comida } \\
\hline & & & Des & Col & Com & Col & Cena \\
\hline Verduras & & 6 & & 2 & 2 & & 2 \\
\hline Frutas & & 6 & 1 & 1 & 2 & 1 & 1 \\
\hline \multirow{2}{*}{$\begin{array}{l}\text { Cereales } \quad y \\
\text { tubérculos }\end{array}$} & a) sin grasa & 4 & 2 & & 1 & 1 & \\
\hline & b) con grasa & & & & & & \\
\hline Leguminosas & & 1 & & & 1 & & \\
\hline \multirow{4}{*}{$\begin{array}{l}\text { Alimentos de } \\
\text { origen animal }\end{array}$} & $\begin{array}{l}\text { a) muy bajo aporte } \\
\text { de grasa }\end{array}$ & & & & & & \\
\hline & $\begin{array}{l}\text { b) bajo aporte de } \\
\text { grasa }\end{array}$ & & & & & & \\
\hline & $\begin{array}{l}\text { c) moderado } \\
\text { aporte de grasa }\end{array}$ & 3 & & & 2 & & 1 \\
\hline & $\begin{array}{l}\text { d) alto aporte de } \\
\text { grasa }\end{array}$ & & & & & & \\
\hline \multirow{4}{*}{ Leche } & a) descremada & 1 & 1 & & & & \\
\hline & b) semidescremada & & & & & & \\
\hline & c) entera & & & & & & \\
\hline & d) con azúcar & & & & & & \\
\hline \multirow{2}{*}{$\begin{array}{ll}\text { Aceites } & y \\
\text { grasas } & \end{array}$} & a) sin proteínas & 4 & & & 3 & & 1 \\
\hline & b) con proteínas & 1 & 1 & & & & \\
\hline \multirow[t]{2}{*}{ Azúcares } & a) sin grasa & 1 & & & 1 & & \\
\hline & b) con grasa & & & & & & \\
\hline \multicolumn{8}{|l|}{$\begin{array}{l}\text { Alimentos } \\
\text { libres en } \\
\text { energía }\end{array}$} \\
\hline $\begin{array}{l}\text { Bebidas } \\
\text { alcohólicas }\end{array}$ & & & & & & & \\
\hline
\end{tabular}




\section{Menú 1}

\begin{tabular}{|c|c|c|c|c|c|c|}
\hline Lunes & Martes & Miércoles & Jueves & Viernes & Sábado & Domingo \\
\hline \multicolumn{7}{|c|}{ Desayuno } \\
\hline $\begin{array}{l}1 \text { taza de } \\
\text { leche } \\
\text { descremada } \\
1 \text { taza de } \\
\text { cereal integral } \\
\text { de arroz } \\
1 \text { taza de piña } \\
\text { picada con } \\
\text { una } \\
\text { cucharadita } \\
\text { de miel } \\
\text { 10 almendras } \\
\text { picadas } 0 \quad 14 \\
\text { cacahuates }\end{array}$ & $\begin{array}{l}1 \text { taza de } \\
\text { licuado con } 1 \\
\text { taza de leche } \\
\text { descremada, } \\
1 / 2 \text { plátano } \\
\text { endulzado } \\
\text { con } \\
\text { cucharadita } \\
\text { de azúcar } \\
2 \text { rebanadas } \\
\text { de pan } \\
\text { integral } \\
\text { tostado con } 1 \\
\text { cucharadita } \\
\text { de } \\
\text { mantequilla } \\
\text { de cacahuate }\end{array}$ & $\begin{array}{l}1 \text { taza de } \\
\text { leche } \\
\text { descremada } \\
1 \text { taza de } \\
\text { cereal integral } \\
\text { de arroz } \\
1 \text { taza de } \\
\text { melón picado } \\
\text { con } 1 \\
\text { cucharadita } \\
\text { de miel } \\
\text { 10 almendras } \\
\text { picadas o } 14 \\
\text { cacahuates }\end{array}$ & $\begin{array}{l}\text { 1 taza de café } \\
\text { con leche } \\
\text { descremada } \\
\text { con splenda } \\
2 \text { hot cakes } \\
\text { pequeños con } \\
\text { dos } \\
\text { cucharaditas } \\
\text { de miel de } \\
\text { abeja } \\
1 \text { cucharadita } \\
\text { de } \\
\text { mantequilla } \\
1 \text { pera }\end{array}$ & $\begin{array}{l}1 \text { taza de } \\
\text { leche } \\
\text { descremada } \\
1 \text { taza de } \\
\text { cereal } \\
\text { integral de } \\
\text { arroz } \\
1 / 2 \text { plátano } \\
\text { con } 1 \\
\text { cucharadita } \\
\text { de miel } \\
10 \\
\text { almendras } \\
\text { picadas } 014 \\
\text { cacahuates }\end{array}$ & $\begin{array}{l}1 \text { taza de } \\
\text { licuado con } \\
1 \text { taza de } \\
\text { leche } \\
\text { descremada } \\
1 / 2 \text { manzana } \\
\text { con } 1 \\
\text { cucharadita } \\
\text { de azúcar } \\
1 \text { barrita de } \\
\text { granola } \\
\text { sabor } \\
\text { manzana } \\
10 \\
\text { almendras } 0 \\
14 \\
\text { cacahuates }\end{array}$ & $\begin{array}{l}\text { 3/4 de taza de } \\
\text { yogurt light } \\
1 \text { taza de } \\
\text { melón } \\
\text { picado con } 1 \\
\text { cucharadita } \\
\text { de miel } \\
10 \\
\text { almendras } \\
\text { picadas o } 14 \\
\text { cacahuates } \\
6 \\
\text { cucharadas } \\
\text { de granola }\end{array}$ \\
\hline \multicolumn{7}{|c|}{ Colación } \\
\hline $\begin{array}{ll}1 / 2 \text { taza } & \text { de } \\
\text { jugo } & \text { de } \\
\text { naranja } & \\
1 \text { taza de } \\
\text { sandía picada }\end{array}$ & $\begin{array}{l}1 / 2 \text { taza de } \\
\text { jugo de } \\
\text { mandarina } \\
1 \text { taza de } \\
\text { sandía picada }\end{array}$ & $\begin{array}{ll}1 / 2 \text { taza } & \text { de } \\
\text { jugo } & \text { de } \\
\text { naranja } & \\
1 \text { taza } & \text { de } \\
\text { gajos } & \text { de } \\
\text { toronja } & \\
\end{array}$ & $\begin{array}{l}1 / 2 \text { taza de } \\
\text { jugo de } \\
\text { mandarina } \\
1 \text { taza de } \\
\text { papaya picada }\end{array}$ & $\begin{array}{ll}1 / 2 \text { taza } & \text { de } \\
\text { jugo } & \text { de } \\
\text { naranja } & \\
1 \text { taza de } \\
\text { sandía } & \\
\text { picada } & \\
\end{array}$ & $\begin{array}{l}1 / 2 \text { taza de } \\
\text { jugo de } \\
\text { mandarina } \\
1 \text { taza de } \\
\text { sandía } \\
\text { picada }\end{array}$ & $\begin{array}{l}1 / 2 \text { de taza } \\
\text { de jugo de } \\
\text { naranja } \\
1 \text { taza de } \\
\text { gajos de } \\
\text { toronja }\end{array}$ \\
\hline \multicolumn{7}{|c|}{ Comida } \\
\hline $\begin{array}{l}1 \text { taza de } \\
\text { consomé de } \\
\text { pollo con } 1 / 4 \text { de } \\
\text { taza de arroz } \\
1 \text { bisteck de } \\
\text { bola de res a } \\
\text { la plancha } \\
1 / 2 \text { taza de } \\
\text { chayote } \\
\text { cocido con } \\
\text { mantequilla y } \\
\text { sal. } \\
1 / 2 \text { taza de } \\
\text { frijoles } \\
\text { Agua de limón } \\
\text { con azúcar } \\
1 \text { taza de kiwi } \\
\text { picada }\end{array}$ & $\begin{array}{l}\text { 1 taza de sopa } \\
\text { de verduras } \\
1 / 2 \text { taza de } \\
\text { espagueti con } \\
\text { aceite de oliva } \\
\text { y especias } \\
\text { Fajitas de } \\
\text { pollo (con } \\
\text { chile pimiento } \\
\text { verde y rojo, } \\
\text { cebolla, } \\
\text { tomate y salsa } \\
\text { inglesa) } \\
1 / 2 \text { taza de } \\
\text { frijoles } \\
\text { Agua } \\
\text { jamaica con de } \\
\text { azúcar } \\
1 \text { pera }\end{array}$ & 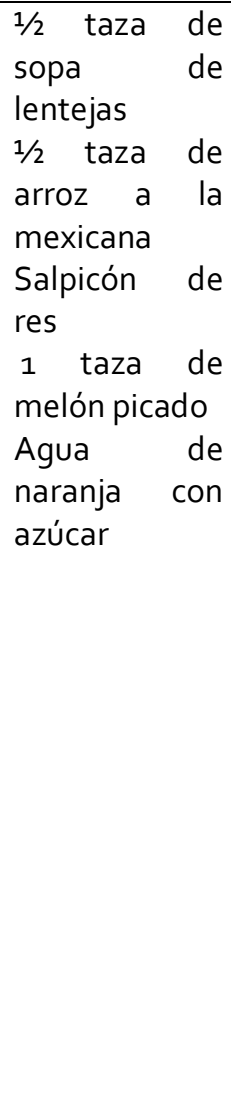 & $\begin{array}{l}1 / 2 \text { taza de } \\
\text { arroz blanco } \\
\text { Tinga de res } \\
1 / 3 \text { taza de } \\
\text { frijol refrito } \\
\text { Agua de limón } \\
\text { con azúcar } \\
\text { 1 naranja }\end{array}$ & $\begin{array}{l}1 / 2 \text { taza de } \\
\text { frijol colado } \\
\text { Cerdo a la } \\
\text { plancha } \\
\text { con media } \\
\text { papa cocida } \\
3 \text { tazas de } \\
\text { lechuga, } \\
\text { aceite de } \\
\text { oliva,limón y } \\
\text { sal } \\
\text { Agua de } \\
\text { jamaica con } \\
\text { azúcar } \\
1 \text { pera }\end{array}$ & $\begin{array}{l}\text { Ensalada: } 3 \\
\text { tazas de } \\
\text { lechuga, } 2 \\
\text { piezas de } \\
\text { tomate } \\
\text { saladet, } 1 / 2 \\
\text { taza de } \\
\text { chícharos } \\
\text { con aderezo } \\
\text { de aceite de } \\
\text { oliva, limón } \\
\text { y sal. } \\
\text { Espagueti a } \\
\text { la boloñesa } \\
\text { (1/2 taza de } \\
\text { espagueti } \\
\text { cocido con } \\
\text { carne } \\
\text { molida de } \\
\text { res y salsa } \\
\text { de tomate } \\
\text { Agua de } \\
\text { mandarina } \\
\text { conazúcar } \\
\begin{array}{l}1 \text { taza de } \\
\text { melón }\end{array}\end{array}$ & $\begin{array}{l}1 \text { taza de } \\
\text { sopa de } \\
\text { coditos con } \\
\text { tomate } \\
2 \text { tostadas } \\
\text { con frijoles } \\
\text { refritos, } \\
\text { pollo } \\
\text { deshebrado, } \\
\text { lechuga, } \\
\text { tomate, } \\
\text { cebolla, } \\
\text { aguacate, } \\
\text { salsa verde y } \\
\text { queso } \\
\text { Agua de } \\
\text { limón con } \\
\text { azúcar } \\
\text { 1/2 manzana }\end{array}$ \\
\hline
\end{tabular}




\begin{tabular}{|c|c|c|c|c|c|c|}
\hline & & & & & picado & \\
\hline \multicolumn{7}{|c|}{ Colación } \\
\hline $\begin{array}{l}1 \text { taza de piña } \\
\text { picada } \\
21 / 2 \text { tazas de } \\
\text { palomitas con } \\
3 \text { cucharadas } \\
\text { de salsa } \\
\text { catsup }\end{array}$ & $\begin{array}{l}\text { 1/2 manzana } \\
21 / 2 \text { tazas de } \\
\text { palomitas con } \\
3 \text { cuchcradas } \\
\text { de salsa } \\
\text { cátsup }\end{array}$ & $\begin{array}{l}1 \text { de taza de } \\
\text { melón picado } \\
2 \text { 1/2 tazas de } \\
\text { palomitas con } \\
3 \text { cuchcradas } \\
\text { de salsa } \\
\text { catsup }\end{array}$ & $\begin{array}{l}1 \text { pera } \\
21 / 2 \text { tazas de } \\
\text { palomitas con } \\
3 \text { cuchcradas } \\
\text { de salsa } \\
\text { catsup }\end{array}$ & $\begin{array}{l}\text { 1 pera } \\
21 / 2 \text { tazas } \\
\text { de palomitas } \\
\text { con } \quad 3 \\
\text { cuchcradas } \\
\text { de salsa } \\
\text { catsup }\end{array}$ & $\begin{array}{l}1 \text { taza de } \\
\text { piña picada } \\
2 \quad 1 / 2 \text { tazas } \\
\text { de } \\
\text { palomitas } \\
\text { con } 3 \\
\text { cuchcradas } \\
\text { de salsa } \\
\text { cátsup }\end{array}$ & $\begin{array}{l}1 \text { taza de } \\
\text { melón } \\
\text { picado } \\
2 \quad 1 / 2 \text { tazas } \\
\text { de } \\
\text { palomitas } \\
\text { con } 3 \\
\text { cucharadas } \\
\text { de salsa } \\
\text { catsup }\end{array}$ \\
\hline \multicolumn{7}{|c|}{ Cena } \\
\hline $\begin{array}{l}1 \text { taza de jugo } \\
\text { de melón } \\
1 \text { taza de piña } \\
\text { picada con } 20 \\
g \text { de queso } \\
\text { holandés }\end{array}$ & $\begin{array}{l}1 / 2 \text { taza de } \\
\text { jugo } \text { de } \\
\text { naranja } \\
1 \text { salchicha } \\
\text { asada } \\
\text { 1 pera }\end{array}$ & $\begin{array}{l}1 \text { taza de jugo } \\
\text { de melón } \\
1 \text { huevo } \\
\text { cocido } \\
1 / 2 \text { manzana }\end{array}$ & $\begin{array}{l}1 / 2 \text { taza de } \\
\text { jugo de } \\
\text { mandarina } \\
1 \text { taza de piña } \\
\text { picada con } 20 \\
\text { g de queso } \\
\text { holandés }\end{array}$ & $\begin{array}{l}\text { 1/2 taza de } \\
\text { jugo de } \\
\text { mandarina } \\
1 \text { taza de } \\
\text { melón } \\
6 \text { rebanadas } \\
\text { de salami de } \\
\text { pavo }\end{array}$ & $\begin{array}{l}1 \text { taza de } \\
\text { jugo de piña } \\
1 \text { pera con } \\
20 \mathrm{~g} \text { de } \\
\text { queso } \\
\text { holandés }\end{array}$ & $\begin{array}{l}1 / 2 \text { taza de } \\
\text { jugo de } \\
\text { naranja } \\
1 \text { huevo } \\
\text { cocido } \\
1 / 2 \text { manzana }\end{array}$ \\
\hline
\end{tabular}


Distribución de equivalentes en los tiempos de comida del menú 2

\begin{tabular}{|c|c|c|c|c|c|c|c|}
\hline \multirow[b]{2}{*}{ Grupo de Alimentos } & \multirow[b]{2}{*}{ Subgrupo } & \multirow{2}{*}{$\begin{array}{l}\text { No. de } \\
\text { Equiv. }\end{array}$} & \multicolumn{5}{|c|}{ Tiempos de Comida } \\
\hline & & & Des & Col & Com & Col & Cena \\
\hline Verduras & & 6 & 2 & & 2 & 2 & \\
\hline Frutas & & 6 & 1 & 1 & 2 & 1 & 1 \\
\hline \multirow{2}{*}{$\begin{array}{ll}\begin{array}{l}\text { Cereales } \\
\text { tubérculos }\end{array} & y \\
\end{array}$} & a) sin grasa & 4 & 2 & & 1 & 1 & \\
\hline & b) con grasa & & & & & & \\
\hline Leguminosas & & 1 & & & 1 & & \\
\hline \multirow[t]{4}{*}{$\begin{array}{l}\text { Alimentos de origen } \\
\text { animal }\end{array}$} & $\begin{array}{l}\text { a) muy bajo } \\
\text { aporte } \\
\text { grasa }\end{array}$ & & & & & & \\
\hline & $\begin{array}{l}\text { b) bajo aporte } \\
\text { de grasa }\end{array}$ & & & & & & \\
\hline & $\begin{array}{l}\text { c) moderado } \\
\text { aporte de } \\
\text { grasa }\end{array}$ & 3 & 1 & & 2 & & \\
\hline & $\begin{array}{l}\text { d) alto aporte } \\
\text { de grasa }\end{array}$ & & & & & & \\
\hline \multirow[t]{4}{*}{ Leche } & $\begin{array}{l}\text { a) } \\
\text { descremada }\end{array}$ & 1 & & & & & 1 \\
\hline & $\begin{array}{l}\text { b) } \\
\text { semidescrema } \\
\text { da }\end{array}$ & & & & & & \\
\hline & c) entera & & & & & & \\
\hline & d) con azúcar & & & & & & \\
\hline \multirow[t]{2}{*}{ Aceites y grasas } & $\begin{array}{ll}\text { a) } \sin \\
\text { proteínas }\end{array}$ & 4 & 1 & & 2 & & 1 \\
\hline & $\begin{array}{l}\text { b) con } \\
\text { proteínas }\end{array}$ & 1 & & 1 & & & \\
\hline \multirow[t]{2}{*}{ Azúcares } & a) sin grasa & 2 & & & 1 & & \\
\hline & b) con grasa & & & & & & \\
\hline \multicolumn{8}{|l|}{$\begin{array}{l}\text { Alimentos libres en } \\
\text { energía }\end{array}$} \\
\hline Bebidas alcohólicas & & & & & & & \\
\hline
\end{tabular}




\section{Menú 2}

\begin{tabular}{|c|c|c|c|c|c|c|}
\hline Lunes & Martes & Miércoles & Jueves & Viernes & Sábado & Domingo \\
\hline \multicolumn{7}{|c|}{ Desayuno } \\
\hline 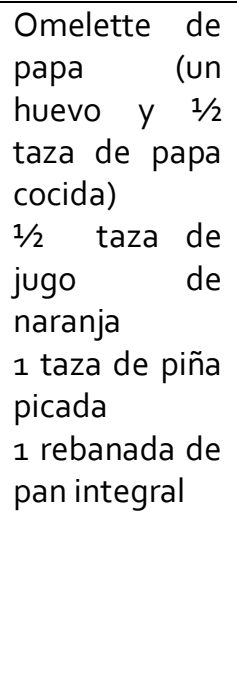 & $\begin{array}{l}2 \text { quesadillas } \\
\text { de tortilla de } \\
\text { maíz y } \\
\text { queso } \\
\text { mozzarella } \\
\text { semi- } \\
\text { descremado } \\
\text { 1 taza de } \\
\text { jugo de piña } \\
1 \text { taza de } \\
\text { melón } \\
\text { picado con } \\
\text { una } \\
\text { cucharada } \\
\text { de crema } \\
\text { ligera }\end{array}$ & $\begin{array}{l}\text { 1 sandwich de } \\
\text { pan integral } \\
\text { con pollo } \\
\text { deshebrado, } \\
\text { y } 1 \\
\text { cucharadita } \\
\text { de mayonesa } \\
1 / 2 \text { taza de } \\
\text { jugo de } \\
\text { mandarina } \\
1 \text { pera }\end{array}$ & $\begin{array}{l}1 \text { huevo } \\
\text { estrellado } \\
2 \text { rebanadas } \\
\text { de pan } \\
\text { integral } \\
1 / 2 \text { vaso de } \\
\text { jugo de } \\
\text { mandarina } \\
1 / 2 \text { manzana } \\
\text { con } \\
\text { cucharada de } \\
\text { cremaligera }\end{array}$ & $\begin{array}{l}2 \text { rebanadas } \\
\text { de pan } \\
\text { integral con } \\
\text { queso } \\
\text { mozzarella } \\
\text { semi- } \\
\text { descemado } \\
\text { gratinado } \\
1 / 2 \text { taza de } \\
\text { jugo de } \\
\text { naranja plátano } \\
1 / 2 \text { picado con } 1 \\
\text { cucharada de } \\
\text { crema ligera }\end{array}$ & $\begin{array}{l}2 \text { tacos de } \\
\text { pollo } \\
1 / 2 \text { taza de } \\
\text { jugo de } \\
\text { mandarina } \\
1 \text { pera con } 1 \\
\text { cucharada de } \\
\text { crema ligera }\end{array}$ & $\begin{array}{l}1 \text { sandwich de } \\
\text { jamón y queso } \\
1 \text { taza de jugo } \\
\text { de piña } \\
1 \text { taza de } \\
\text { melón picado }\end{array}$ \\
\hline \multicolumn{7}{|c|}{ Colación } \\
\hline $\begin{array}{l}\text { 1 taza de piña } \\
\text { picada } \\
10 \text { almendras } \\
0 \quad 14 \\
\text { cacahuates }\end{array}$ & $\begin{array}{l}1 / 2 \text { manzana } \\
10 \\
\text { almendras o } \\
14 \\
\text { cacahuates }\end{array}$ & $\begin{array}{l}1 / 2 \text { plátano } \\
10 \text { almendras } \\
0 \quad 14 \\
\text { cacahuates }\end{array}$ & $\begin{array}{l}\text { 1 taza de piña } \\
\text { picada, } 10 \\
\text { almendras } \\
\text { picadas o } 14 \\
\text { cacahuates }\end{array}$ & $\begin{array}{l}1 \text { pera } \\
14 \text { cacahuates }\end{array}$ & $\begin{array}{l}1 \text { taza de } \\
\text { melón picado } \\
10 \text { almendras } \\
0 \quad 14 \\
\text { cacahuates }\end{array}$ & $\begin{array}{l}1 \text { taza de piña } \\
\text { picada } \\
14 \text { cacahuates }\end{array}$ \\
\hline \multicolumn{7}{|c|}{ Comida } \\
\hline $\begin{array}{l}1 \text { taza de sopa } \\
\text { poblana: } \\
\text { calabaza local, } \\
\text { chile poblano, } \\
\text { elote en grano } \\
\text { en caldo de } \\
\text { pollo } \\
1 / 2 \text { taza de } \\
\text { arroz blanco } \\
2 \text { albóndigas } \\
\text { de carne } \\
\text { molida de res } \\
\text { en salsa roja } \\
1 / 2 \text { taza de } \\
\text { frijoles } \\
\text { Agua de limón } \\
\text { con azúcar } \\
1 \text { taza de } \\
\text { melón picado }\end{array}$ & $\begin{array}{l}\text { 1 taza sopa } \\
\text { de papa con } \\
\text { chícharos } \\
1 / 2 \text { taza de } \\
\text { macarrones } \\
\text { a la } \\
\text { mantequilla } \\
\text { con hierbas } \\
1 \text { filete de } \\
\text { pescado a la } \\
\text { plancha } \\
\text { Ensalada de } \\
\text { aguacate } \\
\text { con aceite } \\
\text { de oliva, } \\
\text { limóny sal } \\
1 / 2 \text { taza de } \\
\text { frijoles } \\
\text { Agua de } \\
\text { jamaica con } \\
\text { azúcar } \\
1 \text { taza de } \\
\text { gajos de } \\
\text { mandarina }\end{array}$ & $\begin{array}{l}\text { 1 taza de sopa } \\
\text { de verduras } \\
1 / 2 \text { taza de } \\
\text { arroz amarillo } \\
1 \text { porción de } \\
\text { bisteck a la } \\
\text { plancha } \\
1 / 2 \text { taza de } \\
\text { frijoles } \\
\text { Agua de } \\
\text { pitahaya con } \\
\text { azúcar } \\
1 \text { pera }\end{array}$ & $\begin{array}{l}1 \text { taza de sopa } \\
\text { de codito con } \\
\text { espinacas } \\
1 \text { porción de } \\
\text { arrachera } \\
\text { Ensalada de } \\
\text { lechuga con } \\
\text { aceite de } \\
\text { oliva, limón y } \\
\text { sal } \\
1 / 2 \text { taza de } \\
\text { frijoles } \\
\text { Agua de limón } \\
\text { con azúcar } \\
18 \text { uvas }\end{array}$ & $\begin{array}{l}1 \text { taza de } \\
\text { tallarines con } \\
\text { especias } \\
1 \text { milanesa de } \\
\text { pollo a la } \\
\text { plancha } \\
\text { Ensalada con } \\
3 \text { tazas } \\
\text { delechuga } \\
\text { con aceite de } \\
\text { oliva, limón y } \\
\text { sal de } \\
1 / 2 \text { taza de } \\
\text { frijoles } \\
\text { Agua de } \\
\text { jamaica con } \\
\text { azúcar } \\
1 / 2 \text { manzana }\end{array}$ & $\begin{array}{l}1 \text { taza de sopa } \\
\text { de fideos } \\
1 \text { milanesa de } \\
\text { cerdo a la } \\
\text { plancha } \\
3 \text { tazas de } \\
\text { lechuga con } \\
\text { aceite de } \\
\text { oliva, sal, } \\
\text { limón } \\
\text { pimienta } \\
1 / 2 \text { taza de } \\
\text { frijoles } \\
\text { Agua de lima } \\
\text { con azúcar } \\
1 \text { taza de } \\
\text { melón picado }\end{array}$ & $\begin{array}{l}1 \text { taza de sopa } \\
\text { de tortilla } \\
1 \text { filete de } \\
\text { pescado al } \\
\text { mojo de ajo } \\
\text { Ensalada de } \\
\text { zanahoria } \\
\text { rallada con } \\
\text { limóny sal } \\
1 \text { tra taza de } \\
\text { frijoles } \\
\text { Agua } \\
\text { melón de } \\
\text { azúcar } \\
18 \text { uvas }\end{array}$ \\
\hline
\end{tabular}




\begin{tabular}{|c|c|c|c|c|c|c|}
\hline \multicolumn{7}{|c|}{ Colación } \\
\hline $\begin{array}{l}1 / 2 \text { taza de } \\
\text { jugo de } \\
\text { mandarina } \\
21 / 2 \text { tazas de } \\
\text { palomitas con } \\
3 \text { cucharadas } \\
\text { de salsa } \\
\text { cátsup } \\
1 \text { taza de piña } \\
\text { picada }\end{array}$ & $\begin{array}{l}1 \text { taza de } \\
\text { jugo de piña } \\
21 / 2 \text { tazas de } \\
\text { palomitas } \\
\text { con } 3 \\
\text { cucharadas } \\
\text { de salsa } \\
\text { cátsup } \\
1 \text { taza de } \\
\text { melón } \\
\text { picado }\end{array}$ & $\begin{array}{l}1 \text { taza de jugo } \\
\text { de melón } \\
21 / 2 \text { tazas de } \\
\text { palomitas con } \\
3 \text { cucharadas } \\
\text { de salsa } \\
\text { cátsup } \\
1 / 2 \text { plátano }\end{array}$ & $\begin{array}{l}1 / 2 \text { taza de } \\
\text { jugo de } \\
\text { mandarina } \\
21 / 2 \text { tazas de } \\
\text { palomitas con } \\
3 \text { cucharadas } \\
\text { de salsa } \\
\text { cátsup } \\
1 \text { pera }\end{array}$ & $\begin{array}{l}1 \text { taza de jugo } \\
\text { de piña } \\
21 / 2 \text { tazas de } \\
\text { palomitas con } \\
3 \text { cucharadas } \\
\text { de salsa } \\
\text { cátsup } \\
1 / 2 \text { manzana }\end{array}$ & $\begin{array}{l}1 \text { taza de jugo } \\
\text { de melón } \\
21 / 2 \text { tazas de } \\
\text { palomitas con } \\
3 \text { cucharadas } \\
\text { de salsa } \\
\text { cátsup } \\
1 \text { taza de piña } \\
\text { picada }\end{array}$ & $\begin{array}{l}1 / 2 \text { taza de } \\
\text { jugo de } \\
\text { naranja } \\
21 / 2 \text { tazas de } \\
\text { palomitas con } \\
3 \text { cucharadas } \\
\text { de salsa } \\
\text { cátsup } \\
1 \text { taza de } \\
\text { melón picado }\end{array}$ \\
\hline \multicolumn{7}{|c|}{ Cena } \\
\hline $\begin{array}{l}1 \text { taza de café } \\
\text { con leche } \\
\text { descremada } \\
\text { con splenda } \\
1 \text { taza de } \\
\text { mango picado } \\
\text { con } 1 \\
\text { cucharada de } \\
\text { queso crema }\end{array}$ & $\begin{array}{l}\text { Licuado: } 1 \\
\text { taza de } \\
\text { leche } \\
\text { descremada } \\
1 / 2 \text { plátano, } \\
\text { vainilla y } \\
\text { splenda }\end{array}$ & $\begin{array}{l}1 \text { taza de } \\
\text { leche café con } \\
\text { leche con } \\
\text { splenda } \\
1 / 2 \text { plátano con } \\
1 \text { cucharada } \\
\text { de crema } \\
\text { ligera y } \\
\text { splenda }\end{array}$ & $\begin{array}{l}3 / 4 \text { de taza de } \\
\text { yogurt } \\
1 / 2 \text { manzana } \\
\text { picada con } \\
\text { splenda }\end{array}$ & $\begin{array}{l}1 \text { taza de } \\
\text { leche café con } \\
\text { leche con } \\
\text { splenda } \\
1 / 2 \text { taza de } \\
\text { fresas con } 1 \\
\text { cucharada de } \\
\text { crema ligera y } \\
\text { splenda }\end{array}$ & $\begin{array}{l}3 / 4 \text { de taza de } \\
\text { yogurt } \\
1 / 2 \text { manzana } \\
\text { picada con } \\
\text { splenda }\end{array}$ & $\begin{array}{l}\text { Licuado: } 1 \\
\text { taza de leche, } \\
1 / 2 \text { plátano, } \\
\text { vainilla } \\
\text { splenda }\end{array}$ \\
\hline
\end{tabular}




\section{Distribución de equivalentes en los tiempos de comida del menú 3}

\begin{tabular}{|c|c|c|c|c|c|c|c|}
\hline \multirow[b]{2}{*}{$\begin{array}{l}\text { Grupo de } \\
\text { Alimentos }\end{array}$} & \multirow[b]{2}{*}{ Subgrupo } & \multirow{2}{*}{$\begin{array}{l}\text { No. de } \\
\text { Equiv. }\end{array}$} & \multicolumn{5}{|c|}{ Tiempos de Comida } \\
\hline & & & Des & Col & Com & Col & Cena \\
\hline Verduras & & 6 & 2 & & 2 & 2 & \\
\hline Frutas & & 6 & 1 & 1 & 2 & & 2 \\
\hline \multirow{2}{*}{$\begin{array}{l}\text { Cereales y } \\
\text { tubérculos }\end{array}$} & a) sin grasa & 4 & 1 & & 2 & 1 & \\
\hline & b) con grasa & & & & & & \\
\hline Leguminosas & & 1 & 1 & & & & \\
\hline \multirow{4}{*}{$\begin{array}{l}\text { Alimentos de } \\
\text { origen animal }\end{array}$} & $\begin{array}{l}\text { a) muy bajo aporte } \\
\text { de grasa }\end{array}$ & & & & & & \\
\hline & $\begin{array}{l}\text { b) bajo aporte de } \\
\text { grasa }\end{array}$ & & & & & & \\
\hline & $\begin{array}{l}\text { c) moderado } \\
\text { aporte de grasa }\end{array}$ & 3 & 1 & & 2 & & \\
\hline & $\begin{array}{l}\text { d) alto aporte de } \\
\text { grasa }\end{array}$ & & & & & & \\
\hline \multirow{4}{*}{ Leche } & a) descremada & 1 & & & & & 1 \\
\hline & b) semidescremada & & & & & & \\
\hline & c) entera & & & & & & \\
\hline & d) con azúcar & & & & & & \\
\hline \multirow{2}{*}{$\begin{array}{ll}\text { Aceites } & y \\
\text { grasas } & \end{array}$} & a) sin proteínas & 4 & 1 & & 3 & & \\
\hline & b) con proteínas & 1 & & 1 & & & \\
\hline \multirow[t]{2}{*}{ Azúcares } & a) sin grasa & 2 & & & 1 & & \\
\hline & b) con grasa & & & & & & \\
\hline \multicolumn{8}{|l|}{$\begin{array}{l}\text { Alimentos } \\
\text { libres en } \\
\text { energía }\end{array}$} \\
\hline $\begin{array}{l}\text { Bebidas } \\
\text { alcohólicas }\end{array}$ & & & & & & & \\
\hline
\end{tabular}




\section{Menú 3}

\begin{tabular}{|c|c|c|c|c|c|c|}
\hline Lunes & Martes & Miércoles & Jueves & Viernes & Sábado & Domingo \\
\hline \multicolumn{7}{|c|}{ Desayuno } \\
\hline $\begin{array}{l}1 / 2 \text { taza de } \\
\text { jugo de } \\
\text { naranja } \\
1 \text { huevo } \\
\text { estrellado } \\
1 \text { rebanada de } \\
\text { pan integral } \\
1 / 2 \text { taza de } \\
\text { frijoles } \\
1 \text { taza de piña } \\
\text { picada }\end{array}$ & $\begin{array}{l}1 \text { taza de jugo } \\
\text { de melón } \\
1 \text { salchicha de } \\
\text { pavo frita } \\
1 \text { rebanada de } \\
\text { pan integral } \\
1 / 2 \text { taza de } \\
\text { frijoles } \\
1 \text { pera }\end{array}$ & $\begin{array}{l}\text { 1 taza de jugo } \\
\text { de piña } \\
1 \text { enfrijolada } \\
\text { rellena de } \\
\text { jamón con } \\
\text { crema ligera y } \\
\text { queso } \\
1 / 2 \text { manzana }\end{array}$ & $\begin{array}{l}1 / 2 \text { taza de } \\
\text { jugo de } \\
\text { mandarina } \\
1 \text { quesadilla } \\
\text { con queso } \\
\text { panela con } 1 \\
\text { cucharada de } \\
\text { crema ligera } \\
1 / 2 \text { taza de } \\
\text { frijoles } \\
1 \text { taza de } \\
\text { melón picado }\end{array}$ & $\begin{array}{l}\text { 1 taza de jugo } \\
\text { de piña } \\
1 \text { sandwich } \\
\text { abierto de } \\
\text { pollo con } \\
\text { mayonesa y } \\
\text { mostaza } \\
1 / 2 \text { taza de } \\
\text { frijoles } \\
1 \text { pera }\end{array}$ & $\begin{array}{l}1 / 2 \text { taza de } \\
\text { jugo de } \\
\text { naranja } \\
1 \text { huevo } \\
\text { revuelto con } \\
\text { papa cocida } \\
1 / 2 \text { taza de } \\
\text { frijoles } \\
1 / 2 \text { manzana }\end{array}$ & $\begin{array}{l}\text { 1 taza de } \\
\text { jugo de } \\
\text { melón } \\
1 / 2 \text { de papa } \\
\text { al horno con } \\
\text { cáscara } \\
\text { rellena de } \\
\text { queso y } 1 \\
\text { cucharada } \\
\text { de crema } \\
\text { ligera } \\
1 / 2 \text { taza de } \\
\text { frijoles } \\
1 \text { taza de } \\
\text { melón } \\
\text { picado }\end{array}$ \\
\hline \multicolumn{7}{|c|}{ Colación } \\
\hline $\begin{array}{l}1 \text { taza de } \\
\text { melón picado } \\
10 \text { almendras }\end{array}$ & $\begin{array}{l}1 \text { pera } \\
10 \text { almendras }\end{array}$ & $\begin{array}{l}1 \text { taza de piña } \\
\text { picada } \\
10 \text { almendras }\end{array}$ & $\begin{array}{l}1 / 2 \text { manzana } \\
10 \text { almendras }\end{array}$ & $\begin{array}{l}1 \text { taza de piña } \\
\text { picada } \\
10 \text { almendras }\end{array}$ & $\begin{array}{l}1 \text { taza de } \\
\text { melón picado } \\
10 \text { almendras }\end{array}$ & $\begin{array}{l}1 \text { pera } \\
10 \\
\text { almendras }\end{array}$ \\
\hline \multicolumn{7}{|c|}{ Comida } \\
\hline $\begin{array}{l}\text { 1 taza de sopa } \\
\text { verduras } \\
\text { Milanesa de } \\
\text { pollo a la } \\
\text { plancha } \\
\text { Ensalada de } \\
\text { aguacate con } \\
\text { aceite de } \\
\text { olive, limón y } \\
\text { sal } \\
1 \text { tortilla } \\
\text { Agua de limón } \\
\text { con azúcar } \\
1 \text { ma manzana }\end{array}$ & $\begin{array}{l}\text { 1 taza de sopa } \\
\text { de codito con } \\
\text { especias } \\
1 \text { bisteck de } \\
\text { res a la } \\
\text { plancha } \\
\text { Ensalada: } 2 \text { 1/2 } \\
\text { tazas de } \\
\text { delechuga, } 2 \\
\text { tomates, } \\
\text { aceite de oliva } \\
\text { sal y limón } \\
1 \text { tortilla } \\
\text { Agua de } \\
\text { jamaica } \\
1 \text { taza de piña } \\
\text { picada }\end{array}$ & $\begin{array}{l}\text { 1 taza de } \\
\text { consomé de } \\
\text { pollo con pico } \\
\text { de gallo } \\
1 / 2 \text { taza de } \\
\text { arroz blanco } \\
1 \text { taza de } \\
\text { picadillo con } \\
\text { verduras } \\
2 \text { tortillas } \\
\text { Agua de piña } \\
\text { con azúcar } \\
1 \text { taza de } \\
\text { melón picado }\end{array}$ & $\begin{array}{l}\text { Ensalada: } 21 / 2 \\
\text { tazas de } \\
\text { delechuga, } 2 \\
\text { tomates, } \\
\text { aceite de oliva } \\
\text { sal y limón } \\
1 \text { taza de } \\
\text { spaguetti a la } \\
\text { boloñesa } \\
\text { Agua de limón } \\
\text { con azúcar } \\
1 \text { pera }\end{array}$ & $\begin{array}{l}\text { 1 taza de sopa } \\
\text { de letras } \\
1 \text { filete de } \\
\text { pescado a la } \\
\text { plancha } \\
1 / 2 \text { taza de } \\
\text { zanahoria } \\
\text { rallada y dos } \\
\text { tomates con } \\
\text { aceite de oliva } \\
\text { limón y sal } \\
1 \text { tortilla } \\
\text { Agua } \\
\text { jamaica con } \\
\text { azúcar } \\
1 / 2 \text { manzana }\end{array}$ & $\begin{array}{l}1 / 2 \text { taza de } \\
\text { arroz amarillo } \\
2 \text { rebanadas } \\
\text { de albóndigón } \\
\text { de res an salsa } \\
\text { roja } \\
\text { Ensalada: } 2 \text { 1/2 } \\
\text { tazas de } \\
\text { delechuga y } \\
\text { aguacate } \\
\text { aceite de oliva } \\
\text { sal y limón } \\
2 \text { tortillas } \\
\text { Agua de piña } \\
\text { con azúcar } \\
1 \text { taza de } \\
\text { melón picado }\end{array}$ & $\begin{array}{l}\text { Ensalada: } 2 \\
1 / 2 \\
\text { tazas de } \\
\text { delechuga y } \\
\text { aguacate, } \\
\text { aceite de } \\
\text { oliva sal y } \\
\text { limón } \\
\text { Lasagna de } \\
\text { carne de res } \\
\text { Agua de } \\
\text { melón con } \\
\text { azúcar } \\
\text { 1 pera }\end{array}$ \\
\hline \multicolumn{7}{|c|}{ Colación } \\
\hline $\begin{array}{l}1 \text { taza de jugo } \\
\text { de melón } \\
21 / 2 \text { tazas de } \\
\text { palomitas con } \\
3 \text { cucharadas } \\
\text { de salsa } \\
\text { catsup }\end{array}$ & $\begin{array}{l}1 \text { taza de jugo } \\
\text { de piña } \\
21 / 2 \text { tazas de } \\
\text { palomitas con } \\
3 \text { cucharadas } \\
\text { de salsa } \\
\text { cátsup }\end{array}$ & $\begin{array}{l}1 / 2 \text { taza de } \\
\text { jugo de } \\
\text { naranja } \\
21 / 2 \text { tazas de } \\
\text { palomitas con } \\
3 \text { cucharadas } \\
\text { de salsa } \\
\text { catsup }\end{array}$ & $\begin{array}{l}1 \text { taza de jugo } \\
\text { de melón } \\
21 / 2 \text { tazas de } \\
\text { palomitas con } \\
3 \text { cucharadas } \\
\text { de salsa } \\
\text { catsup }\end{array}$ & $\begin{array}{l}1 / 2 \text { taza de } \\
\text { jugo de } \\
\text { mandarina } \\
21 / 2 \text { tazas de } \\
\text { palomitas con } \\
3 \text { cucharadas } \\
\text { de salsa } \\
\text { catsup }\end{array}$ & $\begin{array}{l}1 \text { taza de jugo } \\
\text { de piña } \\
21 / 2 \text { tazas de } \\
\text { palomitas con } \\
3 \text { cucharadas } \\
\text { de salsa } \\
\text { catsup }\end{array}$ & $\begin{array}{l}1 / 2 \text { taza de } \\
\text { jugo de } \\
\text { naranja } \\
21 / 2 \text { tazas de } \\
\text { palomitas } \\
\text { con } 3 \\
\text { cucharadas } \\
\text { de salsa } \\
\text { cátsup }\end{array}$ \\
\hline \multicolumn{7}{|c|}{ Cena } \\
\hline $\begin{array}{l}1 \text { vaso de } \\
\text { licuado con } 1 / 2\end{array}$ & $\begin{array}{l}1 \text { taza } \\
\text { leche }\end{array}$ & $\begin{array}{l}1 / 2 \text { taza } \\
\text { yogurt }\end{array}$ & $\begin{array}{l}1 \text { vaso de } \\
\text { licuado con } 1 / 2\end{array}$ & $\begin{array}{ll}1 / 2 \text { taza } & \mathrm{de} \\
\text { yogurt } & \text { con }\end{array}$ & $\begin{array}{l}1 \text { vaso de } \\
\text { licuado con } 1 / 2\end{array}$ & $\begin{array}{l}1 / 2 \text { taza de } \\
\text { yogurt con }\end{array}$ \\
\hline
\end{tabular}




\begin{tabular}{|c|c|c|c|c|c|c|}
\hline $\begin{array}{l}\text { plátano, } 1 \\
\text { taza de leche } \\
\text { descremada, } \\
\text { splenda y } 1 \\
\text { cucharadita } \\
\text { de vainilla } \\
1 \text { pera }\end{array}$ & $\begin{array}{l}\text { descremada } \\
3 / 4 \text { taza de } \\
\text { cereal } \\
1 / 2 \text { palátano y } \\
1 \text { taza de piña } \\
\text { picada }\end{array}$ & $\begin{array}{l}1 \text { taza de } \\
\text { melón picado } \\
1 / 2 \text { plátano }\end{array}$ & $\begin{array}{l}\text { plátano, } 1 \\
\text { taza de leche } \\
\text { descremada, } \\
\text { splenda y } 1 \\
\text { cucharadita } \\
\text { de vainilla } \\
1 \text { taza de } \\
\text { melón picado }\end{array}$ & 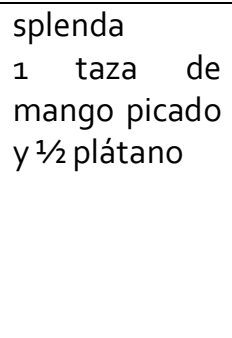 & $\begin{array}{l}\text { plátano, } 1 \\
\text { taza de leche } \\
\text { descremada, } \\
\text { splenda y } 1 \\
\text { cucharadita } \\
\text { de vainilla } \\
\text { 1/2 manzana }\end{array}$ & $\begin{array}{l}\text { splenda } \\
1 \text { taza de } \\
\text { mango } \\
\text { picado y } 1 / 2 \\
\text { plátano }\end{array}$ \\
\hline
\end{tabular}




\section{ANEXO.VII}

\section{MENUS PARA HOMBRES TRATADOS CON DIETA RICA EN LICOPENO (GRUPO EXPERIMENTAL)}

Fórmula dieto-sintética

\begin{tabular}{|c|c|c|c|}
\hline Nutrimentos & Porcentaje & Energía (Kcal) & Gramos \\
\hline $\begin{array}{c}\text { Hidratos de } \\
\text { Carbono }\end{array}$ & $55 \%$ & 990 & 247.5 \\
\hline Proteínas & $15 \%$ & 270 & 67.5 \\
\hline Lípidos* & $30 \%$ & 540 & 60.0 \\
\hline Total & $100 \%$ & 1800 & - \\
\hline
\end{tabular}

Las recomendaciones del porcentaje de lípidos están de acuerdo con la Norma Oficial Mexicana para la prevención, tratamiento y control de las dislipidemias.NOM-037-SSA22002. 



\section{Distribución de Equivalentes}

\begin{tabular}{|c|c|c|c|c|c|c|}
\hline \multirow[b]{2}{*}{$\begin{array}{l}\text { Grupo de } \\
\text { Alimentos }\end{array}$} & \multirow[b]{2}{*}{ Subgrupo } & \multirow{2}{*}{$\begin{array}{l}\text { No. de } \\
\text { Equiv. }\end{array}$} & \multicolumn{4}{|c|}{ Aporte Nutrimental Promedio } \\
\hline & & & $\begin{array}{c}\text { Energía } \\
\text { Kcal }\end{array}$ & $\begin{array}{l}\text { Proteínas } \\
\text { g. }\end{array}$ & $\begin{array}{l}\text { Lípidos } \\
\text { g. }\end{array}$ & $\begin{array}{c}\text { Hidratos } \\
\text { de } \\
\text { Carbono } \\
\text { g. }\end{array}$ \\
\hline Verduras & & 6 & 150 & 12 & 0 & 24 \\
\hline Frutas & & 6 & 360 & 0 & 0 & 90 \\
\hline \multirow{2}{*}{$\begin{array}{ll}\text { Cereales } & y \\
\text { tubérculos } & \end{array}$} & a) sin grasa & 4 & 280 & 8 & 0 & 60 \\
\hline & b) con grasa & 2 & 230 & 4 & 10 & 30 \\
\hline Leguminosas & & 1 & 120 & 8 & 1 & 20 \\
\hline \multirow{4}{*}{$\begin{array}{l}\text { Alimentos de } \\
\text { origen animal }\end{array}$} & $\begin{array}{l}\text { a) muy bajo aporte } \\
\text { de grasa }\end{array}$ & & & & & \\
\hline & $\begin{array}{l}\text { b) bajo aporte de } \\
\text { grasa }\end{array}$ & & & & & \\
\hline & $\begin{array}{l}\text { c) moderado } \\
\text { aporte de grasa }\end{array}$ & 3 & 225 & 21 & 15 & 0 \\
\hline & $\begin{array}{l}\text { d) alto aporte de } \\
\text { grasa }\end{array}$ & & & & & \\
\hline \multirow{4}{*}{ Leche } & a) descremada & 1 & 95 & 9 & 2 & 12 \\
\hline & b) semidescremada & & & & & \\
\hline & c) entera & & & & & \\
\hline & d) con azúcar & & & & & \\
\hline \multirow{2}{*}{$\begin{array}{l}\text { Aceites } \quad y \\
\text { grasas }\end{array}$} & a) sin proteínas & 4 & 180 & 0 & 20 & 0 \\
\hline & b) con proteínas & 1 & 70 & 3 & 5 & 3 \\
\hline \multirow[t]{2}{*}{ Azúcares } & a) sin grasa & 2 & 80 & 0 & 0 & 20 \\
\hline & b) con grasa & & & & & \\
\hline \multicolumn{7}{|l|}{$\begin{array}{l}\text { Alimentos } \\
\text { libres en } \\
\text { energía }\end{array}$} \\
\hline $\begin{array}{l}\text { Bebidas } \\
\text { alcohólicas }\end{array}$ & & & & & & \\
\hline
\end{tabular}




\section{Distribución de equivalentes en los tiempos de comida del menú 1}

\begin{tabular}{|c|c|c|c|c|c|c|c|}
\hline \multirow[b]{2}{*}{$\begin{array}{l}\text { Grupo de } \\
\text { Alimentos }\end{array}$} & \multirow[b]{2}{*}{ Subgrupo } & \multirow{2}{*}{$\begin{array}{l}\text { No. de } \\
\text { Equiv. }\end{array}$} & \multicolumn{5}{|c|}{ Tiempos de Comida } \\
\hline & & & Des & Col & Com & Col & Cena \\
\hline Verduras & & 6 & & 2 & 2 & & 2 \\
\hline Frutas & & 6 & 1 & 1 & 2 & 1 & 1 \\
\hline \multirow{2}{*}{$\begin{array}{l}\text { Cereales } \\
\text { tubérculos }\end{array}$} & a) sin grasa & 4 & 2 & & 1 & 1 & \\
\hline & b) con grasa & 2 & & 1 & & & 1 \\
\hline Leguminosas & & 1 & & & 1 & & \\
\hline \multirow{4}{*}{$\begin{array}{l}\text { Alimentos de } \\
\text { origen animal }\end{array}$} & $\begin{array}{l}\text { a) muy bajo aporte } \\
\text { de grasa }\end{array}$ & & & & & & \\
\hline & $\begin{array}{l}\text { b) bajo aporte de } \\
\text { grasa }\end{array}$ & & & & & & \\
\hline & $\begin{array}{l}\text { c) moderado } \\
\text { aporte de grasa }\end{array}$ & 3 & & & 2 & & 1 \\
\hline & $\begin{array}{l}\text { d) alto aporte de } \\
\text { grasa }\end{array}$ & & & & & & \\
\hline \multirow{4}{*}{ Leche } & a) descremada & 1 & 1 & & & & \\
\hline & b) semidescremada & & & & & & \\
\hline & c) entera & & & & & & \\
\hline & d) con azúcar & & & & & & \\
\hline \multirow{2}{*}{$\begin{array}{ll}\text { Aceites } & y \\
\text { grasas } & \end{array}$} & a) sin proteínas & 4 & & & 3 & & 1 \\
\hline & b) con proteínas & 1 & 1 & & & & \\
\hline \multirow[t]{2}{*}{ Azúcares } & a) sin grasa & 2 & 1 & & 1 & & \\
\hline & b) con grasa & & & & & & \\
\hline \multicolumn{8}{|l|}{$\begin{array}{l}\text { Alimentos } \\
\text { libres en } \\
\text { energía }\end{array}$} \\
\hline $\begin{array}{l}\text { Bebidas } \\
\text { alcohólicas }\end{array}$ & & & & & & & \\
\hline
\end{tabular}




\section{Menú 1}

\begin{tabular}{|c|c|c|c|c|c|c|}
\hline Lunes & Martes & Miércoles & Jueves & Viernes & Sábado & Domingo \\
\hline \multicolumn{7}{|c|}{ Desayuno } \\
\hline $\begin{array}{l}1 \text { taza de } \\
\text { leche } \\
\text { descremada } \\
1 \text { taza de } \\
\text { cereal integral } \\
\text { de arroz } \\
1 \text { taza de } \\
\text { papaya picada } \\
\text { con una } \\
\text { cucharadita } \\
\text { de miel } \\
\text { 10 almendras } \\
\text { picadas } 0 \quad 14 \\
\text { cacahuates }\end{array}$ & $\begin{array}{l}1 \text { taza de } \\
\text { licuado con } 1 \\
\text { taza de leche } \\
\text { descremada, } \\
1 \text { taza de } \\
\text { papaya } \\
\text { endulzado } \\
\text { con } \\
\text { cucharadita } \\
\text { de azúcar } \\
2 \text { rebanadas } \\
\text { de pan } \\
\text { integral } \\
\text { tostado con } 1 \\
\text { cucharita de } \\
\text { mantequilla } \\
\text { de cacahuate } \\
\text { c/u }\end{array}$ & $\begin{array}{l}1 \text { taza de } \\
\text { leche } \\
\text { descremada } \\
1 \text { taza de } \\
\text { cereal integral } \\
\text { de arroz } \\
1 \text { taza de } \\
\text { papaya picada } \\
\text { con } 1 \\
\text { cucharadita } \\
\text { de miel } \\
\text { 10 almendras } \\
\text { picadas } 0 \quad 14 \\
\text { cacahuates }\end{array}$ & $\begin{array}{l}\text { 1 taza de café } \\
\text { con leche } \\
\text { descremada } \\
\text { con splenda } \\
2 \text { hot cakes } \\
\text { pequeños con } \\
\text { dos } \\
\text { cucharaditas } \\
\text { de miel de } \\
\text { abeja } \\
1 \text { cucharadita2 } \\
\text { de } \\
\text { mantequilla } \\
1 \text { taza de } \\
\text { sandía picada }\end{array}$ & $\begin{array}{l}1 \text { taza de } \\
\text { leche } \\
\text { descremada } \\
1 \text { taza de } \\
\text { cereal } \\
\text { integral de } \\
\text { arroz } \\
1 \text { taza de } \\
\text { papaya } \\
\text { picada con } 1 \\
\text { cucharadita } \\
\text { de miel } \\
10 \\
\text { almendras } \\
\text { picadas o } 14 \\
\text { cacahuates }\end{array}$ & $\begin{array}{l}\text { 1 taza de } \\
\text { licuado con } \\
1 \text { taza de } \\
\text { leche } \\
\text { descremada } \\
1 \text { taza de } \\
\text { papaya con } \\
1 \\
\text { cucharadita } \\
\text { de azúcar } \\
1 \text { barrita de } \\
\text { granola } \\
\text { sabor } \\
\text { manzana } \\
10 \\
\text { almendras o } \\
14 \\
\text { cacahuates }\end{array}$ & $\begin{array}{l}3 / 4 \text { de taza de } \\
\text { yogurt light } \\
1 \text { taza de } \\
\text { papaya } \\
\text { picada con } 1 \\
\text { cucharadita } \\
\text { de miel } \\
10 \\
\text { almendras } \\
\text { picadas o } 14 \\
\text { cacahuates } \\
6 \\
\text { cucharadas } \\
\text { de granola }\end{array}$ \\
\hline \multicolumn{7}{|c|}{ Colación } \\
\hline $\begin{array}{l}1 \text { taza de jugo } \\
\text { de tomate } \\
1 \text { galleta de } \\
\text { avena y } \\
\text { manzana } \\
1 \text { taza de } \\
\text { sandía picada }\end{array}$ & $\begin{array}{l}\text { 1 taza de jugo } \\
\text { de tomate } \\
1 \text { galleta de } \\
\text { avena y } \\
\text { manzana } \\
1 \text { taza de } \\
\text { sandía picada }\end{array}$ & $\begin{array}{lr}\text { 1 taza de jugo } \\
\text { de tomate } \\
1 \text { galleta de } \\
\text { avena } & y \\
\text { manzana } & \\
1 \quad \text { taza de } & \text { de } \\
\text { gajos } & \text { de } \\
\text { toronja } & \end{array}$ & $\begin{array}{l}\text { 1 taza de jugo } \\
\text { de tomate } \\
1 \text { galleta de } \\
\text { avena } \text { y } \\
\text { manzana } \\
1 \text { taza de } \\
\text { papaya picada }\end{array}$ & $\begin{array}{lr}\text { taza } & \text { de } \\
\text { jugo } & \text { de } \\
\text { tomate } & \\
1 \text { galleta } & \text { de } \\
\text { avena } & \text { y } \\
\text { manzana } & \\
1 \text { taza de } \\
\text { sandía } & \\
\text { picada } & \\
\end{array}$ & $\begin{array}{ll}1 \text { taza de } & \text { de } \\
\text { jugo de } & \text { domate } \\
\text { 1 galleta de } \\
\text { avena y } \\
\text { manzana } \\
\text { 1 taza de } \\
\text { sandía } \\
\text { picada }\end{array}$ & $\begin{array}{lr}\text { 1 de taza de } \\
\text { jugo de } \\
\text { tomate } \\
1 \text { galleta de } \\
\text { avena y } \\
\text { manzana } \\
\begin{array}{ll}1 \text { taza de } \\
\text { gajos de } \\
\text { toronja }\end{array} \\
\end{array}$ \\
\hline \multicolumn{7}{|c|}{ Comida } \\
\hline $\begin{array}{l}1 \text { taza de } \\
\text { consomé de } \\
\text { pollo con } 1 / 4 \text { de } \\
\text { taza de arroz } \\
1 \text { bisteck de } \\
\text { bola de res } \\
\text { entomatado } \\
2 \text { tomates con } \\
\text { aceite de oliva } \\
\text { limón y sal. } \\
1 / 2 \text { taza de } \\
\text { frijoles } \\
\text { Agua } \\
\text { toronja con de } \\
\text { azúcar } \\
1 \text { taza de } \\
\text { papaya picada }\end{array}$ & $\begin{array}{l}\text { 1 taza de sopa } \\
\text { de verduras } \\
1 / 2 \text { taza de } \\
\text { espagueti con } \\
\text { salsa de } \\
\text { tomate y } \\
\text { tomate picado } \\
\text { Fajitas de } \\
\text { pollo (con } \\
\text { chile pimiento } \\
\text { verde y rojo, } \\
\text { cebolla, } \\
\text { tomate y salsa } \\
\text { inglesa) } \\
\text { 1/2 taza de } \\
\text { frijoles } \\
\text { Agua de } \\
\text { sandía con } \\
\text { azúcar } \\
\begin{array}{l}\text { 1 taza de } \\
\text { gajos de }\end{array}\end{array}$ & 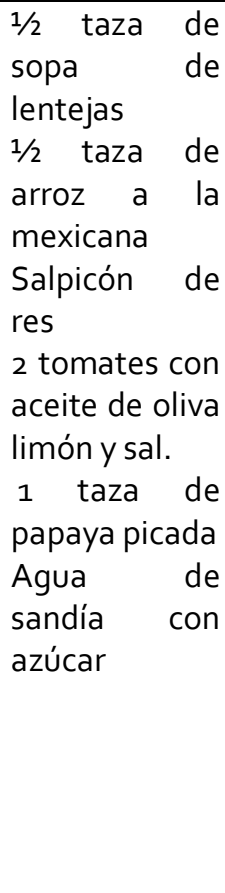 & $\begin{array}{l}\text { 1/2 taza de } \\
\text { arroz rojo } \\
\text { Tinga de res } \\
1 / 3 \text { taza de } \\
\text { frijol refrito } \\
\text { Agua de } \\
\text { toronja con } \\
\text { azúcar } \\
1 \text { taza de } \\
\text { sandía picada }\end{array}$ & $\begin{array}{l}\text { 1/2 taza de } \\
\text { frijol colado } \\
\text { Cerdo } \\
\text { entomatado } \\
\text { con media } \\
\text { papa cocida } \\
2 \text { tomates } \\
\text { con aceite } \\
\text { de oliva } \\
\text { limón y sal. } \\
2 \text { tortillas } \\
\text { Agua de } \\
\text { sandía con } \\
\text { azúcar } \\
1 \text { taza de } \\
\text { gajos de } \\
\text { toronja }\end{array}$ & $\begin{array}{l}\text { Ensalada: } 3 \\
\text { tazas de } \\
\text { lechuga, 2 } \\
\text { piezas de } \\
\text { tomate } \\
\text { saladet, 1/2 } \\
\text { taza de } \\
\text { chícharos } \\
\text { con aderezo } \\
\text { de aceite de } \\
\text { oliva, limón } \\
\text { y sal. } \\
\text { Espagueti a } \\
\text { la boloñesa } \\
\text { (1/2 taza de } \\
\text { espagueti } \\
\text { cocido con } \\
\text { carne } \\
\text { molida de } \\
\text { res y salsa } \\
\text { de tomate }\end{array}$ & $\begin{array}{l}\text { 1 taza de } \\
\text { sopa de } \\
\text { coditos con } \\
\text { salsa roja } \\
2 \text { tostadas } \\
\text { con frijoles } \\
\text { refritos, } \\
\text { pollo } \\
\text { deshebrado, } \\
\text { lechuga, } \\
\text { tomate, } \\
\text { cebolla, } \\
\text { aguacate, } \\
\text { salsa verde y } \\
\text { queso } \\
\text { Agua de } \\
\text { sandía con } \\
\text { azúcar } \\
1 \text { taza de } \\
\text { papaya } \\
\text { picada }\end{array}$ \\
\hline
\end{tabular}




\begin{tabular}{|c|c|c|c|c|c|c|}
\hline & toronja & & & & $\begin{array}{ll}\text { Agua de } & \text { de } \\
\text { toronja con } \\
\text { azúcar } \\
1 \text { taza de } \\
\text { sandía } & \\
\text { picada } & \end{array}$ & \\
\hline \multicolumn{7}{|c|}{ Colación } \\
\hline $\begin{array}{l}\text { 1 taza de } \\
\text { sandía picada } \\
2 \text { 1/2 tazas de } \\
\text { palomitas con } \\
3 \text { cucharadas } \\
\text { de salsa } \\
\text { catsup }\end{array}$ & $\begin{array}{l}1 / 2 \text { manzana } \\
21 / 2 \text { tazas de } \\
\text { palomitas con } \\
3 \text { cucharadas } \\
\text { de salsa } \\
\text { cátsup }\end{array}$ & $\begin{array}{l}1 \text { de taza de } \\
\text { sandía picada } \\
21 / 2 \text { tazas de } \\
\text { palomitas con } \\
3 \text { cucharadas } \\
\text { de salsa } \\
\text { catsup }\end{array}$ & $\begin{array}{l}\text { 1 taza de } \\
\text { papaya picada } \\
2 \text { 1/2 tazas de } \\
\text { palomitas con } \\
3 \text { cucharadas } \\
\text { de salsa } \\
\text { cátsup }\end{array}$ & $\begin{array}{l}1 \text { taza de } \\
\text { papaya } \\
\text { picada } \\
2 \quad 1 / 2 \text { tazas } \\
\text { de palomitas } \\
\text { con } 3 \\
\text { cucharadas } \\
\text { de salsa } \\
\text { catsup }\end{array}$ & $\begin{array}{l}1 \text { taza de } \\
\text { papaya } \\
\text { picada } \\
21 / 2 \text { tazas } \\
\text { de } \\
\text { palomitas } \\
\text { con } 3 \\
\text { cucharadas } \\
\text { de salsa } \\
\text { cátsup }\end{array}$ & $\begin{array}{l}1 \text { taza de } \\
\text { sandía } \\
\text { picada } \\
2 \quad 1 / 2 \text { tazas } \\
\text { de } \\
\text { palomitas } \\
\text { con } 3 \\
\text { cucharadas } \\
\text { de salsa } \\
\text { catsup }\end{array}$ \\
\hline \multicolumn{7}{|c|}{ Cena } \\
\hline $\begin{array}{l}1 \text { taza de jugo } \\
\text { de tomate } \\
1 \text { rebanada de } \\
\text { pan integral } \\
\text { con queso } \\
\text { mozarela y } \\
\text { mayonesa. } \\
\text { 1 taza de } \\
\text { gajos de } \\
\text { toronja }\end{array}$ & $\begin{array}{l}\text { 1 taza de jugo } \\
\text { de tomate } \\
1 \text { salchicha } \\
\text { asada } \\
7 \text { galletas } \\
\text { saladas } \\
\text { cremosas } \\
1 \text { taza de } \\
\text { papaya picada }\end{array}$ & $\begin{array}{l}1 \text { taza de jugo } \\
\text { de tomate } \\
1 \text { bisquet con } \\
\text { queso } \\
\text { manchego } \\
\text { gratinado } \\
1 / 2 \text { manzana }\end{array}$ & $\begin{array}{l}1 \text { taza de jugo } \\
\text { de tomate } \\
1 \text { hot dog con } \\
\text { mayonesa } \\
1 \text { pera }\end{array}$ & $\begin{array}{l}1 \text { taza de } \\
\text { jugo de } \\
\text { tomate } \\
2 \text { piezas de } \\
\text { pan de ajo } \\
\text { conjamón } \\
\text { 1 naranja }\end{array}$ & $\begin{array}{l}\text { 1 taza de } \\
\text { jugo de } \\
\text { tomate } \\
\text { 1 rebanadas } \\
\text { de pan } \\
\text { integral, con } \\
\text { pollo } \\
\text { deshebrado, } \\
\text { mayonesa. } \\
\text { 1 pera }\end{array}$ & $\begin{array}{l}1 \text { taza de } \\
\text { jugo de } \\
\text { tomate } \\
1 \text { huevo a la } \\
\text { mexicana } \\
1 \text { bisquet }\end{array}$ \\
\hline
\end{tabular}


Distribución de equivalentes en los tiempos de comida del menú 2

\begin{tabular}{|c|c|c|c|c|c|c|c|}
\hline \multirow[b]{2}{*}{ Grupo de Alimentos } & \multirow[b]{2}{*}{ Subgrupo } & \multirow{2}{*}{$\begin{array}{l}\text { No. de } \\
\text { Equiv. }\end{array}$} & \multicolumn{5}{|c|}{ Tiempos de Comida } \\
\hline & & & Des & Col & Com & Col & Cena \\
\hline Verduras & & 6 & 2 & & 2 & 2 & \\
\hline Frutas & & 6 & 1 & 1 & 2 & 1 & 1 \\
\hline \multirow{2}{*}{$\begin{array}{ll}\begin{array}{l}\text { Cereales } \\
\text { tubérculos }\end{array} & y \\
\end{array}$} & a) sin grasa & 4 & 2 & & 1 & 1 & \\
\hline & b) con grasa & 2 & & 1 & & & 1 \\
\hline Leguminosas & & 1 & & & 1 & & \\
\hline \multirow[t]{4}{*}{$\begin{array}{l}\text { Alimentos de origen } \\
\text { animal }\end{array}$} & $\begin{array}{l}\text { a) muy bajo } \\
\text { aporte } \\
\text { grasa }\end{array}$ & & & & & & \\
\hline & $\begin{array}{l}\text { b) bajo aporte } \\
\text { de grasa }\end{array}$ & & & & & & \\
\hline & $\begin{array}{l}\text { c) moderado } \\
\text { aporte de } \\
\text { grasa }\end{array}$ & 3 & 1 & & 2 & & \\
\hline & $\begin{array}{l}\text { d) alto aporte } \\
\text { de grasa }\end{array}$ & & & & & & \\
\hline \multirow[t]{4}{*}{ Leche } & $\begin{array}{l}\text { a) } \\
\text { descremada }\end{array}$ & 1 & & & & & 1 \\
\hline & $\begin{array}{l}\text { b) } \\
\text { semidescrema } \\
\text { da }\end{array}$ & & & & & & \\
\hline & c) entera & & & & & & \\
\hline & d) con azúcar & & & & & & \\
\hline \multirow[t]{2}{*}{ Aceites y grasas } & $\begin{array}{ll}\text { a) } & \sin \\
\text { proteínas } & \\
\end{array}$ & 4 & 1 & & 2 & & 1 \\
\hline & $\begin{array}{l}\text { b) con } \\
\text { proteínas }\end{array}$ & 1 & & 1 & & & \\
\hline \multirow[t]{2}{*}{ Azúcares } & a) sin grasa & 2 & & & 1 & & 1 \\
\hline & b) con grasa & & & & & & \\
\hline \multicolumn{8}{|l|}{$\begin{array}{l}\text { Alimentos libres en } \\
\text { energía }\end{array}$} \\
\hline Bebidas alcohólicas & & & & & & & \\
\hline
\end{tabular}




\section{Menú 2}

\begin{tabular}{|c|c|c|c|c|c|c|}
\hline Lunes & Martes & Miércoles & Jueves & Viernes & Sábado & Domingo \\
\hline \multicolumn{7}{|c|}{ Desayuno } \\
\hline $\begin{array}{l}\text { Omelette de } \\
\text { papa (un } \\
\text { huevo y } 1 / 2 \\
\text { taza de papa } \\
\text { cocida) } \\
1 \text { taza de jugo } \\
\text { de tomate } \\
1 \text { taza de } \\
\text { sandía picada } \\
1 \text { rebanada de } \\
\text { pan integral }\end{array}$ & $\begin{array}{l}2 \text { quesadillas } \\
\text { de tortilla de } \\
\text { maíz y } \\
\text { queso } \\
\text { mozzarella } \\
\text { semi- } \\
\text { descremado } \\
1 \text { taza de } \\
\text { jugo de } \\
\text { tomate } \\
\text { 1 taza de } \\
\text { papaya } \\
\text { picada con } \\
\text { una } \\
\text { cucharada } \\
\text { de crema } \\
\text { ligera }\end{array}$ & $\begin{array}{l}\text { a sandwich de } \\
\text { pan integral } \\
\text { con pollo } \\
\text { deshebrado, } \\
\text { y } 1 \\
\text { cucharadita } \\
\text { de mayonesa } \\
\text { 1 taza de jugo } \\
\text { de tomate } \\
1 \text { taza de } \\
\text { sandía picada }\end{array}$ & $\begin{array}{l}1 \text { huevo } \\
\text { estrellado } \\
2 \text { rebanadas } \\
\text { de pan } \\
\text { integral } \\
1 \text { vaso de jugo } \\
\text { de tomate } \\
1 \text { taza de } \\
\text { papaya picada } \\
\text { con } 1 \\
\text { cucharada de } \\
\text { crema ligera }\end{array}$ & $\begin{array}{l}2 \text { rebanadas } \\
\text { de pan } \\
\text { integral con } \\
\text { queso } \\
\text { mozzarella } \\
\text { semi- } \\
\text { descemado } \\
\text { gratinado } \\
1 \text { taza de jugo } \\
\text { de tomate } \\
1 \text { taza de } \\
\text { papaya picada } \\
\text { con } 1 \\
\text { cucharada de } \\
\text { crema ligera }\end{array}$ & $\begin{array}{l}2 \text { tacos de } \\
\text { pollo } \\
1 \text { taza de jugo } \\
\text { de tomate } \\
1 \text { taza de } \\
\text { papaya picada } \\
\text { con } 1 \\
\text { cucharada de } \\
\text { crema ligera }\end{array}$ & $\begin{array}{l}\text { 1 sandwich de } \\
\text { jamón y queso } \\
1 \text { taza de jugo } \\
\text { de tomate } \\
1 \text { taza de } \\
\text { papaya picada }\end{array}$ \\
\hline \multicolumn{7}{|c|}{ Colación } \\
\hline $\begin{array}{l}1 \text { taza de } \\
\text { papaya picada } \\
10 \text { almendras } \\
0 \quad 14 \\
\text { cacahuates } \\
5 \text { galletas } \\
\text { marías }\end{array}$ & $\begin{array}{l}1 \text { taza de } \\
\text { sandía } \\
\text { picada } \\
10 \\
\text { almendras o } \\
14 \\
\text { cacahuates } \\
4 \text { galletas } \\
\text { saladas }\end{array}$ & $\begin{array}{l}1 \text { taza de } \\
\text { papaya picada } \\
10 \text { almendras } \\
0 \quad 14 \\
\text { cacahuates } \\
2 \text { 1/2 tazas de } \\
\text { palomitas de } \\
\text { maíz }\end{array}$ & $\begin{array}{l}\text { taza de } \\
\text { sandía picada, } \\
3 \text { cucharadas } \\
\text { de granola y } \\
10 \text { almendras } \\
\text { picadas o } 14 \\
\text { cacahuates }\end{array}$ & $\begin{array}{l}1 \text { taza de } \\
\text { sandía picada } \\
3 \text { palitos } \\
\text { integrales } \\
\text { 14 cacahuates }\end{array}$ & $\begin{array}{l}\text { taza de } \\
\text { sandía picada } \\
10 \text { almendras } \\
0 \quad 14 \\
\text { cacahuates } \\
5 \quad \text { galletas } \\
\text { marías }\end{array}$ & $\begin{array}{l}1 \text { taza de } \\
\text { sandía picada } \\
2 \text { galletas } \\
\text { dulces sin } \\
\text { relleno } \\
\text { 14 cacahuates }\end{array}$ \\
\hline \multicolumn{7}{|c|}{ Comida } \\
\hline $\begin{array}{l}1 \text { taza de sopa } \\
\text { poblana: } \\
\text { calabaza local, } \\
\text { chile poblano, } \\
\text { elote en grano } \\
\text { en caldo de } \\
\text { pollo } \\
1 / 2 \text { taza de } \\
\text { arroz a la } \\
\text { mexicana } \\
2 \text { albóndigas } \\
\text { de carne } \\
\text { molida de res } \\
\text { en salsa roja } \\
1 / 2 \text { taza de } \\
\text { frijoles } \\
\text { Agua de } \\
\text { toronja con } \\
\text { azúcar } \\
1 \text { taza de } \\
\text { sandía picada }\end{array}$ & $\begin{array}{l}1 \text { taza sopa } \\
\text { de papa con } \\
\text { chícharos } \\
1 / 2 \text { taza de } \\
\text { macarrón en } \\
\text { salsa roja } \\
1 \text { filete de } \\
\text { pescado a la } \\
\text { plancha } \\
\text { Ensalada de } \\
\text { tomate con } \\
\text { aceite de } \\
\text { oliva, limón } \\
\text { y sal } \\
\text { 1/2 taza de } \\
\text { frijoles } \\
\text { Agua de } \\
\text { sandía con } \\
\text { azúcar } \\
1 \text { taza de } \\
\text { gajos de } \\
\text { toronja }\end{array}$ & $\begin{array}{l}\text { 1 taza de sopa } \\
\text { de verduras } \\
1 / 2 \text { taza de } \\
\text { arroz rojo } \\
1 \text { porción de } \\
\text { bisteck } \\
\text { entomatado } \\
1 / 2 \text { taza de } \\
\text { frijoles } \\
\text { Agua } \\
\text { papaya de con } \\
\text { azúcar } \\
1 \text { taza de } \\
\text { gajos } \\
\text { toronja de }\end{array}$ & $\begin{array}{l}\text { 1 taza de sopa } \\
\text { de codito con } \\
\text { espinacas } \\
1 \text { porción de } \\
\text { arrachera } \\
\text { Ensalada de } \\
\text { tomates con } \\
\text { aceite de } \\
\text { oliva, limón y } \\
\text { sal } \\
1 / 2 \text { taza de } \\
\text { frijoles } \\
\text { Agua de } \\
\text { toronja con } \\
\text { azúcar } \\
1 \text { taza de } \\
\text { sandía picada }\end{array}$ & 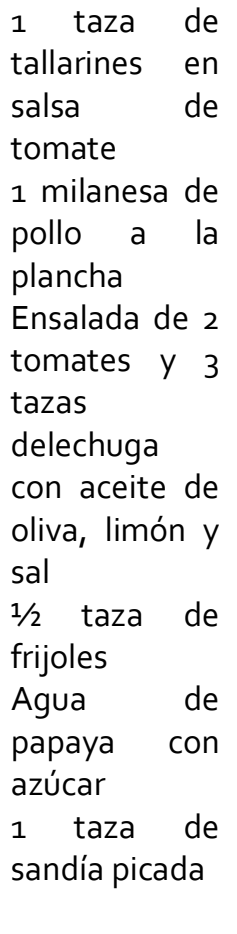 & $\begin{array}{l}1 \text { taza de sopa } \\
\text { de fideos } \\
1 \text { milanesa de } \\
\text { cerdo a la } \\
\text { plancha } \\
\text { Ensalada de } 2 \\
\text { tomates y } 3 \\
\text { tazas } \\
\text { delechuga } \\
\text { con aceite de } \\
\text { oliva, limón y } \\
\text { sal } \\
1 / 2 \text { taza de } \\
\text { frijoles } \\
\text { Agua de } \\
\text { toronja con } \\
\text { azúcar } \\
1 \quad \text { taza de } \\
\text { sandía picada }\end{array}$ & $\begin{array}{l}\text { 1 taza de sopa } \\
\text { de tortilla } \\
1 \text { filete de } \\
\text { pescado a la } \\
\text { veracruzana } \\
\text { Ensalada de } \\
\text { zanahoria } \\
\text { rallada con } \\
\text { limón y sal } \\
\text { 1/2 taza de } \\
\text { frijoles } \\
\text { Agua } \\
\text { toronja con de } \\
\text { azúcar } \\
\text { 1 taza de } \\
\text { papaya picada }\end{array}$ \\
\hline
\end{tabular}




\begin{tabular}{|c|c|c|c|c|c|c|}
\hline \multicolumn{7}{|c|}{ Colación } \\
\hline $\begin{array}{l}1 \text { taza de jugo } \\
\text { de tomate } \\
21 / 2 \text { tazas de } \\
\text { palomitas con } \\
3 \text { cucharadas } \\
\text { de salsa } \\
\text { cátsup } \\
1 \text { taza de } \\
\text { papaya picada }\end{array}$ & $\begin{array}{l}1 \text { taza de } \\
\text { jugo de } \\
\text { tomate } \\
21 / 2 \text { tazas de } \\
\text { palomitas } \\
\text { con } 3 \\
\text { cucharadas } \\
\text { de salsa } \\
\text { cátsup } \\
1 \text { taza de } \\
\text { papaya } \\
\text { picada }\end{array}$ & $\begin{array}{l}1 \text { taza de jugo } \\
\text { de tomate } \\
21 / 2 \text { tazas de } \\
\text { palomitas con } \\
3 \text { cucharadas } \\
\text { de salsa } \\
\text { cátsup } \\
1 \text { taza de } \\
\text { sandía picada }\end{array}$ & $\begin{array}{l}1 \text { taza de jugo } \\
\text { de tomate } \\
21 / 2 \text { tazas de } \\
\text { palomitas con } \\
3 \text { cucharadas } \\
\text { de salsa } \\
\text { cátsup } \\
1 \text { taza de } \\
\text { papaya picada }\end{array}$ & \begin{tabular}{|ll}
1 taza de jugo \\
de tomate \\
$21 / 2$ tazas de \\
palomitas con \\
3 cucharadas \\
de & salsa \\
cátsup & \\
1 taza & de \\
gajos & de \\
toronja &
\end{tabular} & $\begin{array}{l}1 \text { taza de jugo } \\
\text { de tomate } \\
21 / 2 \text { tazas de } \\
\text { palomitas con } \\
3 \text { cucharadas } \\
\text { de salsa } \\
\text { cátsup } \\
1 \text { taza de } \\
\text { papaya picada }\end{array}$ & $\begin{array}{l}1 \text { taza de jugo } \\
\text { de tomate } \\
21 / 2 \text { tazas de } \\
\text { palomitas con } \\
3 \text { cucharadas } \\
\text { de salsa } \\
\text { cátsup } \\
1 \text { taza de } \\
\text { sandía picada }\end{array}$ \\
\hline \multicolumn{7}{|c|}{ Cena } \\
\hline $\begin{array}{l}\text { 1 taza de café } \\
\text { con leche } \\
\text { descremada } \\
\text { con azúcar } \\
4 \text { galletas } \\
\text { integrales con } \\
1 \text { cucharada } \\
\text { de queso } \\
\text { crema } \\
1 \text { taza de } \\
\text { mango picado }\end{array}$ & $\begin{array}{l}\text { Licuado: } 1 \\
\text { taza de } \\
\text { leche } \\
\text { descremada } \\
1 / 2 \text { plátano, } \\
\text { vainilla } \\
4 \quad \text { galletas } \\
\text { integrales } \\
\text { con } 1 \\
\text { cucharada } \\
\text { de } \\
\text { mantequilla } \\
\text { y } \\
\text { mermelada }\end{array}$ & $\begin{array}{l}\text { 1 taza de café } \\
\text { con leche } \\
\text { descremada } \\
\text { con azúcar } \\
1 / 2 \text { plátano } \\
1 \text { barrita de } \\
\text { granola con } \\
\text { chocochip }\end{array}$ & $\begin{array}{l}3 / 4 \text { de taza de } \\
\text { yogurt } \\
1 / 2 \text { manzana } \\
\text { picada } \\
3 \text { cucharadas } \\
\text { de granola } \\
1 \text { cucharada } \\
\text { de azúcar }\end{array}$ & $\begin{array}{l}1 \text { taza de café } \\
\text { con leche } \\
\text { descremada } \\
\text { con azúcar } \\
1 / 2 \text { plátano } \\
1 \text { barrita de } \\
\text { granola con } \\
\text { chocochip }\end{array}$ & $\begin{array}{l}\text { 1 taza de café } \\
\text { con leche } \\
\text { descremada } \\
\text { con azúcar } \\
5 \quad \text { galletas } \\
\text { marías con } \\
\text { cajeta } \\
18 \text { uvas }\end{array}$ & $\begin{array}{l}\text { Licuado: } 1 \\
\text { taza de leche } \\
\text { descremada } \\
1 / 2 \text { plátano, } \\
\text { vainilla } \\
4 \text { galletas } \\
\text { integrales con } \\
1 \text { cucharada } \\
\text { de } \\
\text { mantequilla y } \\
\text { mermelada }\end{array}$ \\
\hline
\end{tabular}




\section{Distribución de equivalentes en los tiempos de comida del menú 3}

\begin{tabular}{|c|c|c|c|c|c|c|c|}
\hline \multirow[b]{2}{*}{$\begin{array}{l}\text { Grupo de } \\
\text { Alimentos }\end{array}$} & \multirow[b]{2}{*}{ Subgrupo } & \multirow{2}{*}{$\begin{array}{l}\text { No. de } \\
\text { Equiv. }\end{array}$} & \multicolumn{5}{|c|}{ Tiempos de Comida } \\
\hline & & & Des & Col & Com & Col & Cena \\
\hline Verduras & & 6 & 2 & & 2 & 2 & \\
\hline Frutas & & 6 & 1 & 1 & 2 & & 2 \\
\hline \multirow{2}{*}{$\begin{array}{l}\text { Cereales y } \\
\text { tubérculos }\end{array}$} & a) sin grasa & 4 & 1 & & 2 & 1 & \\
\hline & b) con grasa & 2 & & & & & 2 \\
\hline Leguminosas & & 1 & 1 & & & & \\
\hline \multirow{4}{*}{$\begin{array}{l}\text { Alimentos de } \\
\text { origen animal }\end{array}$} & $\begin{array}{l}\text { a) muy bajo aporte } \\
\text { de grasa }\end{array}$ & & & & & & \\
\hline & $\begin{array}{l}\text { b) bajo aporte de } \\
\text { grasa }\end{array}$ & & & & & & \\
\hline & $\begin{array}{l}\text { c) moderado } \\
\text { aporte de grasa }\end{array}$ & 3 & 1 & & 2 & & \\
\hline & $\begin{array}{l}\text { d) alto aporte de } \\
\text { grasa }\end{array}$ & & & & & & \\
\hline \multirow{4}{*}{ Leche } & a) descremada & 1 & & & & & 1 \\
\hline & b) semidescremada & & & & & & \\
\hline & c) entera & & & & & & \\
\hline & d) con azúcar & & & & & & \\
\hline \multirow{2}{*}{$\begin{array}{ll}\text { Aceites } & y \\
\text { grasas } & \end{array}$} & a) sin proteínas & 4 & 1 & & 3 & & \\
\hline & b) con proteínas & 1 & & 1 & & & \\
\hline \multirow[t]{2}{*}{ Azúcares } & a) sin grasa & 2 & & & 2 & & \\
\hline & b) con grasa & & & & & & \\
\hline \multicolumn{8}{|l|}{$\begin{array}{l}\text { Alimentos } \\
\text { libres en } \\
\text { energía }\end{array}$} \\
\hline $\begin{array}{l}\text { Bebidas } \\
\text { alcohólicas }\end{array}$ & & & & & & & \\
\hline
\end{tabular}




\section{Menú 3}

\begin{tabular}{|c|c|c|c|c|c|c|}
\hline Lunes & Martes & Miércoles & Jueves & Viernes & Sábado & Domingo \\
\hline \multicolumn{7}{|c|}{ Desayuno } \\
\hline $\begin{array}{l}1 \text { taza de jugo } \\
\text { de tomate } \\
1 \text { huevo } \\
\text { estrellado } \\
1 \text { rebanada de } \\
\text { pan integral } \\
1 / 2 \text { taza de } \\
\text { frijoles } \\
1 \text { taza de } \\
\text { sandía picada }\end{array}$ & $\begin{array}{l}1 \text { taza de jugo } \\
\text { de tomate } \\
1 \text { salchicha de } \\
\text { pavo frita } \\
1 \text { rebanada de } \\
\text { pan integral } \\
1 / 2 \text { taza de } \\
\text { frijoles } \\
1 \text { taza de } \\
\text { gajos de } \\
\text { toronja }\end{array}$ & $\begin{array}{l}\text { 1 taza de jugo } \\
\text { de tomate } \\
1 \text { enfrijolada } \\
\text { rellenas de } \\
\text { jamón con } \\
\text { crema ligera y } \\
\text { queso } \\
1 \text { taza de } \\
\text { papaya picada }\end{array}$ & $\begin{array}{l}\text { 1 taza de jugo } \\
\text { de tomate } \\
1 \text { quesadillas } \\
\text { con queso } \\
\text { panela con } 1 \\
\text { cucharada de } \\
\text { crema ligera } \\
1 / 2 \text { taza de } \\
\text { frijoles } \\
1 \text { taza de } \\
\text { sandía picada }\end{array}$ & $\begin{array}{l}\text { l taza de jugo } \\
\text { de tomate } \\
1 \text { sandwich } \\
\text { abierto de } \\
\text { pollo con } \\
\text { mayonesa y } \\
\text { mostaza } \\
1 / 2 \text { taza de } \\
\text { frijoles } \\
1 \text { taza de } \\
\text { gajos } \\
\text { toronja de }\end{array}$ & $\begin{array}{l}1 \text { taza de jugo } \\
\text { de tomate } \\
1 \text { huevo } \\
\text { revuelto con } \\
\text { papa cocida } \\
1 / 2 \text { taza de } \\
\text { frijoles } \\
1 \text { taza de } \\
\text { papaya picada }\end{array}$ & $\begin{array}{l}\text { 1 taza de } \\
\text { jugo de } \\
\text { tomate } \\
1 / 2 \text { de papa } \\
\text { al horno con } \\
\text { cáscara } \\
\text { rellena de } \\
\text { queso y } 1 \\
\text { cucharada } \\
\text { de crema } \\
\text { ligera } \\
1 / 2 \text { taza de } \\
\text { frijoles } \\
1 \text { taza de } \\
\text { sandía } \\
\text { picada }\end{array}$ \\
\hline \multicolumn{7}{|c|}{ Colación } \\
\hline $\begin{array}{l}1 \text { taza de } \\
\text { papaya picada } \\
10 \text { almendras }\end{array}$ & $\begin{array}{l}1 \text { taza de } \\
\text { sandía picada } \\
10 \text { almendras }\end{array}$ & $\begin{array}{l}1 \text { taza de } \\
\text { gajos de } \\
\text { toronja } \\
\text { 10 almendras }\end{array}$ & $\begin{array}{l}1 \text { taza de } \\
\text { papaya picada } \\
10 \text { almendras }\end{array}$ & $\begin{array}{l}1 \text { taza de } \\
\text { sandía picada } \\
10 \text { almendras }\end{array}$ & $\begin{array}{ll}1 \text { taza de } \\
\text { gajos de } \\
\text { toronja } \\
\text { 10 almendras }\end{array}$ & $\begin{array}{l}1 \text { taza de } \\
\text { papaya } \\
\text { picada } \\
10 \\
\text { almendras }\end{array}$ \\
\hline \multicolumn{7}{|c|}{ Comida } \\
\hline $\begin{array}{l}\text { 1 taza de sopa } \\
\text { de verduras } \\
\text { Milanesa de } \\
\text { pollo a la } \\
\text { plancha } \\
\text { Ensalada de } \\
\text { tomate con } \\
\text { aceite de } \\
\text { oliva, limón y } \\
\text { sal } \\
1 \text { tortilla } \\
\text { Agua } \\
\text { toronja con } \\
\text { azúcar } \\
\text { 1 taza de } \\
\text { papaya picada }\end{array}$ & $\begin{array}{l}\text { 1 taza de sopa } \\
\text { de codito con } \\
\text { salsa de } \\
\text { tomate } \\
1 \text { bisteck de } \\
\text { res a la } \\
\text { mexicana } \\
\text { Ensalada: } 21 / 2 \\
\text { tazas de } \\
\text { delechuga, } 2 \\
\text { tomates, } \\
\text { aceite de oliva } \\
\text { sal ylimón } \\
1 \text { tortilla } \\
\text { Agua de } \\
\text { papaya } \\
1 \text { taza de } \\
\text { sandía picada }\end{array}$ & 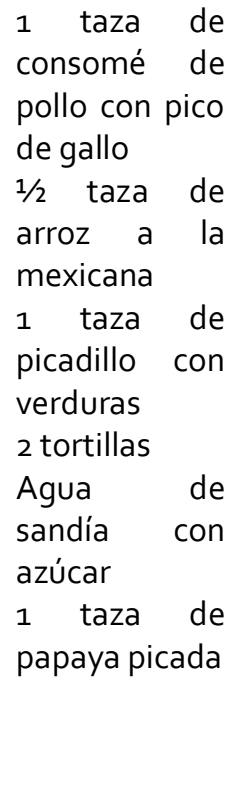 & $\begin{array}{l}\text { Ensalada: } 2 \frac{1 / 2}{2} \\
\text { tazas de } \\
\text { delechuga, } 2 \\
\text { tomates, } \\
\text { aceite de oliva } \\
\text { sal y limón } \\
1 \text { taza de } \\
\text { spaguetti a la } \\
\text { boloñesa } \\
\text { Agua de } \\
\text { papaya con } \\
\text { azúcar } \\
1 \quad \text { taza de } \\
\text { gajos de } \\
\text { toronja }\end{array}$ & $\begin{array}{l}1 \text { taza de sopa } \\
\text { de letras } \\
1 \text { filete de } \\
\text { pescado a la } \\
\text { veracruzana } \\
1 / 2 \text { taza de } \\
\text { zanahoria } \\
\text { rallada y dos } \\
\text { tomates con } \\
\text { aceite de oliva } \\
\text { limón y sal } \\
1 \text { tortilla } \\
\text { Agua } \\
\text { sandía con } \\
\text { azúcar } \\
1 \text { taza de } \\
\text { papaya picada }\end{array}$ & $\begin{array}{l}1 / 2 \text { taza de } \\
\text { arroz a la } \\
\text { mexicana } \\
2 \text { rebandas de } \\
\text { albóndigón de } \\
\text { res en salsa } \\
\text { roja } \\
\text { Ensalada: } 21 / 2 \\
\text { tazas de } \\
\text { delechuga, } 2 \\
\text { tomates, } \\
\text { aceite de oliva } \\
\text { sal y limón } \\
2 \text { tortillas } \\
\text { Agua de } \\
\text { papaya con } \\
\text { azúcar } \\
1 \text { taza de } \\
\text { sandía picada }\end{array}$ & $\begin{array}{l}\text { Ensalada: } 2 \\
1 / 2 \\
\text { tazas de } \\
\text { delechuga, } 2 \\
\text { tomates, } \\
\text { aceite de } \\
\text { oliva sal y } \\
\text { limón } \\
\text { Lasagna de } \\
\text { carne de res } \\
\text { Agua de } \\
\text { sandía } \\
1 \text { taza de } \\
\text { gajos de } \\
\text { toronja }\end{array}$ \\
\hline \multicolumn{7}{|c|}{ Colación } \\
\hline $\begin{array}{l}1 \text { taza de jugo } \\
\text { de tomate } \\
21 / 2 \text { tazas de } \\
\text { palomitas con } \\
3 \text { cucharadas } \\
\text { de salsa } \\
\text { catsup }\end{array}$ & $\begin{array}{l}1 \text { taza de jugo } \\
\text { de tomate } \\
21 / 2 \text { tazas de } \\
\text { palomitas con } \\
3 \text { cucharadas } \\
\text { de salsa } \\
\text { cátsup }\end{array}$ & $\begin{array}{l}1 \text { taza de jugo } \\
\text { de tomate } \\
21 / 2 \text { tazas de } \\
\text { palomitas con } \\
3 \text { cucharadas } \\
\text { de salsa } \\
\text { catsup }\end{array}$ & $\begin{array}{l}1 \text { taza de jugo } \\
\text { de tomate } \\
21 / 2 \text { tazas de } \\
\text { palomitas con } \\
3 \text { cucharadas } \\
\text { de salsa } \\
\text { catsup }\end{array}$ & $\begin{array}{l}1 \text { taza de jugo } \\
\text { de tomate } \\
21 / 2 \text { tazas de } \\
\text { palomitas con } \\
3 \text { cucharadas } \\
\text { de salsa } \\
\text { catsup }\end{array}$ & $\begin{array}{l}1 \text { taza de jugo } \\
\text { de tomate } \\
21 / 2 \text { tazas de } \\
\text { palomitas con } \\
3 \text { cucharadas } \\
\text { de salsa } \\
\text { catsup }\end{array}$ & $\begin{array}{l}1 \text { taza de } \\
\text { jugo de } \\
\text { tomate } \\
21 / 2 \text { tazas de } \\
\text { palomitas } \\
\text { con } \\
\text { cucharadas }\end{array}$ \\
\hline
\end{tabular}




\begin{tabular}{|c|c|c|c|c|c|c|}
\hline & & & & & & $\begin{array}{l}\text { de salsa } \\
\text { cátsup }\end{array}$ \\
\hline \multicolumn{7}{|c|}{ Cena } \\
\hline $\begin{array}{l}\text { 1 vaso de } \\
\text { licuado con } 1 / 2 \\
\text { plátano, } 1 \\
\text { taza de leche } \\
\text { descremada, } \\
\text { splenda y } 1 \\
\text { cucharadita } \\
\text { de vainilla } \\
3 \text { galletas de } \\
\text { nuez } \\
1 \text { taza de } \\
\text { sandía picada }\end{array}$ & $\begin{array}{l}1 \text { taza de } \\
\text { leche } \\
\text { descremada } \\
3 / 4 \text { taza de } \\
\text { cereal } \\
1 / 2 \text { palátano y } \\
1 \text { taza de } \\
\text { papaya picada } \\
1 \text { galleta de } \\
\text { avana y } \\
\text { manzana }\end{array}$ & $\begin{array}{l}\text { 1/2 taza de } \\
\text { yogurt } \\
1 \text { taza de } \\
\text { melón picado } \\
1 \text { taza de } \\
\text { sandía picada } \\
\text { y } 6 \\
\text { cucharadas de } \\
\text { granola }\end{array}$ & $\begin{array}{l}\text { 1 vaso de } \\
\text { licuado con } 1 / 2 \\
\text { plátano, } 1 \\
\text { taza de leche } \\
\text { descremada, } \\
\text { splenda y } 1 \\
\text { cucharadita } \\
\text { de vainilla } \\
3 \text { galletas de } \\
\text { nuez } \\
1 \text { taza de } \\
\text { sandía picada }\end{array}$ & $\begin{array}{l}1 \text { taza de } \\
\text { leche } \\
\text { descremada } \\
2 / 6 \text { taza de } \\
\text { cereal de } \\
\text { almendras } \\
\text { con pasas } \\
1 / 2 \text { plátano y } 1 \\
\text { taza de } \\
\text { mango picado }\end{array}$ & $\begin{array}{l}\text { 1 vaso de } \\
\text { licuado con } 1 / 2 \\
\text { plátano, } 1 \\
\text { taza de leche } \\
\text { descremada, } \\
\text { splenda y } 1 \\
\text { cucharadita } \\
\text { de vainilla } \\
3 \text { galletas de } \\
\text { nuez } \\
1 \text { taza de } \\
\text { sandía picada }\end{array}$ & $\begin{array}{l}1 \text { taza de } \\
\text { leche } \\
\text { descremada } \\
2 / 6 \text { taza de } \\
\text { cereal con } \\
\text { almendras y } \\
\text { pasas } \\
1 \text { taza de } \\
\text { fresas } \\
\text { picadas }\end{array}$ \\
\hline
\end{tabular}




\section{ANEXO.VIII}

\section{MENUS PARA MUJERES TRATADAS \\ CON DIETA RICA EN LICOPENO \\ (GRUPO EXPERIMENTAL)}

Fórmula dieto-sintética

\begin{tabular}{|c|c|c|c|}
\hline Nutrimentos & Porcentaje & $\begin{array}{c}\text { Energía } \\
\text { (Kcal) }\end{array}$ & Gramos \\
\hline Hidratos de Carbono & $55 \%$ & 825 & 206.2 \\
\hline Proteínas & $15 \%$ & 225 & 56.2 \\
\hline Lípidos* & $30 \%$ & 450 & 50.0 \\
\hline Total & $100 \%$ & 1500 & - \\
\hline
\end{tabular}

* Las recomendaciones del porcentaje de lípidos están de acuerdo con la Norma Oficial Mexicana para la prevención, tratamiento y control de las dislipidemias.NOM-037-SSA2-2002 


\section{Distribución de Equivalentes}

\begin{tabular}{|c|c|c|c|c|c|c|}
\hline \multirow[b]{2}{*}{$\begin{array}{l}\text { Grupo de } \\
\text { Alimentos }\end{array}$} & \multirow[b]{2}{*}{ Subgrupo } & \multirow{2}{*}{$\begin{array}{l}\text { No. de } \\
\text { Equiv. }\end{array}$} & \multicolumn{4}{|c|}{ Aporte Nutrimental Promedio } \\
\hline & & & $\begin{array}{c}\text { Energía } \\
\text { Kcal }\end{array}$ & $\begin{array}{c}\text { Proteínas } \\
\mathrm{g} .\end{array}$ & $\begin{array}{l}\text { Lípidos } \\
\text { g. }\end{array}$ & $\begin{array}{c}\text { Hidratos } \\
\text { de } \\
\text { Carbono } \\
\text { g. }\end{array}$ \\
\hline Verduras & & 6 & 150 & 12 & 0 & 24 \\
\hline Frutas & & 6 & 360 & 0 & 0 & 90 \\
\hline \multirow{2}{*}{$\begin{array}{ll}\text { Cereales } & \text { y } \\
\text { tubérculos } & \end{array}$} & a) sin grasa & 4 & 280 & 8 & 0 & 60 \\
\hline & b) con grasa & & & & & \\
\hline Leguminosas & & 1 & 120 & 8 & 1 & 20 \\
\hline \multirow{4}{*}{$\begin{array}{l}\text { Alimentos de } \\
\text { origen animal }\end{array}$} & $\begin{array}{l}\text { a) muy bajo aporte } \\
\text { de grasa }\end{array}$ & & & & & \\
\hline & $\begin{array}{l}\text { b) bajo aporte de } \\
\text { grasa }\end{array}$ & & & & & \\
\hline & $\begin{array}{l}\text { c) moderado aporte } \\
\text { de grasa }\end{array}$ & 3 & 225 & 21 & 15 & 0 \\
\hline & $\begin{array}{l}\text { d) alto aporte de } \\
\text { grasa }\end{array}$ & & & & & \\
\hline \multirow{4}{*}{ Leche } & a) descremada & 1 & 95 & 9 & 2 & 12 \\
\hline & b) semidescremada & & & & & \\
\hline & c) entera & & & & & \\
\hline & d) con azúcar & & & & & \\
\hline \multirow{2}{*}{$\begin{array}{l}\text { Aceites } \quad y \\
\text { grasas }\end{array}$} & a) sin proteínas & 4 & 180 & o & 20 & 0 \\
\hline & b) con proteínas & 1 & 70 & 3 & 5 & 3 \\
\hline \multirow[t]{2}{*}{ Azúcares } & a) sin grasa & 1 & 40 & 0 & 0 & 10 \\
\hline & b) con grasa & & & & & \\
\hline \multicolumn{7}{|l|}{$\begin{array}{l}\text { Alimentos } \\
\text { libres en } \\
\text { energía }\end{array}$} \\
\hline $\begin{array}{l}\text { Bebidas } \\
\text { alcohólicas }\end{array}$ & & & & & & \\
\hline
\end{tabular}




\section{Distribución de equivalentes en los tiempos de comida del menú 1}

\begin{tabular}{|c|c|c|c|c|c|c|c|}
\hline \multirow[b]{2}{*}{$\begin{array}{l}\text { Grupo de } \\
\text { Alimentos }\end{array}$} & \multirow[b]{2}{*}{ Subgrupo } & \multirow{2}{*}{$\begin{array}{l}\text { No. de } \\
\text { Equiv. }\end{array}$} & \multicolumn{5}{|c|}{ Tiempos de Comida } \\
\hline & & & Des & Col & Com & Col & Cena \\
\hline Verduras & & 6 & & 2 & 2 & & 2 \\
\hline Frutas & & 6 & 1 & 1 & 2 & 1 & 1 \\
\hline \multirow{2}{*}{$\begin{array}{l}\text { Cereales } \\
\text { tubérculos }\end{array}$} & a) sin grasa & 4 & 2 & & 1 & 1 & \\
\hline & b) con grasa & & & & & & \\
\hline Leguminosas & & 1 & & & 1 & & \\
\hline \multirow{4}{*}{$\begin{array}{l}\text { Alimentos de } \\
\text { origen animal }\end{array}$} & $\begin{array}{l}\text { a) muy bajo aporte } \\
\text { de grasa }\end{array}$ & & & & & & \\
\hline & $\begin{array}{l}\text { b) bajo aporte de } \\
\text { grasa }\end{array}$ & & & & & & \\
\hline & $\begin{array}{l}\text { c) moderado } \\
\text { aporte de grasa }\end{array}$ & 3 & & & 2 & & 1 \\
\hline & $\begin{array}{l}\text { d) alto aporte de } \\
\text { grasa }\end{array}$ & & & & & & \\
\hline \multirow{4}{*}{ Leche } & a) descremada & 1 & 1 & & & & \\
\hline & b) semidescremada & & & & & & \\
\hline & c) entera & & & & & & \\
\hline & d) con azúcar & & & & & & \\
\hline \multirow{2}{*}{$\begin{array}{ll}\text { Aceites } & y \\
\text { grasas } & \end{array}$} & a) sin proteínas & 4 & & & 3 & & 1 \\
\hline & b) con proteínas & 1 & 1 & & & & \\
\hline \multirow[t]{2}{*}{ Azúcares } & a) sin grasa & 1 & & & 1 & & \\
\hline & b) con grasa & & & & & & \\
\hline \multicolumn{8}{|l|}{$\begin{array}{l}\text { Alimentos } \\
\text { libres en } \\
\text { energía }\end{array}$} \\
\hline $\begin{array}{l}\text { Bebidas } \\
\text { alcohólicas }\end{array}$ & & & & & & & \\
\hline
\end{tabular}




\section{Menú 1}

\begin{tabular}{|c|c|c|c|c|c|c|}
\hline Lunes & Martes & Miércoles & Jueves & Viernes & Sábado & Domingo \\
\hline \multicolumn{7}{|c|}{ Desayuno } \\
\hline $\begin{array}{l}1 \text { taza de } \\
\text { leche } \\
\text { descremada } \\
1 \text { taza de } \\
\text { cereal integral } \\
\text { de arroz } \\
1 \text { taza de } \\
\text { papaya picada } \\
\text { con una } \\
\text { cucharadita } \\
\text { de miel } \\
\text { 10 almendras } \\
\text { picadas } 0 \quad 14 \\
\text { cacahuates }\end{array}$ & $\begin{array}{l}1 \text { taza de } \\
\text { licuado con } 1 \\
\text { taza de leche } \\
\text { descremada, } \\
1 \text { taza de } \\
\text { papaya } \\
\text { endulzado } \\
\text { con } \\
\text { cucharadita } \\
\text { de azúcar } \\
2 \text { rebanadas } \\
\text { de pan } \\
\text { integral } \\
\text { tostado con } 1 \\
\text { cucharadita } \\
\text { de } \\
\text { mantequilla } \\
\text { de cacahuate }\end{array}$ & $\begin{array}{l}1 \text { taza de } \\
\text { leche } \\
\text { descremada } \\
1 \text { taza de } \\
\text { cereal integral } \\
\text { de arroz } \\
1 \text { taza de } \\
\text { papaya picada } \\
\text { con } 1 \\
\text { cucharadita } \\
\text { de miel } \\
\text { 10 almendras } \\
\text { picadas } 0 \quad 14 \\
\text { cacahuates }\end{array}$ & $\begin{array}{l}\text { 1 taza de café } \\
\text { con leche } \\
\text { descremada } \\
\text { con splenda } \\
2 \text { hot cakes } \\
\text { pequeños con } \\
\text { dos } \\
\text { cucharaditas } \\
\text { de miel de } \\
\text { abeja } \\
1 \text { cucharadita } \\
\text { de } \\
\text { mantequilla } \\
1 \text { taza de } \\
\text { sandía picada }\end{array}$ & $\begin{array}{l}1 \text { taza de } \\
\text { leche } \\
\text { descremada } \\
1 \text { taza de } \\
\text { cereal } \\
\text { integral de } \\
\text { arroz } \\
1 \text { taza de } \\
\text { papaya } \\
\text { picada con } 1 \\
\text { cucharadita } \\
\text { de miel } \\
10 \\
\text { almendras } \\
\text { picadas o } 14 \\
\text { cacahuates }\end{array}$ & $\begin{array}{l}\text { 1 taza de } \\
\text { licuado con } \\
1 \text { taza de } \\
\text { leche } \\
\text { descremada } \\
1 \text { taza de } \\
\text { papaya con } \\
1 \\
\text { cucharadita } \\
\text { de azúcar } \\
1 \text { barrita de } \\
\text { granola } \\
\text { sabor } \\
\text { manzana } \\
10 \\
\text { almendras o } \\
14 \\
\text { cacahuates }\end{array}$ & $\begin{array}{l}3 / 4 \text { de taza de } \\
\text { yogurt light } \\
1 \text { taza de } \\
\text { papaya } \\
\text { picada con } 1 \\
\text { cucharadita } \\
\text { de miel } \\
10 \\
\text { almendras } \\
\text { picadas o } 14 \\
\text { cacahuates } \\
6 \\
\text { cucharadas } \\
\text { de granola }\end{array}$ \\
\hline \multicolumn{7}{|c|}{ Colación } \\
\hline $\begin{array}{l}\text { 1 taza de jugo } \\
\text { de tomate } \\
1 \text { taza de } \\
\text { sandía picada }\end{array}$ & $\begin{array}{l}\text { 1 taza de jugo } \\
\text { de tomate } \\
1 \text { taza de } \\
\text { sandía picada }\end{array}$ & $\begin{array}{l}\text { 1 taza de jugo } \\
\text { de tomate } \\
1 \text { taza de } \\
\text { gajos } \\
\text { toronja }\end{array}$ & $\begin{array}{l}1 \text { taza de jugo } \\
\text { de tomate } \\
1 \text { taza de } \\
\text { papaya picada }\end{array}$ & $\begin{array}{ll}\text { taza } & \text { de } \\
\text { jugo } & \text { de } \\
\text { tomate } & \\
1 \text { taza } & \text { de } \\
\text { sandía } & \\
\text { picada } & \\
\end{array}$ & $\begin{array}{ll}\text { taza } & \text { de } \\
\text { jugo } & \text { de } \\
\text { tomate } & \\
1 \text { taza de } \\
\text { sandía } & \\
\text { picada } & \\
\end{array}$ & $\begin{array}{ll}\text { d de taza de } \\
\text { jugo } & \text { de } \\
\text { tomate } & \\
1 \text { taza } & \text { de } \\
\text { gajos } & \text { de } \\
\text { toronja } & \\
\end{array}$ \\
\hline \multicolumn{7}{|c|}{ Comida } \\
\hline $\begin{array}{l}1 \text { taza de } \\
\text { consomé de } \\
\text { pollo con } 1 / 4 \text { de } \\
\text { taza de arroz } \\
1 \text { bisteck de } \\
\text { bola de res } \\
\text { entomatado } \\
2 \text { tomates con } \\
\text { aceite de oliva } \\
\text { limón y sal. } \\
1 / 2 \text { taza de } \\
\text { frijoles } \\
\text { Agua } \\
\text { toronja con de } \\
\text { azúcar } \\
1 \text { taza de } \\
\text { papaya picada }\end{array}$ & $\begin{array}{l}\text { l taza de sopa } \\
\text { de verduras } \\
1 / 2 \text { taza de } \\
\text { espagueti con } \\
\text { salsa de } \\
\text { tomate y } \\
\text { tomate picado } \\
\text { Fajitas de } \\
\text { pollo (con } \\
\text { chile pimiento } \\
\text { verde y rojo, } \\
\text { cebolla, } \\
\text { tomate y salsa } \\
\text { inglesa) } \\
\text { 1/2 taza de } \\
\text { frijoles } \\
\text { Agua de } \\
\text { sandía con } \\
\text { azúcar } \\
\text { 1 taza de } \\
\text { gajos de } \\
\text { toronja }\end{array}$ & 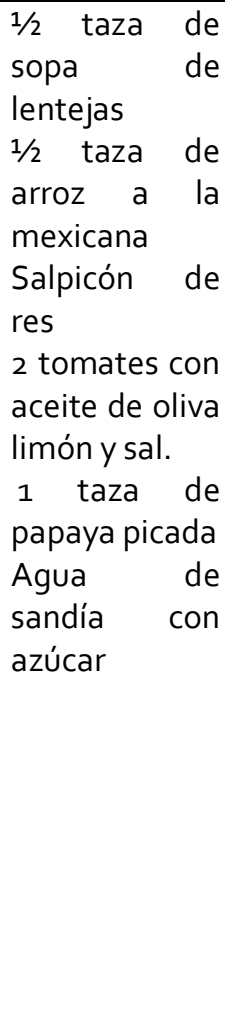 & $\begin{array}{l}1 / 2 \text { taza de } \\
\text { arroz rojo } \\
\text { Tinga de res } \\
1 / 3 \text { taza de } \\
\text { frijol refrito } \\
\text { Agua de } \\
\text { toronja con } \\
\text { azúcar } \\
1 \text { taza de } \\
\text { sandía picada }\end{array}$ & $\begin{array}{l}\text { 1/2 taza de } \\
\text { frijol colado } \\
\text { Cerdo } \\
\text { entomatado } \\
\text { con media } \\
\text { papa cocida } \\
2 \text { tomates } \\
\text { con aceite } \\
\text { de oliva } \\
\text { limón y sal. } \\
2 \text { tortillas } \\
\text { Agua de } \\
\text { sandía con } \\
\text { azúcar } \\
1 \text { taza de } \\
\text { gajos de } \\
\text { toronja }\end{array}$ & $\begin{array}{l}\text { Ensalada: } 3 \\
\text { tazas de } \\
\text { lechuga, } 2 \\
\text { piezas de } \\
\text { tomate } \\
\text { saladet, } 1 / 2 \\
\text { taza de } \\
\text { chícharos } \\
\text { con aderezo } \\
\text { de aceite de } \\
\text { oliva, limón } \\
\text { y sal. } \\
\text { Espagueti a } \\
\text { la boloñesa } \\
\text { (1/2 taza de } \\
\text { espagueti } \\
\text { cocido con } \\
\text { carne } \\
\text { molida de } \\
\text { res y salsa } \\
\text { de tomate } \\
\text { Agua de } \\
\text { toronja con } \\
\text { azúcar }\end{array}$ & $\begin{array}{l}\text { 1 taza de } \\
\text { sopa de } \\
\text { coditos con } \\
\text { salsa roja } \\
2 \text { tostadas } \\
\text { con frijoles } \\
\text { refritos, } \\
\text { pollo } \\
\text { deshebrado, } \\
\text { lechuga, } \\
\text { tomate, } \\
\text { cebolla, } \\
\text { aguacate, } \\
\text { salsa verde y } \\
\text { queso } \\
\text { Agua de } \\
\text { sandía con } \\
\text { azúcar } \\
1 \text { taza de } \\
\text { papaya } \\
\text { picada }\end{array}$ \\
\hline
\end{tabular}




\begin{tabular}{|c|c|c|c|c|c|c|}
\hline & & & & & $\begin{array}{l}1 \text { taza de } \\
\text { sandía } \\
\text { picada }\end{array}$ & \\
\hline \multicolumn{7}{|c|}{ Colación } \\
\hline $\begin{array}{l}\text { taza de } \\
\text { sandía picada } \\
2 \text { 1/2 tazas de } \\
\text { palomitas con } \\
3 \text { cucharadas } \\
\text { de salsa } \\
\text { catsup }\end{array}$ & $\begin{array}{l}1 / 2 \text { manzana } \\
21 / 2 \text { tazas de } \\
\text { palomitas con } \\
3 \text { cuchcradas } \\
\text { de salsa } \\
\text { cátsup }\end{array}$ & $\begin{array}{l}1 \text { de taza de } \\
\text { sandía picada } \\
2 \text { 1/2 tazas de } \\
\text { palomitas con } \\
3 \text { cuchcradas } \\
\text { de salsa } \\
\text { catsup }\end{array}$ & $\begin{array}{l}1 \text { pera } \\
21 / 2 \text { tazas de } \\
\text { palomitas con } \\
3 \text { cuchcradas } \\
\text { de salsa } \\
\text { catsup }\end{array}$ & $\begin{array}{l}1 \text { taza de } \\
\text { papaya } \\
\text { picada } \\
21 / 2 \text { tazas } \\
\text { de palomitas } \\
\text { con } 3 \\
\text { cuchcradas } \\
\text { de salsa } \\
\text { catsup }\end{array}$ & $\begin{array}{l}1 \text { taza de } \\
\text { papaya } \\
\text { picada } \\
21 / 2 \text { tazas } \\
\text { de } \\
\text { palomitas } \\
\text { con } 3 \\
\text { cuchcradas } \\
\text { de salsa } \\
\text { catsup }\end{array}$ & $\begin{array}{l}1 \text { taza de } \\
\text { sandía } \\
\text { picada } \\
2 \quad 1 / 2 \text { tazas } \\
\text { de } \\
\text { palomitas } \\
\text { con } 3 \\
\text { cucharadas } \\
\text { de salsa } \\
\text { catsup }\end{array}$ \\
\hline \multicolumn{7}{|c|}{ Cena } \\
\hline $\begin{array}{l}1 \text { taza de jugo } \\
\text { de tomate } \\
1 \text { taza de } \\
\text { papaya picada } \\
\text { con } 20 \mathrm{~g} \mathrm{de} \\
\text { queso } \\
\text { holandés }\end{array}$ & $\begin{array}{l}1 \text { taza de jugo } \\
\text { de tomate } \\
1 \text { salchicha } \\
\text { asada } \\
1 \text { taza de } \\
\text { gajos de } \\
\text { toronja }\end{array}$ & $\begin{array}{l}1 \text { taza de jugo } \\
\text { de tomate } \\
1 \quad \text { huevo } \\
\text { cocido } \\
1 / 2 \text { manzana }\end{array}$ & $\begin{array}{l}1 \text { taza de jugo } \\
\text { de tomate } \\
1 \text { taza de } \\
\text { papaya picada } \\
\text { con } 20 \mathrm{~g} \mathrm{de} \\
\text { queso } \\
\text { holandés }\end{array}$ & $\begin{array}{l}1 \text { taza de } \\
\text { jugo de } \\
\text { tomate } \\
1 \text { taza de } \\
\text { melón } \\
6 \text { rebanadas } \\
\text { de salami de } \\
\text { pavo }\end{array}$ & $\begin{array}{ll}1 \text { taza } & \text { de } \\
\text { jugo } & \text { de } \\
\text { tomate } & \\
1 \text { taza de } \\
\text { papaya } \\
\text { picada con } \\
20 \text { g de } \\
\text { queso } \\
\text { holandés }\end{array}$ & $\begin{array}{l}1 \text { taza de } \\
\text { jugo de } \\
\text { tomate } \\
1 \text { huevo } \\
\text { cocido } \\
1 / 2 \text { manzana }\end{array}$ \\
\hline
\end{tabular}


Distribución de equivalentes en los tiempos de comida del menú 2

\begin{tabular}{|c|c|c|c|c|c|c|c|}
\hline \multirow[b]{2}{*}{ Grupo de Alimentos } & \multirow[b]{2}{*}{ Subgrupo } & \multirow{2}{*}{$\begin{array}{l}\text { No. de } \\
\text { Equiv. }\end{array}$} & \multicolumn{5}{|c|}{ Tiempos de Comida } \\
\hline & & & Des & Col & Com & Col & Cena \\
\hline Verduras & & 6 & 2 & & 2 & 2 & \\
\hline Frutas & & 6 & 1 & 1 & 2 & 1 & 1 \\
\hline \multirow{2}{*}{$\begin{array}{ll}\begin{array}{l}\text { Cereales } \\
\text { tubérculos }\end{array} & y \\
\end{array}$} & a) sin grasa & 4 & 2 & & 1 & 1 & \\
\hline & b) con grasa & & & & & & \\
\hline Leguminosas & & 1 & & & 1 & & \\
\hline \multirow[t]{4}{*}{$\begin{array}{l}\text { Alimentos de origen } \\
\text { animal }\end{array}$} & $\begin{array}{l}\text { a) muy bajo } \\
\text { aporte } \\
\text { grasa }\end{array}$ & & & & & & \\
\hline & $\begin{array}{l}\text { b) bajo aporte } \\
\text { de grasa }\end{array}$ & & & & & & \\
\hline & $\begin{array}{l}\text { c) moderado } \\
\text { aporte de } \\
\text { grasa }\end{array}$ & 3 & 1 & & 2 & & \\
\hline & $\begin{array}{l}\text { d) alto aporte } \\
\text { de grasa }\end{array}$ & & & & & & \\
\hline \multirow[t]{4}{*}{ Leche } & $\begin{array}{l}\text { a) } \\
\text { descremada }\end{array}$ & 1 & & & & & 1 \\
\hline & $\begin{array}{l}\text { b) } \\
\text { semidescrema } \\
\text { da }\end{array}$ & & & & & & \\
\hline & c) entera & & & & & & \\
\hline & d) con azúcar & & & & & & \\
\hline \multirow[t]{2}{*}{ Aceites y grasas } & $\begin{array}{l}\text { a) } \sin \\
\text { proteínas }\end{array}$ & 4 & 1 & & 2 & & 1 \\
\hline & $\begin{array}{l}\text { b) con } \\
\text { proteínas }\end{array}$ & 1 & & 1 & & & \\
\hline \multirow[t]{2}{*}{ Azúcares } & a) sin grasa & 2 & & & 1 & & \\
\hline & b) con grasa & & & & & & \\
\hline \multicolumn{8}{|l|}{$\begin{array}{l}\text { Alimentos libres en } \\
\text { energía }\end{array}$} \\
\hline Bebidas alcohólicas & & & & & & & \\
\hline
\end{tabular}




\section{Menú 2}

\begin{tabular}{|c|c|c|c|c|c|c|}
\hline Lunes & Martes & Miércoles & Jueves & Viernes & Sábado & Domingo \\
\hline \multicolumn{7}{|c|}{ Desayuno } \\
\hline $\begin{array}{l}\text { Omelette de } \\
\text { papa (un } \\
\text { huevo y } 1 / 2 \\
\text { taza de papa } \\
\text { cocida) } \\
1 \text { taza de jugo } \\
\text { de tomate } \\
1 \text { taza de } \\
\text { sandía picada } \\
1 \text { rebanada de } \\
\text { pan integral }\end{array}$ & $\begin{array}{l}\text { 2 quesadillas } \\
\text { de tortilla de } \\
\text { maíz y } \\
\text { queso } \\
\text { mozzarella } \\
\text { semi- } \\
\text { descremado } \\
1 \text { taza de } \\
\text { jugo de } \\
\text { tomate } \\
1 \text { taza de } \\
\text { papaya } \\
\text { picada con } \\
\text { una } \\
\text { cucharada } \\
\text { de crema } \\
\text { ligera }\end{array}$ & $\begin{array}{l}\text { 1 sandwich de } \\
\text { pan integral } \\
\text { con pollo } \\
\text { deshebrado, } \\
\text { y } 1 \\
\text { cucharadita } \\
\text { de mayonesa } \\
1 \text { taza de jugo } \\
\text { de tomate } \\
1 \text { taza de } \\
\text { sandía picada }\end{array}$ & $\begin{array}{l}1 \text { huevo } \\
\text { estrellado } \\
2 \text { rebanadas } \\
\text { de pan } \\
\text { integral } \\
1 \text { vaso de jugo } \\
\text { de tomate } \\
1 \text { taza de } \\
\text { papaya picada } \\
\text { con } 1 \\
\text { cucharada de } \\
\text { crema ligera }\end{array}$ & $\begin{array}{l}2 \text { rebanadas } \\
\text { de pan } \\
\text { integral con } \\
\text { queso } \\
\text { mozzarella } \\
\text { semi- } \\
\text { descemado } \\
\text { gratinado } \\
1 \text { taza de jugo } \\
\text { de tomate } \\
1 \text { taza de } \\
\text { papaya picada } \\
\text { con } 1 \\
\text { cucharada de } \\
\text { crema ligera }\end{array}$ & $\begin{array}{l}2 \text { tacos de } \\
\text { pollo } \\
1 \text { taza de jugo } \\
\text { de tomate } \\
1 \text { taza de } \\
\text { papaya picada } \\
\text { con } 1 \\
\text { cucharada de } \\
\text { crema ligera }\end{array}$ & $\begin{array}{l}\text { 1 sandwich de } \\
\text { jamón y queso } \\
1 \text { taza de jugo } \\
\text { de tomate } \\
1 \text { taza de } \\
\text { papaya picada }\end{array}$ \\
\hline \multicolumn{7}{|c|}{ Colación } \\
\hline $\begin{array}{l}1 \text { taza de } \\
\text { papaya picada } \\
10 \text { almendras } \\
0 \quad 14 \\
\text { cacahuates }\end{array}$ & $\begin{array}{l}1 \text { taza de } \\
\text { sandía } \\
\text { picada } \\
10 \\
\text { almendras o } \\
14 \\
\text { cacahuates }\end{array}$ & $\begin{array}{lr}1 & \text { taza de } \\
\text { papaya picada } \\
10 \text { almendras } \\
0 \\
\text { cacahuates }\end{array}$ & $\begin{array}{l}1 \text { taza de } \\
\text { sandía picada, } \\
10 \text { almendras } \\
\text { picadas } 014 \\
\text { cacahuates }\end{array}$ & $\begin{array}{l}1 \text { taza de } \\
\text { sandía picada } \\
14 \text { cacahuates }\end{array}$ & $\begin{array}{l}1 \text { taza de } \\
\text { sandía picada } \\
10 \text { almendras } \\
\text { O } \\
\text { cacahuates }\end{array}$ & $\begin{array}{l}1 \text { taza de } \\
\text { sandía picada } \\
14 \text { cacahuates }\end{array}$ \\
\hline \multicolumn{7}{|c|}{ Comida } \\
\hline $\begin{array}{l}1 \text { taza de sopa } \\
\text { poblana: } \\
\text { calabaza local, } \\
\text { chile poblano, } \\
\text { elote en grano } \\
\text { en caldo de } \\
\text { pollo } \\
1 / 2 \text { taza de } \\
\text { arroz a la } \\
\text { mexicana } \\
2 \text { albóndigas } \\
\text { de carne } \\
\text { molida de res } \\
\text { en salsa roja } \\
1 / 2 \text { taza de } \\
\text { frijoles } \\
\text { Agua de } \\
\text { toronja con } \\
\text { azúcar } \\
1 \text { taza de } \\
\text { sandía picada }\end{array}$ & $\begin{array}{l}1 \text { taza sopa } \\
\text { de papa con } \\
\text { chícharos } \\
1 / 2 \text { taza de } \\
\text { macarrón en } \\
\text { salsa roja } \\
1 \text { filete de } \\
\text { pescado a la } \\
\text { plancha } \\
\text { Ensalada de } \\
\text { tomate con } \\
\text { aceite de } \\
\text { oliva, limón } \\
\text { y sal } \\
\text { 1/2 taza de } \\
\text { frijoles } \\
\text { Agua de } \\
\text { sandía con } \\
\text { azúcar } \\
1 \text { taza de } \\
\text { gajos de } \\
\text { toronja }\end{array}$ & $\begin{array}{l}\text { 1 taza de sopa } \\
\text { de verduras } \\
1 / 2 \text { taza de } \\
\text { arroz rojo } \\
1 \text { porción de } \\
\text { bisteck } \\
\text { entomatado } \\
1 / 2 \text { taza de } \\
\text { frijoles } \\
\text { Agua de } \\
\text { papaya con } \\
\text { azúcar } \\
1 \text { taza de } \\
\text { gajos } \\
\text { toronja de }\end{array}$ & $\begin{array}{l}\text { 1 taza de sopa } \\
\text { de codito con } \\
\text { espinacas } \\
1 \text { porción de } \\
\text { arrachera } \\
\text { Ensalada de } \\
\text { tomates con } \\
\text { aceite de } \\
\text { oliva, limón y } \\
\text { sal } \\
1 / 2 \text { taza de } \\
\text { frijoles } \\
\text { Agua de } \\
\text { toronja con } \\
\text { azúcar } \\
1 \text { taza de } \\
\text { sandía picada }\end{array}$ & $\begin{array}{l}\text { 1 taza de } \\
\text { tallarines en } \\
\text { salsa } \\
\text { tomate de } \\
1 \text { milanesa de } \\
\text { pollo a la } \\
\text { plancha } \\
\text { Ensalada de } 2 \\
\text { tomates y } 3 \\
\text { tazas } \\
\text { delechuga } \\
\text { con aceite de } \\
\text { oliva, limón y } \\
\text { sal } \\
1 \text { traza de } \\
\text { frijoles } \\
\text { Agua } \\
\text { papaya con } \\
\text { azúcar } \\
1 \text { taza de } \\
\text { sandía picada }\end{array}$ & $\begin{array}{l}1 \text { taza de sopa } \\
\text { de fideos } \\
1 \text { milanesa de } \\
\text { cerdo a la } \\
\text { plancha } \\
\text { Ensalada de } 2 \\
\text { tomates y } 3 \\
\text { tazas } \\
\text { delechuga } \\
\text { con aceite de } \\
\text { oliva, limón y } \\
\text { sal } \\
1 / 2 \text { taza de } \\
\text { frijoles } \\
\text { Agua de } \\
\text { toronja con } \\
\text { azúcar } \\
1 \quad \text { taza de } \\
\text { sandía picada }\end{array}$ & $\begin{array}{l}\text { 1 taza de sopa } \\
\text { de tortilla } \\
1 \text { filete de } \\
\text { pescado a la } \\
\text { veracruzana } \\
\text { Ensalada de } \\
\text { zanahoria } \\
\text { rallada con } \\
\text { limón y sal } \\
\text { 1/2 taza de } \\
\text { frijoles } \\
\text { Agua } \\
\text { toronja con de } \\
\text { azúcar } \\
\text { 1 taza de } \\
\text { papaya picada }\end{array}$ \\
\hline
\end{tabular}




\begin{tabular}{|c|c|c|c|c|c|c|}
\hline \multicolumn{7}{|c|}{ Colación } \\
\hline $\begin{array}{l}1 \text { taza de jugo } \\
\text { de tomate } \\
21 / 2 \text { tazas de } \\
\text { palomitas con } \\
3 \text { cucharadas } \\
\text { de salsa } \\
\text { cátsup } \\
1 \text { taza de } \\
\text { papaya picada }\end{array}$ & $\begin{array}{l}\text { taza de } \\
\text { jugo de } \\
\text { tomate } \\
21 / 2 \text { tazas de } \\
\text { palomitas } \\
\text { con } 3 \\
\text { cucharadas } \\
\text { de salsa } \\
\text { cátsup } \\
1 \text { taza de } \\
\text { papaya } \\
\text { picada }\end{array}$ & $\begin{array}{l}1 \text { taza de jugo } \\
\text { de tomate } \\
21 / 2 \text { tazas de } \\
\text { palomitas con } \\
3 \text { cucharadas } \\
\text { de salsa } \\
\text { cátsup } \\
1 \text { taza de } \\
\text { sandía picada }\end{array}$ & $\begin{array}{l}1 \text { taza de jugo } \\
\text { de tomate } \\
21 / 2 \text { tazas de } \\
\text { palomitas con } \\
3 \text { cucharadas } \\
\text { de salsa } \\
\text { cátsup } \\
1 \text { taza de } \\
\text { papaya picada }\end{array}$ & \begin{tabular}{|ll}
1 taza de jugo \\
de tomate \\
$21 / 2$ tazas de \\
palomitas con \\
3 cucharadas \\
de & salsa \\
cátsup & \\
1 taza & de \\
gajos & de \\
toronja &
\end{tabular} & $\begin{array}{l}1 \text { taza de jugo } \\
\text { de tomate } \\
21 / 2 \text { tazas de } \\
\text { palomitas con } \\
3 \text { cucharadas } \\
\text { de salsa } \\
\text { cátsup } \\
1 \text { taza de } \\
\text { papaya picada }\end{array}$ & $\begin{array}{l}1 \text { taza de jugo } \\
\text { de tomate } \\
21 / 2 \text { tazas de } \\
\text { palomitas con } \\
3 \text { cucharadas } \\
\text { de salsa } \\
\text { cátsup } \\
1 \text { taza de } \\
\text { sandía picada }\end{array}$ \\
\hline \multicolumn{7}{|c|}{ Cena } \\
\hline $\begin{array}{l}1 \text { taza de café } \\
\text { con leche } \\
\text { descremada } \\
\text { con splenda } \\
1 \text { taza de } \\
\text { mango picado } \\
\text { con } 1 \\
\text { cucharada de } \\
\text { queso crema }\end{array}$ & $\begin{array}{l}\text { Licuado: } 1 \\
\text { taza de } \\
\text { leche } \\
\text { descremada } \\
1 / 2 \text { plátano, } \\
\text { vainilla y } \\
\text { splenda }\end{array}$ & $\begin{array}{l}\text { 1 taza de } \\
\text { leche café con } \\
\text { leche con } \\
\text { splenda } \\
\text { 1/2 plátano con } \\
1 \text { cucharada } \\
\text { de crema } \\
\text { ligera y } \\
\text { splenda }\end{array}$ & $\begin{array}{l}3 / 4 \text { de taza de } \\
\text { yogurt } \\
1 / 2 \text { manzana } \\
\text { picada con } \\
\text { splenda }\end{array}$ & $\begin{array}{l}1 \text { taza de } \\
\text { leche café con } \\
\text { leche con } \\
\text { splenda } \\
1 / 2 \text { taza de } \\
\text { fresas con } 1 \\
\text { cucharada de } \\
\text { crema ligera y } \\
\text { splenda }\end{array}$ & $\begin{array}{l}3 / 4 \text { de taza de } \\
\text { yogurt } \\
1 / 2 \text { manzana } \\
\text { picada con } \\
\text { splenda }\end{array}$ & $\begin{array}{l}\text { Licuado: } 1 \\
\text { taza de leche, } \\
1 / 2 \text { plátano, } \\
\text { vainilla y } \\
\text { splenda }\end{array}$ \\
\hline
\end{tabular}


Distribución de equivalentes en los tiempos de comida del menú 3

\begin{tabular}{|c|c|c|c|c|c|c|c|}
\hline \multirow[b]{2}{*}{$\begin{array}{l}\text { Grupo de } \\
\text { Alimentos }\end{array}$} & \multirow[b]{2}{*}{ Subgrupo } & \multirow{2}{*}{$\begin{array}{l}\text { No. de } \\
\text { Equiv. }\end{array}$} & \multicolumn{5}{|c|}{ Tiempos de Comida } \\
\hline & & & Des & Col & Com & Col & Cena \\
\hline Verduras & & 6 & 2 & & 2 & 2 & \\
\hline Frutas & & 6 & 1 & 1 & 2 & & 2 \\
\hline \multirow{2}{*}{$\begin{array}{l}\text { Cereales } \\
\text { tubérculos }\end{array}$} & a) sin grasa & 4 & 1 & & 2 & 1 & \\
\hline & b) con grasa & & & & & & \\
\hline Leguminosas & & 1 & 1 & & & & \\
\hline \multirow{4}{*}{$\begin{array}{l}\text { Alimentos de } \\
\text { origen animal }\end{array}$} & $\begin{array}{l}\text { a) muy bajo aporte } \\
\text { de grasa }\end{array}$ & & & & & & \\
\hline & $\begin{array}{l}\text { b) bajo aporte de } \\
\text { grasa }\end{array}$ & & & & & & \\
\hline & $\begin{array}{l}\text { c) moderado } \\
\text { aporte de grasa }\end{array}$ & 3 & 1 & & 2 & & \\
\hline & $\begin{array}{l}\text { d) alto aporte de } \\
\text { grasa }\end{array}$ & & & & & & \\
\hline \multirow{4}{*}{ Leche } & a) descremada & 1 & & & & & 1 \\
\hline & b) semidescremada & & & & & & \\
\hline & c) entera & & & & & & \\
\hline & d) con azúcar & & & & & & \\
\hline \multirow{2}{*}{$\begin{array}{l}\text { Aceites } \quad y \\
\text { grasas }\end{array}$} & a) sin proteínas & 4 & 1 & & 3 & & \\
\hline & b) con proteínas & 1 & & 1 & & & \\
\hline \multirow[t]{2}{*}{ Azúcares } & a) sin grasa & 2 & & & 1 & & \\
\hline & b) con grasa & & & & & & \\
\hline \multicolumn{8}{|l|}{$\begin{array}{l}\text { Alimentos } \\
\text { libres en } \\
\text { energía }\end{array}$} \\
\hline $\begin{array}{l}\text { Bebidas } \\
\text { alcohólicas }\end{array}$ & & & & & & & \\
\hline
\end{tabular}




\section{Menú 3}

\begin{tabular}{|c|c|c|c|c|c|c|}
\hline Lunes & Martes & Miércoles & Jueves & Viernes & Sábado & Domingo \\
\hline \multicolumn{7}{|c|}{ Desayuno } \\
\hline $\begin{array}{l}1 \text { taza de jugo } \\
\text { de tomate } \\
1 \text { huevo } \\
\text { estrellado } \\
1 \text { rebanada de } \\
\text { pan integral } \\
1 / 2 \text { taza de } \\
\text { frijoles } \\
1 \text { taza de } \\
\text { sandía picada }\end{array}$ & $\begin{array}{l}1 \text { taza de jugo } \\
\text { de tomate } \\
1 \text { salchicha de } \\
\text { pavo frita } \\
1 \text { rebanada de } \\
\text { pan integral } \\
1 / 2 \text { taza de } \\
\text { frijoles } \\
1 \text { taza de } \\
\text { gajos de } \\
\text { toronja }\end{array}$ & $\begin{array}{l}\text { 1 taza de jugo } \\
\text { de tomate } \\
1 \text { enfrijolada } \\
\text { rellena de } \\
\text { jamón con } \\
\text { crema ligera y } \\
\text { queso } \\
1 \text { taza de } \\
\text { papaya picada }\end{array}$ & $\begin{array}{l}1 \text { taza de jugo } \\
\text { de tomate } \\
1 \text { quesadilla } \\
\text { con queso } \\
\text { panela con } 1 \\
\text { cucharada de } \\
\text { crema ligera } \\
1 / 2 \text { taza de } \\
\text { frijoles } \\
1 \text { taza de } \\
\text { sandía picada }\end{array}$ & $\begin{array}{l}1 \text { taza de jugo } \\
\text { de tomate } \\
1 \text { sandwich } \\
\text { abierto de } \\
\text { pollo con } \\
\text { mayonesa y } \\
\text { mostaza } \\
1 / 2 \text { taza de } \\
\text { frijoles } \\
1 \text { taza de } \\
\text { gajos de } \\
\text { toronja }\end{array}$ & $\begin{array}{l}1 \text { taza de jugo } \\
\text { de tomate } \\
1 \text { huevo } \\
\text { revuelto con } \\
\text { papa cocida } \\
1 / 2 \text { taza de } \\
\text { frijoles } \\
1 \text { taza de } \\
\text { papaya picada }\end{array}$ & $\begin{array}{l}\text { 1 taza de } \\
\text { jugo de } \\
\text { tomate } \\
1 / 2 \text { de papa } \\
\text { al horno con } \\
\text { cáscara } \\
\text { rellena de } \\
\text { queso y } 1 \\
\text { cucharada } \\
\text { de crema } \\
\text { ligera } \\
1 / 2 \text { taza de } \\
\text { frijoles } \\
1 \text { taza de } \\
\text { sandía } \\
\text { picada }\end{array}$ \\
\hline \multicolumn{7}{|c|}{ Colación } \\
\hline $\begin{array}{l}\text { taza de } \\
\text { papaya picada } \\
10 \text { almendras }\end{array}$ & $\begin{array}{l}1 \text { taza de } \\
\text { sandía picada } \\
\text { 10 almendras }\end{array}$ & $\begin{array}{l}1 \text { taza de } \\
\text { gajos } \\
\text { toronja } \\
\text { 10 almendras }\end{array}$ & $\begin{array}{l}1 \text { taza de } \\
\text { papaya picada } \\
10 \text { almendras }\end{array}$ & $\begin{array}{l}1 \text { taza de } \\
\text { sandía picada } \\
10 \text { almendras }\end{array}$ & $\begin{array}{ll}\text { taza } & \text { de } \\
\text { gajos } & \text { de } \\
\text { toronja } & \\
10 \text { almendras }\end{array}$ & $\begin{array}{l}1 \text { taza de } \\
\text { papaya } \\
\text { picada } \\
10 \\
\text { almendras }\end{array}$ \\
\hline \multicolumn{7}{|c|}{ Comida } \\
\hline $\begin{array}{l}\text { 1 taza de sopa } \\
\text { de tortilla } \\
\text { Milanesa de } \\
\text { pollo a la } \\
\text { plancha } \\
\text { Ensalada de } \\
\text { tomate con } \\
\text { aceite de } \\
\text { olive, limón y } \\
\text { sal } \\
1 \text { tortilla } \\
\text { Agua } \\
\text { toronja de } \\
\text { azúcar } \\
1 \quad \text { taza de } \\
\text { papaya picada }\end{array}$ & $\begin{array}{l}\text { 1 taza de sopa } \\
\text { de codito con } \\
\text { salsa de } \\
\text { tomate } \\
1 \text { bisteck de } \\
\text { res a la } \\
\text { mexicana } \\
\text { Ensalada: } 2 \text { 1/2 } \\
\text { tazas de } \\
\text { delechuga, } 2 \\
\text { tomates, } \\
\text { aceite de oliva } \\
\text { sal ylimón } \\
1 \text { tortilla } \\
\text { Agua de } \\
\text { papaya de } \\
1 \text { taza de } \\
\text { sandía picada }\end{array}$ & $\begin{array}{l}\text { 1 taza de } \\
\text { consomé de } \\
\text { pollo con pico } \\
\text { de gallo } \\
1 / 2 \text { taza de } \\
\text { arroz a la } \\
\text { mexicana } \\
1 \text { taza de } \\
\text { picadillo con } \\
\text { verduras } \\
2 \text { tortillas } \\
\text { Agua } \\
\text { sandía de con } \\
\text { azúcar } \\
\text { 1 taza de } \\
\text { papaya picada }\end{array}$ & 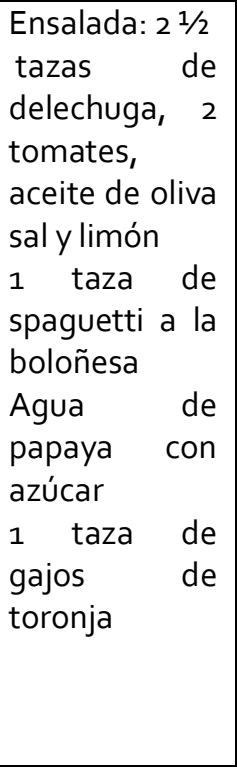 & $\begin{array}{l}1 \text { taza de sopa } \\
\text { de fideos } \\
1 \text { filete de } \\
\text { pescado a la } \\
\text { veracruzana } \\
1 / 2 \text { taza de } \\
\text { zanahoria } \\
\text { rallada y dos } \\
\text { tomates con } \\
\text { aceite de oliva } \\
\text { limóny sal } \\
1 \text { tortilla } \\
\text { Agua de } \\
\text { sandía con } \\
\text { azúcar de } \\
1 \text { taza de } \\
\text { papaya picada }\end{array}$ & 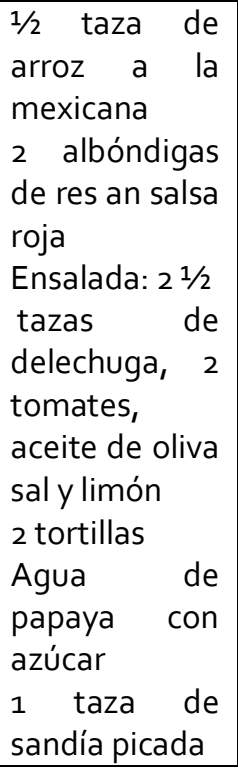 & 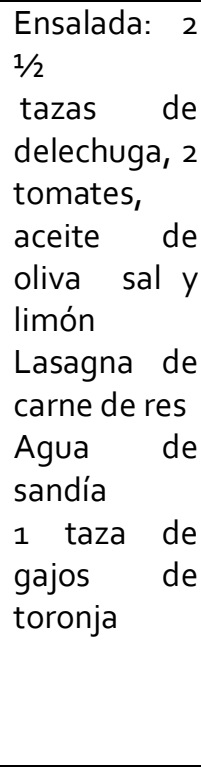 \\
\hline \multicolumn{7}{|c|}{ Colación } \\
\hline $\begin{array}{l}1 \text { taza de jugo } \\
\text { de tomate } \\
21 / 2 \text { tazas de } \\
\text { palomitas con } \\
3 \text { cucharadas } \\
\text { de salsa } \\
\text { catsup }\end{array}$ & $\begin{array}{l}1 \text { taza de jugo } \\
\text { de tomate } \\
21 / 2 \text { tazas de } \\
\text { palomitas con } \\
3 \text { cucharadas } \\
\text { de salsa } \\
\text { cátsup }\end{array}$ & $\begin{array}{l}\text { 1 taza de jugo } \\
\text { de tomate } \\
21 / 2 \text { tazas de } \\
\text { palomitas con } \\
3 \text { cucharadas } \\
\text { de salsa } \\
\text { catsup }\end{array}$ & $\begin{array}{l}\text { 1 taza de jugo } \\
\text { de tomate } \\
21 / 2 \text { tazas de } \\
\text { palomitas con } \\
3 \text { cucharadas } \\
\text { de salsa } \\
\text { catsup }\end{array}$ & $\begin{array}{l}1 \text { taza de jugo } \\
\text { de tomate } \\
21 / 2 \text { tazas de } \\
\text { palomitas con } \\
3 \text { cucharadas } \\
\text { de salsa } \\
\text { catsup }\end{array}$ & $\begin{array}{l}\text { 1 taza de jugo } \\
\text { de tomate } \\
21 / 2 \text { tazas de } \\
\text { palomitas con } \\
3 \text { cucharadas } \\
\text { de salsa } \\
\text { catsup }\end{array}$ & $\begin{array}{l}1 \text { taza de } \\
\text { jugo de } \\
\text { tomate } \\
21 / 2 \text { tazas de } \\
\text { palomitas } \\
\text { con } 3 \\
\text { cucharadas } \\
\text { de salsa } \\
\text { catsup }\end{array}$ \\
\hline
\end{tabular}




\begin{tabular}{|c|c|c|c|c|c|c|}
\hline \multicolumn{7}{|c|}{ Cena } \\
\hline $\begin{array}{l}\text { vaso de } \\
\text { licuado con } 1 / 2 \\
\text { plátano, } 1 \\
\text { taza de leche } \\
\text { descremada, } \\
\text { splenda y } 1 \\
\text { cucharadita } \\
\text { de vainilla } \\
1 \text { taza de } \\
\text { sandía picada }\end{array}$ & $\begin{array}{l}\text { 1 taza de } \\
\text { leche } \\
\text { descremada } \\
3 / 4 \text { taza de } \\
\text { cereal } \\
1 / 2 \text { palátano y } \\
1 \text { taza de } \\
\text { papaya picada }\end{array}$ & $\begin{array}{l}1 / 2 \text { taza de } \\
\text { yogurt } \\
1 \text { taza de } \\
\text { melón picado } \\
1 \text { taza de } \\
\text { sandía picada }\end{array}$ & $\begin{array}{l}1 \text { vaso de } \\
\text { licuado con } 1 / 2 \\
\text { plátano, } 1 \\
\text { taza de leche } \\
\text { descremada, } \\
\text { splenda y } 1 \\
\text { cucharadita } \\
\text { de vainilla } \\
\text { 1 taza de } \\
\text { sandía picada }\end{array}$ & $\begin{array}{l}1 / 2 \text { taza de } \\
\text { yogurt con } \\
\text { splenda } \\
1 \text { taza de } \\
\text { mango picado } \\
\text { y } 1 / 2 \text { plátano }\end{array}$ & $\begin{array}{l}\text { vaso de } \\
\text { licuado con } 1 / 2 \\
\text { plátano, } 1 \\
\text { taza de leche } \\
\text { descremada, } \\
\text { splenda y } 1 \\
\text { cucharadita } \\
\text { de vainilla } \\
1 \text { taza de } \\
\text { sandía picada }\end{array}$ & $\begin{array}{l}1 / 2 \text { taza de } \\
\text { yogurt con } \\
\text { splenda } \\
1 \text { taza de } \\
\text { mango } \\
\text { picado y } 1 / 2 \\
\text { plátano }\end{array}$ \\
\hline
\end{tabular}

